FLÁVIO MONTEIRO RACHEL

PROPOSTA DE UM CONTROLADOR AUTOMÁTICO DE TRENS UTILIZANDO LÓGICA NEBULOSA PREDITIVA 
FLÁVIO MONTEIRO RACHEL

\section{PROPOSTA DE UM CONTROLADOR AUTOMÁTICO DE TRENS UTILIZANDO LÓGICA NEBULOSA PREDITIVA}

Dissertação apresentada à Escola Politécnica da Universidade de São Paulo para a obtenção do título de Mestre em Engenharia.

Área de Concentração: Sistemas Digitais

Orientador: Prof. Dr. Paulo Sérgio Cugnasca

SÃO PAULO

2006 
Este exemplar foi revisado e alterado em relação à versão original, sob responsabilidade única do autor e com a anuência de seu orientador.

São Paulo, 24 de agosto de 2006.

Assinatura do autor

Assinatura do orientador

\section{FICHA CATALOGRÁFICA}

Rachel, Flávio Monteiro

Proposta de um controlador automático de trens utilizando lógica nebulosa preditiva. / Flávio Monteiro Rachel; orient. Prof. Dr. Paulo Sérgio Cugnasca -- São Paulo, 2006.

$160 \mathrm{p}$.

Dissertação (Mestrado) - Escola Politécnica da Universidade de São Paulo. Departamento de Engenharia de Computação e Sistemas Digitais.

1. Fuzzy (Inteligência Artificial) 2. Sistemas de controle de tráfego 3. Metrô I. Universidade de São Paulo. Escola Politécnica. Departamento de Engenharia de Computação e Sistemas Digitais II. $\mathrm{t}$ 
Aos meus pais, cuja presença material ou espiritual continua e sempre continuará a me ensinar os mistérios da vida. 


\section{AGRADECIMENTOS}

Ao Deus Criador, pelo dom da vida que se renova em cada dia e cujos mistérios insistimos em tentar compreender.

Aos meus pais, presentes física ou espiritualmente ao meu lado em todos os momentos de minha vida.

Ao Prof. Dr. Paulo Sérgio Cugnasca, pelo constante apoio, paciência e confiança demonstrados em minha capacidade de trabalho.

Ao Prof. Dr. João Batista Camargo Júnior, que me recebeu e me encaminhou aos procedimentos de ingresso no programa de pós-graduação da Escola Politécnica.

Ao Prof. Dr. Jorge Rady de Almeida Júnior, ao Prof. Dr. João Batista Camargo Júnior e ao Prof. Dr. Paulo Sérgio Cugnasca pelas valiosas críticas e sugestões na ocasião do Exame de Qualificação e pelo constante apoio na elaboração deste trabalho.

Ao Prof. Dr. Marco Túlio Carvalho de Andrade e ao pessoal do KNOMA, na pessoa do colega Gustavo Monteiro, pelo apoio na compreensão e utilização do simulador de sistemas utilizando lógica nebulosa desenvolvido no KNOMA.

À Companhia do Metropolitano de São Paulo, por intermédio da Gerência de Manutenção cujos incentivos e investimentos foram fundamentais na produção desta dissertação, em especial na pessoa do amigo e colega Jorge Martins Secall.

Aos meus amigos e colegas de trabalho pela paciência, apoio e compreensão.

A todos aqueles que direta ou indiretamente colaboraram na execução desta dissertação. 


\section{RESUMO}

Esta dissertação apresenta um estudo da viabilidade de aplicação de ferramentas de Inteligência Artificial, em especial da aplicação da lógica nebulosa preditiva (lógica fuzzy), em sistemas de controle automático de trens. Para isto, um panorama do contexto de aplicação do estudo é apresentado, incluindo a problemática dos transportes nas grandes cidades e a utilização de técnicas de computação em sistemas metroferroviários. Também são apresentados os princípios básicos de controle automático de trens, de lógica nebulosa preditiva e de sistemas de controle, particularmente os sistemas especialistas e as aplicações críticas de controle. Um modelo de um sistema de controle utilizando lógica nebulosa preditiva é então proposto e detalhado. Em seguida, estudos de caso para os trens do metropolitano de Sendai (Japão) e de São Paulo são efetuados. Simulações, testes comparativos e a análise dos resultados são realizados, levando às considerações finais sobre a viabilidade da aplicação. A conclusão é que, mesmo se tratando de uma aplicação crítica de controle, envolvendo a segurança dos passageiros, a utilização de ferramentas de Inteligência Artificial, especialmente a lógica nebulosa preditiva, é perfeitamente viável, desde que uma atenção especial com a segurança do sistema seja tomado. Neste caso, esta atenção é tomada por meio da implantação de um módulo supervisor (módulo ATP) que realiza uma monitoração constante das entradas e saídas do sistema de controle. O ATP atua, preferencialmente, ao sistema de controle para garantir a sua segurança. Embora as normas européias (IEE e CENELEC) não recomendem a utilização de ferramentas de Inteligência Artificial em aplicações críticas de controle, este estudo demonstra que é possível efetuar a aplicação destas ferramentas, aproveitando os benefícios por elas proporcionados, sem comprometer a segurança do sistema. 


\begin{abstract}
This dissertation presents a study on the viability of applying Artificial Intelligence tools, especially predictive fuzzy logic application, in automatic train control systems. For this purpose, an overview of the study application context is presented, including transportation troubling in big cities and computational techniques used in subway and railway systems. The basic principles of automatic train control, predictive fuzzy logic and control systems, particularly specialist and control critical systems applications are also presented. A model for a control system using predictive fuzzy logic is then proposed and detailed. Next, study cases for Sendai (Japan) and São Paulo subway trains are conducted. Simulations, comparative tests and results analysis are carried out, leading to the final considerations about the application viability. The conclusion is that, even being a critical control application, involving passenger safety, the use of Artificial Intelligence tools, especially predictive fuzzy logic, is perfectible viable, since special attention is given to the safety of the system. In this case, this attention is given by means of the implementation of a supervisory module (ATP module) that constantly monitors control system inputs and outputs. The ATP acts preferably on the control system in order to guarantee its safety. Although European standards (IEE and CENELEC) do not recommend the use of Artificial Intelligence tools in critical system applications, this study shows that it is possible to apply these tools, enjoying the benefits provided by them, without compromising the system safety.
\end{abstract}




\section{SUMÁRIO}

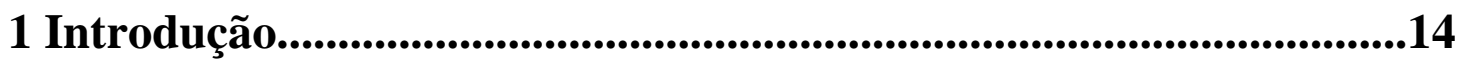

1.1 Histórico...........................................................................................................14

1.2 Motivação......................................................................................................................19

1.3 Objetivos...........................................................................................................20

1.4 Organização do Trabalho...........................................................................................21

1.5 Considerações Finais do Capítulo...........................................................................23

2 Sistemas de Controle Automático de Trens..........................................24

2.1 Histórico.........................................................................................................................24

2.2 Sistemas de Sinalização de Via.................................................................................32

2.3 Sistemas de Controle de Bordo.................................................................................39

2.4 Sistemas Auxiliares.......................................................................................................42

2.5 Considerações Finais do Capítulo...........................................................................43

3 Elementos de Lógica Nebulosa Preditiva..........................................44

3.1 Introdução.........................................................................................................................44

3.2 Conjuntos Nebulosos....................................................................................49

3.3 Lógica Nebulosa..............................................................................................59

3.4 Considerações Finais do Capítulo.........................................................................63

4 Sistemas de Controle, Sistemas de Inferência e Sistemas

Especialistas........................................................................................64

4.1 Introdução...........................................................................................................64

4.2 Sistemas de Controle Nebulosos....................................................................70

4.3 Etapas de Projeto de um Controlador Nebuloso....................................................71

4.4 Considerações Finais do Capítulo.............................................................................81

5 Modelagem do Sistema de Controle Nebuloso Proposto...................82

5.1 Introdução.................................................................................................................82

5.2 O Controlador Nebuloso Proposto.........................................................................87

5.3 Considerações Finais do Capítulo.............................................................................96 
6 Exemplos de Aplicação de Sistemas de Controle de Metrô..............97

6.1 O Metrô de Sendai..........................................................................................................97

6.2 O Metrô de São Paulo...........................................................................................106

6.3 Considerações Finais do Capítulo.......................................................................114

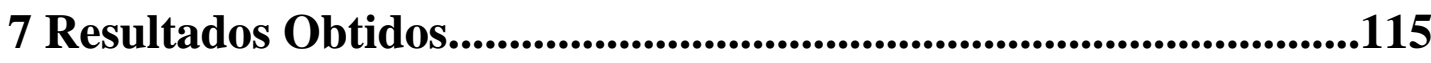

7.1 Introdução.............................................................................................................115

7.2 Circulação Normal de Trens (Situação Operacional Normal)........................118

7.3 Circulação de Trens com a Presença de um Trem Extra Parado entre

Duas Estações (Situação de Falha no Sistema)................................................126

7.4 Circulação de Trens com a Presença de um Trem Extra Movendo-se com

Velocidade Constante entre Duas Estações (Manutenção do Sistema)........130

7.5 Circulação de Trens com a Presença de um Trem Extra Movendo-se com

Velocidade de Via entre Duas Estações (Adensamento de Trens)................136

7.6 Outras Simulações..................................................................................................141

7.7 Considerações Finais do Capítulo.......................................................................143

8 Considerações Finais...............................................................................144

8.1 Introdução.............................................................................................................144

8.2 Dificuldades Encontradas.................................................................................146

8.3 Questão da Segurança na Utilização de Ferramentas de Inteligência

Artificial em Sistemas Críticos de Controle.......................................................148

8.4 Estudos Futuros........................................................................................................150

8.5 Conclusões..............................................................................................151

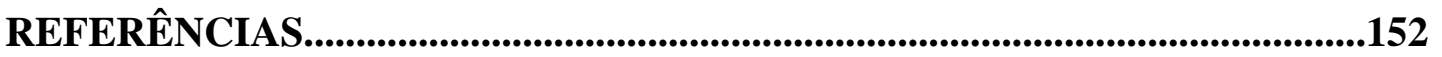

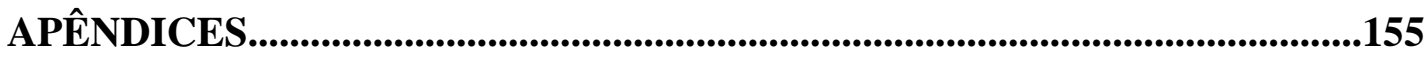

APÊNDICE A - Simulação Utilizando o Simulink do MatLab............................156

APÊNDICE B - Simulação Utilizando o Simulador do Knoma............................157

APÊNDICE C - Medições Reais Efetuadas no Metrô de São Paulo....................158 


\section{ÍNDICE DE FIGURAS}

Figura 1. Sistema de sinalização fixa (UNIVERSITY..., 2005)............................ 26

Figura 2. Sistema com sinaleiro repetidor (UNIVERSITY..., 2005)................... 26

Figura 3. Sistema de sinalização com sinaleiro triplo (UNIVERSITY..., 2005).

Figura 4. Funcionamento da antena de B-Point................................................... 32

Figura 5. Funcionamento do sistema de detecção e transmissão por balizas..... 33

Figura 6. Configuração trançada para refinamento da posição dos trens ao

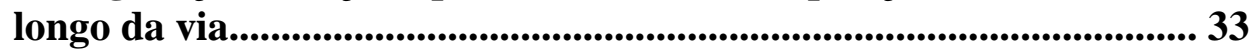

Figura 7. Circuitos de via do tipo DC - bloco desocupado (UNIVERSITY..., 2005)

Figura 8. Circuitos de via do tipo DC - bloco ocupado (UNIVERSITY..., 2005).

Figura 9. Regiões de overlap (UNIVERSITY..., 2005).......................................... 37

Figura 10. Bandas de velocidade (UNIVERSITY..., 2005)................................... 38

Figura 11. Ilustração da técnica "distance to go" (UNIVERSITY..., 2005)......... 38

Figura 12. Diagramas de Venn para as operações entre conjuntos clássicos...... 51

Figura 13. Diagramas de Venn estendidos para representação de operações entre conjuntos nebulosos (JAMSHIDI; VADIEE; ROSS, 1993)...... 54

Figura 14. Demonstração gráfica da não validade das leis de meio exclusivo e contradição para conjuntos nebulosos

(JAMSHIDI; VADIEE; ROSS, 1993).

Figura 15. Descrição das características de uma função de pertinência (JAMSHIDI; VADIEE; ROSS, 1993).................................................... 54

Figura 16. Representações esquemáticas para um conjunto não nebuloso e para um fuzzy singleton (PEDRYCZ, 1993)........................................ 55

Figura 17. Exemplos de conjuntos nebulosos convexos e não-convexos................ 56

Figura 18. Diagrama de um sistema de controle - ciclo fechado (PEDRYCZ,

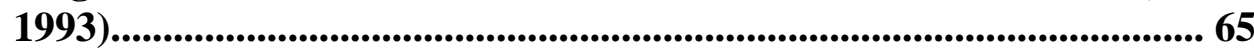

Figura 19. Estrutura do sistema de controle (PEDRYCZ, 1993).........................66 66

Figura 20. Estrutura do sistema de inferência..................................................67 67

Figura 21. Sistemas de controle direto (a) e com supervisão (b)............................ 68

Figura 22. Criação de partições de uma variável de entrada a partir da divisão de sua escala em partições iguais

(JAMSHIDI; VADIEE; ROSS, 1993).

Figura 23. Existência de valores e intervalos típicos na escala da variável (a) e associação de funções de pertinência a estes valores (b)

(JAMSHIDI; VADIEE; ROSS, 1993).

Figura 24. Exemplo de superfície tridimensional de controle................................ 76

Figura 25. Método do “Mínimo de Mamdani” para inferência nebulosa (JAMSHIDI; VADIEE; ROSS, 1993).

Figura 26. Método do "Produto de Larsen” para inferência nebulosa

(JAMSHIDI; VADIEE; ROSS, 1993).

Figura 27. Exemplo de aplicação do método "Média dos Máximos". ................. 80

Figura 28. Exemplo de aplicação do método "Média Ponderada". ..................... 80

Figura 29. Exemplo de aplicação do método do “Centro de Massa”. .................. 80

Figura 30. Diagrama de blocos que representa o sistema proposto. .................... 86

Figura 31. Variáveis de entrada e saída do sistema nebuloso proposto................ 88 
Figura 32. Distribuição das funções de pertinência relativa à variável Distância.

Figura 33. Distribuição das funções de pertinência relativa à variável Velocidade.

Figura 34. Distribuição das funções de pertinência relativa à variável

Aceleração.

Figura 35. Superfície de controle do sistema controlador nebuloso proposto... 91

Figura 36. Exemplo de aplicação do mecanismo de inferência. ............................ 92

Figura 37. Esquema do fluxo de informações no sistema de inferência............... 94

Figura 38. Diagrama de blocos do controlador nebuloso utilizado no

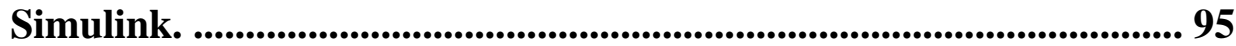

Figura 39. Rede de metrô da cidade de Sendai (URBANRAIL, 2004)................ 98

Figura 40. Trem utilizado no metrô de Sendai (JAPAN...,1988). ....................... 99

Figura 41. Configuração dos equipamentos de bordo do metrô de Sendai

(YASUNOBU et al., 1984).

Figura 42. Diagrama de blocos do controlador do metrô de Sendai

(YASUNOBU et al., 1984).

Figura 43. Esquema de operação do metrô de Sendai (JAPAN..., 1988)............101

Figura 44. Função de Pertinência da Variável Segurança. ................................103

Figura 45. Função de Pertinência da Variável Conforto. .....................................103

Figura 46. Função de Pertinência da Variável Economia de Energia............... 104

Figura 47. Função de Pertinência da Variável Rastreamento de Velocidade.. 104

Figura 48. Função de Pertinência da Variável Tempo de Corrida. .................. 105

Figura 49. Função de Pertinência da Variável Espaçamento de Parada........... 105

Figura 50. Mapa das linhas do Metrô de São Paulo............................................. 107

Figura 51. Trens do metrô de São Paulo das frotas (a)198/108,

(b) Cobrasma/Mafersa e (c) Alstom Milênio.

Figura 52. Modulação do sinal relativo ao código de velocidade.

Figura 53. Configuração dos equipamentos de bordo do metrô de São Paulo. 111

Figura 54. Diagrama de blocos do sistema de controle do metrô de São Paulo.

Figura 55. Representaçãão gráfica dos sinais P e BRK para as diversas situações de propulsão e freio dos trens do metrô de São Paulo. . 113

Figura 56. Mapeamento dos circuitos de via entre as estações Santa Cruz e Praça da Árvore do metrô de São Paulo. ........................................ 117

Figura 57. Gráfico das velocidades dos trens para a $1^{\mathrm{a}}$ Simulação. ................ 118

Figura 58. Gráfico das acelerações dos trens para a $1^{\text {a }}$ Simulação. ................ 121

Figura 59. Gráfico da distância percorrida pelos trens na $1^{\text {a }}$ Simulação. ...... 125

Figura 60. Gráfico das velocidades dos trens para a $2^{\mathrm{a}}$ Simulação. ................ 126

Figura 61. Gráfico das acelerações dos trens para a $2^{\mathrm{a}}$ Simulação. ................ 128

Figura 62. Gráfico da distribuição espacial dos trens na $2^{a}$ Simulação. ........ 129

Figura 63. Gráfico das velocidades dos trens para a $3^{\mathrm{a}}$ Simulação. ................ 130

Figura 64. Gráfico das acelerações dos trens para a $3^{\text {a }}$ Simulação. ................ 132

Figura 65. Gráfico da distribuição espacial dos trens na $3^{a}$ Simulação. ......... 134

Figura 66. Gráfico das velocidades dos trens para a $4^{\mathrm{a}}$ Simulação com o trem da frente utilizando controlador PID. ...................................... 136

Figura 67. Gráfico das velocidades dos trens para a $4^{\mathrm{a}}$ Simulação com o trem da frente utilizando controlador nebuloso.

Figura 68. Gráfico das acelerações dos trens para a $4^{\text {a }}$ Simulação com o trem da frente utilizando controlador PID. 
Figura 69. Gráfico das acelerações dos trens para a $4^{\text {a }}$ Simulação com o trem da frente utilizando controlador nebuloso.

Figura 70. Gráfico da distribuição espacial dos trens na $4^{a}$ Simulação. .......... 139

Figura 71. Gráfico da distribuição espacial dos trens na $4^{\text {a }}$ Simulação. .......... 140

Figura 72. Variação de ND do controlador dos trens do metrô de São Paulo. 142

Figura 73. Resultados gráficos da velocidade (a), aceleração (b) e distância percorrida (c) da $1^{\mathrm{a}}$ simulação - Circulação Normal de Trens utilizando o Simulink

Figura 74. Resultados gráficos da velocidade (a), aceleração (b) e distância percorrida (c) da $1^{a}$ simulação - Circulação Normal de Trens utilizando o simulador desenvolvido no KNOMA/PCS/EPUSP

Figura 75. Resultados gráficos das medições de velocidade e aceleração para o trem do Metrô de São Paulo circulando entre SCZ e ARV nas condições: trem parado entre estações ( $2^{\mathrm{a}}$ simulação) $(\mathrm{a})$; trem movendo-se com velocidade constante entre estações ( $3^{\mathrm{a}}$ simulação) (b) e trem movendo-se com velocidade de via entre estações $\left(4^{\mathrm{a}}\right.$ simulação) (c).

Figura 76. Resultados gráficos das medições de velocidade e aceleração para o trem do Metrô de São Paulo em circulação normal entre SCZ e ARV ( $1^{\mathrm{a}}$ simulação) com ND = 1 (a), ND = 2 (b) e ND = 3 (c). 159

Figura 77. Resultados gráficos das medições de velocidade e aceleração para o trem do Metrô de São Paulo em circulação normal entre SCZ e ARV ( $1^{\mathrm{a}}$ simulação) com ND = 4 (a), ND = 5 (b) e ND = 6 (c). 160 


\section{ÍNDICE DE TABELAS}

Tabela 1 - Notação matemática válida para conjuntos clássicos.

50

Tabela 2 - Tabela da verdade para as proposições $P$ e $Q$ e seus conectivos lógicos (JAMSHIDI; VADIEE; ROSS, 1993).

Tabela 3 - Exemplo de formação da base de regras por matriz de relacionamento. 75

Tabela 4 - Formação do conjunto de regras do sistema nebuloso proposto. ...91

Tabela 5 - Freqüências utilizadas para transmissão dos códigos de velocidade.

Tabela 6 - Bits relativos aos códigos de velocidade disponíveis. 


\section{LISTA DE SIGLAS}

AC
Alternating Current (Corrente Alternada)

Audio Frequency (Freqüência de Áudio)

Estação Praça da Árvore - Metrô de São Paulo

Automatic Train Control (Controle Automático do Trem)

Automatic Train Operation (Operação Automática do Trem)

Automatic Train Protection (Proteção Automática do Trem)

Automatic Train Supervision (Supervisão Automática de Trens)

Automatic Warning System (Sistema de Advertência Automática)

Brake Notch (Comando de Freio - Metrô de Sendai)

Brake Profile Monitor (Monitoração do Perfil de Frenagem)

Communication Based Train Control

(Controle de Trens Baseado em Comunicações)

Centro de Controle Operacional

Constant Speed Control (Controle de Velocidade Constante)

Direct Current (Corrente Contínua)

Departament of Defense (Departamento de Defesa dos Estados Unidos)

Escola Politécnica da Universidade de São Paulo

European Safety and Reliability Association

(Associação Européia de Confiabilidade e Segurança)

Frequency Shift Keying (Modulação por Mudança de Freqüência)

Grupo de Análise de Segurança da Escola Politécnica da Universidade de São Paulo

Global Positioning System (Sistema de Posicionamento Global)

High Voltage Impulse (Impulsos de Alta Tensão) 
IA Inteligência Artificial

IEC International Eletrotechnical Comitee

(Comitê Eletrotécnico Internacional)

IEEE Institute of Electrical, Eletrotechnical and Electronics Engineering (Instituto de Engenharia Elétrica, Eletrotécnica e Eletrônica)

KNOMA Laboratório de Engenharia do Conhecimento da Escola Politécnica da Universidade de São Paulo

LFN Left Fuzzy Number (Número Nebuloso Esquerdo)

MCS Manual Controlado pelo Sistema

MIT Massachussets Institute of Technology

(Instituto de Tecnologia de Massachussets)

NASA National Aeronautics and Space Administration

(Aeronáutica Nacional e Administração Espacial)

ND Nível de Desempenho

OCC Occupation (Ocupação)

P/BRK Propulsion/Brake (Propulsão/Freio)

PCS Departamento de Computação e Sistemas Digitais da Escola

Politécnica da Universidade de São Paulo

PID Proportional Integrational Derivative

(Controlador Proporcional Integral/Diferencial)

PM

Performance Modification (Nível de Desempenho)

PN Power Notch (Comando de Propulsão - Metrô de Sendai)

RFN Right Fuzzy Number (Número Nebuloso Direito)

SCZ Estação Santa Cruz - Metrô de São Paulo

TASC Train Automatic Stop Control

(Controle de Parada Automática do Trem)

TFN

Triangular Fuzzy Number (Número Nebuloso Triangular) 


\section{Introdução}

A história dos meios de transporte se confunde com a história da humanidade, sendo estes um fator de desenvolvimento nos grandes centros urbanos. A engenharia de sistemas de controle encontra na área dos meios de transporte uma de suas diversas aplicações, em especial na área de sistemas críticos de controle para transportes em massa. É neste cenário promissor que o trabalho apresentado nesta dissertação se estabelece como uma busca de alternativas para um sistema metro-ferroviário mais rápido, seguro e confortável, com um custo menor. Um breve histórico, a motivação, os objetivos e a estruturação deste trabalho são apresentados neste capitulo.

\subsection{Histórico}

Uma das necessidades básicas do ser humano que sempre esteve e ainda está presente em sua história é a necessidade de se movimentar dentro de seu espaço. Por causa de seu caráter nômade, o homem primitivo precisava se locomover e carregar seus pertences à procura de lugares onde a sobrevivência era mais fácil. Segundo Ferraz e Torres (2001), grupos humanos costumavam se mover, inicialmente a pé e depois utilizando animais de carga, à procura de comida, água e proteção.

De acordo com o relatório sintético sobre mobilidade elaborado pelo Conselho de Negócios Mundiais para o Desenvolvimento Sustentável (WORLD..., 2001), a mobilidade é uma necessidade essencial à sobrevivência e à interação social, uma vez que estas dependem diretamente da capacidade de deslocamento de pessoas e mercadorias. A mobilidade é um elemento balizador do desenvolvimento urbano, de forma que proporcionar mobilidade a todas as classes sociais é essencial ao desenvolvimento econômico e social das cidades.

O desenvolvimento dos núcleos urbanos depende da facilidade de troca de informações e de produtos com outras localidades, estando diretamente relacionado à evolução dos meios de transporte, que exerceu influência direta na localização e no tamanho das cidades (FERRAZ; TORRES, 2001). 
Não foi por acaso que as primeiras cidades surgiram à beira do mar e de grandes rios e lagos, pois os meios de transportes preponderantes na época eram as embarcações. As atividades comerciais, industriais, econômicas, recreativas etc., essenciais à vida nas cidades modernas, só são possíveis com o deslocamento de pessoas e produtos. Desta forma, o transporte urbano é tão importante quanto os serviços de abastecimento de água, coleta de esgoto, fornecimento de energia elétrica, telefonia, etc., visando a qualidade de vida da população.

O surgimento quase que simultâneo do transporte público em várias cidades decorreu da Revolução Industrial. A produção de bens, que era até então feita nas próprias casas dos trabalhadores, de forma artesanal e utilizando ferramentas rudimentares, passou a ser realizada com a ajuda de máquinas e ferramentas especiais localizadas nas fábricas, obrigando os trabalhadores a se deslocarem diariamente de suas casas às fábricas.

Com isto, surgiram os primeiros sistemas de transporte coletivo, denominados de omnibus, palavra que, em latim, significa para todos. Estes veículos eram carruagens com capacidade entre 10 e 20 passageiros e possuíam tração animal. Diversas tentativas foram feitas para proporcionar tração mecânica aos omnibus, mas nenhuma delas teve sucesso, até o início de 1890, quando surgiram os primeiros ônibus movidos à gasolina. Já em 1920 surgiram os primeiros ônibus movidos a óleo diesel. O ônibus elétrico (trólebus) encontrou grande aplicação entre 1920 e 1950, sendo ainda hoje aplicado em algumas cidades. O custo de operação superior ao do ônibus a diesel, a rigidez das rotas e a menor confiabilidade do sistema contribuíram para o declínio do trólebus no Brasil.

Em 1832, surgiram os primeiros bondes - veículos que se moviam sobre trilhos e eram inicialmente puxados por animais. Na última década do século XIX, surgiram os primeiros bondes com tração elétrica.

A utilização de trens convencionais para o transporte urbano só ocorreu na segunda metade do século XIX, quando algumas cidades já possuíam um grande tamanho e passou a ser viável o transporte de passageiros entre os subúrbios e a zona central das cidades. Inicialmente com tração a vapor, os trens apresentaram um crescimento mais acelerado a partir do surgimento das locomotivas elétricas.

O transporte do tipo metrô, que consistia em uma ferrovia subterrânea ou elevada, surgiu em 1863, em Londres, para aliviar o congestionamento de trânsito nas regiões centrais das grandes cidades em horários de maior movimento (FERRAZ; TORRES, 2001). 
Com o surgimento da locomotiva elétrica no final do século XIX, os sistemas de metrô se expandiram em algumas grandes cidades do mundo. Em 1930 já havia metrô em muitos dos grandes centros urbanos dos países desenvolvidos. Embora apresente um custo de implantação bastante elevado, o metrô é o sistema de transporte mais indicado para as grandes cidades, a fim de evitar o colapso do trânsito na superfície (FERRAZ; TORRES, 2001).

Desta forma, torna-se vital a busca de alternativas para evitar o colapso dos sistemas de transporte nas grandes cidades. A tecnologia de sistemas de controle fornece ferramentas para o desenvolvimento de alternativas de transporte, sempre buscando o atendimento às necessidades de redução de custos, rapidez e segurança. Também é importante a busca de soluções que preservem o meio ambiente, minimizando os problemas de poluição e alterações climáticas (WORLD..., 2001).

Em se tratando de sistemas de controle, Weyrick (1975) afirma que o advento do controle automático representou uma segunda revolução industrial, pois a primeira Revolução Industrial disponibilizou uma maior variedade e uma maior quantidade de energia para utilização pelo homem. Fontes de energia, como a água e o vento abriram espaço para outras fontes, como o vapor e a eletricidade, enquanto combustíveis como carvão, gás e petróleo eram as principais fontes de energia utilizadas na produção e no transporte.

Para a utilização da energia de forma eficiente, é necessário efetuar o controle e a regulação desta utilização, e novamente a Revolução Industrial é o marco indicativo da aquisição desta habilidade pelo homem. Com potência e controle, uma parte do trabalho físico e mental podia ser executado por máquinas, com um desempenho até então impossível de ser alcançado. As atividades industriais então necessitavam de um controle automático, abrindo uma nova área de aplicação para a teoria de sistemas de controle.

Historicamente, o primeiro sistema de controle automático existente foi desenvolvido por James Watt, em 1788, e era denominado de governador de bola girante. Watt concluiu que o controle manual de abertura e fechamento de uma válvula a vapor não era a forma mais eficiente de controlar a velocidade de um motor a vapor e projetou um controlador totalmente mecânico composto por uma bola mecanicamente acoplada a um eixo do motor a vapor. Quando a velocidade do motor aumentava, a bola acoplada ao eixo girava mais rapidamente e movia-se para fora, provocando o fechamento da válvula e a diminuição da velocidade do motor; quando a velocidade do motor diminuía, a bola girava mais devagar e movia-se para dentro, abrindo a válvula a vapor e aumentando a velocidade do motor (WEYRICK, 1975). 
O advento da segunda guerra mundial, a criação da NASA (National Aeronautics and Space Administration) e o lançamento do programa espacial americano, em 1958, trouxeram um aumento de demanda no campo de sistemas de controle automático. A necessidade de um controle rápido, preciso e seguro de navios, aviões, aeronaves, foguetes e sistemas de radar trouxe numerosos avanços na teoria de controle (WEYRICK, 1975).

O desenvolvimento da eletrônica permitiu a miniaturização dos sistemas, levando à criação dos primeiros sistemas embarcados de controle. O primeiro sistema moderno embarcado de controle foi utilizado nas aeronaves da missão Apolo e foi desenvolvido por Charles Stark Draper nos laboratórios de instrumentação do MIT, na década de 60.

Com o surgimento das restrições de segurança e a criação do departamento de defesa (DoD) em 1949, nos Estados Unidos, surgia uma especialização na área de sistemas de controle - a área de sistemas críticos, que tratava dos sistemas onde a segurança era um importante requisito de operação. Para atender a este requisito foram desenvolvidos os primeiros trabalhos na área de tolerância a falhas (CAMARGO JÚNIOR, 1996).

Johnson (1989) relatou em seu livro que o primeiro trabalho teórico no campo da computação tolerante a falhas é creditado a John Von Neumann, em 1956. Neste trabalho, Neumann apresentou uma série de artigos sobre o uso de módulos de lógica replicados e associados para aumentar a confiabilidade de um sistema e apresentou o conceito de votação majoritária para diminuir a probabilidade de um sistema produzir resultados errôneos.

Os primeiros computadores digitais foram produzidos utilizando técnicas de detecção de erros e técnicas de tolerância a falhas para compensar a baixa confiabilidade de seus componentes básicos. Assim, alguns computadores possuíam duas unidades centrais de processamento ou mecanismos para repetições de operações ou verificação de dados durante transferências de informações (JOHNSON, 1989).

Desde então, uma maior atenção foi dispensada em relação às aplicações críticas, levando à criação de normas e associações específicas para a padronização e tratamento comum de problemas relativos às áreas de aplicações críticas de controle, como aviação, processos químicos e nucleares e aplicações metro-ferroviárias, como por exemplo as normas IEC (International Electrotechnical Commission) que tratam da segurança funcional em sistemas elétricos, eletrônicos e programáveis, e a ESRA (European Safety and Reliability Association), uma associação de entidades européias que cuida de assuntos relativos à confiabilidade e segurança de sistemas, em especial na área de transporte metro-ferroviário. 
A Universidade de Sheffield, em suas Páginas Técnicas Ferroviárias (Railway Technical Web Pages), relata em seu artigo sobre o desenvolvimento da sinalização ferroviária (UNIVERSITY..., 2005) que desde o surgimento da locomotiva a vapor e das primeiras ferrovias, a tecnologia e a engenharia sempre estiveram intimamente ligadas com o seu desenvolvimento. Inicialmente, as primeiras locomotivas possuíam somente componentes mecânicos e eram utilizados conceitos da mecânica e da termodinâmica no projeto e na operação destas locomotivas.

Com a descoberta da eletricidade, alguns componentes eletromecânicos como chaves, relés e contatores foram introduzidos nos projetos de trens, vias e sinalização. Os motores a vapor foram sendo substituídos gradualmente pelos motores elétricos, que não poluíam o ambiente e eram mais fáceis de serem manuseados, não necessitando de foguista para a alimentação da fornalha (UNIVERSITY..., 2005).

Com o desenvolvimento da eletrônica, a parte de sinalização e controle foi sendo gradualmente substituída por componentes eletrônicos, com maior confiabilidade e um menor consumo de energia. $\mathrm{O}$ advento dos transistores trouxe um aumento de confiabilidade nos componentes eletrônicos de estado sólido, em comparação com as válvulas até então utilizadas nos dispositivos de sinalização e controle. Com o tempo, a tecnologia de integração de circuitos permitiu a fabricação de circuitos integrados que realizavam um maior número de operações em uma mesma pastilha semicondutora.

O advento dos microprocessadores também fez com que os sistemas de controle de sinalização de via e de bordo se tornassem sistemas computadorizados. De acordo com a empresa Hitachi, em seu artigo sobre o futuro dos sistemas ferroviários (HITACHI, 2003), muitas funções até então controladas e efetuadas por circuitos eletrônicos passaram a ser efetuadas por programas executados por microprocessadores e micro-controladores, principalmente com aplicação em sistemas embarcados.

Portanto, os sistemas de computação têm, especialmente considerando as aplicações em sistemas críticos de controle, uma grande importância no desenvolvimento de sistemas de controle metro-ferroviários. Estudos na área de inteligência artificial, como a aplicação de lógica nebulosa preditiva apresentada neste trabalho, bem como estudos nas áreas de utilização de redes neurais e de gestão do conhecimento para o projeto e desenvolvimento de sistemas especialistas, têm sido cada vez mais aprimorados, com o desenvolvimento de novas técnicas e de novas tecnologias de aplicação prática no setor. 


\subsection{Motivação}

O problema crítico dos transportes nas grandes cidades, em particular na cidade de São Paulo, e o sistema de controle implementado atualmente por meio de computadores nos sistemas metro-ferroviários constituem uma importante motivação para a realização deste trabalho. A necessidade de um melhor aproveitamento dos recursos devido à limitação de investimentos e o desafio de se efetuar este aproveitamento sob o ponto de vista de melhoria da qualidade dos processos operacionais e de manutenção complementa esta.motivação.

A possibilidade da implementação de uma solução utilizando lógica nebulosa para o problema crítico dos transportes nas grandes cidades utilizando técnicas de engenharia de sistemas de controle, em especial na aplicação de sistemas críticos de controle, representa outra forte motivação para o estudo. A área de sistemas de controle utilizando sistemas computacionais vem sendo, a cada dia, suprida com novas ferramentas e novas tecnologias, sendo que o trabalho desenvolvido neste estudo apresenta uma oportunidade de aplicação e análise destas ferramentas.

As características da lógica nebulosa preditiva como solução proposta para o controle de trens representa outro fator de motivação para o estudo. McNeill (1994) mostra que existe um sistema de controle de trens utilizando lógica nebulosa em funcionamento, desde 1987, na cidade de Sendai, no Japão. Este sistema mantém os trens rodando de forma eficiente, freando e acelerando suavemente e parando precisamente ao longo das plataformas, otimizando o intervalo de tempo decorrido entre estações. O sucesso desta aplicação (metrô de Sendai) demonstra que a lógica nebulosa preditiva é viável para este tipo de controle.

Por fim, a análise da possibilidade de utilização de uma técnica da área de Inteligência Artificial, a lógica nebulosa preditiva, para a obtenção de um controlador de tráfego de trens mais eficiente, sem que sejam comprometidas as margens de segurança do sistema, complementa a motivação para o estudo. O fato do sistema em estudo ser um sistema crítico de controle exige que todo um cuidado seja tomado com relação à segurança da aplicação proposta, de forma a obedecer toda uma série de especificações expressas em normas desenvolvidas por associações internacionais de segurança metro-ferroviárias. Esta exigência representa um desafio ao desenvolvimento do estudo proposto, complementando a motivação para o desenvolvimento deste trabalho. 


\subsection{Objetivos}

O objetivo desta dissertação é utilizar ferramentas e tecnologias disponíveis nas áreas de engenharia de sistemas de controle computacionais, em especial nas áreas de sistemas críticos de controle, inteligência artificial e gestão do conhecimento, para propor uma forma mais eficiente de controle de tráfego de trens de acordo com a necessidade de demanda operacional de um sistema metro-ferroviário, bem como a verificação e análise da viabilidade da aplicação destas ferramentas e tecnologias.

O sistema de controle proposto deve permitir um melhor aproveitamento dos recursos existentes em função da demanda de passageiros. Para isso, são utilizados conceitos de lógica nebulosa preditiva no projeto de um sistema especialista para o controle do tráfego de trens. $\mathrm{O}$ sistema de controle proposto incorpora, também, o conhecimento do especialista humano (operador de trens) e deve atender aos requisitos de segurança de uma aplicação crítica de controle.

A variável normalmente utilizada para o controle de tráfego de trens de acordo com a demanda operacional é denominada headway, que é o intervalo de tempo decorrido entre dois trens consecutivos. Este conceito é traduzido operacionalmente como sendo o tempo médio necessário para um trem percorrer o espaço entre duas estações consecutivas.

No caso do metrô de São Paulo, o controle do headway é efetuado modificando-se o desempenho operacional de um trem por meio do controle de sua velocidade máxima e de sua taxa de aceleração máxima no próximo trecho entre estações a ser percorrido. O comando de modificação de desempenho é transmitido durante a partida do trem na plataforma da estação, podendo ser alterado somente durante a partida do trem na próxima estação. Esta característica não permite muita flexibilidade ao comando de modificação de desempenho e as mudanças de comando devem ser efetuadas em intervalos de tempo determinados.

As características da lógica nebulosa preditiva tornam o sistema de controle proposto ideal para este tipo de aplicações, por possuir embutido o conhecimento especialista do operador do trem e por permitir uma lógica operacional mais próxima da forma humana de operação. Yasunobu e Miyamoto (1985) afirmam que, como conseqüência destas características da lógica nebulosa preditiva, a operação se torna mais suave, eliminando os trancos nos trens provocados pela mudança brusca de comandos de propulsão e frenagem utilizados com a lógica tradicional. 
Com a eliminação dos trancos nos trens, um maior conforto aos passageiros é proporcionado. Do ponto de vista da manutenção, existe um menor número de acionamentos de propulsão e frenagem, prolongando a vida útil dos componentes eletromecânicos de acionamento dos motores e dos freios e proporcionando também uma diminuição no consumo de energia.

Outro objetivo deste trabalho é analisar a viabilidade de aplicação da lógica nebulosa preditiva em sistemas críticos de controle, em especial nos sistemas de controle automático de trens. Esta viabilidade é analisada em termos dos benefícios e desvantagens proporcionados pelo sistema de controle nebuloso, bem como em termos da análise das implicações de segurança resultantes desta aplicação.

O sistema de controle de trens proposto deve proporcionar um controle mais flexível do headway em função da demanda do sistema. Além disso, as características da lógica nebulosa preditiva fazem com que o controlador proposto apresente um menor consumo de energia, necessite de um menor número de manutenções e proporcione um maior conforto aos passageiros com a eliminação dos trancos causados por mudanças nos comandos de propulsão e frenagem do trem.

\subsection{Organização do Trabalho}

Esta dissertação está organizada em 8 capítulos. Nos primeiros capítulos são descritas técnicas utilizadas nos sistemas de controle automático de trens, conceitos matemáticos necessários à compreensão e aplicação da lógica nebulosa preditiva e conceitos de engenharia de sistemas de controle necessários à compreensão e ao projeto de sistemas especialistas de controle. Com base nestes conceitos, é efetuada uma modelagem para a proposta de um controlador de tráfego de trens utilizando a lógica nebulosa preditiva.

Nos capítulos seguintes, exemplos práticos de sistemas de controle de trens, como os sistemas utilizados nos metrôs da cidade de Sendai, no Japão e da cidade de São Paulo, no Brasil, são apresentados. Com base nesta comparação de resultados, são efetuadas as conclusões e considerações finais do estudo, levando à viabilidade de utilização da lógica nebulosa preditiva para o controle automático de trens. 
No Capítulo 2 os sistemas de controle automático de trens (ATC) são apresentados, situando-os no contexto do controle de tráfego de trens, bem como seus relacionamentos com os sistemas de controle de via e com os sistemas auxiliares de controle de propulsão e frenagem dos trens. Um breve histórico das técnicas utilizadas no desenvolvimento de sistemas de controle automático de trens e as funções básicas deste tipo de sistema são apresentadas e detalhadas.

O Capítulo 3 apresenta os elementos da lógica nebulosa preditiva, efetuando uma introdução ao estudo de conjuntos nebulosos a partir da teoria clássica de conjuntos. Também é efetuado um paralelo na apresentação dos conceitos de lógica nebulosa em comparação aos conceitos da lógica clássica. As propriedades dos conjuntos e da lógica nebulosa são de grande utilidade na conceituação e no projeto do sistema de controle proposto.

Os sistemas de controle, em especial os sistemas especialistas e de inferência, são apresentados no Capítulo 4, com um destaque para os sistemas nebulosos de inferência. A estruturação dos sistemas de gestão do conhecimento, com suas bases de dados (expressas em bases de regras e nas variáveis de entrada e saída) e bases de conhecimento (expressas nas decisões e nas implicações efetuadas a partir dos dados de entrada do sistema), é detalhada e analisada, usando sua organização e funcionamento. A forma como o conhecimento especialista é aproveitado também é apresentada neste contexto.

No Capítulo 5 é efetuada a modelagem do sistema de controle nebuloso proposto. O modelo de sistema especialista nebuloso de inferência para utilização em controle automático de trens é apresentado e todas as fases do seu desenvolvimento são detalhadas. As propriedades apresentadas nos Capítulos 2, 3 e 4 são então aplicadas na modelagem do sistema de controle nebuloso proposto.

O Capítulo 6 trata de exemplos de aplicação de controle automático de trens. O sistema utilizado no metrô da cidade de Sendai, no Japão, utilizado como base para o desenvolvimento deste trabalho, é apresentado e suas características são detalhadas e analisadas, bem como o modelo de controle PID utilizado atualmente para o controle dos trens utilizado no metrô de São Paulo.

Os resultados das simulações efetuadas sobre a modelagem matemática do sistema nebuloso de controle são apresentados no Capítulo 7. Algumas situações operacionais específicas são simuladas e os resultados apresentados e analisados. 
Por fim, o Capítulo 8 apresenta as considerações finais deste trabalho, com as conclusões sobre a viabilidade da aplicação da lógica nebulosa em sistemas de controle automático de trens, as vantagens e desvantagens do sistema proposto com relação ao sistema utilizado atualmente no metrô de São Paulo, as propostas para trabalhos de pesquisa futuros e as considerações a serem analisadas para uma eventual implantação do sistema.

\subsection{Considerações Finais do Capítulo}

Este capítulo teve por objetivo apresentar o estudo objeto desta dissertação, localizando-o no contexto metro-ferroviário. Uma vez apresentada esta introdução contendo o resumo do trabalho, seu cenário, as motivações para o estudo e o dimensionamento do problema que ele se propõe a resolver, bem como os objetivos a serem alcançados e a organização do estudo, o próximo passo consiste na apresentação dos conceitos teóricos sobre sistemas de controle automático de trens necessários à compreensão e à aplicação do modelo proposto. 


\section{Sistemas de Controle Automático de Trens}

Para efetuar o controle automático das funções do trem, o sistema de controle de bordo deve estar interligado ao sistema de sinalização de via e aos sistemas auxiliares do trem. O sistema de sinalização de via transmite ao sistema de controle de bordo comandos de velocidade para uma circulação de trens eficiente e segura. Com base nestes comandos, os equipamentos de controle de bordo efetuam o controle dos sistemas auxiliares de propulsão e

freio do trem, fazendo com que este se movimente de uma maneira segura. Neste capítulo são apresentadas algumas técnicas utilizadas nos sistemas de sinalização de via, controle de bordo e sistemas auxiliares envolvidos.

\subsection{Histórico}

A história dos meios de transporte sempre esteve ligada à história do homem e ao desenvolvimento da tecnologia. Até o início do século XIX, os meios de transporte disponíveis evoluíram dos deslocamentos a pé e com animais de carga até carroças e carruagens de tração animal e barcos a vela. Com a descoberta da máquina a vapor, no final do século XVIII, foram inventados os barcos e as locomotivas a vapor, iniciando a história dos sistemas ferroviários. Depois, no início do século XX, foram inventados os primeiros automóveis e aviões (FERRAZ; TORRES, 2001).

Somente em 1830 foram inaugurados os primeiros sistemas ferroviários existentes. Nesta época, não havia sinalização de via para informar ao maquinista o estado da linha de trilhos à frente e os trens eram dirigidos baseados na experiência e nos sentidos do maquinista, que tinha de olhar a linha à frente em busca de qualquer obstáculo, de forma a poder parar o trem antes de uma possível colisão com o obstáculo. Alguns acidentes demonstraram que era muito difícil parar o trem no intervalo de alcance de vista do maquinista, devido ao sistema de freios até então ser deficiente e à baixa aderência do contato rodas-trilho (UNIVERSITY..., 2005). 
Alguma solução prática deveria ser implantada para evitar que os trens se chocassem uns com os outros ou com algum obstáculo na via. Uma solução prática da época baseava-se em intervalos de tempo, tendo sido a primeira tentativa de estabelecimento de um headway (intervalo de tempo entre trens). Este é o princípio do sistema de despacho de trens (dispatching).

Barwell (1973) define despacho de trens como um sistema de atendimento à demanda baseado no intervalo de trens. As ferrovias escolheram um intervalo de tempo definido (algo em torno de 10 minutos) a partir do qual um trem somente poderia rodar à máxima velocidade depois de decorrido este intervalo de tempo desde a partida ou passagem do trem anterior pela estação.

O primeiro sistema de sinalização estava também estabelecido: funcionários da ferrovia manuseavam bandeirolas vermelhas, amarelas e verdes para sinalizar ao maquinista como este deveria proceder - a bandeirola vermelha era manuseada durante os primeiros cinco minutos desde a partida do trem anterior, a bandeirola amarela entre cinco e dez minutos (sinalizando que o maquinista deveria se preparar para a partida) e a bandeirola verde após dez minutos, sinalizando que o trem poderia partir.

O sistema de intervalo de tempo também apresentava problemas: a confiabilidade dos trens era baixa e muito freqüentemente os trens apresentavam problemas e paravam entre as estações, sem sinalização ao trem seguinte, podendo causar um choque entre os trens. Por causa do aumento da demanda de utilização da ferrovia, o intervalo entre trens também necessitava ser reduzido, aumentando ainda mais o risco de colisões (UNIVERSITY..., 2005).

O sistema de sinalização fixa surgiu para solucionar estes problemas. A idéia básica consistia em se dividir a via em blocos, onde dentro de um bloco era permitida a circulação de apenas um trem por vez. Cada bloco possuía um sinaleiro na entrada, indicando sua situação (se estava ocupado por outro trem ou estava desocupado). Se o bloco estivesse ocupado, o trem deveria esperar até que o bloco fosse desocupado, sendo permitido assim o acesso. Este sistema era considerado eficiente, desde que o maquinista conseguisse visualizar o sinaleiro a tempo de parar o trem antes do início do bloco e desde que este fosse suficientemente grande para conter o espaçamento necessário à parada total do próximo trem (BARWELL, 1973).

A Figura 1 mostra o princípio básico de funcionamento do sistema de sinalização fixa, indicando dois blocos - um ocupado (bloco 3) e outro sem ocupação (bloco 2), demonstrando o funcionamento dos sinaleiros no sistema de sinalização fixa (UNIVERSITY..., 2005). 


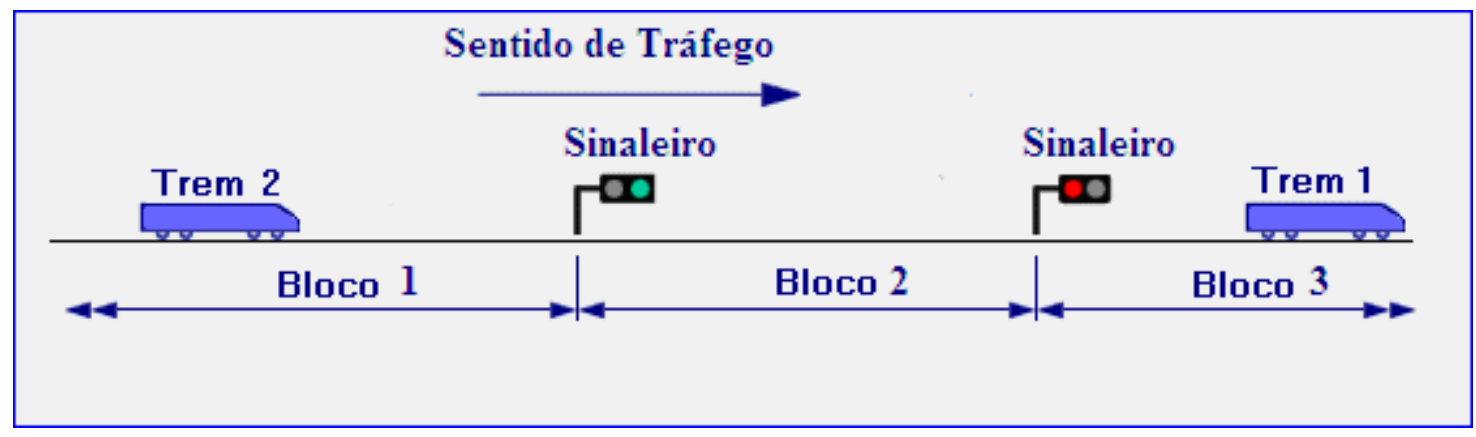

Figura 1. Sistema de sinalização fixa (UNIVERSITY..., 2005).

Para auxiliar a visualização em áreas onde a curvatura da via ou outros obstáculos naturais impedissem a visão do maquinista, sinaleiros repetidores antecediam os sinaleiros de início do bloco, alertando sua proximidade, conforme mostrado na Figura 2.

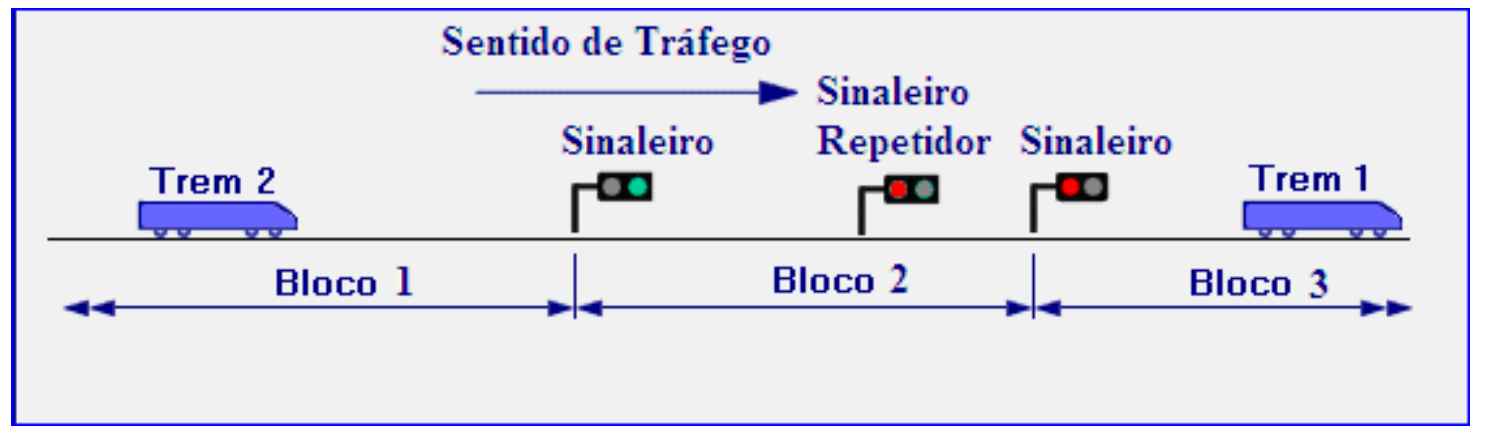

Figura 2. Sistema com sinaleiro repetidor (UNIVERSITY..., 2005).

Para a operação com velocidades mais altas, o operador do trem precisava de um sinal de advertência antes que um sinal vermelho fosse visualizado e houvesse espaço suficiente à parada do trem. Para resolver este problema, foram criados os sinaleiros com múltiplas informações. A Figura 3 mostra sinaleiros triplos que indicam a ocupação do bloco seguinte e a situação de ocupação de dois blocos à frente (UNIVERSITY..., 2005).

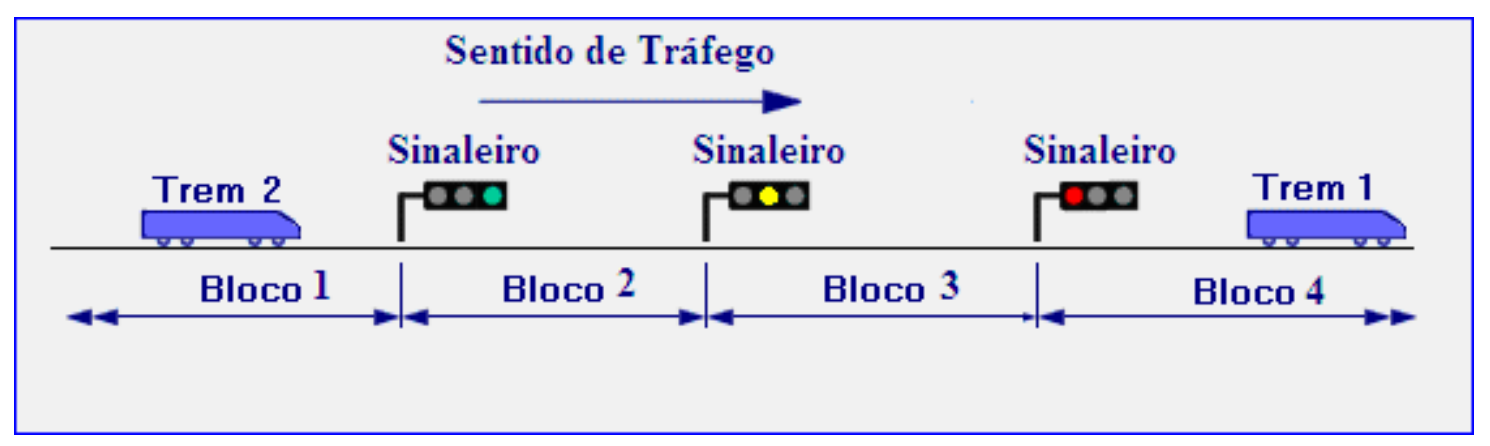

Figura 3. Sistema de sinalização com sinaleiro triplo (UNIVERSITY..., 2005). 
A sinalização múltipla mais utilizada nas ferrovias inglesas é o sinaleiro quádruplo, que possui duas sinalizações amarelas para indicar a presença de um sinaleiro vermelho em até três blocos à frente do bloco atual, em contrapartida ao sinaleiro triplo, que indica a ocupação em até dois blocos à frente (UNIVERSITY..., 2005).

De acordo com a Institution of Railway Signal Engineers (INSTITUTION..., 1995), os sinaleiros utilizados na sinalização fixa eram sinais mecânicos e operados manualmente por funcionários da ferrovia. Com a invenção do telégrafo, as mensagens entre os sinaleiros passaram a ser transmitidas por este sistema de códigos. Os dispositivos mecânicos foram substituídos por relés eletromagnéticos e, depois, por circuitos eletrônicos, para garantir a segurança e a integridade das operações.

No final do século XIX foram inventados os primeiros circuitos de via, que eram trechos da via com detecção e sinalização automática de trens. O metrô de Londres foi o primeiro a utilizar circuitos de via em larga escala, entre 1904 e 1906 . Com o tempo, os circuitos de via foram aperfeiçoados para também funcionar como meios de transmissão de dados entre os equipamentos de via e os equipamentos de bordo do trem.

Este sistema é conhecido como sistema de transmissão contínua de dados, porque os dados estão sendo continuamente transmitidos do equipamento de controle ao equipamento de bordo do trem por meio dos trilhos de rolamento. Um outro tipo de sistema de transmissão de dados entre os equipamentos de bordo e de via é o sistema de transmissão intermitente de dados, feito com o uso de balizas dispostas ao longo da via. As balizas possuem a função de transmissão de dados, enquanto as funções de localização e sinalização do trem continuam sendo feitas pelo circuito de via. As balizas efetuam a transmissão somente no intervalo de tempo em que o trem está próximo às balizas.

Uma característica de segurança introduzida no meio do século XIX foi o intertravamento de máquinas de chave ${ }^{1}$ e sinaleiros para configurar as rotas dos trens de forma segura. O objetivo era evitar conflitos de utilização de um mesmo trecho da via por trens com rotas diferentes. Inicialmente, estes equipamentos eram compostos por conexões mecânicas que acionavam as máquinas de chave e os sinaleiros, evitando este acionamento em caso de conflito de rotas. Com o tempo, estas conexões mecânicas foram substituídas por chaves e botões e, posteriormente, por relés e contatores eletromagnéticos (UNIVERSITY..., 2005).

\footnotetext{
${ }^{1}$ Máquina de chave - Equipamento utilizado para proporcionar a mudança de via pelo trem em desvios.
} 
À medida que a tecnologia de sinalização foi sendo desenvolvida, houve muitos refinamentos ao sistema de sinalização fixa, mas nos últimos anos houve uma ênfase na tentativa de se eliminar os blocos fixos. Uma primeira tentativa de se eliminar os blocos fixos foi efetuada no sistema Seltrac da Alcatel, utilizado no Canadá, e na ferrovia Docklands Light, em Londres, onde um cabo era disposto entre os trilhos, efetuando loops de indução a cada 25 metros, para localizar mais precisamente os trens ao longo da via. Os dados da posição dos trens são transmitidos do equipamento de bordo ao centro de controle com o uso de loops. $\mathrm{O}$ centro de controle efetua o controle da velocidade dos trens baseado na posição do trem à frente, calculando um perfil seguro para frenagem (UNIVERSITY..., 2005).

Com o sistema de sinalização móvel, a distância entre os trens pode variar de acordo com suas velocidades relativas. Em teoria, dois trens com a mesma capacidade de frenagem podem andar a uma mesma velocidade com espaço mínimo entre eles. Porém, a prática revelou a necessidade de se implementar uma distância segura para compensação do tempo de reação do sistema e das diferenças na capacidade de frenagem apresentadas pelos trens. A principal vantagem na utilização do sistema de sinalização móvel é sua independência dos equipamentos colocados ao longo da via. Por outro lado, o sistema de controle deverá possuir uma resposta em tempo real com um mínimo de atrasos possível.

O sistema de sinalização móvel, entretanto, requer um sistema de comunicação entre os trens denominado de CBTC - Communications Based Train Control ou TBS Transmission Based Signalling, de forma a permitir a localização, a obtenção de informações sobre a velocidade e o sentido de tráfego dos trens. Neste caso, para permitir uma maior aproximação entre os trens de uma forma segura, este sistema de comunicação possui uma função crítica no sistema de controle, devendo prover mecanismos para proteção do sistema em caso de perda de comunicação, bem como mecanismos de validação e atualização da informação transmitida. O sistema de rádio-transmissão é considerado o meio prático que melhor atende às necessidades críticas deste sistema de controle.

A principal função dos equipamentos de via é sinalizar ao operador do trem as condições da via à sua frente, permitindo um tráfego seguro. Desta forma, os equipamentos de sinalização de via devem ser projetados utilizando a filosofia fail-safe (falha segura), na qual qualquer falha do sistema deve conduzi-los a uma condição segura (INSTITUTION..., 1995). 
Os primeiros sistemas de controle de bordo surgiram com a necessidade de monitoração do trem ao longo da via. Os sistemas de sinalização fixa até então existentes dependiam totalmente da vigilância do maquinista. Se o maquinista falhasse em parar o trem diante de um sinaleiro fechado, o trem poderia invadir um trecho ocupado e colidir com o trem à frente. Para evitar que isto acontecesse, sistemas de advertência e de proteção foram então implementados.

O primeiro sistema de advertência monitorava o estado da sinalização fixa dos circuitos de via. Se o sinaleiro indicasse que o próximo trecho estava livre (sinalização verde), nada ocorria; porém, se o sinaleiro indicasse ocupação do próximo trecho (sinalização vermelha), um sinal sonoro era acionado na cabine de operação e o maquinista teria de tomar ciência do ocorrido, pressionando um botão de cancelamento em um intervalo de quatro segundos antes que o freio de emergência fosse acionado. Este sistema foi conhecido como Sistema de Advertência Automático (ou AWS - Automatic Warning System).

O primeiro sistema de proteção foi estabelecido para evitar acidentes em caso de acionamento indevido do botão de cancelamento de advertência. O sistema consistia de um braço mecânico acoplado ao sinaleiro. Quando indicava ocupação do trecho (sinalização vermelha), o braço era levantado e físicamente acionava uma alavanca instalada no trem, caso este passasse por um sinaleiro vermelho. Isto causava um corte da potência dos motores e a aplicação de freios de emergência. Se o sinaleiro indicasse que o próximo trecho estava livre (sinalização verde), o braço mecânico permanecia abaixado e o sistema não era acionado no trem. Este sistema foi denominado de Sistema de Proteção Automática do Trem (ou ATP Automatic Train Protection) e foi utilizado pela primeira vez na Inglaterra em 1904 (UNIVERSITY..., 2005).

O sistema ATP engloba as funções do sistema AWS e forma a base dos sistemas eletrônicos e computadorizados de ATP utilizados nos trens de hoje. O congresso americano (UNITED...,1976) estabelece que o sistema de ATP consiste em todos os componentes do sistema que efetuam a proteção automática do trem e suas principais funções são: detecção da posição do trem, garantia de espaçamento seguro entre trens (para se evitar colisões), intertravamento de rotas (para evitar conflitos de ocupação simultânea de um mesmo trecho da via), proteção contra sobrevelocidade e descarrilamento, além da vigilância das condições de segurança do trem e da via. 
$\mathrm{O}$ estabelecimento de limites para velocidade em circuitos anteriores a um trecho ocupado faz parte do sistema de ATP, embora esta função esteja localizada nos equipamentos de sinalização de via. Por exemplo, um trecho imediatamente anterior a um trecho ocupado sempre possuirá um código de velocidade zero, para evitar que um trem adentre no circuito e efetue uma colisão com o trem à frente. Após um trecho com velocidade zero, os códigos de velocidade vão aumentando até completar o perfil de velocidades, permitindo um controle eficiente do trem sem causar desconforto nem insegurança aos passageiros (UNIVERSITY..., 2005).

O sistema de via, além de executar parte das funções de ATP, realiza as funções de supervisão do trem e da via, denominadas de ATS (Automatic Train Supervision). As funções de ATS incluem a detecção do posicionamento de todos os trens e a monitoração do espaçamento entre eles. O sistema de bordo que efetua a monitoração e controle da velocidade real do trem em função dos limites de velocidade estabelecidos, nos diversos circuitos de via, também faz parte dos sistemas de ATP, assim como os sistemas auxiliares de acionamento do freio elétrico e pneumático do trem. Por se tratar de funções que envolvem segurança, estas funções devem ser realizadas utilizando a filosofia fail-safe (falha segura), na qual qualquer falha do sistema deve conduzi-lo a uma condição segura.

A maioria dos sistemas de ATP de hoje em dia incorpora um perfil de frenagem para o trem que, além de garantir que o trem esteja sempre a uma velocidade abaixo da velocidade limite para o trecho que está percorrendo, garante também que a velocidade limite do próximo trecho será atingida segundo um perfil de frenagem confortável para os passageiros, caso seja necessário. Este controle do perfil de frenagem é calculado em função da capacidade de frenagem do trem, da distância ao próximo circuito de via e da velocidade permitida para o próximo circuito de via, sendo denominado de controle de BPM (Brake Profile Monitor). Desta forma, o sistema de ATP efetua uma constante comparação entre a velocidade real do trem e a velocidade comandada para cada circuito de via.

Normalmente, em lugar de sinalizar ao operador a ocupação ou não de um trecho, o sistema de ATP sinaliza a velocidade limite do trecho no qual o trem está (e usualmente a velocidade limite do trecho seguinte), bem como a velocidade real do trem. No caso do trem poder ser operado manualmente, o sistema ATP deverá aplicar freio máximo no caso da velocidade limite do trecho ser atingida (UNITED..., 1976). 
Além de realizar as funções que envolvem a segurança dos trens, os sistemas de bordo também realizam uma série de atividades que estão relacionadas à operação do trem sem envolver sua segurança. É o caso, por exemplo, das funções relativas à abertura e fechamento das portas, parada programada na plataforma das estações, transmissão e recepção de identificação entre o trem e as estações e o controle de desempenho ${ }^{2}$ do trem. Estas funções são denominadas de funções ATO (Automatic Train Operation).

Os equipamentos de via que executam as funções de ATO estão normalmente nas estações, por efetuarem controles de funções na plataforma. As informações de identificação e de controle de desempenho dos trens também são normalmente transmitidas ao trem no tempo em que este está parado na plataforma (UNIVERSITY..., 2005).

Os equipamentos de bordo que realizam as funções de ATO processam as informações transmitidas pelos equipamentos de estação sobre a posição do trem ao longo da plataforma, os comandos de abertura e fechamento de portas, os comandos de modificação de desempenho do trem e as informações de identificação do trem, comandando as ações de desaceleração para parada programada, abertura e fechamento de portas e registro das informações de identificação. Por outro lado, o trem também transmite aos equipamentos de estação informações sobre o estado das portas (abertura e fechamento), a posição do trem ao longo da plataforma e as informações sobre identificação e nível de desempenho do trem.

As funções de ATO, ao contrário das funções de ATP, não precisam ser realizadas utilizando a filosofia fail-safe (falha segura), uma vez que qualquer falha nestas funções não implica na insegurança do trem e dos usuários, embora possam influir no desempenho das funções de movimentação do trem (UNITED..., 1976).

Os sistemas auxiliares são aqueles que, com base nas informações processadas pelo sistema de controle de bordo, efetuam o acionamento e desacionamento dos sistemas de propulsão, frenagem e portas. Os sistemas auxiliares incluem os sistemas de suprimento de ar, para o acionamento pneumático dos freios e do controle de abertura de portas, os sistemas de controle de potência, os sistemas elétricos e os sistemas de ventilação, que efetuam a troca do ar no salão de passageiros e a refrigeração dos motores do trem (UNIVERSITY..., 2005).

\footnotetext{
${ }^{2}$ Controle de Desempenho - Limitações à velocidade e à aceleração do trem, de forma a adaptar o desempenho do trem às necessidades operacionais.
} 


\subsection{Sistema de Sinalização de Via}

Para realizar as funções de proteção, supervisão e operação do trem, os circuitos de via precisam realizar a detecção e o controle de velocidade do trem, além de efetuar a sinalização das condições de proximidade do trem considerado a outros trens e da condição de ocupação da via ao sistema de controle de bordo e também ao operador do trem. Para efetuar a detecção de trens ao longo da via são utilizadas algumas técnicas:

- B-Points (Bound Points): São antenas transmissoras de código de velocidade situadas ao longo dos trilhos e que permitem a localização mais precisa de um trem dentro de um circuito de via. Utilizando B-Points é possível transmitir códigos diferentes de velocidade não-simultâneos, além de permitir a localização mais precisa de um trem dentro de um mesmo circuito de via. A Figura 4 ilustra o princípio de funcionamento de uma antena de B-Point.

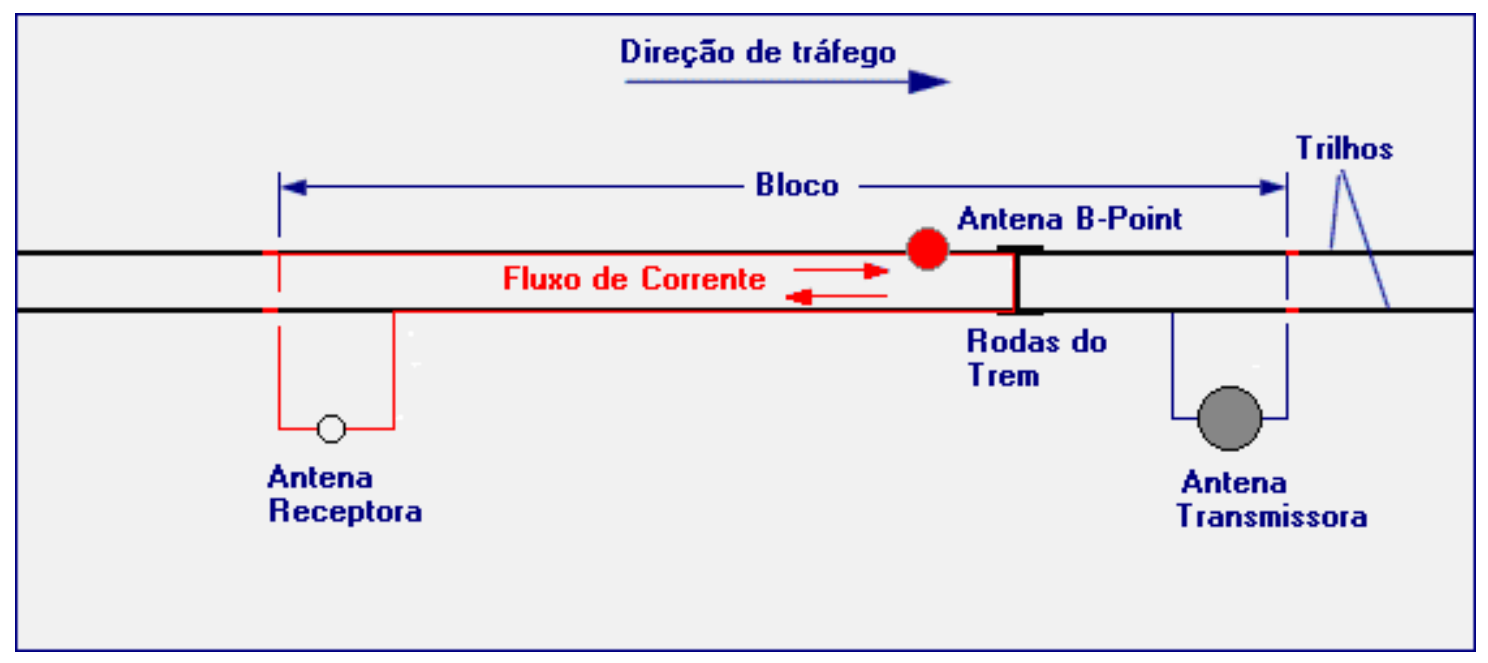

Figura 4. Funcionamento da antena de B-Point.

- Transponders (balizas): São pequenos transmissores e/ou receptores de rádio freqüência que são colocados entre os trilhos ao longo da via e permitem a detecção, sinalização e transmissão de informações simultaneamente ao equipamento de bordo dos trens por meio das antenas receptoras do trem, conforme ilustrado na Figura 5 (UNIVERSITY..., 2005). 


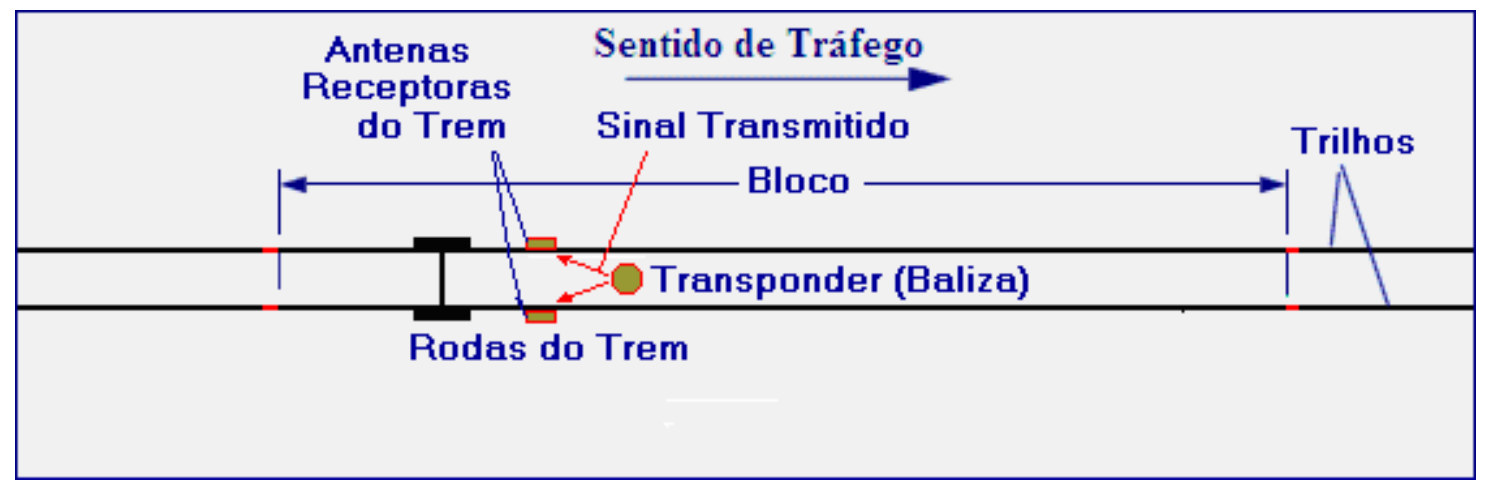

Figura 5. Funcionamento do sistema de deteç̧ão e transmissão por balizas.

- Condutores trançados: Um sistema para localização mais precisa dos trens desenvolvido pela British Railways e aplicado pela Deutsche Bundesbahn nos anos 60 foi a utilização de um loop constituído por um condutor isolado, através do qual circula um sinal de corrente alternada na faixa de 20 a $150 \mathrm{kHz}$ com uma informação modulada em freqüência (BARWELL, 1973).

Várias configurações foram experimentadas para se efetuar uma medida direta da posição e da velocidade do trem. Uma das configurações possíveis consiste em se trançar o condutor, formando loops de comprimento determinado, conforme mostrado na Figura 6. Uma antena situada a bordo pode captar as mudanças de fase provocadas pela intersecção dos condutores, contando as inversões do sinal. Com isto, consegue-se uma determinação precisa do posicionamento do trem dentro de um circuito de via, especialmente útil em paradas automáticas junto às plataformas das estações (BARWELL, 1973).

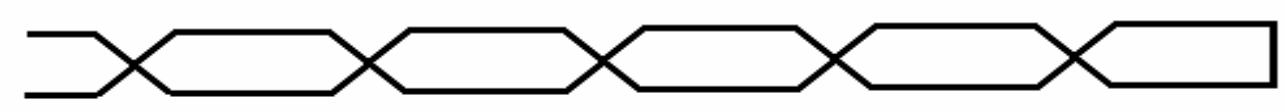

Figura 6. Configuração trançada para refinamento da posição dos trens.

- Contadores de Eixo: São sensores mecânicos, magnéticos, eletromecânicos ou óticos que detectam a passagem de cada roda do trem individualmente. A saída destes sensores é conectada a um circuito contador de forma a efetuar a contagem do número de eixos que passam pelo sensor (INSTITUTION..., 1995). A ocupação é estabelecida enquanto a contagem do número de eixos que passaram pelo sensor anterior ao circuito de via não corresponder ao número de eixos que passaram pelo sensor posterior ao mesmo circuito. 
- Circuitos de via: Os circuitos de via são trechos compostos pelos próprios trilhos de rolamento com dispositivos eletromecânicos para se efetuar a detecção de trens e comando da sinalização de ocupação. Os primeiros tipos de circuito de via utilizados eram do tipo DC, nos quais se fazia circular uma baixa corrente pelos trilhos de rolamento.

Em uma das extremidades do circuito ficava uma bateria e, na outra extremidade, um relé eletromecânico cujos contatos eram utilizados para acionar o sinaleiro do circuito, conforme mostrado na Figura 7 (UNIVERSITY..., 2005).

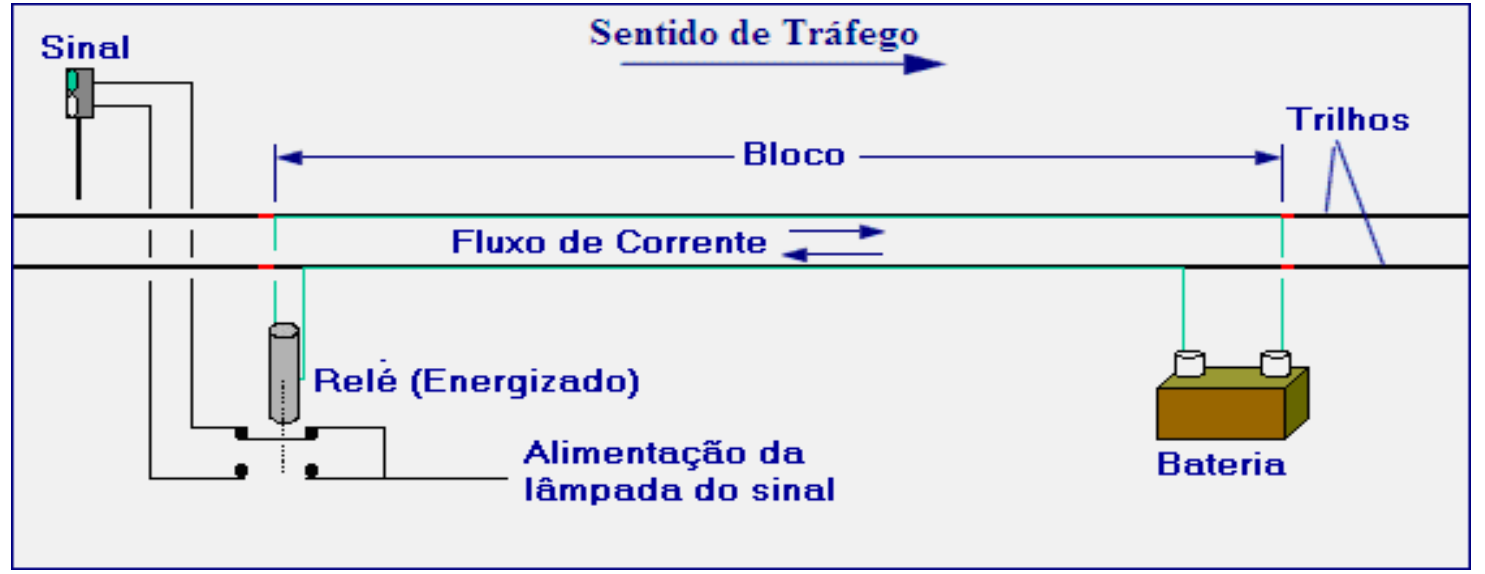

Figura 7. Circuitos de via do tipo DC - bloco desocupado (UNIVERSITY..., 2005).

$\mathrm{Na}$ condição do trecho estar desocupado, uma corrente circulava da bateria pelos trilhos até o relé, mantendo-o energizado. O relé, por sua vez, mantinha o sinaleiro indicando a luz verde (trecho desocupado). Quando um trem adentrava o circuito, as rodas do trem curto-circuitavam o sinal, desenergizando o relé e acendendo a luz vermelha, conforme mostrado na Figura 8.

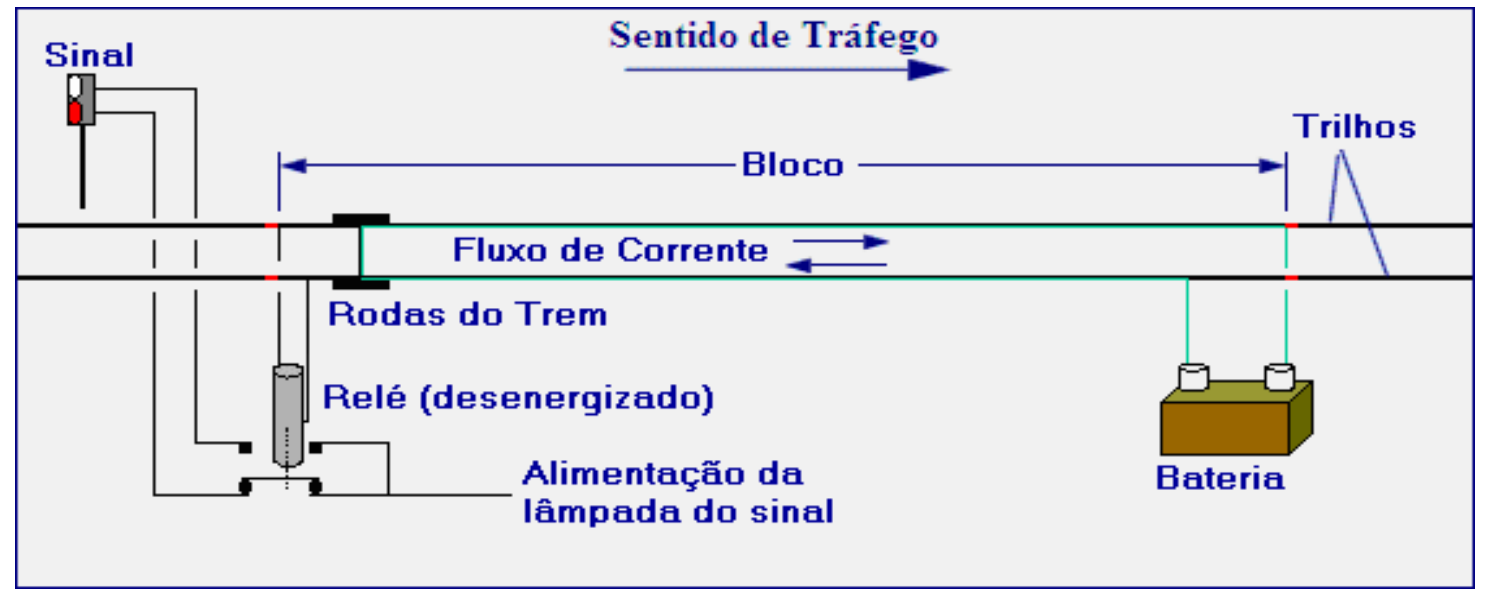

Figura 8. Circuitos de via do tipo DC - bloco ocupado (UNIVERSITY..., 2005). 
Este sistema de operação era considerado fail-safe, ou livre de falhas, porque em caso de defeito no relé ou no circuito de via, a tendência era a indicação de ocupação do trecho, porque o sinaleiro somente indicaria que o trecho estava livre se houvesse circulação de corrente pelo circuito (BARWELL, 1973).

Outra característica dos circuitos de via do tipo DC é a necessidade de juntas isolantes nas extremidades dos circuitos de via para que a corrente que circulava por um circuito de via não acionasse indevidamente os relés associados aos circuitos de via vizinhos. Utilizando um contato auxiliar do relé de acionamento do sinaleiro, poderia se ter um controle do posicionamento dos trens ao longo da via. Com o tempo, os circuitos de via foram aperfeiçoados, permitindo, além da detecção dos trens, a transmissão de informações de um sistema centralizado para o equipamento de bordo pelo circuito de via (INSTITUTION..., 1995).

Existem outros tipos de circuitos de via, dependendo do tipo de dispositivo utilizado para a detecção de trens, conforme segue:

- Circuitos de via do tipo AC (Corrente Alternada): Opera de forma semelhante ao circuito de via do tipo DC, com exceção do fato de que a corrente que circula nos trilhos é uma corrente alternada.

- Circuitos de via do tipo HVI (Impulso de Alta Voltagem): Os circuitos de via do tipo HVI também operam de forma semelhante aos circuitos do tipo DC e AC, exceto pelo fato de que a corrente que circula pelos trilhos é formada por impulsos de alta voltagem gerados por um circuito transmissor.

- Circuitos de via do tipo AF (Áudio Freqüência): O circuito de via do tipo AF utiliza um sinal alternado com freqüência na faixa de áudio $(20 \mathrm{~Hz}-20 \mathrm{kHz})$ circulando nos trilhos. Para isto, uma antena transmissora de sinal AF é posicionada em uma extremidade do circuito (no lugar da bateria ou do gerador de sinais) e uma antena receptora é posicionada na outra extremidade (no lugar do relé eletromecânico ou do receptor de sinais). Este circuito de via permite a transmissão de informações ao equipamento de bordo, pois antenas receptoras instaladas a bordo do trem recebem o sinal induzido nos trilhos pela antena transmissora da estação e o retransmite ao equipamento de bordo para posterior processamento (INSTITUTION..., 1995). 
O circuito de via do tipo AF possui uma dupla função: ao mesmo tempo em que detecta o posicionamento dos trens ao longo da via, permitindo a correta sinalização de ocupação, permite a transmissão de informações ao equipamento de bordo como, por exemplo, a velocidade máxima permitida ao trem para trafegar no circuito de via considerado.

Os sistemas de sinalização de via são classificados em dois tipos, de acordo com o tipo de transmissão das informações ao sistema de controle de bordo utilizado: sistemas de sinalização fixa (blocos fixos) e sistemas de sinalização móvel (blocos móveis).

No sistema de sinalização fixa, a via é dividida em trechos (ou blocos) de comprimento fixo denominados de "blocos fixos". Neste tipo de sinalização, os circuitos de via compõem os blocos de comprimento determinado e existe uma sinalização de velocidade máxima permitida para cada trecho, de acordo com a localização dos circuitos de via em relação às estações e de acordo com as condições físicas da via (presença de curvas, aclives ou declives). No caso de haver ocupação de um trecho, a sinalização é remodelada de forma a bloquear o acesso ou limitar a velocidade nos circuitos de via anteriores à ocupação.

No sistema de sinalização móvel não existem blocos fixos, baseando-se no fato de que dois trens com a mesma capacidade de frenagem podem manter uma distância mínima de segurança entre eles ao trafegar na mesma velocidade, desde que a taxa de frenagem do trem subseqüente seja igual ou superior à do trem antecedente e desde que o sistema de transmissão de dados consiga informar ao trem subseqüente qualquer variação de velocidade efetuada pelo trem antecedente em tempo real, de forma que o trem subseqüente possa efetuar o controle de sua velocidade e aceleração em função do trem antecedente (UNIVERSITY..., 2005).

Para isto, os dados da movimentação dos trens ao longo da via são transmitidos por rádio. Neste caso, a comunicação entre trens passa a ser vital, necessitando de medidas de segurança adicionais, como a existência de um canal reserva (spare ou backup) para evitar a perda de sinal e um sistema de validação da informação transmitida. Normalmente, a via é dividida em áreas que são controladas por um computador e um sistema de transmissão de rádio.

Recentemente estão sendo utilizados sistemas de transmissão e identificação de trens por satélite com o uso de ferramentas GPS. Com isso, a localização dos trens é efetuada geograficamente por satélite e transmitida para os demais trens do sistema. A tecnologia atual permite a utilização do sistema mesmo em túneis subterrâneos, possibilitando o seu uso em sistemas metroviários (UNIVERSITY..., 2005). 
Para a sinalização fixa, o controle do espaçamento entre trens é efetuado por meio da capacidade de frenagem do trem. Um trem típico circulando a $100 \mathrm{mph}(160 \mathrm{~km} / \mathrm{h})$, por exemplo, leva quase 1 milha $(1,6 \mathrm{~km})$ para parar totalmente. O tamanho do circuito de via era então projetado considerando o espaçamento para que o trem pudesse parar dentro do circuito de via bloqueado, denominado de overlap ${ }^{3}$.

Nos metrôs com sistemas de controle automático, o espaçamento entre trens é calculado em função da capacidade de frenagem dos trens, do perfil da via na região e da velocidade máxima permitida na região. Este cálculo possui uma alta complexidade, sendo elaborado durante o projeto da via a ser utilizada. A Figura 9 ilustra a utilização dos overlaps no cálculo do espaçamento entre trens (UNIVERSITY..., 2005).

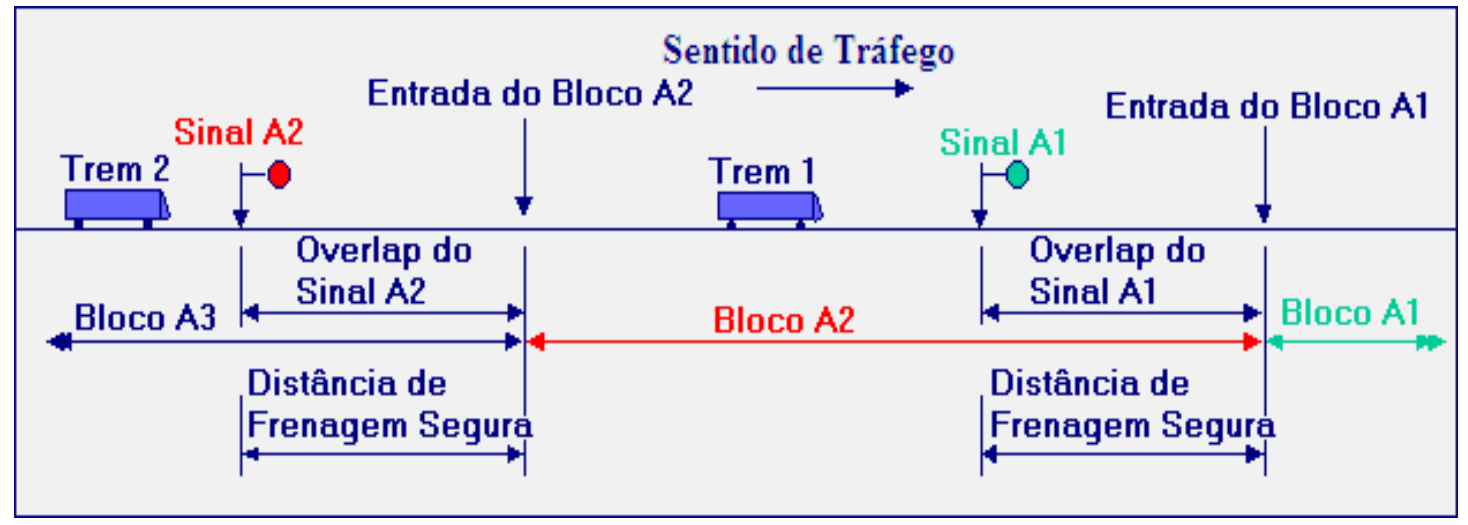

Figura 9. Regiões de overlap (UNIVERSITY..., 2005).

Posteriormente, os overlaps foram incorporados a uma outra técnica denominada de "bandas de velocidade", limitando a velocidade dos trens nos trechos anteriores a um trecho ocupado e estabelecendo um perfil de velocidades a serem adotadas nos circuitos precedentes a um circuito ocupado. Este perfil é denominado de "rastro" ou "sombra" do trem e está ilustrado na Figura 10 a seguir (UNIVERSITY..., 2005).

Outra técnica utilizada para eliminar os overlaps é denominada de "distance to go" e consiste em uma série de restrições de velocidade intermediárias, de forma a trazer a velocidade do trem para dentro do perfil de frenagem. Este método possui a desvantagem de necessitar de uma constante verificação da velocidade e da taxa de frenagem do trem. A Figura 11 a seguir ilustra esta técnica, com uma margem de segurança de 25 metros e o alívio da taxa de frenagem ao fim da parada (flare out), para proporcionar aos passageiros uma parada confortável.

\footnotetext{
${ }^{3}$ Overlap - Distância necessária à parada total do trem após um sinaleiro fechado.
} 


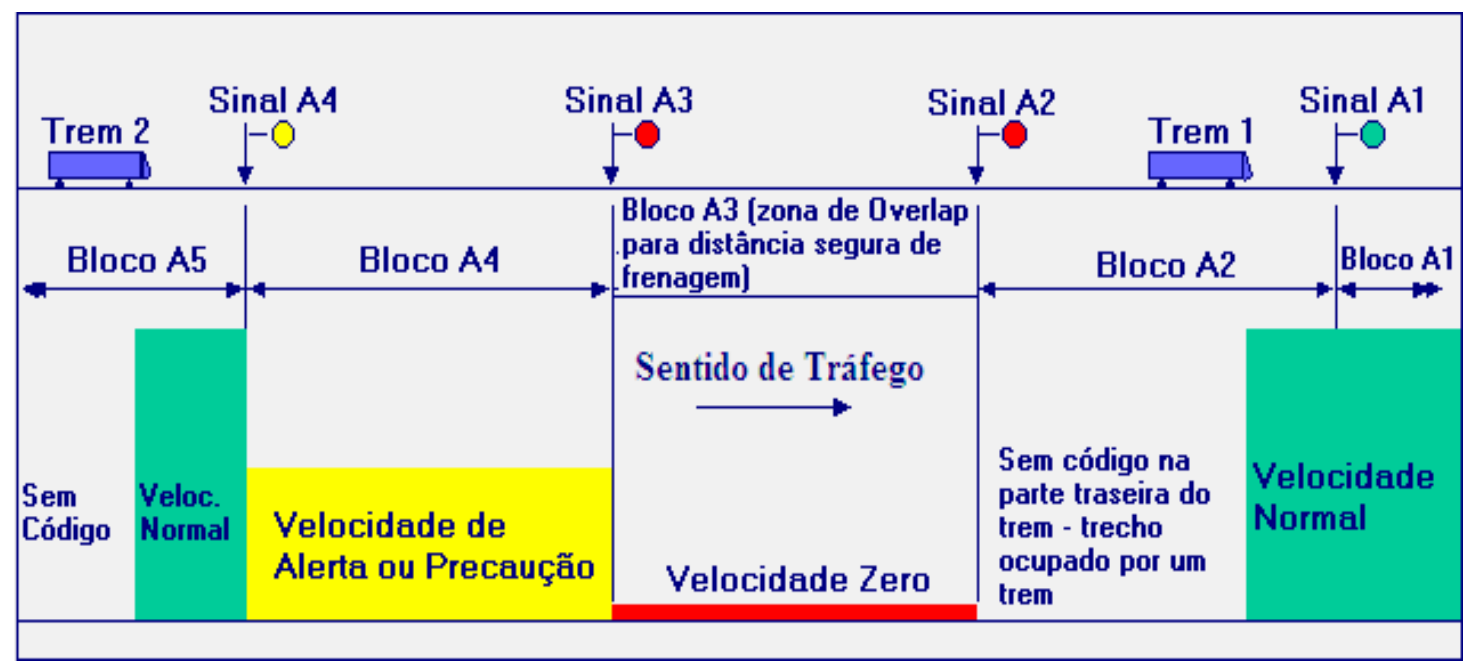

Figura 10. Bandas de velocidade (UNIVERSITY..., 2005).

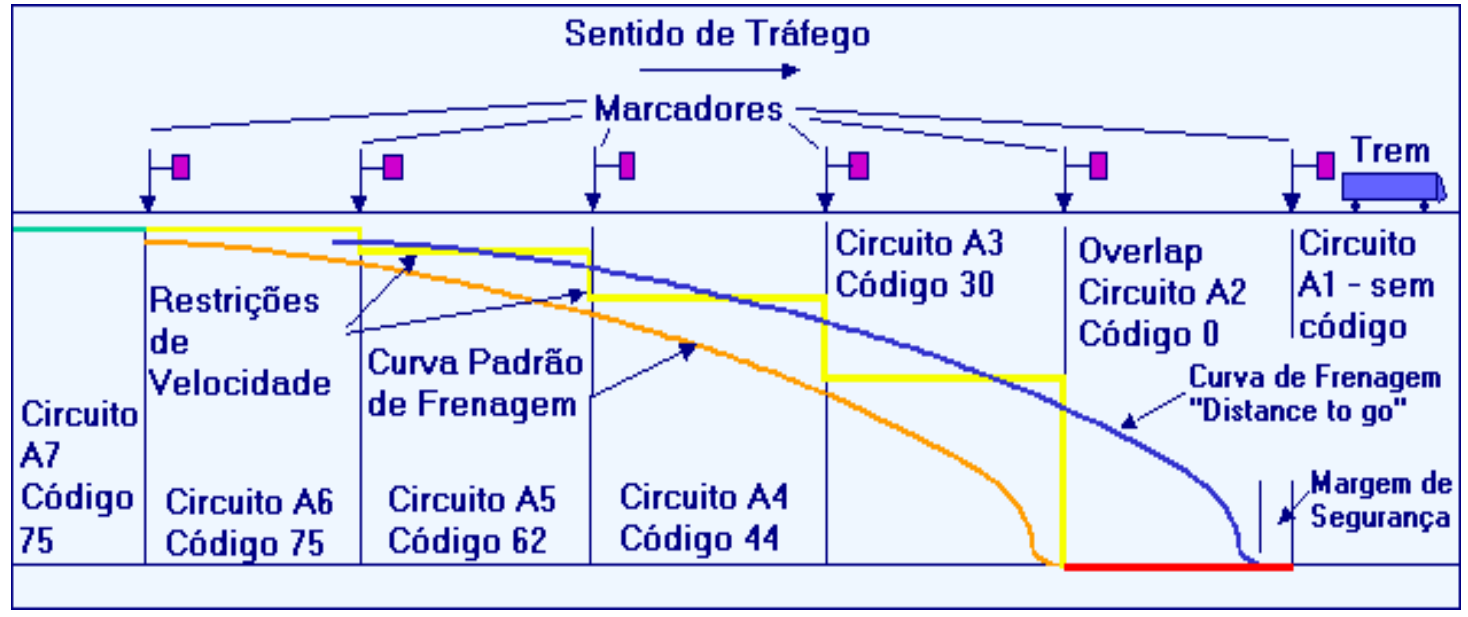

Figura 11. Ilustração da técnica “distance to go” (UNIVERSITY..., 2005).

Neste tipo de sistema, o comprimento do circuito tem um efeito determinado sobre o headway do sistema. No caso da ocupação de um trecho, pelo menos no trecho anterior ao ocupado é imposto um limite de velocidade zero e, se o circuito de via for muito comprido, levará muito tempo após a desocupação do trecho para que o trem subseqüente volte a atingir a velocidade de percurso, limitando o headway do sistema. Em compensação, com a eliminação dos espaços de overlap, a capacidade da linha pode ser aumentada em até $20 \%$, dependendo dos comprimentos dos circuitos de via e das velocidades limites envolvidas, além de poder proporcionar uma redução do número de circuitos de via necessários devido à monitoração constante da capacidade de frenagem do trem (UNIVERSITY..., 2005).

Neste trabalho é proposta a implementação de um sistema de blocos móveis utilizando a técnica "distance to go". 


\subsection{Sistemas de Controle de Bordo}

Existem algumas siglas que se referem aos vários sistemas de controle de trem existentes, que levam a algumas confusões de interpretação. Para efeito de esclarecimento, as siglas desta natureza utilizadas nesta dissertação serão aqui definidas:

ATP - Automatic Train Protection - É o sistema Automático de Proteção do Trem descrito anteriormente. Não há a necessidade de um controle centralizado do sistema, mas normalmente ele é implementado desta forma.

ATO - Automatic Train Operation - É o sistema de Operação Automática do Trem. É um sistema que permite a operação do trem controlando e monitorando a aplicação de propulsão ou freio aos motores. Este sistema envolve outras funções de operação do trem que não são parte do sistema de proteção, como: parada programada nas estações, abertura e fechamento de portas e comunicação de dados (não pertinentes à velocidade) do trem.

ATC - Automatic Train Control - É o sistema de Controle Automático do Trem, composto pela combinação dos sistemas ATO e ATP descritos anteriormente, ou seja, ATC = ATO + ATP.

ATS - Automatic Train Supervision - É o sistema de Supervisão Automática de Trens, baseado em um controle central de movimentação de trens. O centro de controle possui uma visão geral de toda a linha e pode coordenar a movimentação necessária dos trens (UNITED..., 1976).

Os sistemas ATP são do tipo "fail-safe", ou seja, à prova de falhas. Este conceito é amplamente utilizado em sistemas críticos e significa que o sistema de controle deve ser projetado de tal forma que, em caso de falha, conduza o sistema a um estado seguro. Os métodos mais confiáveis que evitam um estado inseguro são denominados de "vitais". São exemplos de métodos vitais: um sistema de votação "dois entre três" e um processamento paralelo, onde exista a redundância de informações (INSTITUTION..., 1995). 
As funções de um controlador de trens podem ser divididas basicamente em duas categorias: as funções de ATP e as funções de ATO. As funções de ATP compreendem a detecção de trens, a separação entre trens, o intertravamento de rotas, a proteção contra sobrevelocidade e a vigilância das condições do trem e da via (UNITED..., 1976).

O controlador de bordo efetua o controle de proteção contra sobrevelocidade efetuando uma comparação constante entre a velocidade real do trem e a velocidade comandada transmitida pelos equipamentos de via. Com base nos valores de velocidade real e comandada do trem, o controlador efetua o denominado controle de BPM (Brake Profile Monitor). Este controle compreende desde o corte de tração dos motores até a aplicação de freios de emergência, dependendo da diferença encontrada entre a velocidade comandada e a velocidade real do trem.

O controlador efetua um cálculo também sobre a taxa de aceleração e frenagem do trem, acionando o corte de tração se a velocidade do trem estiver se aproximando da velocidade comandada com uma taxa de aceleração grande e efetua a aplicação do freio de emergência caso a velocidade do trem ultrapasse a velocidade comandada pelo equipamento de via para aquele trecho que o trem estiver percorrendo no momento. Para uma transição restritiva de um código de velocidade, um perfil de frenagem confortável e seguro é adotado (UNIVERSITY..., 2005).

As funções de ATO compreendem a regulação de velocidade, parada programada, abertura e fechamento de portas e processamento das informações de identificação e modificação de desempenho do trem (UNITED..., 1976).

O controlador de bordo efetua a comunicação com os equipamentos de estação por meio de antenas transmissoras e receptoras na forma de ondas eletromagnéticas. Outras tecnologias envolvem a transmissão de informações por meio de ondas de rádio.

Com base na informação de posicionamento do trem ao longo da plataforma da estação, recebida pela antena de parada programada, o controlador de bordo realiza a desaceleração do trem em função da distância final de parada do trem, construindo um perfil de frenagem da mesma forma que o perfil construído na técnica "distance to go", vista anteriormente. 
Com base na informação do comando de abertura e fechamento de portas, o controlador de bordo verifica se o trem está corretamente parado ao longo da plataforma da estação e o lado correto para abertura de portas. Em seguida, o controlador comanda os circuitos pneumáticos para a abertura das portas, de acordo com os comandos recebidos e as verificações efetuadas. Após o tempo de abertura, determinado pela estação, a estação comanda o fechamento das portas para o trem. $\mathrm{O}$ trem, ao receber este comando, comanda os circuitos pneumáticos para o fechamento das portas (UNIVERSITY..., 2005).

A informação de identificação possui alguns dados importantes, como o número de série e destino do trem, bem como as restrições de velocidade e aceleração que devem ser impostas de forma a permitir um controle de desempenho do trem por parte do controle central, de forma a efetuar um controle do número de trens em função da demanda de passageiros. Todas estas informações são passadas da estação para o trem e do trem para a estação, como forma de confirmação do recebimento dos comandos de identificação e controle do desempenho do trem.

A regulação de velocidade é efetuada simplesmente comparando-se a velocidade real do trem com a velocidade comandada pelos equipamentos de via e acionando os circuitos de propulsão e frenagem, de acordo com a propulsão ou frenagem do trem requerida pelo operador, no caso de operação manual ou operação manual supervisionada pelo sistema de controle do trem. No caso de operação automática, o controlador das funções de ATP é que efetua a frenagem do trem.

A informação de velocidade comandada para o trem é transmitida ao equipamento de controle de bordo por meio de antenas eletromagnéticas, que captam o sinal que circula nos circuitos de via, ou por meio de rádio, no caso de utilização do sistema de transmissão por blocos móveis. As informações de velocidade e aceleração real do trem são obtidas com o uso de tacômetros e acelerômetros, instalados nos rodeiros do trem. Estes sensores efetuam uma medição da velocidade e da aceleração do trem, de forma a fornecer parâmetros de comparação com a velocidade comandada e permitir um controle efetivo da velocidade e aceleração do trem.

Os comandos de propulsão e frenagem saem do controlador de bordo do trem e acionam o sistema pneumático para efetuar a frenagem ou o sistema de controle de potência para acionar os contatores de configuração e fornecer corrente aos motores de tração, visando efetuar a propulsão do trem (UNIVERSITY..., 2005). 


\subsection{Sistemas Auxiliares}

Os sistemas auxiliares são todos aqueles sistemas que permitem a execução dos comandos de controle processados pelo sistema de controle de bordo. Os sistemas auxiliares providenciam o acionamento dos motores para a propulsão do trem ou dos freios pneumáticos para a frenagem do trem. Além disso, os circuitos auxiliares também realizam a abertura e o fechamento das portas do trem.

Para poder efetuar o acionamento de componentes pneumáticos, deve haver um sistema auxiliar para suprir o ar comprimido necessário ao acionamento destes componentes. Assim, alguns trens são supridos com compressores e reservatórios de ar comprimido para o acionamento pneumático dos freios e das válvulas de abertura e fechamento das portas.

Para poder controlar a corrente dos motores de tração, deve haver um sistema auxiliar para efetuar a configuração e o suprimento de corrente aos motores. Este controle é obtido utilizando-se um sistema de propulsão, que consiste em um módulo lógico de comando, contatores e semicondutores que efetuam a configuração e o chaveamento dos motores de tração, de forma a fornecer a propulsão necessária ao trem. Alguns contatores possuem acionamento pneumático, utilizando ar comprimido do sistema de suprimento de ar para seu acionamento. A utilização de ar comprimido para este fim é controlada por válvulas eletromagnéticas por meio do módulo lógico de controle.

Para se realizar a frenagem do trem, existe ainda uma técnica, denominada de freio elétrico, que consiste em se retirar corrente dos motores de tração, de forma a diminuir o movimento de rotação, como forma de controlar eletricamente a velocidade do trem. Desta forma, quando o controlador do trem efetua uma solicitação de frenagem do trem, uma solicitação de retirada de corrente dos motores é efetuada ao controle de propulsão, realizando o freio elétrico. O freio pneumático somente é acionado em complementação ao freio elétrico e no final deste, para produzir uma parada mais eficiente e com a economia de pastilhas de freio.

Além disso, para se efetuar a alimentação elétrica do sistema de controle e dos sistemas auxiliares, um sistema elétrico, composto por baterias, carregadores, retificadores, conversores, geradores e alternadores é utilizado para suprir a forma de energia mais adequada para cada finalidade necessária à realização das funções no trem (UNIVERSITY..., 2005). 


\subsection{Considerações Finais do Capítulo}

Este capítulo teve por objetivo apresentar as técnicas atualmente utilizadas na realização das funções de um controlador automático de trens. Uma vez apresentadas estas técnicas, toda uma caracterização do cenário de aplicação do estudo proposto foi efetuada, tornando mais clara a área de atuação do sistema de controle nebuloso proposto. O próximo passo consiste na apresentação dos conceitos teóricos sobre a lógica nebulosa preditiva e sistemas de controle, para que se possa compreender como os conceitos teóricos contidos no conjunto de ferramentas propostos pela engenharia de sistemas de controle podem ser aplicados na solução de um problema prático na área de controle de trens. 


\section{Elementos de Lógica Nebulosa Preditiva}

Este capitulo tem como objetivo apresentar os elementos básicos da lógica nebulosa preditiva utilizada como fundamento no projeto do controlador de trens proposto. Um panorama geral sobre a lógica nebulosa é apresentado, localizando-a como importante ferramenta da Inteligência Artificial. São apresentados os principais conceitos de conjuntos nebulosos, de lógica nebulosa e suas propriedades, como base teórica na elaboração do projeto de sistemas de inferência nebulosa.

\subsection{Introdução}

O marco inicial da história da lógica nebulosa está relacionado à publicação dos trabalhos do pesquisador americano Lotfi Zadeh, em 1965, mais precisamente à publicação do artigo denominado Fuzzy Sets (ZADEH, 1965). Neste trabalho, Zadeh propõe uma forma para expressar e operar matematicamente conceitos subjetivos, permitindo o tratamento de problemas que envolvem conceitos abstratos e subjetivos, aproximando-se da forma com que os seres humanos tratam a maioria dos problemas do mundo real.

Embora o surgimento da lógica nebulosa esteja associado à década de 60 , as idéias por trás destes conceitos remontam há cerca de 2500 anos atrás. O filósofo grego Aristóteles realizou trabalhos em lógica (por exemplo, no tratado Prior Analytics) onde afirmou que "o presente é preciso e apenas o futuro contém imprecisão", estabelecendo graus de veracidade ou falsidade de informações a respeito de eventos futuros (JAMSHIDI; VADIEE; ROSS, 1993).

O professor de Aristóteles, Platão, considerou em suas idéias o conceito de que um elemento pode pertencer parcialmente a determinados conjuntos. O termo platônico incorpora o conceito de que o ideal intelectual pode ser apenas realizado parcialmente em termos humanos ou físicos, mas Platão rejeitou os conceitos sobre a imprecisão do futuro. Heráclito e Anaximandro desenvolveram sistemas lógicos de múltiplos estados (lógica de múltiplos níveis), cerca de duzentos anos antes de Aristóteles (MCNEILL; THRO, 1994). 
Os paradoxos, como o Paradoxo de Zeno (“Quantos grãos de areia podem ser retirados de um monte até que este não seja mais um monte de areia?") ou um paradoxo grego antigo de autoria desconhecida ("Se todos os cretenses são mentirosos, quando um cretense diz que está mentindo ele está falando a verdade?”), ilustram o problema lógico do estabelecimento da idéia de veracidade ou falsidade de afirmações (PEDRYCZ, 1993).

A história está repleta de exemplos onde os conceitos de veracidade ou falsidade de afirmações não são precisos nem absolutos, mas vagos e relativos. No século XIV, William de Ockham especulou a idéia denominada de "Navalha de Ockham", na qual toda afirmação poderia ser colocada sobre o fio de uma navalha e esta navalha dividiria a afirmação em duas partes: a parte verdadeira e a parte falsa, mostrando a existência de afirmações que não são absolutamente verdadeiras nem absolutamente falsas (TRILLAS; GUTIERREZ, 1992).

No século XVIII, Kant considerou que apenas a matemática poderia fornecer definições claras e muitos princípios contraditórios (paradoxos) não poderiam ser resolvidos. Os filósofos irlandeses George Berkeley e Scot David Hume afirmaram que cada conceito tem um núcleo concreto aos quais conceitos que o remontam são, de certa forma, atraídos para este núcleo. Hume, em especial, considerava que a lógica deveria ter um senso comum um raciocínio baseado no conhecimento que as pessoas adquirem em sua vida cotidiana.

No século XIX, a escola de filosofia americana denominada de pragmatismo, fundada por Charles Sanders Pierce, foi a primeira a considerar o conceito de que idéias vagas, preferencialmente o conceito da dualidade veracidade-falsidade, formam a base para a explicação do funcionamento do mundo e das pessoas (MCNEILL; THRO, 1994).

No início do século XX, o filósofo e matemático inglês Bertrand Russell estudou a imprecisão da linguagem, concluindo que a linguagem ordinária é vaga e que esta característica é irredutível. Russell também afirmou que a lógica formal supõe a utilização de símbolos precisos, mas não se aplica ao mundo real, mas a uma existência celestial imaginada. Alfred Tarsky mostrou que "graus de verdade" podem ser aplicados a eventos reais de maneira consistente e formal (MARKS II, 1994).

As idéias a respeito da matemática, dos eventos do mundo real e da complexidade destes eventos levaram a uma análise da dualidade presente na lógica formal. Como conseqüência, surgiram as importantes descobertas físicas dos conceitos do princípio da relatividade, por Albert Einstein, e do princípio da incerteza, por Werner Heisenberg (MCNEILL; THRO, 1994). 
Albert Einstein afirmou que "quanto mais uma lei matemática se referir à realidade, mais ela é incerta, e quanto menos uma lei matemática for incerta, menos se referirá à realidade".

A teoria clássica dos conjuntos foi inventada no século XIX pelo matemático Alemão Georg Kantor. Nesta teoria, o conceito de pertinência com relação a um determinado conjunto é restrito a apenas duas possibilidades: o elemento pertence (1) ou não pertence (0) ao conjunto. Considerando este conceito, foi desenvolvida toda a lógica booleana baseada em dois valores - 0 e 1 - que estabelecem apenas duas possibilidades para as afirmações: a afirmação é verdadeira (valor 1) ou falsa (valor 0) (JAMSHIDI; VADIEE; ROSS, 1993).

A primeira lógica envolvendo graus de incerteza foi desenvolvida pelo filósofo polonês Jan Lukasiewicz, que estabelecia alguns conjuntos aos quais os elementos poderiam pertencer, pertencer parcialmente ou não pertencer ao conjunto, estabelecendo valores de pertinência iguais a $0,1 / 2$ ou 1 . Mais tarde este conceito foi estendido a um número infinito de graus de pertinência expresso por infinitos valores entre 0 e 1 (MCNEILL; THRO, 1994).

Em seu trabalho Fuzzy Sets (ZADEH, 1965), Zadeh concentrou todas estas idéias de que existem elementos no universo que não estão classificados como verdade ou falsidade absoluta na elaboração do conceito de conjuntos nebulosos. Além disso, este trabalho também estabeleceu o chamado princípio da incompatibilidade, que diz que "à medida que a complexidade de um sistema aumenta, diminui a habilidade humana em se fazer afirmações precisas e significativas sobre o comportamento do sistema, até um limite no qual precisão e significado (ou relevância) tornam-se características mutuamente exclusivas". Um corolário deste princípio estabelece que "quanto mais próximo alguém examinar um problema do mundo real, mais nebulosa será a solução para este problema”.

Mais tarde, em 1973, Zadeh também publicou um trabalho (ZADEH, 1973) no qual incentiva o enfoque lingüístico para o processamento de problemas nebulosos e propõe uma “computação com palavras”, estabelecendo uma relação entre a linguagem e a inteligência humana com o uso da matemática e afirmando que "os elementos-chave no pensamento humano não são números, mas rótulos lingüísticos que representam conjuntos nebulosos".

O trabalho de Zadeh veio de encontro a uma tendência na época de se utilizar técnicas quantitativas para o tratamento de problemas na área humanística, como por exemplo, nas áreas econômica, social e biológica, técnicas estas adaptadas de soluções para problemas mecânicos (ZADEH, 1973). 
O engenheiro britânico Ebrahim Mamdani foi o primeiro a utilizar o conceito de conjuntos nebulosos no projeto de um sistema de controle prático. Em 1974, Mamdani desenvolveu um controle automático de uma máquina a vapor baseado no conhecimento de um operador humano especialista (MCNEILL; THRO, 1994).

A idéia inicial era criar um sistema, baseado na teoria bayesiana de decisões, que define probabilidades em situações incertas, nas quais os eventos são considerados após correções que alteram seu comportamento futuro. O operador ajustou a válvula de controle e a temperatura da caldeira de forma a manter a velocidade do motor e a pressão de ebulição da caldeira. Mamdani incorporou este ajuste em um algoritmo matemático inteligente que "aprendeu" a controlar o motor. Mas o desempenho do algoritmo foi bem inferior ao desempenho do operador humano (MAMDANI, 1974).

Mamdani poderia continuar melhorando o processo de aprendizagem do algoritmo, mas decidiu aplicar um método de inteligência artificial chamado de sistema especialista baseado em regras, que combinava o conhecimento especialista com uma série de regras lógicas para utilizar este conhecimento. Utilizando as técnicas propostas por Zadeh, Mamdani produziu um controlador nebuloso e surpreendeu-se com a facilidade de projeto de um controlador baseado em regras que utilizavam uma combinação de variáveis matemáticas e lingüísticas. Rutherford, em 1976, também efetuou a análise de diversos algoritmos de controle, sob a ótica da lógica nebulosa, efetuando uma avaliação de seu desempenho (MCNEILL; THRO, 1994).

Em 1977, dois engenheiros dinamarqueses, Holmblad e Ostergaard, desenvolveram o primeiro sistema comercial de controle nebuloso. Este sistema fazia o controle de um trocador de calor para um forno de produção de cimento. Na mesma época, também foi produzido um controlador para um forno de cal, na Suécia, e em 1979 Kolomov produziu o primeiro autômato finito nebuloso (LEE, 1990a; LEE, 1990b).

Nos anos 80, surgiram as primeiras aplicações industriais utilizando lógica nebulosa. Em 1980, Tong utilizou a lógica nebulosa para efetuar um controle de processo de tratamento de águas residuais. Já os pesquisadores Fukami, Mizumoto e Tanaka estabeleceram a inferência condicional nebulosa. Em 1983, Sugeno e Takagi elaboraram uma derivação das regras de inferência para efetuar um controle nebuloso linear que prevê uma função de saída nebulosa formada a partir de uma combinação linear das variáveis nebulosas de entrada do sistema (TRILLAS; GUTIERREZ, 1992). 
Também em 1983, Pedrycz e Hirota produziram um trabalho na área de controle nebuloso probabilístico, enquanto os pesquisadores japoneses Yasunobu e Miyamoto elaboraram um trabalho na área de controle nebuloso preditivo. Estes trabalhos contribuíram para o trabalho de Dubois e Prade, em 1988 sobre raciocínio aproximado (PEDRYCZ, 1993).

As aplicações continuaram a surgir em 1984, quando Sugeno e Murakami efetuaram o controle de estacionamento de um carrinho de brinquedo. Em 1985, os pesquisadores Gupta e Kiszka estudaram a estabilidade de sistemas nebulosos. Na área de hardware, em 1985, Togai e Watanabe desenvolveram o primeiro circuito integrado nebuloso e, em 1986, Yamakawa desenvolveu o primeiro hardware para um controlador nebuloso (TRILLAS; GUTIERREZ, 1992).

Em 1983, Yasunobu, Miyamoto e Ihara desenvolveram o primeiro controlador automático de trens para o metrô da cidade de Sendai, no Japão, que encontra-se ainda em funcionamento, mantendo os trens circulando na rota, acelerando-os e freando-os de forma suave e parando-os precisamente nas estações (YASUNOBU; MIYAMOTO; IHARA, 1983). Este controlador foi utilizado como base para a elaboração desta dissertação e será detalhado no Capítulo 6 deste trabalho.

A partir dos anos 90, houve um aumento vertiginoso nas aplicações utilizando lógica nebulosa, bem como a utilização do hardware para controle nebuloso. Grandes fabricantes japoneses, como a Matsushita, a Sony e a Nissan, incorporaram controladores "nebulosos" em seus produtos, levando-os à produção de aspiradores de pó, máquinas de lavar roupa, câmeras de vídeo, televisores, carros e elevadores utilizando essa concepção.

Uma das razões para que o principal desenvolvimento da teoria e das aplicações do controlador nebuloso ocorresse no Japão e em outras nações asiáticas decorre do fato que as grandes empresas japonesas foram os primeiros patrocinadores dos trabalhos de Zadeh nos anos 60 .

Nas nações ocidentais, os aspectos culturais levaram ao desenvolvimento dos denominados controladores PID (Proportional Integral Derivative), baseados na lei que assume que os sistemas a serem controlados possuem um comportamento uniforme ou linear. Apesar desta simplificação, os controladores PID foram populares no ocidente porque apresentam um bom desempenho, com uma margem pequena de erro, mesmo com fatores externos alterando a estabilidade dos sistemas (MCNEILL; THRO, 1994). 


\subsection{Conjuntos Nebulosos}

A teoria clássica de conjuntos é uma importante ferramenta no estudo da matemática. A própria definição de números está ligada à definição de conjuntos, que estabelecem propriedades a respeito. Quando, por exemplo, define-se o conjunto dos números racionais, o conceito clássico de pertinência define uma propriedade sobre todos os elementos do universo considerado (números) que estabelece se um determinado elemento (número) pertence ou não ao conjunto. Desta forma, todos os números que podem ser escritos de forma racional (ou na forma $a / b$, onde $a$ e $b$ representam números pertencentes ao conjunto dos números inteiros) pertencem ao conjunto dos números racionais. Este critério de pertinência permite classificar, por exemplo, o número $3 / 4$ como pertencente ao conjunto e o número $\pi$ como não pertencente ao conjunto.

Lotfi A. Zadeh (ZADEH, 1965) diz que a definição de conjuntos nebulosos decorre da observação da própria natureza, onde mais freqüentemente encontram-se classes de objetos em que o conceito de pertinência não é bem definido. Ao contrário do que acontece na teoria clássica de conjuntos matemáticos, o mundo físico real possui diversos exemplos onde o conceito de pertinência não é bem definido.

Por exemplo, os conjuntos de animais, dos números reais muito maiores do que 1 , dos homens altos ou das mulheres bonitas não possuem uma propriedade na qual pode-se estabelecer seguramente se um elemento pertence ou não ao conjunto. No caso do conjunto de animais, pode-se claramente classificar elementos como cães, cavalos e pássaros como elementos do conjunto, da mesma forma que pedras, plantas e fluídos são classificados como não sendo elementos do conjunto. Porém, quando se tenta classificar elementos como estrelado-mar, bactérias e vírus, não se obtém um critério preciso para a classificação destes elementos. Da mesma maneira, os conceitos de "números muito maiores do que 1", "homens altos" ou "mulheres bonitas" são conceitos subjetivos, que não permitem uma classificação precisa dos elementos do universo considerado.

Um conjunto nebuloso pode ser definido como um conjunto caracterizado por uma função de pertinência que associa cada elemento do universo considerado a um número no intervalo $[0,1]$ que representa o grau de pertinência do elemento ao conjunto. Quanto mais próximo de 1, maior é o grau de pertinência do elemento ao conjunto e, quanto mais próximo de 0 , menor é o grau de pertinência do elemento ao conjunto (KLIR, 1995). 
Conceitualmente, um conjunto nebuloso é uma coleção em um universo de informação onde os limites do conjunto são ambíguos, vagos ou nebulosos. Para um melhor entendimento da teoria dos conjuntos nebulosos, uma comparação é efetuada com a teoria clássica dos conjuntos, em que o conjunto de todos os objetos com as mesmas características é denominado de universo de discurso (representado pela letra $U$ ), os elementos deste conjunto são representados por letras minúsculas (por exemplo, $x$ ), enquanto coleções de alguns elementos do universo do discurso são denominadas de conjuntos e representadas por letras maiúsculas (por exemplo, $A$ ). Os elementos do conjunto podem ser discretos e finitos, ou contínuos e infinitos, sendo que o número total de elementos do universo é denominado de cardinalidade e representado por $n_{U}$ (DRIANKOV; HELLENDOORN: REINFRANK, 1996). A Tabela 1 mostra a notação matemática válida para os conjuntos clássicos.

Tabela 1 - Notação matemática válida para conjuntos clássicos.

\begin{tabular}{|c|c|}
\hline Símbolo & Significado \\
\hline 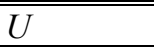 & Universo de discurso considerado \\
\hline$x$ & Elementos do universo considerado \\
\hline$A$ & Conjuntos no universo considerado \\
\hline$\varnothing$ & Conjunto vazio (sem elementos) \\
\hline$x \in U$ & O elemento $x$ pertence ao universo $U$ \\
\hline$x \in A$ & O elemento $x$ pertence ao conjunto $A$ \\
\hline$x \notin A$ & O elemento $x$ não pertence ao conjunto $A$ \\
\hline$A \subset B$ & O conjunto $A$ está contido no conjunto $B$ \\
\hline$A \supset B$ & O conjunto $A$ contém o conjunto $B$ \\
\hline$A \not \subset B$ & O conjunto $A$ não está contido no conjunto $B$ \\
\hline$A=B$ & O conjunto $A$ é igual ao conjunto $B$ \\
\hline$A \neq B$ & O conjunto $A$ é diferente do conjunto $B$ \\
\hline
\end{tabular}

Todos os subconjuntos do universo $U$ compreendem um conjunto especial, denominado de conjunto potência de $U$, ou $P(U)$. A cardinalidade do conjunto potência é definida como $n_{P(U)}=2^{n_{U}}$. Quando a cardinalidade do universo é infinita, a cardinalidade do conjunto potência também será infinita (JAMSHIDI; VADIEE; ROSS, 1993).

São definidas, também, algumas operações entre conjuntos:

- A união entre dois conjuntos $A$ e $B$, representada por $A \cup B$, denota todos os elementos que pertencem ao conjunto $A$ ou pertencem ao conjunto $B$;

- $\quad$ A interseção entre dois conjuntos $A$ e $B$, representada por $A \cap B$, denota todos os elementos que pertencem ao conjunto $A$ e, simultaneamente, pertencem ao conjunto $B$; 
- $\quad$ O complemento de um conjunto $A$, representado por $\bar{A}$, denota todos os elementos do universo que não pertencem ao conjunto $A$; e

- A diferença do conjunto $A$ com relação ao conjunto $B$, representada por $A / B$, denota todos os elementos do universo que pertencem ao conjunto $A$ e não pertencem ao conjunto $B$ simultaneamente.

Também é comum se efetuar a descrição de conjuntos por meio das características de seus elementos, expressos em notação algébrica. Nesta notação, utilizam-se alguns símbolos especiais, como: $\exists$ (existe), $\forall$ (para todo ou qualquer que seja), $\wedge$ (conectivo $e$ ),$\vee$ (conectivo ou) e | (tal que). As operações de conjuntos clássicos podem ser descritas por:

- União: $A \cup B=\{x / x \in A \vee x \in B\}$

- Interseção: $A \cap B=\{x / x \in A \wedge x \in B\}$

- $\quad$ Complemento: $\bar{A}=\{x / x \in U \wedge x \notin A\}$

- Diferença de $A$ com relação a $B: A / B=\{x / x \in A \wedge x \notin B\}$

Os diagramas de Venn são diagramas simplificados que representam os conjuntos no universo de forma geométrica e permitindo a compreensão das operações entre conjuntos. A Figura 12 mostra os diagramas de Venn para as quatro operações apresentadas.
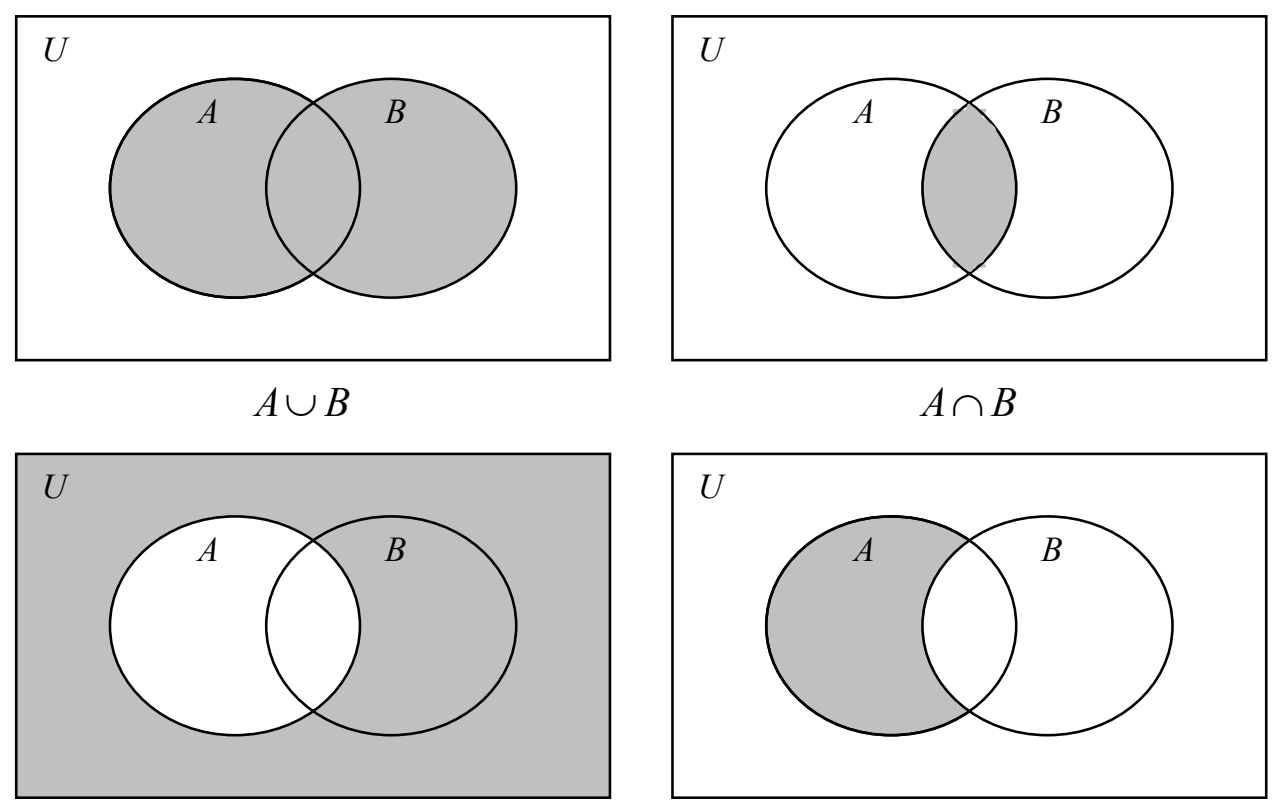

$\bar{A}$

A/B

Figura 12. Diagramas de Venn para algumas operações entre conjuntos clássicos. 
As seguintes propriedades das operações entre conjuntos são importantes devido à sua influência na manipulação de conjuntos (JAMSHIDI; VADIEE; ROSS, 1993):

- $\quad$ Comutatividade:

$$
\begin{aligned}
& A \cup B=B \cup A \\
& A \cap B=B \cap A \\
& A \cup(B \cup C)=(A \cup B) \cup C \\
& A \cap(B \cap C)=(A \cap B) \cap C
\end{aligned}
$$

- Associatividade:

- Distributividade:

$A \cup(B \cap C)=(A \cup B) \cap(A \cup C)$

$A \cap(B \cup C)=(A \cap B) \cup(A \cap C)$

- Idempotência:

$$
A \cup A=A
$$

$A \cap A=A$

- Identidade:

$$
\begin{aligned}
& A \cup \varnothing=A \\
& A \cup U=U \\
& A \cap \varnothing=\varnothing \\
& A \cap U=A
\end{aligned}
$$

- Transitividade:

$$
A \subset B \subset C \rightarrow A \subset C
$$

- Involução:

$$
\overline{\bar{A}}=A
$$

- $\quad$ Lei do meio exclusivo:

$$
A \cup \bar{A}=U
$$

- Lei da contradição:

$$
A \cap \bar{A}=\varnothing
$$

- $\quad$ Leis de De Morgan:

$$
\begin{aligned}
& (\overline{A \cap B})=\bar{A} \cup \bar{B} \\
& (\overline{A \cup B})=\bar{A} \cap \bar{B}
\end{aligned}
$$

O mapeamento é um conceito importante no relacionamento entre conjuntos. Em sua forma mais geral, o mapeamento pode ser utilizado para mapear elementos ou conjuntos de um universo de discurso em elementos ou conjuntos de outro universo de discurso. Se um elemento no universo de discurso $U$ corresponde a um elemento no universo $V$, esta correspondência é denominada como um mapeamento de $U$ em $V$, ou f: $U \rightarrow V$.

Em especial, o mapeamento $\chi_{A}(x)$, definido por: $\quad \chi_{A}(x)= \begin{cases}1, & x \in A \\ 0, & x \notin A\end{cases}$ expressa a noção de pertinência do elemento $x$ com relação ao conjunto $A$. Esta relação é um mapeamento de um elemento $x$ do universo $U$ para o universo $V$ composto por apenas dois elementos (0 e 1) (MCNEILL; THRO, 1994).

As operações entre conjuntos podem ser expressas em termos de mapeamentos (JAMSHIDI; VADIEE; ROSS, 1993), como por exemplo: 
- União: $A \cup B \rightarrow \chi_{A \cup B}(x)=\chi_{A}(x) \vee \chi_{B}(x)=\max \left(\chi_{A}(x), \chi_{B}(x)\right)$

- $\quad$ Interseção: $A \cap B \rightarrow \chi_{A \cap B}(x)=\chi_{A}(x) \wedge \chi_{B}(x)=\min \left(\chi_{A}(x), \chi_{B}(x)\right)$

- $\quad$ Complemento: $\bar{A} \rightarrow \chi_{\bar{A}}(x)=1-\chi_{A}(x)$

- $\quad$ Continência: $A \subseteq B \rightarrow \chi_{A}(x) \leq \chi_{B}(x)$

Conforme mencionado anteriormente, os conjuntos nebulosos não possuem uma definição exata de pertinência de conjuntos e, portanto, os conjuntos nebulosos não possuem limites definidos, não podendo ser representados pelos diagramas normais de Venn. Desta forma, um elemento do universo de discurso será representado pelo seu mapeamento no intervalo real $[0,1]$. Se o universo de discurso é discreto e finito, um conjunto nebuloso (representado por uma letra maiúscula sublinhada, por exemplo, $\underline{A}$ ) será representado por:

$$
\underline{A}=\frac{\mu_{\underline{A}}\left(x_{1}\right)}{x_{1}}+\frac{\mu_{\underline{A}}\left(x_{2}\right)}{x_{2}}+\ldots=\sum_{i} \frac{\mu_{\underline{A}}\left(x_{i}\right)}{x_{i}} \text {, onde } \mu_{\underline{A}}(x) \text { é a função de pertinência do }
$$

elemento $x$ ao conjunto nebuloso $\underline{A}$.

Quando o universo de discurso é contínuo e infinito, o conjunto A é representado por (DRIANKOV; HELLENDOORN; REINFRANK, 1996):

$$
\underline{A}=\int \frac{\mu_{A}(x)}{x}
$$

Deve ser notado que a barra horizontal nas representações dos conjuntos nebulosos não configura um quociente, mas uma separação entre o grau de pertinência do elemento e seu valor; já a somatória e o símbolo de adição não indicam uma soma algébrica, mas sim uma união, da mesma forma que o símbolo de integral não representa uma integral numérica, mas a união de cada parcela.

As mesmas propriedades das operações entre conjuntos clássicos valem para os conjuntos nebulosos, com exceção das leis de meio exclusivo e de contradição, que não são válidas para os conjuntos nebulosos, pois os conjuntos nebulosos podem se sobrepor (conjunto e seu complemento), invalidando as relações (JAMSHIDI; VADIEE; ROSS, 1993).

A Figura 13 mostra o diagrama estendido de Venn para a representação do mapeamento entre conjuntos nebulosos e suas propriedades. 

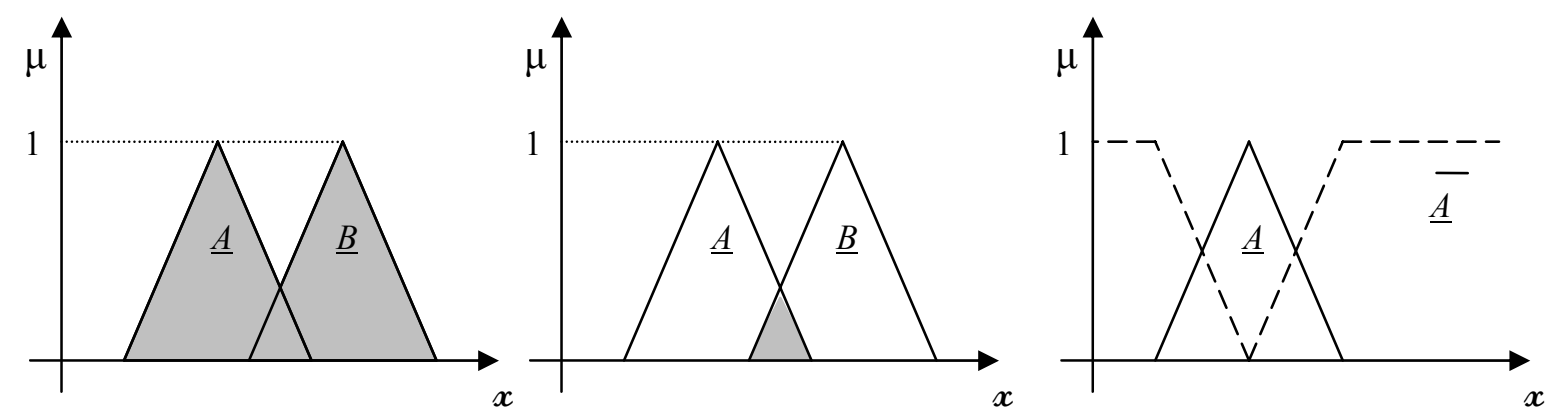

$\underline{A} \cup \underline{B}$

$\underline{A} \cap \underline{B}$

$\underline{\bar{A}}$

Figura 13. Diagramas de Venn estendidos para representação de operações entre conjuntos nebulosos (JAMSHIDI; VADIEE; ROSS, 1993).

A Figura 14 demonstra a não validade das leis do meio exclusivo e da contradição para conjuntos nebulosos.
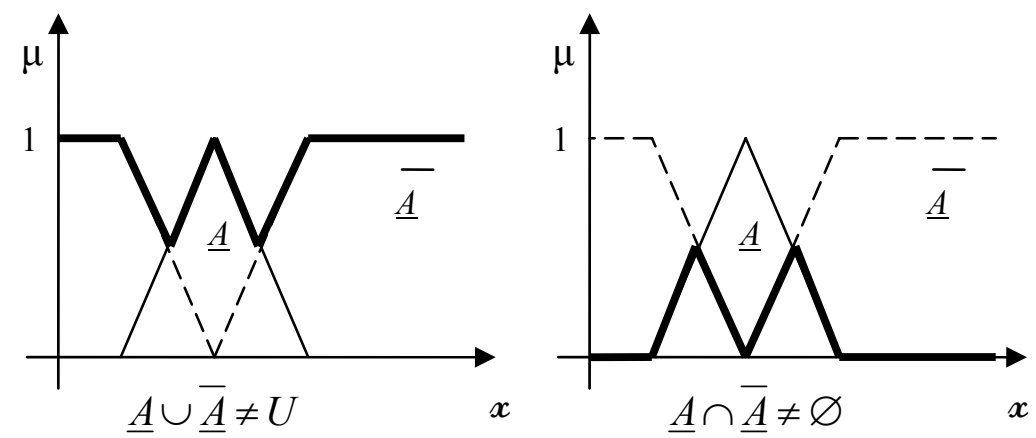

Figura 14. Demonstração gráfica da não validade das leis de meio exclusivo e contradição para conjuntos nebulosos (JAMSHIDI; VADIEE; ROSS, 1993).

Como toda a informação contida em um conjunto nebuloso é descrita por meio da função de pertinência, é importante descrever os termos que descrevem as características especiais desta função. A Figura 15 mostra estes termos(MCNEILL; THRO, 1994).

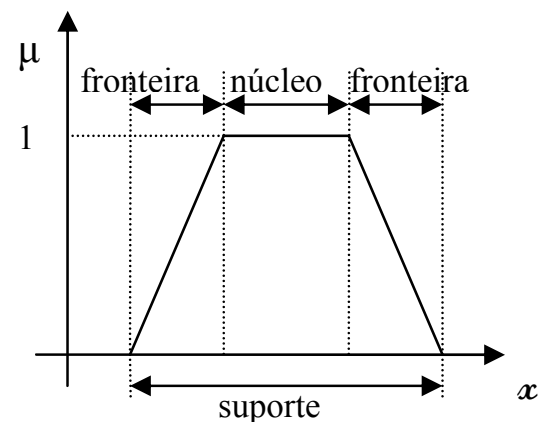

Figura 15. Descrição das características de uma função de pertinência (JAMSHIDI; VADIEE; ROSS, 1993). 
Conforme mostrado na Figura 15, o suporte de uma função de pertinência é definido como sendo a região do universo cujos valores de pertinência são diferentes de zero; o núcleo de uma função de pertinência é a região cujos valores de pertinência são iguais a 1 (pertinência total) e as fronteiras de uma função de pertinência é a região cujos valores de pertinência estão compreendidos entre 0 e 1 (pertinência parcial). Uma função de pertinência é dita normal se possuir pelo menos um elemento do universo com valor de pertinência igual a 1. Para conjuntos nebulosos onde somente um elemento possui o valor de pertinência igual a 1, este elemento é denominado elemento prototípico (KLIR, 1995).

As fronteiras de um conjunto nebuloso apresentam uma importante característica do conjunto, uma vez que tentam descrever a forma da nebulosidade ou vaguidade do conjunto. A forma da fronteira pode ter uma distribuição linear, exponencial, normal, etc. e a curva determina o comportamento da nebulosidade do conjunto. Nos conjuntos clássicos, a fronteira simplesmente é inexistente, uma vez que a pertinência assume apenas dois valores: 0 ou 1 . A representação de um único elemento clássico é efetuada por uma função de pertinência que é identicamente nula em todo o universo, exceto no valor do elemento considerado, em que assume o valor 1. Este caso, onde o suporte e o núcleo se restringem a apenas um ponto (o valor do elemento), é denominado de fuzzy singleton. As Figuras 16 (a) e (b) mostram estas representações em termos do diagrama de Venn estendido (PEDRYCZ, 1993).

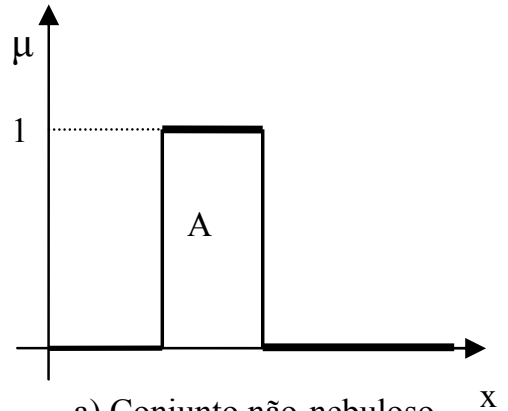

a) Conjunto não-nebuloso

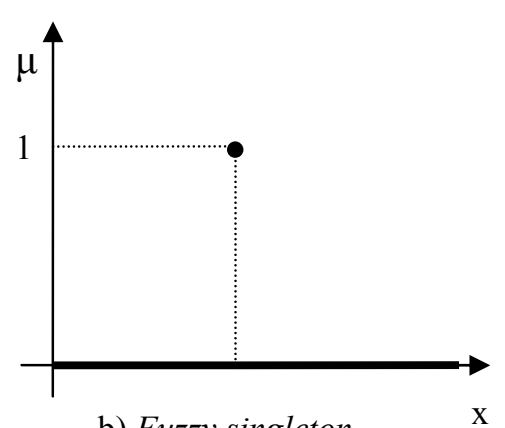

b) Fuzzy singleton

Figura 16. Representações esquemáticas para um conjunto não nebuloso e para um fuzzy singleton (PEDRYCZ, 1993).

Uma característica importante de uma função de pertinência diz respeito ao fato do conjunto nebuloso ser convexo ou não. Um conjunto nebuloso convexo é aquele cujas fronteiras são descritas por funções de pertinência estrita e monotonicamente crescentes para valores menores que os valores do núcleo do conjunto e por funções estrita e monotonicamente decrescentes para valores maiores que os valores do núcleo. A Figura 17 mostra exemplos de representações de conjuntos nebulosos convexos e não-convexos. 


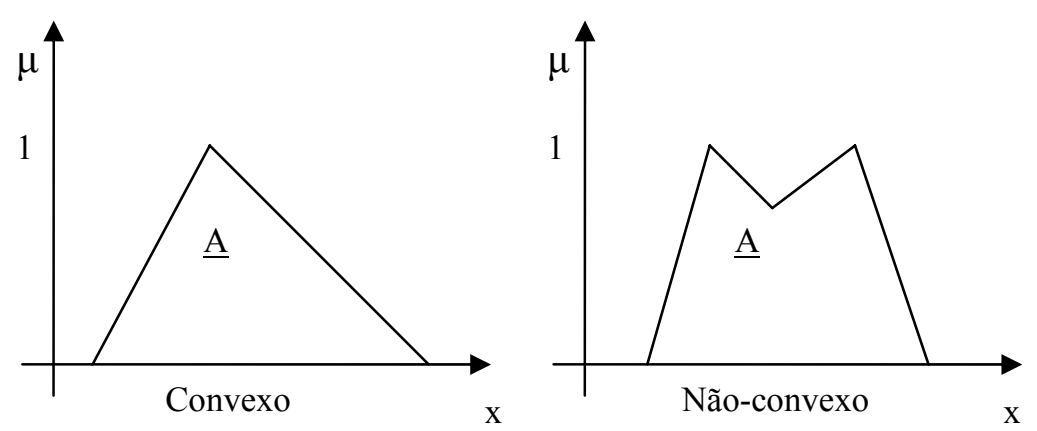

Figura 17. Exemplos de conjuntos nebulosos convexos e não-convexos.

Dubois (1993) afirmou em seu trabalho que, dentre os diversos tipos de conjuntos nebulosos, existe um tipo especial, definido sobre o conjunto de números reais, que representa uma grande importância dentro da lógica nebulosa porque, além de representar um conjunto lingüístico, representa um conceito quantitativo. Tais conjuntos são denominados números nebulosos ou intervalos nebulosos.

Lingüisticamente, estes conjuntos incorporam o conceito de números ou intervalos aproximados como "números próximos a um determinado número real" ou "números localizados próximo a um intervalo de números reais". Estes conceitos permitem a caracterização de valores para variáveis nebulosas que são muito utilizadas em controle nebuloso, tomada de decisão, raciocínio aproximado, otimização e cálculo estatístico utilizando valores probabilísticos imprecisos (CUGNASCA, 1999 apud DUBOIS, 1993).

Aritmeticamente, estes conjuntos permitem a realização de operações matemáticas com variáveis nebulosas, embora exista um procedimento especial para se tratar os elementos contidos na fronteira destes conjuntos nebulosos, de forma a tornar coerente a operação matemática desejada em todos os elementos do suporte de números nebulosos. As operações matemáticas somente são realizadas em sistemas de controle nos quais decisões são tomadas sobre operações matemáticas realizadas sobre as variáveis de entrada.

Para que um conjunto nebuloso possa ser considerado um número ou um intervalo nebuloso, três propriedades básicas devem ser obedecidas: o conjunto nebuloso deve ser normal, com valor de pertinência igual a um para o próprio número ou números do intervalo que se deseja representar, e um valor de pertinência entre zero e um para os valores situados nas fronteiras do conjunto nebuloso; o suporte do conjunto nebuloso deve ser limitado, de forma a definir um conjunto nebuloso limitado, e o conjunto nebuloso deve ser convexo, de maneira a definir intervalos fechados para todos os valores de pertinência situados no intervalo [0,1] (CUGNASCA, 1999 apud KLIR, 1995). 
A relação entre dois conjuntos também é uma importante operação que pode ser realizada. $\mathrm{O}$ mapeamento ou a relação utilizada para a representação da noção de pertinência dos conjuntos é um exemplo de relação entre dois conjuntos, pois associa cada um dos elementos do conjunto dos números reais a um valor situado no intervalo $[0,1]$ relativo ao valor de pertinência do número real ao conjunto nebuloso considerado.

Uma relação especial, que combina todos os elementos de um universo $U$ com todos os elementos de outro universo $V$ na forma de pares ordenados, nos quais o primeiro elemento pertence ao universo $U$ e o segundo elemento pertence ao universo $V$, é denominado de produto cartesiano de $U$ e $V$, ou (MCNEILL; THRO, 1994):

$$
U x V=\{(x, y) / x \in U, y \in V\}
$$

Esta é a relação mais ampla que pode ocorrer entre os dois universos $U$ e $V$, sendo todas as demais relações que associam elementos do universo $U$ a elementos do universo $V$ subconjuntos do produto cartesiano $U \mathrm{x} V$. Igualmente ao mapeamento de elementos, as relações entre dois conjuntos pode ser mapeada no produto cartesiano, sendo associado o valor 1 quando a relação mapeada contiver o par ordenado $(x, y)$ do produto cartesiano e o valor 0 quando a relação entre os conjuntos não contemplar o par ordenado $(x, y)$.

Quando a relação é discreta e finita, os elementos de um dos conjuntos são representados nas linhas de uma matriz, enquanto os elementos do outro conjunto são representados nas colunas da matriz. Os valores das células da matriz podem assumir os valores 1 e 0 , representando a existência ou não, respectivamente, de relação entre os elementos dispostos nas linhas e nas colunas da matriz (PEDRYCZ, 1993).

A cardinalidade de uma relação é dada pelo produto das cardinalidades de cada um dos conjuntos da relação, ou seja, $n_{(U, V)}=n_{U} \cdot n_{V}$, e a cardinalidade do conjunto potência é dada por: $n_{P(U, V)}=2^{n_{U} \cdot n_{V}}$. Para os conjuntos nebulosos, a cardinalidade da relação é infinita, pois sua cardinalidade também é infinita. (JAMSHIDI; VADIEE; ROSS, 1993).

As propriedades das relações e dos conjuntos nebulosos também podem ser representadas por meio de seus mapeamentos, de forma similar à realizada para os conjuntos clássicos. Vale ressaltar que, da mesma forma que para os conjuntos nebulosos, as únicas leis que não valem para as relações entre conjuntos nebulosos são a lei do meio exclusivo e a lei da contradição (MCNEILL; THRO, 1994). 
Os mapeamentos entre conjuntos nebulosos obedecem a um importante princípio, estabelecido por Zadeh em 1975, aperfeiçoado por Yager em 1986 e denominado de princípio da extensão. Este princípio estabelece que, se há um mapeamento de elementos de um universo de discurso nebuloso em elementos de outro conjunto nebuloso por meio de uma função, este mapeamento é feito de "um para um”, sendo que a função também forma um conjunto nebuloso, cujos elementos são compostos pela imagem nebulosa de cada elemento do domínio da função, com o mesmo valor de pertinência destes elementos (PEDRYCZ, 1993).

Seja $R$ uma relação entre elementos do universo $U$ e elementos do universo $V$ e seja $S$ uma relação entre elementos do universo $V$ e elementos do universo $W$. Uma relação que efetua a mesma associação de elementos do universo $U$ diretamente em elementos do universo $W$ é denominada de relação composta, produzida por uma operação denominada de composição. A relação composta é representada por $T=R \circ S$ e possui duas representações em termos de mapeamentos: a composição pelo máximo $(\vee)$ dos mínimos $(\wedge)$ e a composição pelo máximo $(\vee)$ do produto $(\bullet)$ (DRIANKOV; HELLENDOORN; REINFRANK, 1996). As representações são apresentadas a seguir:

$$
\begin{aligned}
& \chi_{T}(x, z)=\bigvee_{y \in V}\left(\chi_{R}(x, y) \wedge \chi_{S}(y, z)\right) \text { (Máximo dos mínimos) } \\
& \chi_{T}(x, z)=\bigvee_{y \in V}\left(\chi_{R}(x, y) \bullet \chi_{S}(y, z)\right) \text { (Máximo do produto) }
\end{aligned}
$$

As mesmas representações são válidas para conjuntos nebulosos. É importante notar, que, tanto para os conjuntos clássicos como para os conjuntos nebulosos, em geral as relações não possuem inversas, ou seja, $R \circ S \neq S \circ R$. Isto decorre da não comutatividade do produto de matrizes que representam as relações e, mesmo para matrizes quadradas, a composição inversa não é garantida (JAMSHIDI; VADIEE; ROSS, 1993).

A seguir serão apresentados os conceitos de lógica nebulosa preditiva, que permitirá a manipulação dos conceitos lingüísticos expressos nos conjuntos nebulosos, permitindo a um sistema de controle utilizando lógica nebulosa preditiva efetuar inferências a partir destes conceitos. A partir deste ponto, por simplicidade de notação, este tipo de sistema de controle será denominado controlador nebuloso. 


\subsection{Lógica Nebulosa}

A teoria dos conjuntos encontra uma grande aplicação na lógica de predicados clássica, na qual uma proposição é definida como uma afirmação lingüística contida em um universo de proposições e pode ser identificada como sendo estritamente verdadeira ou estritamente falsa. Conforme visto anteriormente, na lógica de predicados clássica, a veracidade de uma proposição $P$ é associada a um valor binário ( 0 ou 1$)$, conforme a proposição seja falsa ou verdadeira (PEDRYCZ, 1993). Assim, se $U$ for o universo de todas as proposições, o estabelecimento da veracidade das proposições é um mapeamento destas proposições ao conjunto binário contendo apenas dois valores: falso e verdadeiro ou 0 e 1 :

$$
T: U \rightarrow\{0,1\}
$$

$\mathrm{Na}$ lógica clássica de predicados, as proposições são representadas por letras maiúsculas e são utilizados os seguintes conectivos lógicos que formam expressões lógicas envolvendo proposições (JAMSHIDI; VADIEE; ROSS, 1993):

- $\quad$ Proposição: $P: x \in A$

- $\quad$ Disjunção $(\vee): \begin{aligned} & P \vee Q \rightarrow x \in A \text { ou } x \in B \\ & T(P \vee Q)=\max (T(P), T(Q))\end{aligned}$

- $\quad$ Conjunção $(\wedge): \begin{aligned} & P \wedge Q \rightarrow x \in A \text { e } x \in B \\ & T(P \wedge Q)=\min (T(P), T(Q))\end{aligned}$

- $\quad$ Negação $(\neg): \neg P: x \notin A$

- $\quad \operatorname{Implicação~}(\rightarrow): \begin{aligned} & P \rightarrow Q \equiv \neg P \vee Q: x \notin A \text { ou } x \in B \\ & T(P \rightarrow Q)=T(\neg P \vee Q)=\max (T(\neg P), T(Q))\end{aligned}$

- $\quad$ Equalidade $(\equiv o u \leftrightarrow): \begin{aligned} & P \leftrightarrow Q \Rightarrow x \in A, x \in B \\ & T(P \leftrightarrow Q)=T(P)=T(Q)\end{aligned}$

Os conectivos apresentados referem-se a subconjuntos $A$ e $B$ do universo de proposições $U$ e podem representar idéias lingüísticas ou pensamentos. $\mathrm{O}$ cálculo proposicional existe quando a proposição $P$ mede a veracidade de que uma afirmação $x$ do universo $U$ esteja contida nos subconjuntos $A$ e $B$ (MCNEILL; THRO, 1994). 
Como as duas proposições $P$ e $Q$ podem assumir um entre dois valores, existe um total de 4 possibilidades de situações proposicionais. A Tabela 2 mostra a tabela da verdade para as quatro possibilidades dessas proposições e para as afirmações compostas pelos conectivos lógicos (JAMSHIDI; VADIEE; ROSS, 1993).

Tabela 2 - Tabela da verdade para as proposições $P$ e $Q$ e seus conectivos lógicos (JAMSHIDI; VADIEE; ROSS, 1993).

\begin{tabular}{|c|c|c|c|c|c|c|}
\hline $\mathbf{P}$ & $\mathbf{Q}$ & $\neg P$ & $P \vee Q$ & $P \wedge Q$ & $P \rightarrow Q$ & $P \leftrightarrow Q$ \\
\hline 0 & 0 & 1 & 0 & 0 & 1 & 1 \\
\hline 0 & 1 & 1 & 1 & 0 & 1 & 0 \\
\hline 1 & 0 & 0 & 1 & 0 & 0 & 0 \\
\hline 1 & 1 & 0 & 1 & 1 & 1 & 1 \\
\hline
\end{tabular}

As proposições compostas por meio da lógica clássica que têm a propriedade de serem sempre verdadeiras, independentemente do valor das proposições que a constituem, são denominadas de tautologias. As tautologias são úteis para o raciocínio dedutivo e no processo de inferência dedutiva, tornando-as particularmente úteis nos mecanismos de inferência de sistemas especialistas. Assim, se uma proposição composta pode ser expressa na forma de uma tautologia, seu valor lógico é sempre verdadeiro (MCNEILL; THRO, 1994).

Entre as tautologias, existem duas em particular muito utilizadas no mecanismo de inferência em sistemas especialistas de tomada de decisão, conhecidas como: Modus Ponens e Modus Tollens (PEDRYCZ, 1993).

As tautologias do tipo Modus Ponens representam regras de inferência do tipo: "SE $<$ antecedente> ENTÃO <conseqüente>" e permitem encontrar o valor lógico de um conseqüente dado o valor de um antecedente na produção de uma regra para orientar o processo de tomada de decisão de um sistema. Desta forma, sempre que for verificada a veracidade da condição do antecedente, um conseqüente será produzido. A forma mais conhecida do Modus Ponens conclui que, dadas uma proposição $P$ e que esta proposição implica em uma outra proposição $Q, P \rightarrow Q$, se a veracidade de $P$ e $P \rightarrow Q$ forem verificadas, a veracidade da proposição $Q$ estará automaticamente inferida (MCNEILL; THRO, 1994). 
O Modus Ponens pode ser representado por (JAMSHIDI; VADIEE; ROSS, 1993):

$$
(A \wedge(A \rightarrow B)) \rightarrow B
$$

As tautologias do tipo Modus Tollens representam regras de inferência do tipo: "SE NÃO < conseqüente> ENTÃO NÃO < antecedente> " e permitem a investigação reversa de que se não ocorreu um conseqüente, não houve a produção de um antecedente. Este modo é utilizado em sistemas especialistas que efetuam a verificação reversa dos resultados.

A forma mais conhecida do Modus Tollens conclui que, dadas a não ocorrência de uma proposição $(\neg Q)$ e a proposição de que uma outra proposição causaria a ocorrência desta proposição $(P \rightarrow Q)$, se a falsidade de $Q(\neg Q)$ e a veracidade da implicação $(P \rightarrow Q)$ forem verificadas, então a falsidade da proposição $P(\neg P)$ estará automaticamente inferida (MCNEILL; THRO, 1994).

O Modus Tollens pode ser representado por (JAMSHIDI; VADIEE; ROSS, 1993):

$$
(\neg B \wedge(A \rightarrow B)) \rightarrow \neg A
$$

Ao contrário das tautologias, existem proposições compostas por meio da lógica clássica que tem a propriedade de serem sempre falsas, independentemente do valor das proposições que a constituem e são denominadas de contradições. Assim, se uma proposição composta pode ser expressa na forma de uma contradição, seu valor lógico é sempre falso. Alguns exemplos de contradição são: $\neg P \wedge P, A \cap \varnothing, \bar{A} \cap \varnothing(\mathrm{PEDRYCZ}, 1993)$.

O método de dedução fornecido pelo Modus Ponens é utilizado como ferramenta de inferência nos sistemas baseados em regras, que são afirmações do tipo: "SE $A$ ENTÃO $B$ ”. O processo que permite, com base no método dedutivo fornecido pelo Modus Ponens, inferir um valor para um conseqüente $B^{\prime}$ diferente de $B$, dado um antecedente $A$ ' diferente de $A$ é denominado de Modus Ponens Generalizado (MCNEILL; THRO, 1994).

Este processo é possível por meio do uso da composição de relações: como a relação deduzida pelo Modus Ponens pode ser traduzida em uma relação que é um subconjunto do produto cartesiano dos conjuntos $A$ e $B$, se esta relação for aplicada em um outro antecedente pertencente ao conjunto $A$, o resultado será um conseqüente pertencente ao conjunto $B$ (DRIANKOV; HELENDOORN; REINFRANK, 1996).

O Modus Ponens Generalizado pode ser representado por:

$$
[(A \wedge(A \rightarrow B)) \rightarrow B] \rightarrow\left[\left(A^{\wedge} \wedge\left(A^{\prime} \rightarrow B^{\prime}\right)\right) \rightarrow B^{\prime}\right](\text { JAMSHIDI; VADIEE; ROSS, 1993) }
$$


A lógica nebulosa prevê a aplicação das proposições, conectivos lógicos e processos de dedução a afirmações que não possuem um grau definido de veracidade ou falsidade. Afirmações lingüísticas que tendem a possuir interpretações subjetivas envolvem afirmações nebulosas, vagas ou imprecisas, presentes na maior parte das afirmações da linguagem natural humana. O mapeamento da veracidade das afirmações nebulosas se dá no intervalo real $[0,1]$ e não mais no conjunto binário \{0,1\} (MCNEILL; THRO, 1994).

O valor da veracidade de uma proposição não é mais verdadeiro ou falso, mas o grau de veracidade da proposição é dado pelo valor de sua função de pertinência, que se confunde com a própria proposição. O conectivo de negação é expresso pelo complemento do conjunto nebuloso que expressa a proposição. Para os demais conectivos lógicos e processos de dedução, todas as propriedades mostradas para a lógica clássica de predicados vale também para a lógica nebulosa (PEDRYCZ, 1993).

Da mesma forma que para a lógica clássica, o Modus Ponens Generalizado também pode ser utilizado no processo dedutivo de proposições nebulosas. Este método é denominado de raciocínio aproximado e é análogo ao raciocínio exato utilizado na lógica clássica de predicados, sendo uma extensão do cálculo proposicional lógico clássico para lidar com proposições que possuem verdade parcial (MCNEILL; THRO, 1994).

Vale ressaltar que, apesar do processo dedutivo previsto pelo Modus Ponens Generalizado induzir a idéia da existência de uma relação inversa entre conseqüentes e antecedentes devido ao processo de composição de relações, esta relação inversa não existe, não sendo possível gerar os antecedentes a partir dos conseqüentes de uma regra estabelecida pelo Modus Ponens.

O objetivo final da lógica nebulosa é fornecer a base teórica para possibilitar o raciocínio a partir de proposições imprecisas (ou nebulosas). Este raciocínio é denominado de raciocínio aproximado e é análogo ao raciocínio utilizado na lógica de predicados para proposições precisas, sendo uma extensão do cálculo proposicional clássico; porém, esta extensão permite lidar com verdades parciais ou nebulosas ou, em outras palavras, com conceitos lingüísticos expressos em conjuntos nebulosos.

Seja uma informação nebulosa expressa na forma de uma base de regras do tipo "SE $x$ é $A$, ENTÃO $y$ é $B$ ”, onde $A$ e $B$ são proposições nebulosas e $x$ e $y$ são variáveis de entrada e saída, respectivamente. 
Se um novo antecedente $A$ ' for introduzido e for considerada a seguinte regra: "SE $x$ é $A$ ', ENTÃO $y$ é $B$ "', a pergunta a ser respondida pelo raciocínio aproximado é se, a partir da informação $A$ ' derivada da primeira regra é possível também derivar o conseqüente $B$ ' na segunda regra. O raciocínio aproximado responde afirmativamente a esta questão e mostra que o procedimento para a obtenção do conseqüente $B$ ' é a composição de funções (ou relações) nebulosas, ou seja, o conseqüente $B$ ' pode ser obtido por meio da seguinte operação de composição (JAMSHIDI; VADIEE; ROSS, 1993):

$$
B^{`}=A^{\circ} \circ R
$$

Neste caso, a relação R é a mesma relação que, a partir do antecedente $x$, que contém o valor nebuloso $A$, produziu o conseqüente $y$, que contém o valor nebuloso $B$. O raciocínio aproximado permite a utilização da mesma relação para produzir o conseqüente $y$ (que agora contém o valor nebuloso $B^{\prime}$ ) a partir do mesmo antecedente $x$ (que agora contém o valor $A^{\prime}$ ).

\subsection{Considerações Finais do Capítulo}

Este capítulo teve por objetivo introduzir os conceitos básicos sobre conjuntos e sobre lógica nebulosa preditiva ${ }^{4}$, relacionando-os com os conceitos da teoria clássica dos conjuntos e da lógica clássica. As propriedades matemáticas presentes nos conjuntos e na lógica nebulosa se refletem em importantes características dos sistemas de controle nebulosos. Devido a estas propriedades é possível manipular de forma matemática conceitos nebulosos. A lógica nebulosa funciona, assim, como uma espécie de linguagem, pois permite a manipulação de conceitos lingüísticos, permitindo que se façam deduções e inferências a partir destes conceitos. O próximo passo consiste na apresentação de elementos da engenharia de sistemas de controle, onde a estruturação dos sistemas especialistas e dos sistemas de inferência será detalhada. Em seguida, os conceitos vistos no capítulo anterior, neste capítulo e no próximo serão aplicados na modelagem de uma proposta de um controlador nebuloso de movimentação de trens.

\footnotetext{
${ }^{4}$ Preditiva: este termo refere-se à capacidade da técnica apresentada de prever os resultados das variáveis de saída, dado um conjunto de variáveis de entrada. Este termo não está relacionado à manutenção preditiva, em que consegue-se prever o momento da ocorrência de uma falha em um sistema, dado seu histórico de falhas.
} 


\section{Sistemas de Controle, Sistemas de Inferência e Sistemas Especialistas}

Este capitulo tem como objetivo apresentar sistemas de controle, sistemas de inferência e sistemas especialistas por meio de seus conceitos básicos de funcionamento. Em seguida, um controlador nebuloso é ilustrado pelas suas características que podem melhorar as qualidades esperadas de um controlador. Por fim, as fases de projeto de um controlador nebuloso são detalhadas, por meio da especificação do mecanismo de inferência utilizado e das interfaces de entrada e saída do sistema. O resultado é um projeto de um sistema de controle, apresentado na forma de uma proposta de modelagem para um controlador nebuloso automático de trens no capítulo seguinte.

\subsection{Introdução}

Antes de proceder a uma discussão detalhada de como um sistema de controle opera, deve-se compreender como as tarefas do dia-a-dia, embora complexas, são realizadas pelos seres humanos, e como uma forma padronizada de automação pode ser empregada nestes casos. Atividades que são simples para os seres humanos, como estacionar ou dirigir um veículo, levantar e carregar um objeto frágil, empacotar compras ou reconhecer sons e faces, envolvem desafios contínuos para a sua automação e realização por máquinas artificiais, como robôs, cujos desempenhos estão muito aquém daqueles apresentados por seres humanos, mesmo com todo o avanço da tecnologia de automação e controle.

Quando um ser humano precisa realizar uma atividade (como por exemplo, a superação de um obstáculo em sua trajetória), ele coleta intuitivamente toda a informação necessária e disponível sobre a situação atual (a topologia do terreno e informações sobre o obstáculo, como tamanho, forma, mobilidade, velocidade, etc.). Com base nestas informações e com a ajuda de situações experimentadas anteriormente, que são resgatadas da memória, uma série de atividades de controle é então tomada (remoção do obstáculo, mudança de trajetória, etc.) (PEDRYCZ, 1993). 
Devido à realimentação fornecida entre o processo que se quer controlar e o ser humano (que está exercendo o papel de controlador), um objetivo final pode ser atingido. $\mathrm{O}$ principal objetivo dos sistemas de controle é a substituição do ser humano na realização destas atividades de controle e, portanto, no processo de tomada de decisão. O sistema de controle em si é uma construção matemática e, portanto, não pode incorporar o completo conhecimento necessário ao controle sem a realização de uma série de experimentos projetados e racionalmente organizados.

A estrutura de ciclo fechado destes sistemas de controle (mostrado na Figura 18) tem sido o tópico de várias e intensivas pesquisas na área de teoria e engenharia de controle. Embora existam diversas abordagens para o projeto destes sistemas de controle, eles estão baseados em duas premissas básicas:

- O sistema a ser controlado deve ser conhecido, de forma que se possa predizer como o sistema responde sob determinadas situações de entrada. Para realizar esta predição, todo o conhecimento sobre o sistema deve ser agregado em sua modelagem. Esta fase de identificação é fundamental ao sucesso do desempenho dos algoritmos de controle; e

- O objetivo do sistema de controle deve ser bem definido em termos de formulação matemática clara e concisa que envolva diretamente as variáveis do sistema. Uma vez identificado e articulado o objetivo do controle, este é utilizado para uma constante avaliação dos índices de desempenho do sistema (PEDRYCZ, 1993).

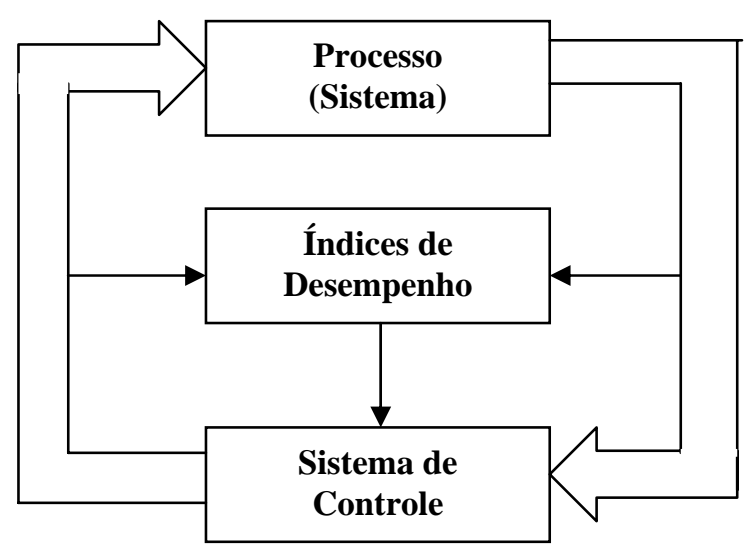

Figura 18. Diagrama de um sistema de controle - ciclo fechado (PEDRYCZ, 1993). 
Estando obedecidas estas premissas básicas, a estrutura do controlador e os parâmetros numéricos do processo podem ser computados por meio dos métodos existentes na engenharia de controle (incluindo as técnicas de conjuntos nebulosos). Infelizmente, apesar do embasamento matemático descrito, à medida que a complexidade dos sistemas aumenta, o conhecimento sobre o sistema de controle e sobre os objetivos de controle tornam-se de difícil implementação e execução e a sua modelagem não pode ser efetuada de maneira precisa, devido à presença de não-linearidades, instabilidades e falta de conjuntos representativos de dados.

A Figura 19 mostra um detalhamento do processo de controle, que consiste de interfaces de entrada e saída e de um mecanismo de inferência cuja função é avaliar o índice de desempenho do sistema e tomar ações sobre as entradas do sistema a serem controladas, de forma a atingir o melhor índice de desempenho para o sistema. Este índice é obtido comparando-se as variáveis de saída do sistema a ser controlado com índices padrões previamente estabelecidos. A diferença entre os parâmetros de saída do sistema e os índices esperados leva a um processo de tomada de decisão (inferência) de forma a diminuir este erro entre os valores obtidos e os esperados (PEDRYCZ, 1993).

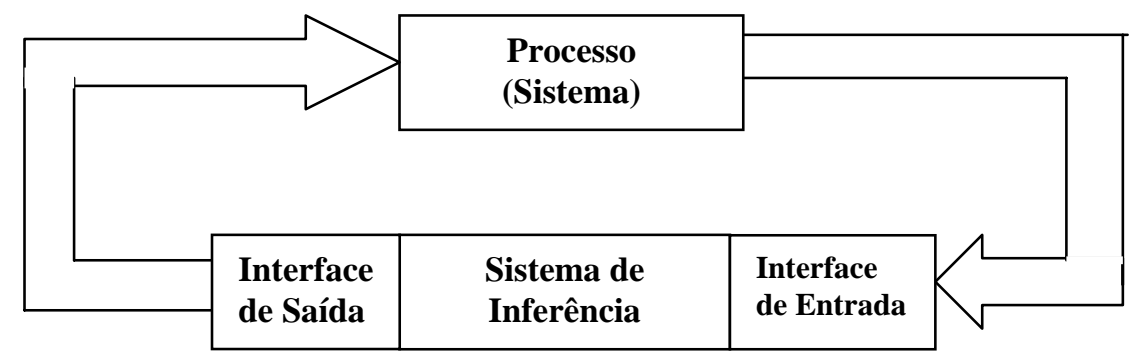

Figura 19. Detalhamento da estrutura do sistema de controle (PEDRYCZ, 1993).

Um sistema de inferência é composto por uma base de dados, uma base de regras e um mecanismo de inferência, que nada mais é do que a comparação dos dados de entrada com os antecedentes presentes na base de regras, conforme mostrado na Figura 20. As regras que verificam as condições dos antecedentes produzem os conseqüentes de saída (de acordo com o mecanismo de inferência lógica escolhido) que formarão as ações a serem tomadas sobre o processo de forma a atingir o objetivo do controle sobre o sistema. 


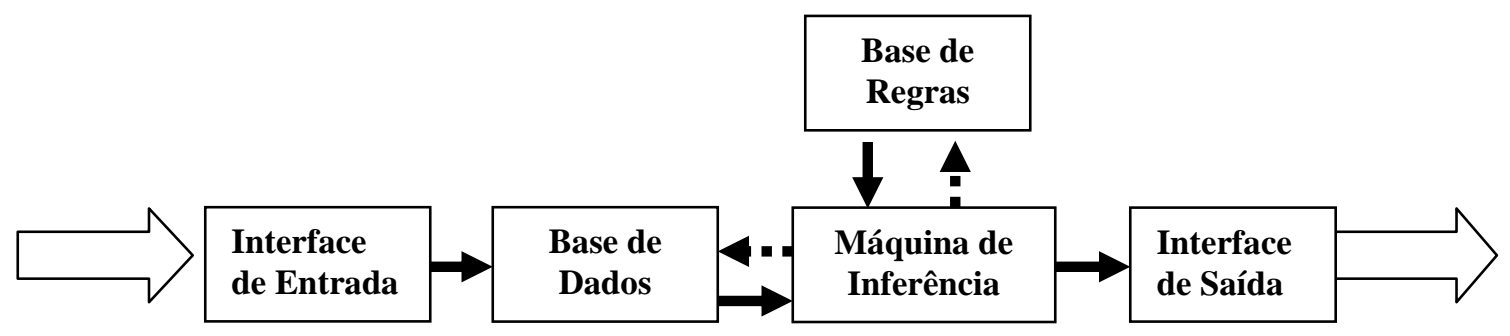

Figura 20. Estrutura do sistema de inferência (MITCHELL, 1997).

Os sistemas de inferência podem também embutir em sua máquina de inferência um mecanismo para aprendizagem. Neste caso, a máquina de inferência interage com a base de dados, recebendo informações desta base e criando novos dados, por inferência, a partir da aplicação das regras nos dados recebidos. A máquina de inferência também interage com a base de regras, criando novas regras a partir do aprendizado de novos conceitos vindos da observação do comportamento dos dados em função da aplicação das regras em situações anteriores (histórico). Esta interação está mostrada na Figura 20 por meio de setas pontilhadas e somente está presente em sistemas inteligentes que efetuam aprendizado a respeito do controle efetuado.

A maioria dos sistemas industriais de controle não utiliza sistemas de inferência com aprendizagem, uma vez que não se tem um controle preciso do comportamento do sistema em virtude do possível aprendizado de novas regras. Além disso, o sistema de aprendizagem torna a base de regras vulnerável, pois esta base pode ser modificada dinamicamente. A quantidade de novos exemplos de aprendizagem deve também ser controlada para não haver sobrecarga das bases de dados e de regras do sistema (MITCHELL, 1997).

Os sistemas de controle podem ser basicamente de dois tipos: sistemas de controle direto e sistemas de controle com supervisão. Nos sistemas de controle direto, as funções de avaliação dos índices de desempenho do sistema e de conhecimento do funcionamento do sistema sob controle são combinadas e o controle é efetuado de forma direta sobre as variáveis de saída do sistema sob controle (JAMSHIDI; VADIEE; ROSS, 1993). 
Nos sistemas de controle com supervisão, as funções de avaliação dos índices de desempenho e de conhecimento do sistema são separadas, sendo que um sistema de controle direto é utilizado para tomar as ações de controle do sistema, enquanto que um sistema de supervisão executa as funções de avaliação do desempenho do sistema sob controle, atuando preferencialmente sobre as decisões do sistema de controle direto e garantindo que as variáveis de saída do sistema permaneçam dentro de limites de controle pré-determinado.

Os sistemas de controle com supervisão são preferencialmente utilizados nos sistemas críticos de controle, onde as ações de controle são críticas com relação à segurança e devem obrigatoriamente permanecer dentro de limites que levem à segurança do sistema A Figura 21 mostra os esquemas dos sistemas de controle direto (a) e com supervisão (b) (DRIANKOV; HELLENDOORN; REINFRANK, 1996).

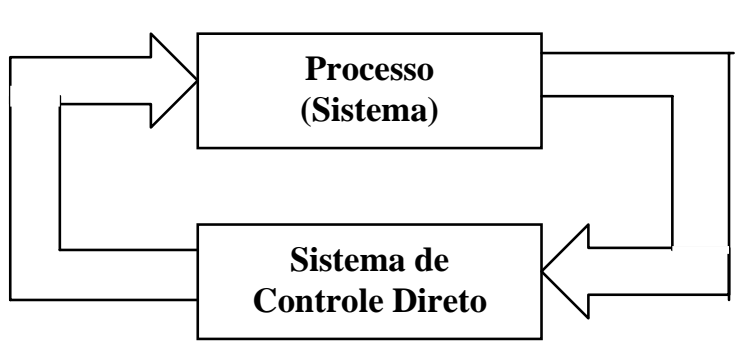

(a)

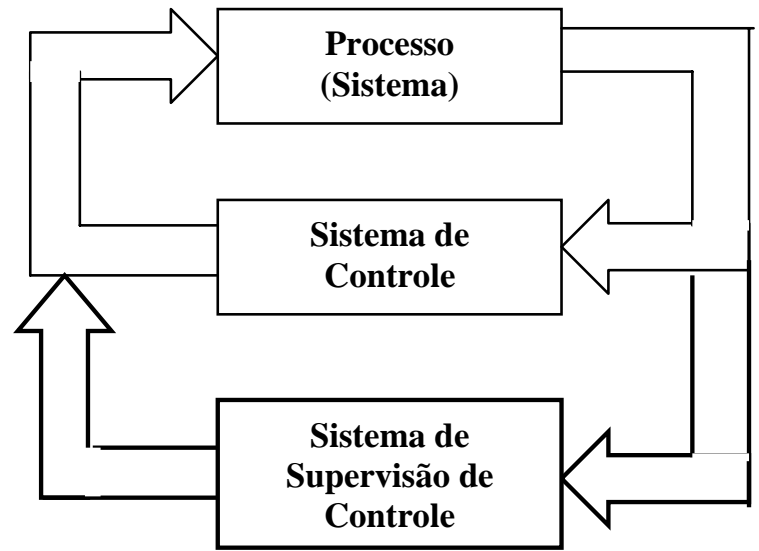

(b)

Figura 21. Esquemas dos sistemas de controle direto (a) e com supervisão (b) (DRIANKOV; HELENDOORN; REINFRANK, 1996).

Sistemas especialistas são aqueles que substituem o conhecimento humano especializado em determinadas áreas de controle, como sistemas biológicos, médicos, econômicos e em sistemas de controle crítico, que envolvem segurança, como controle metroferroviário, aeroviário ou controle de instalações e processos químicos industriais. É o caso do simulador de trens proposto nesta dissertação, onde o sistema de controle direto efetua o controle das funções de operação automática do trem (ATO) e o sistema de supervisão efetua o controle das funções de proteção automática do trem (ATP). 
Analogamente aos sistemas de controle, o principal objetivo dos sistemas especialistas é a substituição do ser humano na execução de tarefas de controle especialistas. O principal problema no projeto de sistemas especialistas envolve a aquisição, representação e gestão do conhecimento especialista em termos de variáveis e formulações matemáticas (PEDRYCZ, 1993).

A aquisição do conhecimento normalmente envolve a transmissão verbal de regras a serem aplicadas no sistema por parte do operador humano especialista. Esta transmissão é feita utilizando linguagem natural e termos específicos ao domínio do sistema especialista, o que torna difícil a tradução destas regras em termos matemáticos inteligíveis ao sistema. Além da transmissão verbal, existem comportamentos na operação do sistema pelo especialista que contêm informações que não podem ser transmitidas verbalmente.

Neste caso, estas informações dependem de outros métodos de aquisição, como acompanhamento da operação do sistema ou entrevistas práticas estruturadas. A aquisição do conhecimento depende, portanto, fundamentalmente da sensibilidade e percepção do analista em perceber informações através da observação do comportamento do especialista e dos resultados em função dos comandos efetuados na operação do sistema.

Os sistemas especialistas traduzem a forma como o operador especialista pensa, coleta e gerencia o conhecimento na resolução de problemas específicos. O pensamento humano efetua caracterizações sobre informações incompletas e trabalha com tais informações, efetuando inferências por similaridades e avaliação de objetivos complexos, tendo a capacidade de tomar decisões e efetuar julgamentos em circunstâncias incertas.

Por todos estes aspectos, a lógica nebulosa representa uma ferramenta adequada para tratar o conhecimento traduzido em informações vagas e imprecisas e produzir resultados satisfatórios. Toda a caracterização matemática de conjuntos e lógica nebulosa apresentada no capítulo anterior permite a manipulação de informações vagas e imprecisas que compõem o conhecimento do especialista humano. 


\subsection{Sistemas de Controle Nebulosos}

Conforme mostrado no item anterior deste capítulo, a lógica nebulosa representa uma ferramenta adequada para o tratamento de informações imprecisas dos sistemas especialistas. A implementação da lógica nebulosa no projeto de um controlador lógico nebuloso se dá de maneira análoga à forma dos sistemas de ciclo fechado de inferência, com a única diferença que a lógica utilizada é a lógica nebulosa no lugar da lógica clássica, com mecanismos de inferência nebulosa e raciocínio aproximado.

Os diagramas das Figuras 18, 19, 20 e 21 apresentados continuam sendo válidos para sistemas nebulosos, porém as interfaces de entrada e saída mostradas nas Figuras 19 e 20 recebem os nomes de bloco fuzificador ${ }^{5}$ e bloco defuzificador ${ }^{6}$, respectivamente. O bloco fuzificador tem a função de adquirir variáveis de entrada do mundo real e transformar estas variáveis em variáveis nebulosas, para que estas variáveis possam ser processadas pelo controlador nebuloso. De forma inversa, o bloco defuzificador tem a função de transformar as ações produzidas pelo controlador nebuloso e transformá-las em números, que correspondem a grandezas físicas relativas a ações determinadas pelo controlador (LEE, 1990a; LEE, 1990b).

A principal vantagem dos controladores nebulosos sobre os controladores PID (Proportional Integral Diferencial) tradicionais é que a representação do conhecimento especialista pode ser, via de regra, elaborada mais facilmente, uma vez que as definições das variáveis de controle e das regras que regem os sistemas especialistas se apresentar em linguagem natural, mais próxima da forma do raciocínio humano.

\footnotetext{
${ }^{5}$ Fuzificador - Neologismo aceito na comunidade científica, originado da palavra inglesa Fuzzyfier, que significa um processo ou um módulo que transforma uma grandeza física em uma variável nebulosa. Também é aceito o neologismo Fuzificação, que se refere a este processo de transformação.

${ }^{6}$ Defuzificador - Neologismo aceito na comunidade científica, originado da palavra inglesa Defuzzyfier, que significa um processo ou módulo que transforma uma variável nebulosa em uma grandeza física. Também é aceito o neologismo Defuzificação, que se refere a este processo de transformação.
} 


\subsection{Etapas de Projeto de um Controlador Nebuloso}

Da mesma forma que para os sistemas de controle tradicionais, o conhecimento do funcionamento do sistema a ser controlado, bem como do objetivo que o sistema de controle visa alcançar, é fundamental na fase de identificação do problema a ser resolvido pelo controlador nebuloso (PEDRYCZ, 1993).

A próxima fase consiste na tradução do conhecimento do especialista em termos de parâmetros a serem utilizados no projeto do controlador. Existem diversas técnicas que podem ser utilizadas para a aquisição do conhecimento sobre o funcionamento do sistema, como:

- Entrevistas diretas com os especialistas do sistema objeto. Estas entrevistas podem ser efetuadas por meio de uma pesquisa estruturada, com o preenchimento de um questionário, ou por meio de uma pesquisa não-estruturada, que consiste em uma conversa informal com o especialista durante a qual perguntas sobre a operação do sistema são efetuadas;

- Observação direta ou indireta da operação do sistema por parte do especialista. Esta observação pode ser feita com o conhecimento do especialista (observação direta) ou indiretamente, sem que o operador saiba que está sendo monitorado. Esta última forma de observação é efetuada quando há a suspeita de que a operação do sistema é efetuada de forma diferente se o operador estiver sob monitoração ou se ninguém o estiver observando;

- Observação direta do comportamento do sistema pela medição e monitoração das variáveis de entrada, de saída e de controle do sistema. A injeção de falhas pode permitir a análise do comportamento do sistema em função de erros em suas variáveis; e

- Estudos de caso junto a outros sistemas que operem de forma semelhante, com a comparação dos dados fornecidos pelos dois sistemas.

Durante a fase de tradução do conhecimento especialista é importante que o conjunto de regras do sistema reflita as estratégias, políticas e heurísticas fornecidas pelo especialista. 
A próxima fase do projeto do controlador nebuloso envolve o dimensionamento dos blocos que compõem o sistema de inferência nebulosa, ou seja: o bloco fuzificador, a base de regras, o mecanismo de inferência e o bloco defuzificador. Para efetuar este dimensionamento, uma escolha deve ser feita sobre a forma de representação do conhecimento especialista.

O método de fuzificação das variáveis de entrada do sistema de controle envolve também a aplicação do conhecimento especialista, uma vez que considera a forma como o especialista interpreta as condições de entrada do sistema de controle. A determinação das funções de pertinência das variáveis de entrada do sistema de controle e a partição do universo de discurso em categorias lingüísticas de classificação das variáveis de entrada é um processo intuitivo ao especialista do sistema, podendo ser até subjetivo, uma vez que pode estar sujeito a uma interpretação particular do comportamento destas variáveis. Pode ocorrer até mesmo o fato de que nem mesmo o especialista do sistema esteja habilitado a determinar as funções de pertinência e a partição do universo de discurso de forma precisa; dessa forma, cabe ao analista projetista efetuar esta determinação, com base na observação do funcionamento do sistema.

Existem duas diferentes situações para determinar as funções de pertinência e a partição do universo de discurso para as variáveis de entrada de um sistema de controle nebuloso.

A primeira destas situações consiste em se associar funções de pertinência de maneira uniforme aos valores presentes na escala da variável. Esta associação é feita da seguinte forma:

a) Determina-se a escala das variáveis de entrada obtendo-se os valores mínimo e máximo possíveis para a variável;

b) Efetua-se a divisão da escala em $n$ partes iguais, de forma a se determinar $n$ categorias para a classificação lingüística dos valores da variável. O número de divisões $n$ deve ser no mínimo 1, determinando apenas uma categoria lingüística para a variável e no máximo 7 categorias, de forma a permitir uma classificação lingüística adequada de valores possíveis para a variável;

c) Efetua-se a associação de funções de pertinência às divisões efetuadas na escala, da seguinte forma: aos pontos das fronteiras dos intervalos formados pela divisão da escala são associados valor 1 para a função de pertinência. 
Os intervalos formados devem representar conjuntos nebulosos e, para isso, devem ser associadas funções aos valores presentes na região de fronteira destes conjuntos nebulosos (vide figura 15). A forma da função da fronteira deve ser monotonicamente decrescente a partir do valor máximo da função de pertinência associado aos pontos de fronteira dos intervalos, descrevendo funções triangulares para as funções de pertinência de cada intervalo, cujos vértices associam valor 0 para o ponto máximo da função de pertinência de cada uma das partições vizinhas e o valor 1 para o ponto máximo da função de pertinência da partição considerada. Fora desta região compreendida pelas funções triangulares, a função de pertinência deve assumir o valor 0 em todo o universo considerado. $O$ conjunto das funções de pertinência forma a partição do universo considerado; e

d) Os elementos extremos devem possuir valor de pertinência igual a um para os elementos situados fora da escala de variação, para prever o comportamento do sistema numa eventual entrada indevida do sistema. A Figura 22 mostra esta situação, na qual a escala de uma variável de entrada é dividida em n partições iguais (JAMSHIDI; VADIEE; ROSS, 1993).

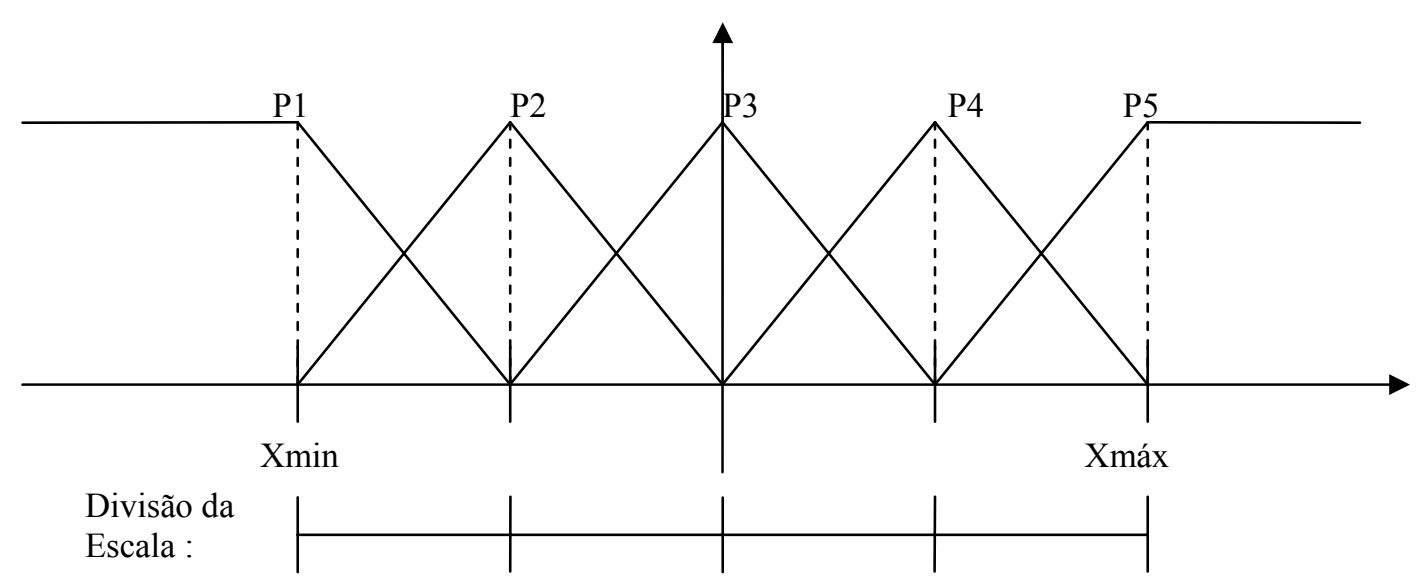

Figura 22. Criação de partições de uma variável de entrada a partir da divisão de sua escala em partições iguais (JAMSHIDI; VADIEE; ROSS, 1993).

As partições triangulares P2, P3 e P4 são conhecidas como do tipo TFN (Triangular Fuzzy Number), enquanto as partições P1 e P5 são conhecidas, respectivamente, como dos tipos RFN (Right Fuzzy Number) e LFN (Left Fuzzy Number). A outra forma para se determinar funções de pertinência consiste na identificação de valores ou intervalo de valores típicos que classifiquem adequadamente uma categoria lingüística da variável de entrada, feita com entrevista com o especialista ou por uma classificação efetuada junto a valores típicos apresentados pelas variáveis de entrada do sistema. 
A Figura 23 mostra esta situação, na qual são associadas funções de pertinência a determinados valores ou intervalo de valores para as variáveis de entrada que são mais comumente verificadas, da mesma forma como foram feitas as associações para a situação anterior (JAMSHIDI; VADIEE; ROSS, 1993).

(a)

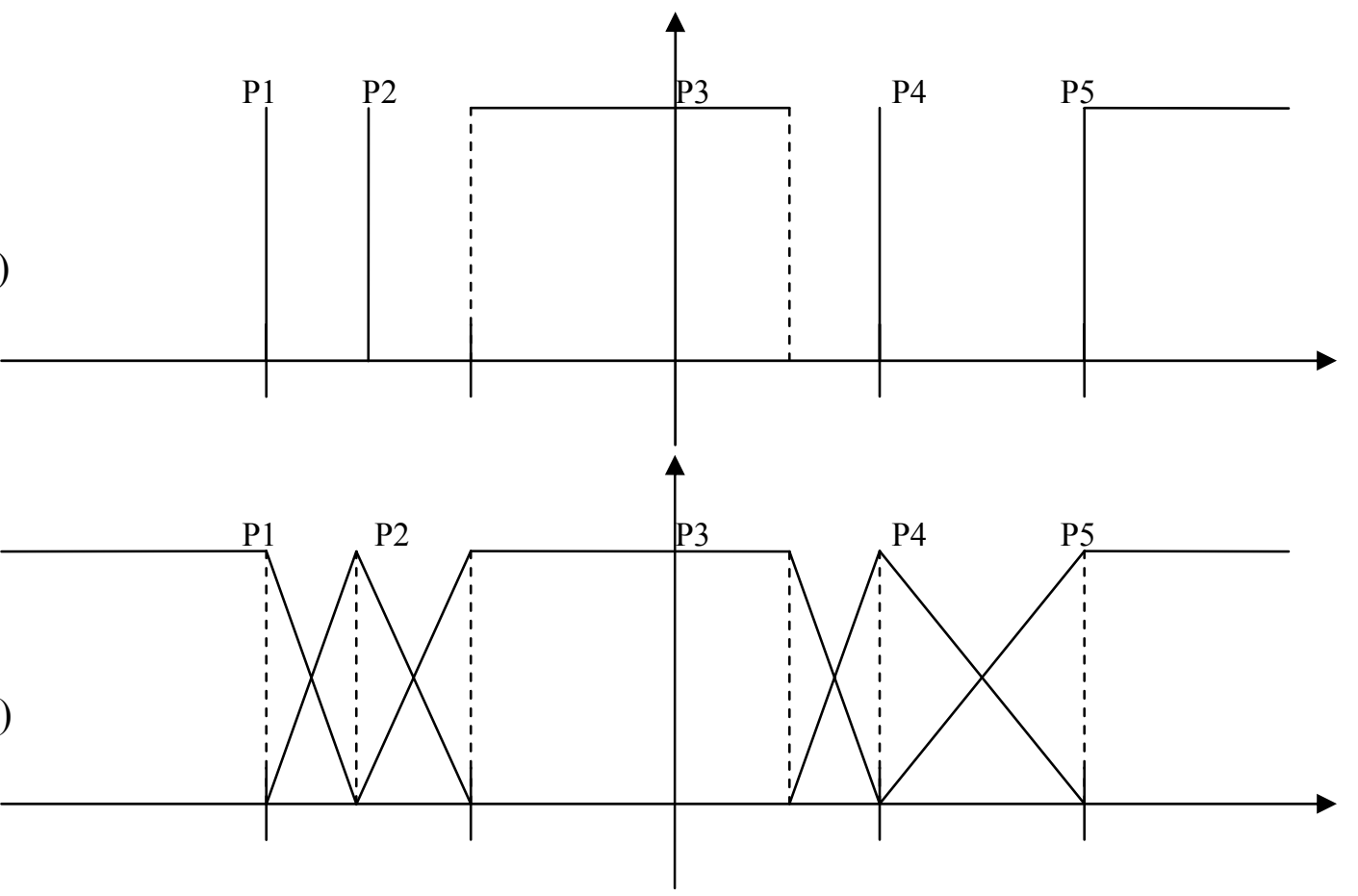

Figura 23. Existência de valores e intervalos típicos na escala da variável (a) e associação de funções de pertinência a estes valores (b) (JAMSHIDI; VADIEE; ROSS, 1993).

Uma vez definida a forma da interface de entrada (processo de fuzificação), o próximo passo consiste na tradução do conhecimento do especialista em termos da base de regras a ser utilizada no sistema de inferência. Neste momento, são utilizados todos os resultados obtidos por meio de entrevistas com os especialistas, da observação da operação do sistema e da análise dos resultados mais comuns produzidos pelo sistema (JAMSHIDI; VADIEE; ROSS, 1993).

A construção da base de regras é feita na forma "SE < antecedente> ENTÃO <conseqüente>". O antecedente pode ser uma única condição lógica ou a associação de condições lógicas utilizando conectivos lógicos E, OU e NÃO. Declarações de atribuição (por exemplo, velocidade $=$ média) ou ações incondicionais (comandos, como por exemplo, multiplicar por 2) também podem ser escritos na forma "SE <antecedente> ENTÃO $<$ conseqüente>", ficando nas formas "SE < atribuição $>$ ENTÃO < nenhum conseqüente>" e "SE $<$ nenhum antecedente $>$ ENTÃO < ação incondicional >”, respectivamente. 
Regras na forma "SE < antecedente $>$ ENTÃO < conseqüente1 $>$ SENÃO < conseqüente $2>$ " também podem ser desmembradas em duas regras, na forma "SE < antecedente> ENTÃO $<$ conseqüente>". O mesmo ocorre para regras aninhadas, do tipo "SE < antecedente> ENTÃO (SE $<$ antecedente $>$ ENTÃO $<$ conseqüente $>$ )".

Para sistemas lineares, a base de regras também pode ser obtida resolvendo-se as equações diferenciais que descrevem a modelagem matemática do sistema. Uma vez obtidas as soluções das equações diferenciais, o próximo passo consiste na agregação das possíveis soluções, colocando-as na forma "SE < antecedente> ENTÃO < conseqüente>”, denominada forma canônica de regras (PEDRYCZ, 1993).

Uma outra técnica para a construção da base de regras é a chamada de determinação da matriz do relacionamento. Esta matriz é produzida colocando todas as variáveis de entrada em linhas ou colunas de uma matriz n-dimensional e as células da matriz representam as ações de saída a serem tomadas para cada combinação das variáveis de entrada (JAMSHIDI; VADIEE; ROSS, 1993).

Para um sistema com 2 variáveis de entradas e 1 variável de saída, por exemplo, as $m$ partições da primeira variável de entrada definem as linhas da matriz e as $n$ partições da segunda variável de entrada definem as colunas da matriz. Os conteúdos das células representam as partições da variável de saída correspondente à combinação das variáveis de entrada. A base de regras contém, portanto, $(m \times n)$ regras, conforme ilustrado na Tabela 3 .

Tabela 3 - Exemplo de formação da base de regras por matriz de relacionamento.

\begin{tabular}{|c|c|c|c|c|c|}
\hline & & \multicolumn{4}{|c|}{ Partições da variável de entrada 2} \\
\hline & & $n_{1}$ & $n_{2}$ & ... & $n_{n}$ \\
\hline \multirow{4}{*}{$\begin{array}{c}\text { Partições da } \\
\text { variável de } \\
\text { entrada } 1\end{array}$} & $m_{1}$ & Regra 1 & Regra 2 & $\ldots$ & Regra $n$ \\
\hline & $\boldsymbol{m}_{2}$ & Regra $(n+1)$ & Regra $(n+2)$ & $\ldots$ & Regra 2.n \\
\hline & $\cdots$ & $\cdots$ & $\cdots$ & $\cdots$ & $\cdots$ \\
\hline & $\boldsymbol{m}_{m}$ & $\operatorname{Regra}[(m-1) \cdot n+1)]$ & $\operatorname{Regra}[(m-1) \cdot n+2]$ & $\ldots$ & Regra $m . n$ \\
\hline
\end{tabular}

Na Tabela 3, a indicação "Regra n" não indica a regra propriamente dita, mas o valor do conseqüente resultante da aplicação da regra ao conjunto de partições de entrada determinadas pelos índices da linha e da coluna da matriz. 
A vantagem deste método de construção da base de regras é que, pelo produto cartesiano das partições das variáveis de entrada, produzem-se todas as situações possíveis para a atuação do controlador. Porém, conforme o número de variáveis de entrada e saída cresce, este método torna-se inadequado.

É importante destacar que o conteúdo das células deve reproduzir a ação de controle a ser tomada pelo especialista, dada a combinação das variáveis de entrada para cada situação. Se o sistema de controle possuir mais que uma variável de saída, o conteúdo de cada célula da matriz deve expressar a partição a ser assumida para cada variável de saída do sistema.

A representação gráfica das partições das variáveis de saída determina uma função em um espaço n-dimensional, denominada de superfície de controle do sistema. Esta curva só é visível tridimensionalmente se o sistema possuir até duas variáveis de entrada para o controle. O gráfico tridimensional é construindo utilizando-se as variáveis de entrada como duas das dimensões, sendo a terceira utilizada para representar as partições da variável de saída. $\mathrm{O}$ sistema poderá possuir mais do que uma variável de saída, mas somente é possível a visualização tridimensional de uma variável de saída por vez e, caso o sistema possua mais que duas variáveis de entrada, a superfície não poderá ser visualizada tridimensionalmente.

Para um sistema com uma única variável de entrada, a superfície de controle restringese a uma função bidimensional que associa cada partição da variável de entrada a uma partição da variável de saída. A Figura 24 ilustra o exemplo de uma superfície tridimensional para um sistema com duas variáveis de entrada e uma variável de saída.

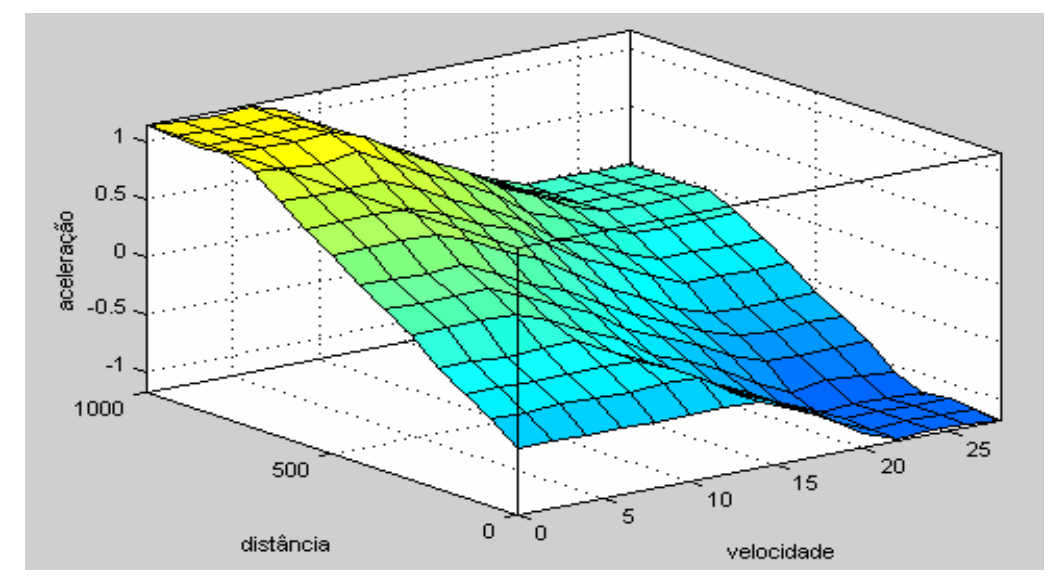

Figura 24. Exemplo de superfície tridimensional de controle. 
A seguir, o próximo passo no projeto e desenvolvimento de um controlador nebuloso consiste na escolha do método de inferência utilizado. A partir de um conjunto de dados de entrada e uma base de regras estabelecida, o mecanismo de inferência efetua um teste sobre os antecedentes das regras e, uma vez verificadas as condições de entrada, um conseqüente é produzido na saída. A forma como o conseqüente é produzido na saída depende do método escolhido para composição de relações nebulosas (conforme descrito no item 3.2): composição máximo-mínimo ou composição máximo-produto (também denominado de ponto máximo) (JAMSHIDI; VADIEE; ROSS, 1993).

O método de inferência resulta para o conseqüente um conjunto nebuloso de natureza semelhante à dos antecedentes. Em particular, quando as variáveis de entrada são pontualmente definidas, elas podem ser representadas por um conjunto nebuloso do tipo singleton (vide item 3.2) e o método de inferência produzirá na saída uma variável de saída também do tipo singleton. Se as variáveis de entrada estiverem compreendidas em um intervalo, a variável de saída produzida pelo método de inferência também produzirá um intervalo (LEE, 1990a; LEE, 1990b).

Uma forma especial de projeto do sistema do controlador nebuloso ocorre quando as variáveis de saída são combinações lineares das variáveis de entrada. Neste caso, o modelo do controlador nebuloso é denominado de modelo nebuloso quasi-linear. Este modelo foi utilizado no desenvolvimento de um carrinho de brinquedo por Sugeno, em 1985, e, por isso, o modelo quase-linear é também conhecido como método de Takagi-Sugeno (SUGENO; KANG, 1998).

O método de inferência que utiliza a composição de relações nebulosas do tipo máximo-mínimo para a produção de conseqüentes na saída do sistema é comumente conhecido como método do "Mínimo de Mamdani” (JAMSHIDI; VADIEE; ROSS, 1993).

Neste método, as variáveis de entrada (na forma de conjuntos nebulosos) são combinadas utilizando-se o máximo valor de pertinência para diferentes partições da mesma variável e o mínimo valor de pertinência para a combinação das variáveis de entrada correspondente aos antecedentes das regras. Este valor mínimo da função de pertinência é então aplicado às variáveis de saída correspondentes aos conseqüentes produzidos pelas regras. 
O valor final da variável de saída é determinado pela combinação das funções de pertinência dos conseqüentes para todas as regras nas quais os antecedentes forem verificados. $\mathrm{O}$ processo que transforma a combinação das funções de pertinência em um número correspondente a uma ação a ser tomada na saída do sistema é denominado de defuzificação e será detalhado mais adiante neste capítulo. A Figura 25 a seguir ilustra o método do "Mínimo de Mamdani” (JAMSHIDI; VADIEE; ROSS, 1993).
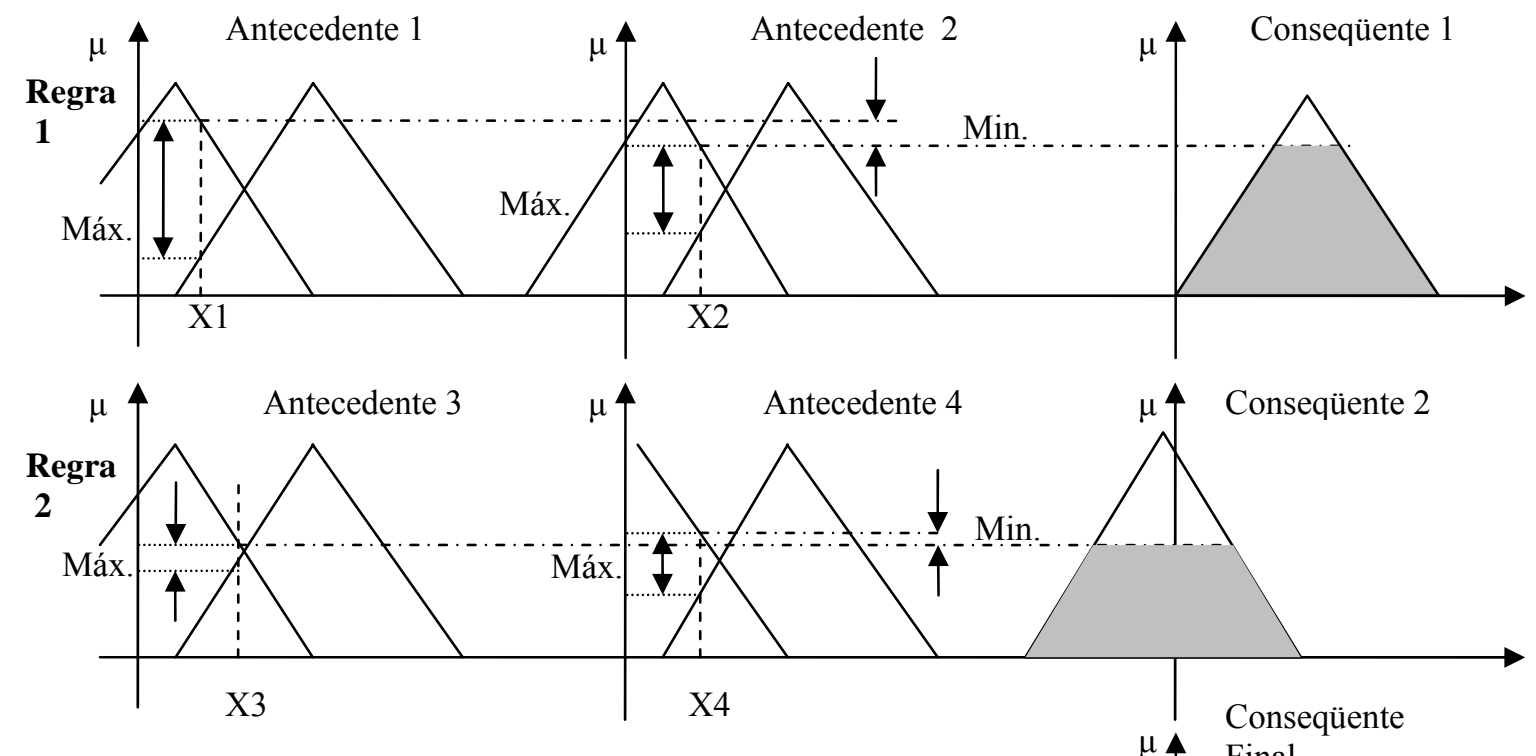

Regra 1:

$\mathrm{SE}((\mathrm{X} 1=\mathrm{A}) \mathrm{OU}(\mathrm{X} 1=\mathrm{B})) \mathrm{E}((\mathrm{X} 2=\mathrm{C}) \mathrm{OU}(\mathrm{X} 2=\mathrm{D}))$

ENTÃO Conseqüente 1

Regra 2:

$\mathrm{SE}((\mathrm{X} 3=\mathrm{A}) \mathrm{OU}(\mathrm{X} 3=\mathrm{B})) \mathrm{E}((\mathrm{X} 4=\mathrm{C}) \mathrm{OU}(\mathrm{X} 4=\mathrm{D}))$

ENTÃO Conseqüente 2

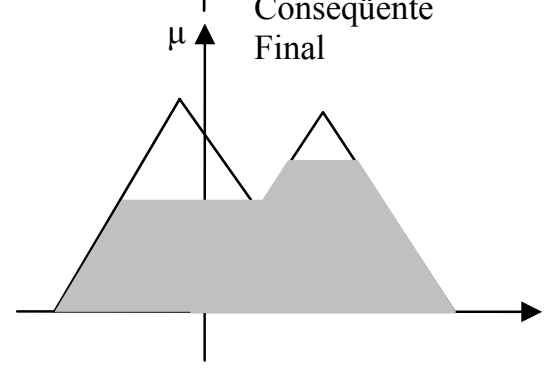

\section{Figura 25. Método do "Mínimo de Mamdani” para inferência nebulosa (JAMSHIDI; VADIEE; ROSS, 1993).}

O método de inferência que utiliza a composição de relações nebulosas do tipo máximo produto para a produção de conseqüentes na saída do sistema é comumente conhecido como método do "Produto de Larsen". Neste método, as variáveis de entrada são combinadas da mesma forma que no método do "Mínimo de Mamdani”, porém o valor da variável de saída (conseqüente) é determinado pelo valor mínimo da função de pertinência das variáveis de entrada (antecedentes) sendo usado como limitante máximo de pertinência para a variável de saída. 
Da mesma forma que para o método do mínimo de Mamdani, o valor final da variável de saída é obtido pela combinação das funções de todas as regras cujos antecedentes forem verificados. O processo de defuzificação também é aplicado para a determinação do valor correspondente à combinação das funções de pertinência das variáveis de saída. A Figura 26 ilustra o método do "Produto de Larsen" (JAMSHIDI; VADIEE; ROSS, 1993).
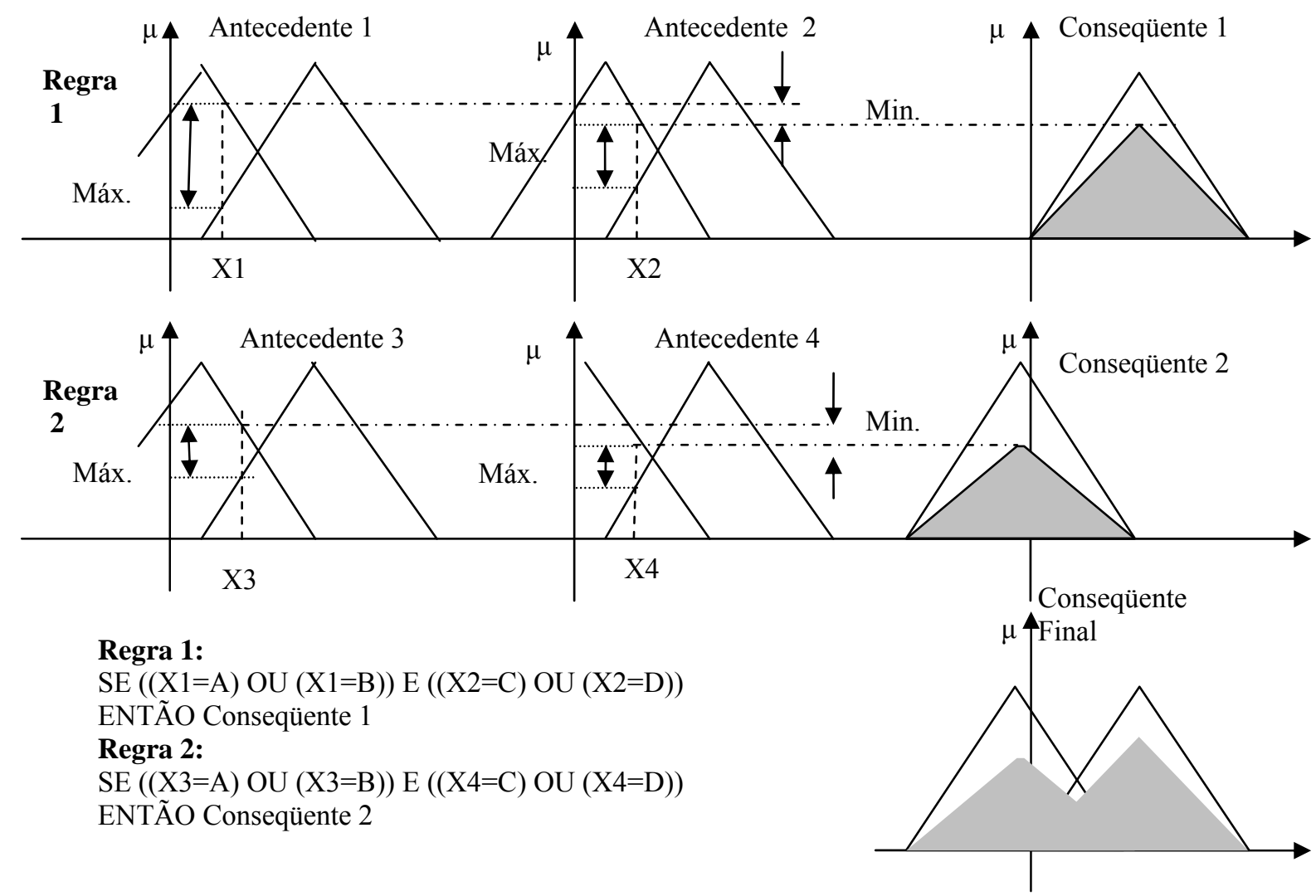

Figura 26. Método do "Produto de Larsen” para inferência nebulosa (JAMSHIDI; VADIEE; ROSS, 1993).

O passo final no projeto de um controlador nebuloso consiste na especificação da interface de saída, com a determinação do método de defuzificação a ser utilizado. A saída de um controlador nebuloso consiste em um conjunto nebuloso de controle. Entretanto, o processo sob controle necessita de uma variável numérica para efetuar a ação de controle. A seguir estão descritos alguns métodos de defuzificação (LEE, 1990a; LEE, 1990b), considerando o resultado obtido na Figura 26.

- Média dos Máximos: Neste método, é efetuada uma média entre os valores correspondentes aos máximos das funções de pertinência da variável de saída. A Figura 27 ilustra a aplicação do método da média dos máximos. 


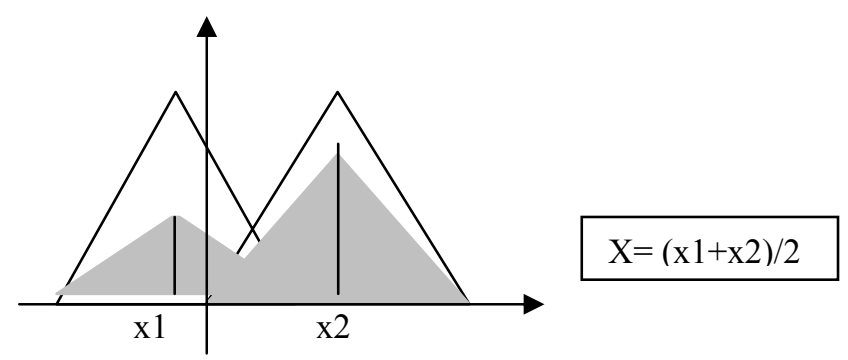

Figura 27. Exemplo de aplicação do método “Média dos Máximos”.

- Média Ponderada: A Figura 28 ilustra a aplicação deste método e o valor numérico final do conjunto é obtido por:

$$
x=\frac{x_{1} P_{1}+x_{2} P_{2}+\ldots+x_{n} P_{n}}{P_{1}+P_{2}+\ldots+P_{n}}
$$

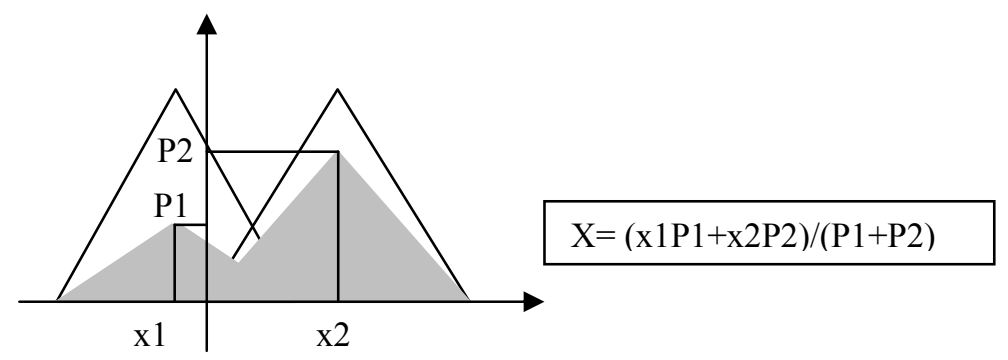

Figura 28 - Exemplo de aplicação do método “Média Ponderada”.

- Centro de Massa: Neste método, a coordenada do valor correspondente ao centro de massa do conjunto nebuloso formado é utilizada como sendo o valor numérico correspondente ao conjunto nebuloso. Este valor de coordenada é obtido pela seguinte expressão:

$$
x=\frac{\int_{X} x \cdot P(x) d x}{\int_{X} P(x) d x}
$$

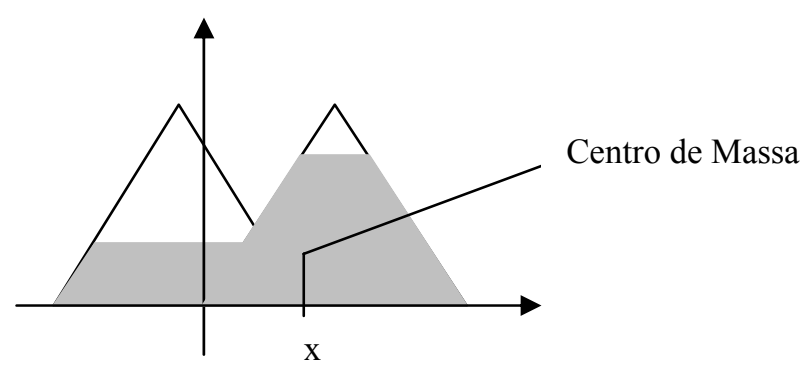

Figura 29. Exemplo de aplicação do método do “Centro de Massa”. 
- Outros métodos: Existem ainda outros métodos para associar um valor numérico ao conjunto nebuloso resultante da inferência nebulosa. Um destes métodos se resume a tomar como valor correspondente o maior valor de pertinência no intervalo determinado ou o valor médio do intervalo de máximos. Outro método toma como valor correspondente o ponto médio do suporte do conjunto nebuloso. Cada um dos métodos tem sua vantagem de aplicação, dependendo do resultado que se deseja obter.

Uma vez especificados os blocos que compõem o sistema de inferência nebulosa, (bloco fuzificador, base de regras, mecanismo de inferência e bloco defuzificador), o próximo passo consiste em efetuar a integração dos blocos. A modelagem de um sistema nebuloso de inferência utilizando estes conceitos será feita no próximo capítulo.

\subsection{Considerações Finais do Capítulo}

Este capítulo teve por objetivo introduzir os conceitos básicos de engenharia de sistemas de controle, bem como a estruturação e o funcionamento dos sistemas especialistas e sistemas de inferência. Em seguida, o controlador nebuloso foi apresentado sob a luz destes conceitos de engenharia de controle e todas as fases para projeto e implementação de um sistema de controle nebuloso foram detalhadas.

O próximo passo consiste na elaboração da modelagem do sistema nebuloso, aplicando-se os conceitos vistos nos três últimos capítulos. O controlador nebuloso a ser

projetado deverá apresentar todas as características de conjuntos e lógica de inferência nebulosa aplicadas a um sistema de controle especialista de inferência. 


\section{Modelagem do Sistema de Controle Nebuloso Proposto}

Uma vez apresentados os principais fundamentos teóricos necessários à compreensão do sistema, agora estes fundamentos são reunidos para a modelagem do sistema controlador nebuloso proposto. A Engenharia de Sistemas de Controle fornece a linguagem conveniente para descrever o sistema em termos de diagramas de blocos, enquanto o programa Matlab fornece um meio para a compreensão do comportamento dinâmico do sistema. Uma modelagem do sistema nebuloso proposto, incluindo as especificações das variáveis de entrada e saída e do mecanismo de inferência utilizado é apresentada e detalhada neste capitulo.

\subsection{Introdução}

A idéia de se utilizar um controlador lógico nebuloso para controle de trens surgiu da observação da forma como um controlador PID (Proportional Integral Derivative), normalmente utilizado para efetuar a função de regulação de velocidade, efetua a comparação entre a velocidade real do trem e a velocidade máxima permitida para o circuito de via. $\mathrm{O}$ controlador PID efetua a comparação entre as velocidades real e comandada para o trem, enquanto o sistema ATP realiza a aplicação de freios caso a velocidade real do trem ultrapasse a máxima velocidade permitida para o circuito de via considerado. Caso a velocidade real do trem esteja abaixo da velocidade de via, nenhuma ação de frenagem é efetuada.

Um dos efeitos indesejáveis da comparação efetuada pelo controlador PID é a ocorrência de trancos causados pela aplicação dos freios pelo sistema ATP. Outro efeito indesejável é que esta comparação proporciona muitas transições entre propulsão e frenagem. Para solucionar o problema dos trancos e para proporcionar um melhor controle da velocidade e da transição de velocidades do trem, o controlador de ATP foi implementado com um sistema denominado BPM (Brake Profile Monitor) - Monitoração do Perfil de Frenagem (CMW, 1985). 
O sistema BPM efetua um controle mais preciso quando a velocidade do trem se aproxima da velocidade comandada pelos equipamentos de via ou quando ocorre uma transição para um código de velocidade menor. Para evitar a aplicação de freios, quando a velocidade do trem está se aproximando da velocidade de via, o controlador analisa a taxa de aceleração do trem, para verificar a taxa de aproximação entre a velocidade do trem e da via. Quando a velocidade do trem está cerca de $5 \mathrm{~km} / \mathrm{h}$ abaixo do código de via e continua acelerando, o controlador efetua o corte do sistema de tração, de forma que a velocidade do trem se aproxime da velocidade da via de uma maneira mais suave. Se mesmo assim a velocidade do trem continuar subindo e igualar-se à velocidade de via, o sistema ATP efetua a aplicação de freios.

$\mathrm{Na}$ transição de um código de velocidade para um código menor, a tendência do controlador PID seria a aplicação de freios até que a velocidade do trem fique abaixo do novo código de velocidade comandado. O sistema BPM, entretanto, prevê um perfil para que a velocidade do trem abaixe para o novo código de maneira mais confortável ao passageiro. Neste caso, o controlador analisa, além da taxa de desaceleração do trem e da sua velocidade real, o espaço percorrido pelo trem desde a transição para o código de velocidade menor atualmente considerado. Novamente, a primeira ação do controlador é efetuar o simples corte da tração do trem. Caso a desaceleração proporcionada pelo trem não seja suficiente para trazer a velocidade abaixo do perfil previsto, o sistema ATP efetua a aplicação dos freios ao trem.

Para solucionar o problema do número excessivo de transições entre propulsão e frenagem, o sistema de propulsão foi dotado com temporizadores e técnicas para aplicação mais gradativa de propulsão e freios, de forma também a proporcionar um maior conforto aos passageiros. Os contatores que configuram o sistema elétrico e os motores necessitam de um tempo para a mudança de uma configuração de tração para uma configuração de freio e, mesmo que ocorram comandos mais rápidos de transição entre propulsão e freio, o sistema apresenta um tempo mínimo de resposta para as mudanças de configuração.

O sistema metroviário possui uma característica de procurar ser o mais rápido possível e, por outro lado, as distâncias entre suas estações não são grandes quando comparadas com as distâncias entre estações ferroviárias. Assim, o sistema metroviário prevê que o trem acelere com a maior taxa possível, de forma a atingir a máxima velocidade possível entre estações e, devido à pequena distância entre elas, freie com a maior taxa possível, de forma a percorrer o espaço entre duas estações em um menor intervalo de tempo possível. 
Esta característica, embora eficiente com relação ao tempo de percurso, não é tão eficiente em termos de consumo de energia e de exigência dos equipamentos de propulsão e freio, provocando uma maior manutenção do sistema.

Em horários de menor movimento existem menos composições operando e um número reduzido de passageiros. Assim, os trens não precisam desenvolver uma velocidade tão grande entre as estações e o trem pode acelerar e frear com uma taxa menor de aceleração e desaceleração. Isto faz com que o trem gaste mais tempo para percorrer o espaço entre estações, porém consuma menos energia e tenha uma exigência menor dos equipamentos de propulsão e freio, causando uma menor manutenção do sistema.

O controle do número de trens e do intervalo entre trens (headway) é, portanto, função da demanda de passageiros ao longo do dia. Para efetuar este controle, os trens utilizam um comando denominado PM (Performance Modification) ou ND (Nível de Desempenho). Com o uso deste comando é possível determinar a máxima velocidade e as taxas de aceleração e frenagem que o trem poderá desenvolver no percurso até a próxima estação. Em horários de pico de demanda de passageiros, utilizam-se comandos com maior velocidade e maior taxa de aceleração e frenagem e, nos horários de vale, são utilizados comandos com menor velocidade e menor taxa de aceleração e frenagem.

Para o metrô de São Paulo os comandos de nível de desempenho são transmitidos ao trem pelos equipamentos de estação, no momento em que o trem está partindo da plataforma da estação e são aplicados no espaço entre a estação atual que fornece os comandos e a próxima estação.

O controlador nebuloso, entretanto, possui as características de se aproximar da forma humana de raciocínio e, por isso, permite um controle mais suave da aceleração e frenagem do trem. $\mathrm{O}$ controlador nebuloso leva em conta a distância do trem atual à próxima estação ou ao trem que está à sua frente, bem como a sua velocidade atual e a do trem à frente para desenvolver perfis de aceleração e frenagem otimizados à distância a ser percorrida.

Para a implantação do controlador nebuloso, a proposta envolve também a mudança do sistema de sinalização fixa para o sistema de sinalização por blocos móveis. A idéia principal consiste em se desprender do paradigma da sinalização de códigos de velocidade fixos transmitidos nos circuitos de via, regulando diretamente o espaçamento entre trens. Para isto, um registro mais apurado do posicionamento dos trens deverá ser efetuado, com os circuitos de via indicando o posicionamento dos trens ao longo da via. 
Transponders (ou balizas) deverão ser colocados na via para permitir uma maior precisão na localização dos trens ao longo da via. A informação da velocidade, aceleração e da posição do trem à frente deverão ser informados via rádio, por meio do sistema centralizado (ATS), para que o trem possa dimensionar seu perfil de aceleração e frenagem, de forma a otimizar o acionamento dos circuitos de propulsão e freio, otimizando o seu desempenho no trecho que estiver livre à sua frente.

Assim, as entradas do sistema controlador nebuloso proposto serão a posição e a velocidade reais do trem corrente e a posição e a velocidade do trem à frente. O sistema então calcula a posição e a velocidade relativa entre os trens, gerando um sinal de aceleração para que o trem possa otimizar o percurso do trecho à sua frente. A aceleração do trem da frente pode entrar como um limitante da aceleração do trem corrente, caso o trem corrente tenha um intervalo de frenagem menor que o do trem da frente, necessário até a parada total do trem.

Para fins didáticos, o sistema pode ser comparado a um sistema no qual um carro trafega por uma estrada com uma única pista. Enquanto não houver nenhum carro à frente, o motorista pode imprimir qualquer velocidade possível (desde que abaixo da permitida) ao veículo por meio do pedal do acelerador. Para fins de segurança, o motorista deve considerar que, em caso de necessidade de frear o carro, este ainda percorrerá uma distância proporcional à velocidade atual e à capacidade de frenagem segura (taxa de desaceleração) do veículo.

Esta distância é denominada de overlap. Assim, enquanto não houver nenhum obstáculo dentro de uma distância de overlap, o veículo pode andar a qualquer velocidade abaixo da máxima permitida. Porém, se a distância ao veículo da frente for igual ou menor do que a distância de overlap, a informação sobre a velocidade e aceleração do veículo da frente torna-se vital para a segurança dos dois veículos. A velocidade do veículo fica, a partir desse instante, limitada à do veículo da sua frente, e se o veículo da frente iniciar uma frenagem, o veículo de trás deverá também frear com uma taxa igual ou maior à do veículo da frente.

Por isso, todos os veículos automotores são equipados com luzes de freio, que permitem ao motorista a visualização do veículo da frente e a identificação de que o veículo da frente está freando, de forma que o motorista do veículo de trás também possa frear, com uma taxa igual ou maior do que o veículo da frente, sob o risco de efetuar uma colisão com o veículo da frente, caso isso não seja feito. 
No caso de trens, como o contato roda-trilho é pequeno e devido ao fato do material das rodas e do trilho serem metálicos, as distâncias de overlap são muito grandes e variam de acordo com a velocidade do trem.

A Figura 30 mostra o diagrama de blocos que representa o sistema proposto.

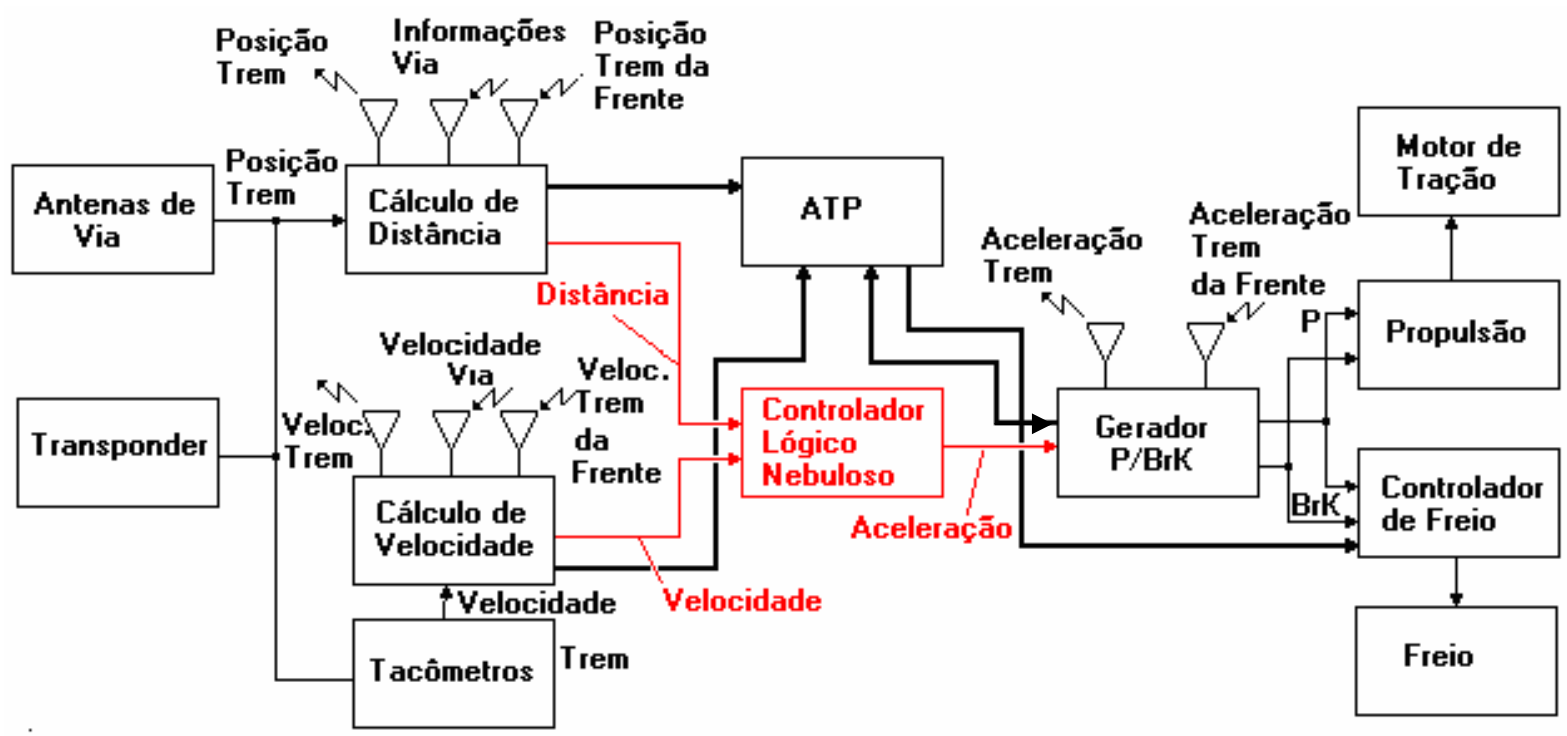

Figura 30. Diagrama de blocos que representa o sistema proposto.

No diagrama apresentado na Figura 30, o posicionamento do trem é obtido por antenas e transponders dispostos ao longo da via, além de um circuito eletrônico que integra a informação do tacômetro, como formas de determinação do posicionamento do trem ao longo da via.

O sistema central de controle (ATS) efetua o controle do posicionamento de todos os trens ao longo da via. Por meio de antenas de rádio, o sistema informa a cada um dos trens a posição do trem da frente e as características físicas do trecho em que o trem estiver localizado (curvas, aclives, declives, etc.). Com base nas informações relativas ao posicionamento do trem e ao posicionamento do trem da frente, o sistema efetua um cálculo de distância relativa, utilizada como variável de entrada para o controlador nebuloso.

Da mesma forma, o sistema central de controle (ATS) transmite a todos os trens, por meio de antenas de rádio, a informação da velocidade do trem à sua frente. Com base nesta informação e com a informação da velocidade real do trem, obtida pela leitura de tacômetros, o sistema efetua um cálculo da velocidade relativa entre trens, utilizada como outra variável de entrada para o controlador nebuloso. 
Além de utilizar as informações de posição e velocidade real do trem para o processamento do controlador nebuloso, o sistema também transmite estas informações ao sistema central de controle (ATS) para que estas informações sejam repassadas ao trem de trás, de forma que este também possa fazer o processamento da distância e da velocidade relativas ao trem em questão.

Com base nas informações de distância e velocidade relativas, o controlador nebuloso produz o valor de aceleração mais adequado para a situação determinada pelas variáveis de entrada. Este valor de aceleração é encaminhado ao Gerador P/BRK que, com base nesta informação e na informação da aceleração do trem da frente (transmitida via rádio pelo sistema de controle central - ATS), efetua a produção dos valores de corrente propulsão e freio aos motores de tração e acionadores de freio. Além disso, o gerador P/BRK também transmite o valor de aceleração produzido pelo controlador nebuloso ao sistema de controle central - ATS, para utilização pelo trem de trás.

O sistema ATP monitora continuamente todas as variáveis (distância, velocidade e aceleração relativas), de forma a garantir a segurança do trem e atua preferencialmente sobre o controle de freios se alguma condição insegura durante a movimentação do trem for verificada.

\subsection{O Controlador Nebuloso Proposto}

O controlador nebuloso proposto utiliza um sistema de inferência nebuloso para calcular a aceleração adequada de um trem tomando como base a posição relativa entre dois trens (ou a distância até a próxima estação, no caso de não haver outro trem no trecho entre duas estações consecutivas) e a velocidade relativa entre os dois trens (ou a velocidade atual do trem, no caso de não haver outro trem entre duas estações consecutivas).

As variáveis de entrada são duas: Distância (D) e Velocidade (V) e a variável de saída é a Aceleração (A) a ser imposta ao trem. A Figura 31 mostra o sistema nebuloso proposto. 


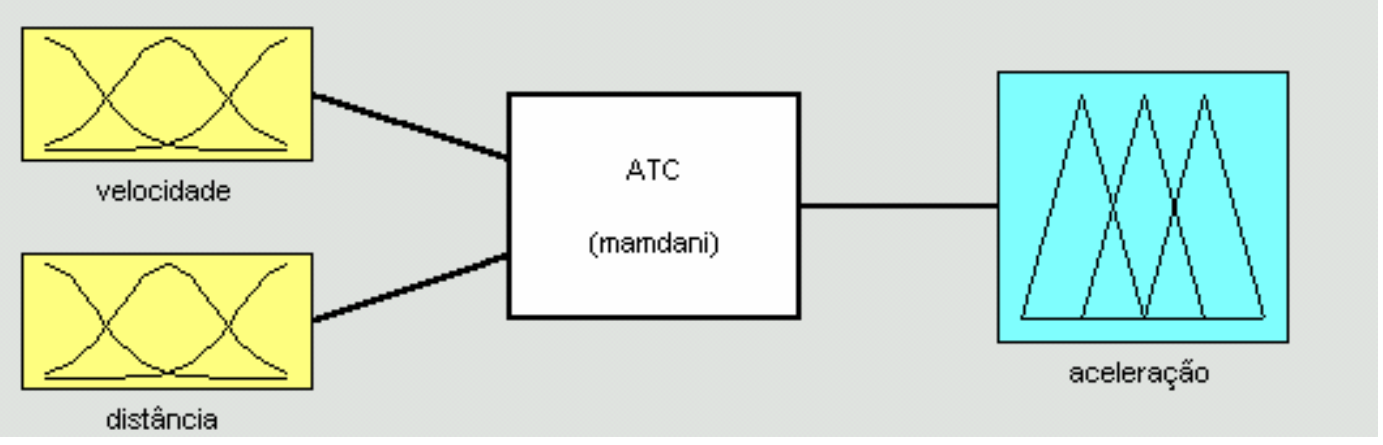

Figura 31. Variáveis de entrada e saída do sistema nebuloso proposto.

Conforme mostrado na Figura 31, o método de inferência a ser utilizado no sistema controlador nebuloso proposto é o método do "Mínimo de Mamdani" descrito no item 4.3 deste trabalho. Este método foi utilizado por ser tradicionalmente desenvolvido e utilizado em sistemas de controle industriais e porque realiza cálculos de forma mais simples do que os outros métodos, como o do "Produto de Larsen".

A variável Distância é avaliada como a distância relativa entre dois trens ou a distância entre o trem e a próxima estação onde o trem deverá efetuar a parada. $\mathrm{O}$ universo de discurso está compreendido entre 0 e 1000 metros (que é a distância média aproximada entre estações) e compreende cinco variáveis lingüísticas: Grande, Média-Grande, Média, MédiaPequena e Pequena. As funções de pertinência utilizadas são do tipo TFN (Triangle Fuzzy Number), exceto para as variáveis Grande e Pequena, onde foram utilizadas funções do tipo LFN (Left Fuzzy Number) e RFN (Right Fuzzy Number), respectivamente. A Figura 32 mostra a distribuição gráfica das funções de pertinência relativa à variável Distância., onde as partições foram concebidas segundo procedimento descrito no item 4.3.

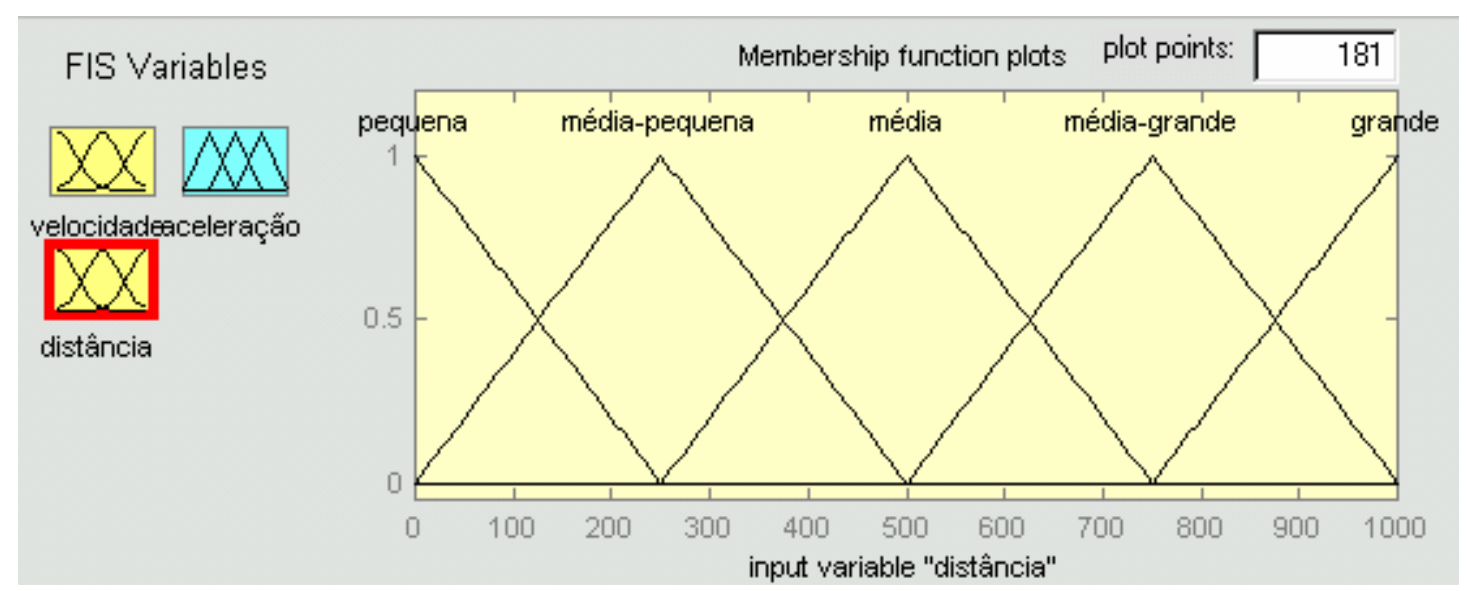

Figura 32. Distribuição das funções de pertinência relativa à variável Distância. 
A variável Velocidade é avaliada como sendo a velocidade relativa entre dois trens ou a própria velocidade atual do trem, conforme cálculo efetuado pelo bloco cálculo de velocidade na Figura 30. O universo de discurso está compreendido entre 0 e $100 \mathrm{~km} / \mathrm{h}$ - ou entre 0 e $28 \mathrm{~m} / \mathrm{s}$ (que é a atual limitação para a velocidade dos trens) - e compreende cinco variáveis lingüísticas: Alta, Média-Alta, Média, Média-Baixa e Baixa. Da mesma forma que para a variável Distância, as funções de pertinência utilizadas são do tipo TFN, exceto para as variáveis Alta e Baixa, onde foram utilizadas funções do tipo LFN e RFN, respectivamente. A Figura 33 mostra a distribuição gráfica das funções de pertinência relativas à variável Velocidade. As partições da variável foram construídas da mesma forma que a variável Distância.

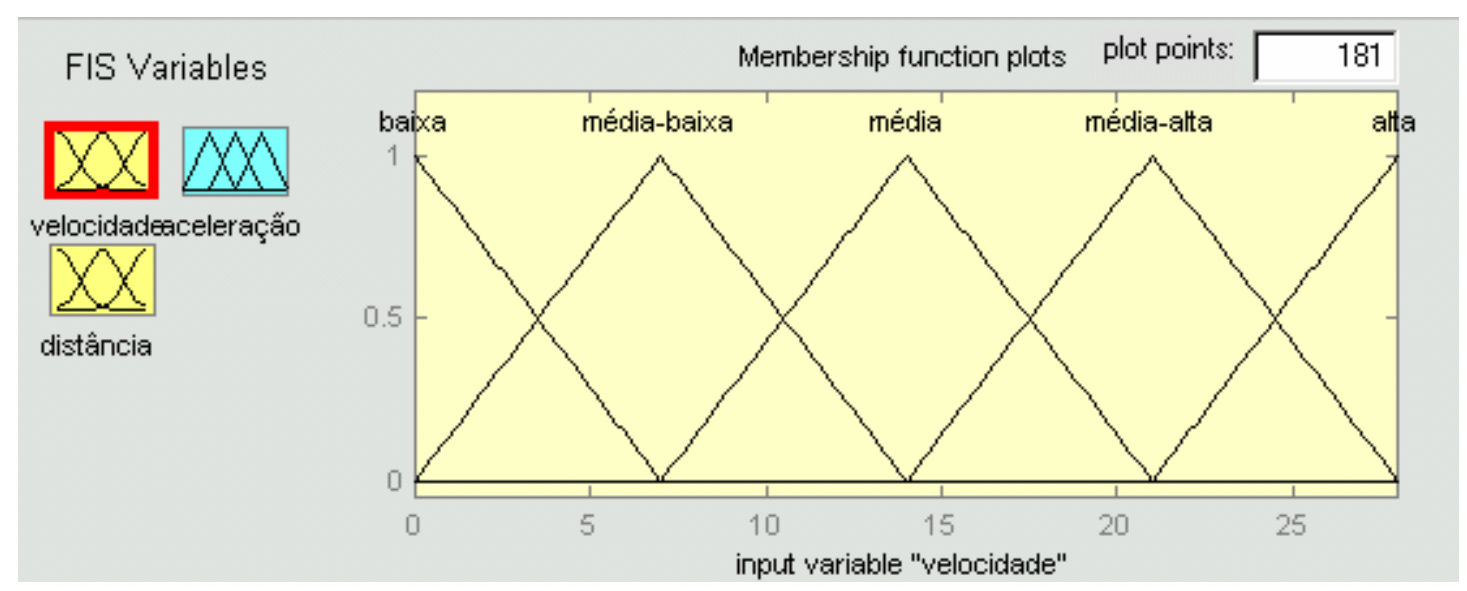

Figura 33. Distribuição das funções de pertinência relativa à variável Velocidade.

A variável Aceleração é avaliada como sendo a aceleração imposta ao trem e pode assumir valores positivos (propulsão) ou negativos (freio). O universo de discurso está compreendido entre $-1,2 \mathrm{~m} / \mathrm{s}^{2}$ (para freio máximo) e $1,12 \mathrm{~m} / \mathrm{s}^{2}$ (para propulsão máxima), que são os limites normalmente utilizados para a aceleração dos trens. $O$ freio de emergência possui uma taxa de aceleração de $-1,5 \mathrm{~m} / \mathrm{s}^{2}$, mas não é utilizado exceto em casos de emergência. A variável Aceleração compreende cinco variáveis lingüísticas: Propulsão Máxima, Propulsão, Neutro, Freio e Freio Máximo. Da mesma forma que para as variáveis Distância e Velocidade, as funções de pertinência utilizadas são do tipo TFN, exceto para as variáveis Propulsão Máxima e Freio Máximo, onde foram utilizadas funções do tipo LFN e RFN, respectivamente. A Figura 34 mostra a distribuição gráfica das funções de pertinência relativa à variável Aceleração. 


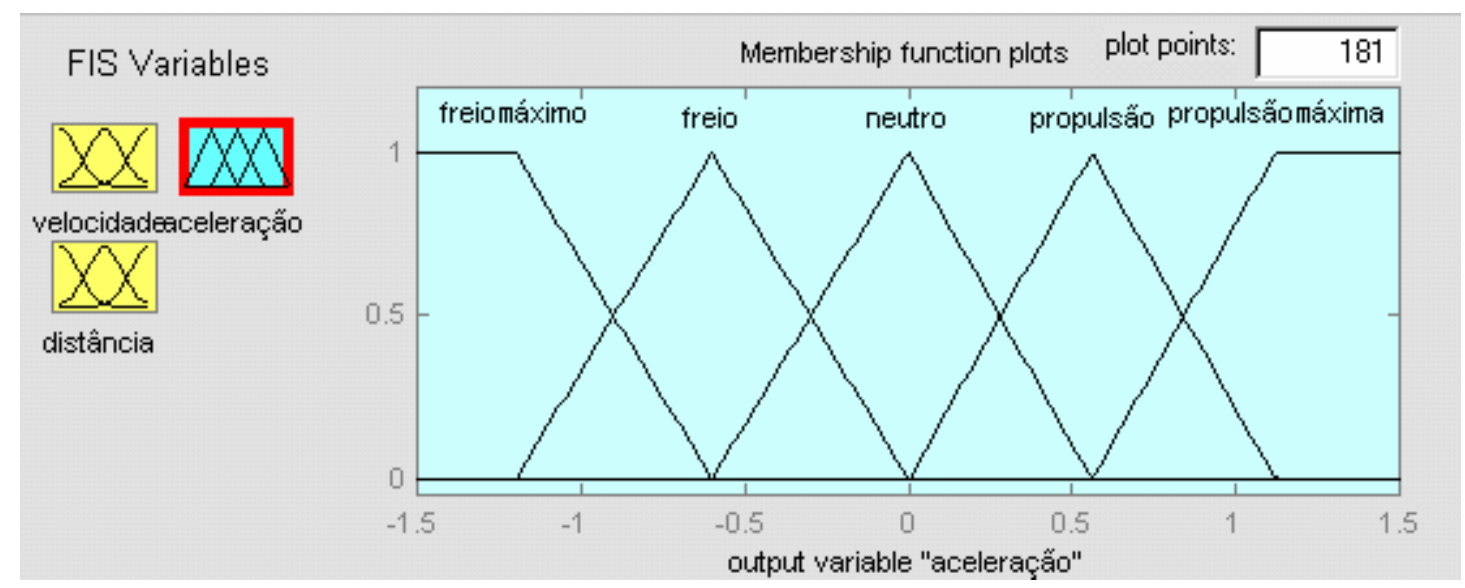

Figura 34. Distribuição das funções de pertinência relativa à variável Aceleração.

O conjunto de regras utilizadas foi obtido pelo método da construção da Matriz do Relacionamento, analisando-se todas as situações possíveis previstas para as variáveis de entrada sob o ponto de vista de um operador de trem. Como existem 5 atributos lingüísticos para a variável Distância e 5 atributos lingüísticos para a variável Velocidade, obtém-se um total de 25 combinações lingüísticas diferentes, geradas por meio do produto cartesiano dos dois conjuntos. Cada combinação lingüística das variáveis de entrada (Distância e Velocidade) fornece a partição de uma das 5 variáveis lingüísticas possíveis para a variável de saída Aceleração.

Para cada uma das situações propostas foi analisado o comportamento do operador de trem, obtendo-se o resultado em termos da variável lingüística de saída, correspondente ao posicionamento do controlador manual de propulsão e frenagem do trem para cada situação em função das duas variáveis nebulosas de entrada: Distância ao trem da frente (ou estação) e Velocidade relativa entre os trens. A Tabela 4 a seguir mostra a formação das 25 regras que compõem o conjunto de regras do sistema nebuloso proposto.

As regras presentes na Tabela 4 devem ser expressas da seguinte forma: Por exemplo, para a primeira regra,

"Se $($ Velocidade $=$ Baixa $)$ e $($ Distância $=$ Pequena $)$ então $($ Aceleração $=$ Freio $) "$.

Se o comportamento da variável de saída Aceleração for representada graficamente em termos das variáveis de entrada Distância e Velocidade, então este comportamento representará uma superfície no espaço, denominada de Superficie de Controle. A Figura 35 mostra a Superficie de Controle para as regras da Tabela 4. 
Tabela 4 - Formação do conjunto de regras do sistema nebuloso proposto.

\begin{tabular}{|c|c|c|c|c|c|}
\hline Distância & Pequena & $\begin{array}{l}\text { Média- } \\
\text { Pequena }\end{array}$ & Média & $\begin{array}{l}\text { Média- } \\
\text { Grande }\end{array}$ & Grande \\
\hline Baixa & Freio (1) & Neutro (2) & $\begin{array}{l}\text { Propulsão } \\
\text { (3) }\end{array}$ & $\begin{array}{l}\text { Propulsão } \\
\text { Máxima (4) }\end{array}$ & $\begin{array}{l}\text { Propulsão } \\
\text { Máxima (5) }\end{array}$ \\
\hline Média-Baixa & Freio (6) & Neutro (7) & $\begin{array}{l}\text { Propulsão } \\
\text { (8) }\end{array}$ & $\begin{array}{l}\text { Propulsão } \\
\text { Máxima (9) }\end{array}$ & $\begin{array}{l}\text { Propulsão } \\
\text { Máxima (10) }\end{array}$ \\
\hline Média & Freio (11) & Freio (12) & Neutro (13) & $\begin{array}{l}\text { Propulsão } \\
\text { (14) }\end{array}$ & $\begin{array}{l}\text { Propulsão } \\
\text { (15) }\end{array}$ \\
\hline Média-Alta & $\begin{array}{l}\text { Freio } \\
\text { Máximo (16) }\end{array}$ & $\begin{array}{l}\text { Freio } \\
\text { Máximo (17) }\end{array}$ & Freio (18) & Neutro (19) & Neutro (20) \\
\hline Alta & $\begin{array}{l}\text { Freio } \\
\text { Máximo (21) }\end{array}$ & $\begin{array}{l}\text { Freio } \\
\text { Máximo (22) }\end{array}$ & Freio (23) & Neutro (24) & Neutro (25) \\
\hline
\end{tabular}

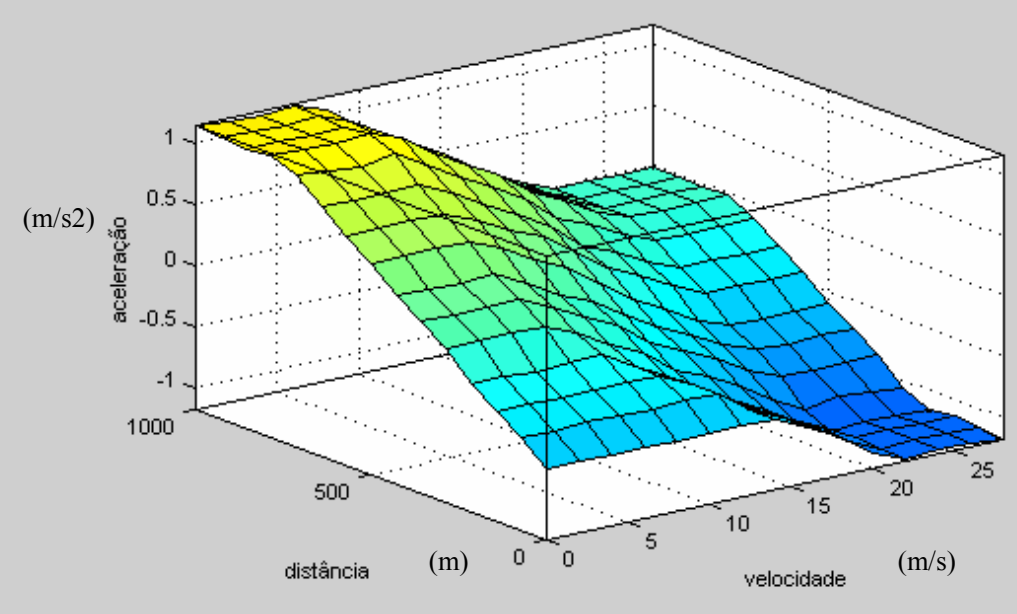

Figura 35. Superfície de controle do sistema controlador nebuloso proposto. 
O método de inferência escolhido para esta aplicação foi o método do "Mínimo de Mamdani”. Neste método, para uma determinada leitura das variáveis de entrada são associadas as variáveis lingüísticas das partições de entrada correspondentes ao máximo do valor obtido de entrada. Em seguida, os conseqüentes produzidos por todas as regras que forem verificadas são combinados, utilizando-se os valores mínimos destes conseqüentes (conforme apresentado no item 4.3 deste trabalho).

O método de defuzificação escolhido para a produção dos valores numéricos de saída foi o "Método do Centro de Massa", que efetua o cálculo do centro de massa da figura geométrica resultante da combinação das funções de pertinência dos conseqüentes produzidos pelo banco de regras. Este valor passa a ser o valor numérico da variável de saída Aceleração (não nebulosa) resultante do processamento da combinação dos valores numéricos das variáveis não nebulosas de entrada: Distância e Velocidade (MATHWORKS, 1996).

A Figura 36 mostra um exemplo de aplicação do método do "Mínimo de Mamdani”, com a produção dos conseqüentes na saída a partir dos valores de Distância e Velocidade obtidos na entrada e com a utilização do método de defuzificação citado.

\section{Regra Velocidade}

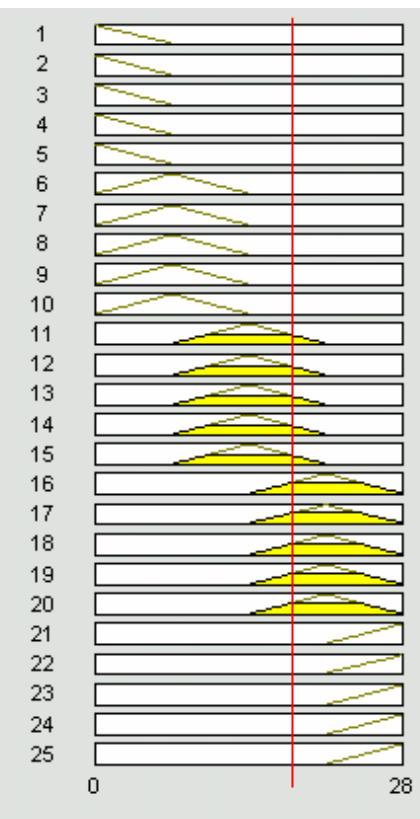

$\mathbf{v}=18 \mathrm{~m} / \mathrm{s}$
Distância

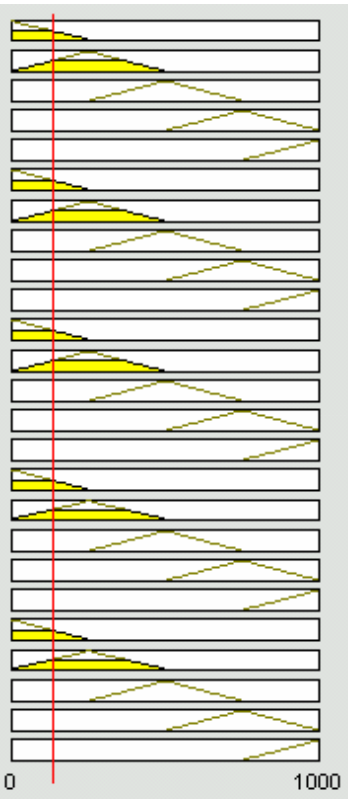

$\mathrm{d}=\mathbf{1 3 4 m}$
Aceleração

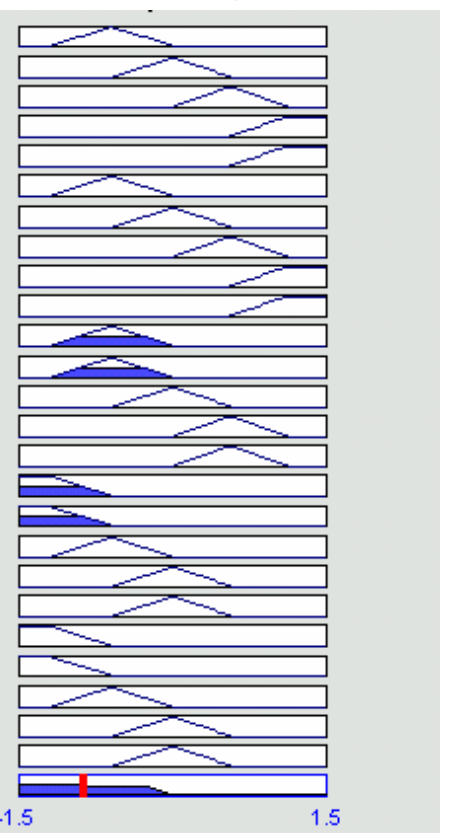

$\mathrm{a}=-\mathbf{0 , 8 5 9} \mathrm{m} / \mathrm{s}^{2}$

Figura 36. Exemplo de aplicação do mecanismo de inferência. 
No exemplo da Figura 36, o valor numérico da variável não nebulosa de entrada Distância é 134 m, o valor numérico da variável não nebulosa de entrada Velocidade é $18 \mathrm{~m} / \mathrm{s}$ e a classificação nebulosa destes valores ativam determinadas regras $(1,2,6,7,11,12,16,17$, 21 e 22, no caso da variável Distância e $11,12,13,14,15,16,17,18,19$ e 20, no caso da variável Velocidade). A combinação dos antecedentes só produz conseqüentes nas regras em que ambas as variáveis de entrada provocam a ativação das regras (regras 11, 12, 16 e 17). Os conseqüentes de saída são então combinados, produzindo um valor numérico para a variável Aceleração, $\left(-0,859 \mathrm{~m} / \mathrm{s}^{2}\right)$ correspondente ao processo de defuzificação utilizado sobre estes conseqüentes de saída.

Com a definição das interfaces de entrada (bloco fuzificador), de saída (bloco defuzificador), da base de regras e do mecanismo de inferência utilizado, o projeto do controlador nebuloso proposto está completo.

A Figura 37 mostra um diagrama de blocos esquemático do sistema controlador nebuloso proposto, destacando de forma alternativa o fluxo de informação entre as qualificações das informações de entrada, sua combinação usando a base de regras, determinando as qualificações das informações de saída, de forma a produzir uma variável numérica de controle para ser utilizado no controle da propulsão e do freio do trem.

Definido todo o projeto do controlador nebuloso proposto, o próximo passo consiste em se efetuar simulações deste modelo em condições operacionais presentes nos sistemas metroviários. Para isto, foram utilizadas três ferramentas:

- $\quad$ O módulo de lógica fuzzy do programa Matlab. Este módulo foi utilizado no projeto do controlador nebuloso proposto e consiste em uma interface gráfica, na qual são efetuadas todas as caracterizações das variáveis de entrada e saída do sistema controlador que se deseja projetar. Uma outra interface gráfica permite a construção e edição da base de regras utilizadas, bem como a visualização do processo de inferência nebulosa e da superfície de controle. As Figuras 31 a 36 deste trabalho foram produzidas a partir das telas da interface gráfica deste módulo do Matlab (MATHWORKS, 1996); 


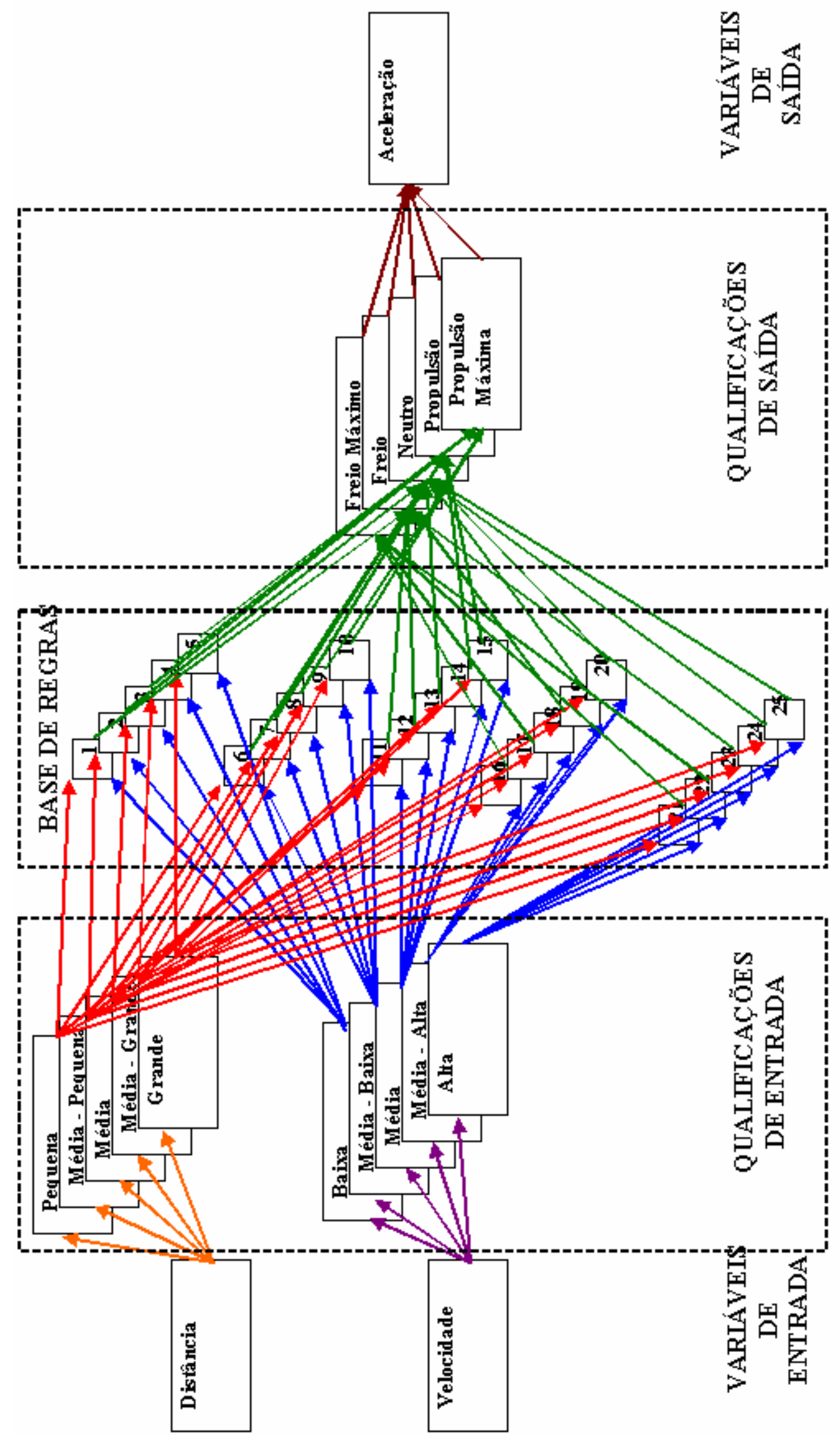

Figura 37. Esquema do fluxo de informações no sistema de inferência. 
- $\quad$ O módulo Simulink do programa Matlab. Para a utilização do Simulink, o diagrama de blocos do sistema a ser analisado deve ser desenhado no editor gráfico do módulo e as funções de transferência para cada bloco devem também ser determinadas e especificadas, em caixas de diálogo para a configuração de cada bloco do sistema. O editor permite a interligação entre os blocos do sistema e a inclusão de instrumentos de medida para possibilitar a verificação de funcionamento e análise do sistema. No caso do controlador proposto, alguns blocos foram acrescentados para representar o movimento cinemático do trem como forma de interação aos comandos. A Figura 38 mostra o diagrama de blocos do controlador nebuloso que foi inserido no módulo Simulink (MATHWORKS, 1996) e o Apêndice A (Figura 73) deste trabalho apresenta os resultados de simulações efetuadas com este simulador.

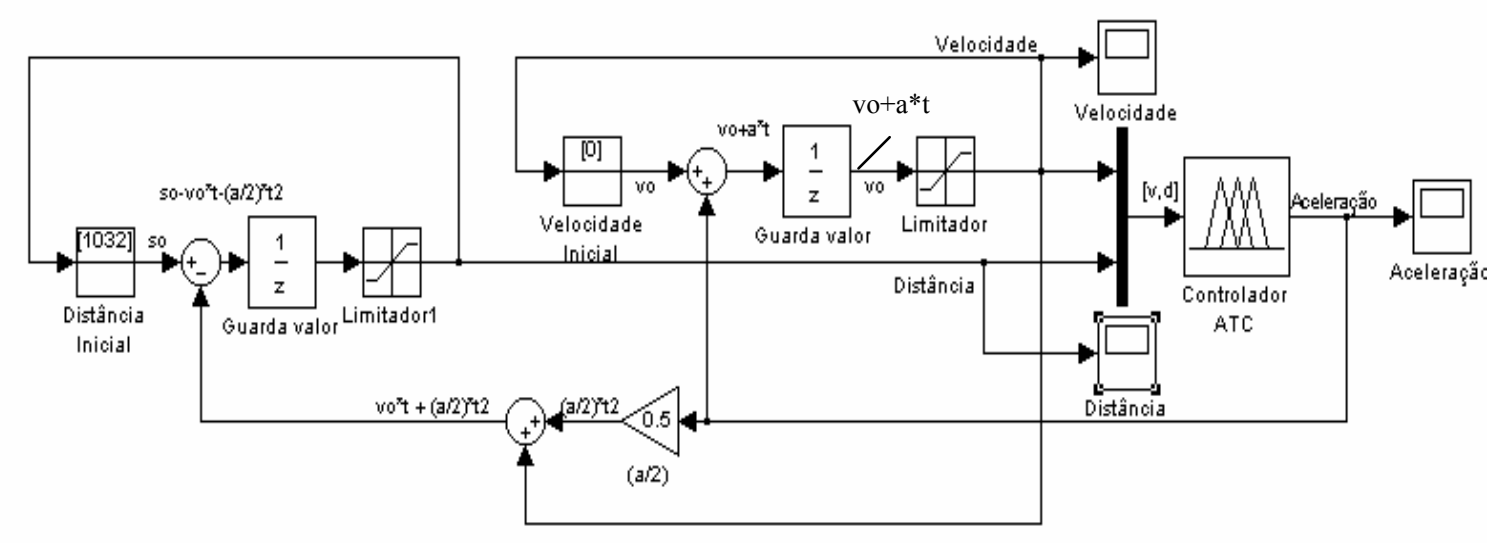

Figura 38. Diagrama de blocos do controlador nebuloso utilizado no Simulink.

- Um simulador nebuloso desenvolvido em linguagem $\mathrm{C}$ pelos pesquisadores do KNOMA/PCS/EPUSP - Laboratório de Engenharia de Conhecimento do Departamento de Engenharia da Computação e Sistemas Digitais da Escola Politécnica da Universidade de São Paulo, sob a supervisão do Prof. Dr. Marco Túlio Carvalho de Andrade. Este simulador apresenta uma interface gráfica na qual podem ser especificadas as variáveis de entrada e de saída, suas partições e funções de pertinência. Uma outra interface gráfica permite a elaboração da base de regras a partir das variáveis de entrada e saída especificadas. Definidas as características do sistema, um conjunto de dados de entrada em um formato de arquivo texto pode ser fornecida ao simulador, que efetua o processamento nebuloso, resultando em um conjunto de dados de saída, também no formato de arquivo texto. O Apêndice B (Figura 74) deste trabalho apresenta os resultados de simulações efetuadas com este simulador. 


\subsection{Considerações Finais do Capítulo}

Este capítulo teve por objetivo apresentar toda a modelagem do sistema nebuloso proposto, aplicando conceitos teóricos sobre sistemas de controle de trens, elementos de lógica nebulosa preditiva e conceitos da área de engenharia de sistemas de controle. Uma especificação completa das variáveis de entrada e de saída, da base de regras utilizada, bem como os métodos de inferência, fuzificação e defuzificação utilizados foi efetuada.

O próximo passo consiste na apresentação de alguns exemplos de aplicação de sistemas de controle de trens, de forma a obter alguns parâmetros para comparação com o sistema de controle nebuloso proposto. Em seguida, o modelo apresentado será submetido a algumas simulações de condições operacionais encontradas nos sistemas metro-ferroviários e os resultados destas simulações são comparados com os exemplos apresentados. 


\section{Exemplos de Aplicação de Sistemas de Controle de Metrô}

Neste capitulo são apresentados dois exemplos de aplicação de sistemas de controle na área metroviária: o sistema de controle do metrô de Sendai, utilizado como base para a elaboração desta dissertação, e o sistema de controle do metrô de São Paulo, que fornecerá parâmetros operacionais para efeitos de análise e comparação do modelo do controlador nebuloso proposto. A filosofia utilizada no metrô de Sendai envolve a lógica nebulosa preditiva, enquanto a filosofia utilizada no metrô de São Paulo envolve a utilização de circuitos de via e sinalização fixa.

\subsection{O Metrô de Sendai}

O sistema de controle de trens utilizado no metrô de Sendai, no Japão, é sempre referenciado na literatura como sendo o primeiro a utilizar lógica nebulosa preditiva (MCNEILL, 1994). A cidade de Sendai está localizada no nordeste da ilha de Honshu (principal ilha do Japão), a 350 km ao norte de Tóquio, na costa do oceano Pacífico.

A rede de metrô de Sendai está em operação desde 1987, possui $15 \mathrm{~km}$ de comprimento (12 km subterrâneos) com 17 estações, sendo 13 subterrâneas. Dados operacionais mostram que o metrô de Sendai não é um sistema grande, conforme os padrões das cidades de Tóquio ou Osaka, atendendo a um pouco menos que 1.000.000 usuários/dia. O headway utilizado é de 4 a 6 minutos e o horário de operação é das $05 \mathrm{~h} 45 \mathrm{~min}$ às $23 \mathrm{~h} 45 \mathrm{~min}$ (URBANRAIL, 2004).

A Figura 39 mostra a rede de metrô de Sendai. A linha 2 indicada na figura como planejada, teve a sua construção iniciada em 2004, com previsão de término para 2016, mas com início de operação prevista para 2015. A linha 2 terá 14 km de extensão com 13 estações, todas subterrâneas, e utilizará a tecnologia de motor linear para tração dos trens. 


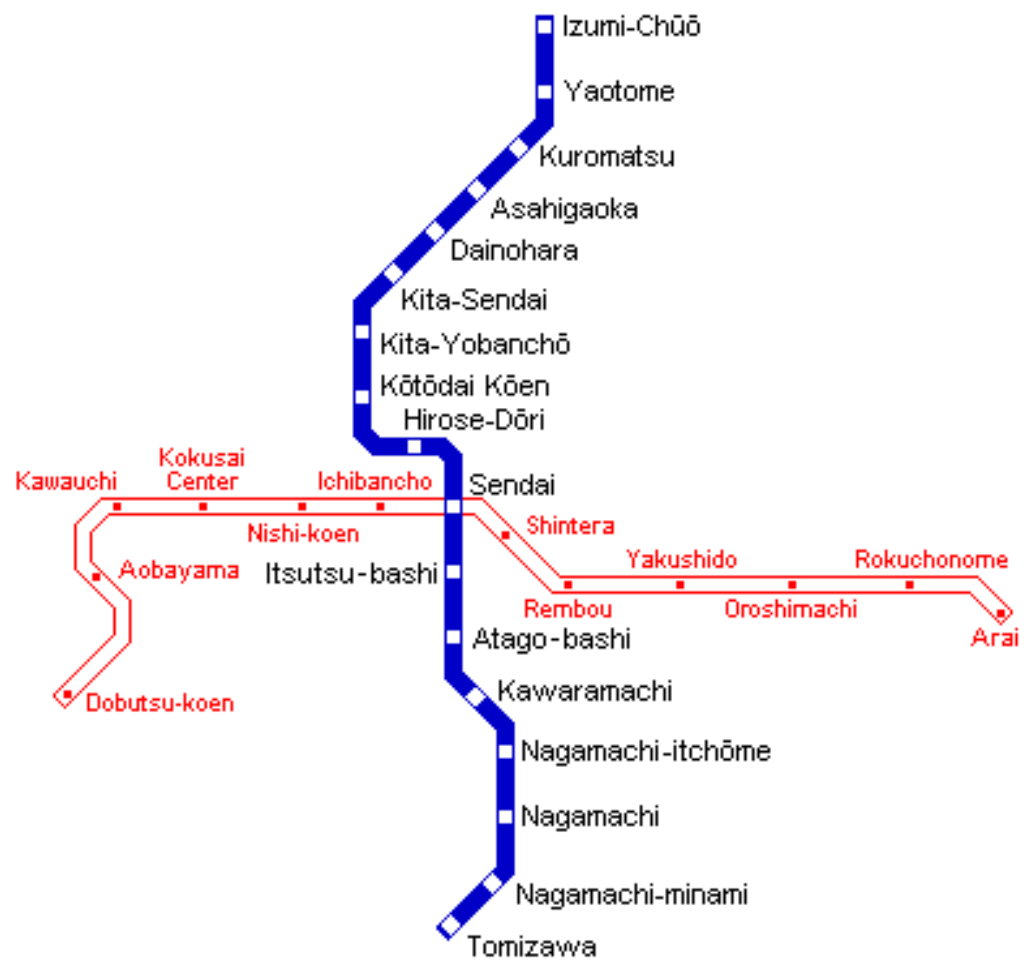

\section{SENDAI Subway}

2004 (C) UrbanRail.Net (R. Schwand)

Line 1

Figura 39. Rede de metrô da cidade de Sendai (URBANRAIL, 2004).

O metrô de Sendai possui 21 trens, com quatro carros por trem, totalizando 84 carros. Os trens possuem uma bitola de $1067 \mathrm{~mm}$ e são alimentados por catenária com 1500 VDC. O trem possui $83,5 \mathrm{~m}$ de comprimento (20,875 $\mathrm{m}$ por carro), enquanto as plataformas possuem $130 \mathrm{~m}$ de comprimento. A Figura 40 mostra o trem utilizado no metrô de Sendai.

Embora a primeira decisão para a construção do metrô em Sendai tenha ocorrido em 1965, a sua construção efetiva somente se iniciou em 1983 e, quatro anos depois, ele entrou em operação. Para o sistema metroviário de Sendai, um equipamento de controle já havia sido instalado quando o controlador nebuloso foi proposto. A incorporação do controlador nebuloso envolveu somente mudanças no programa do minicomputador de controle central e no microprocessador de controle de bordo, que ficava no sobestrado do trem (sob o piso do salão de passageiros) (TERANO; ASAI; SUGENO, 1994). 


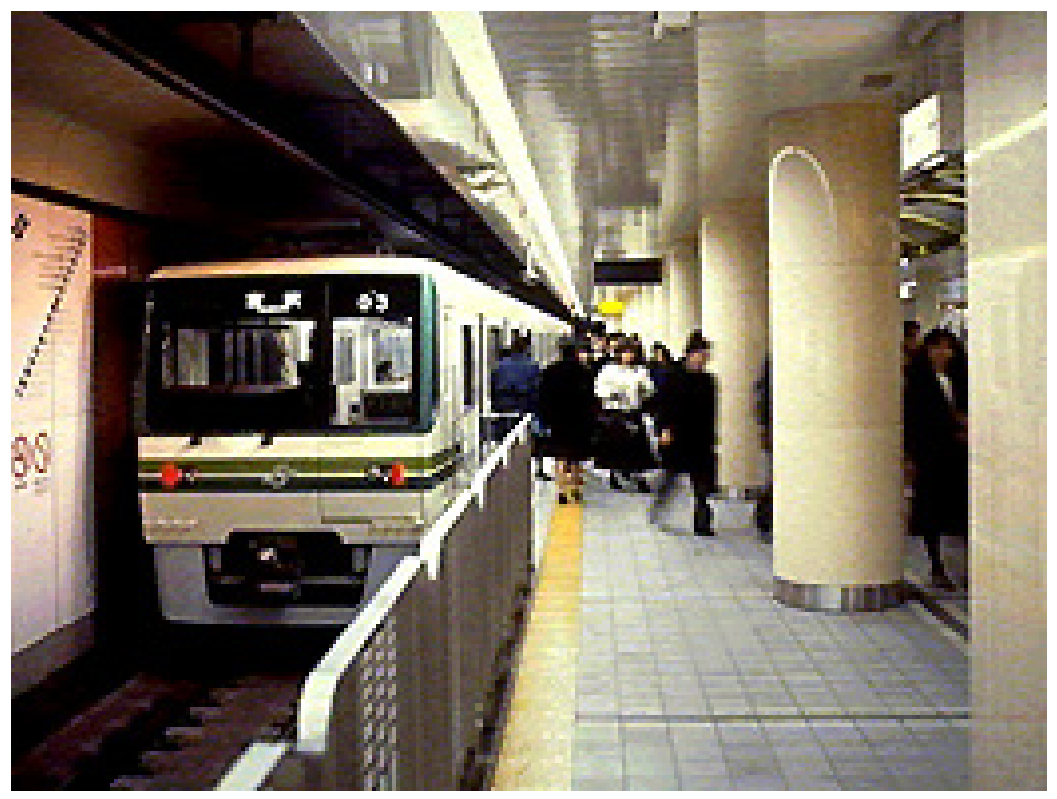

Figura 40. Trem utilizado no metrô de Sendai (JAPAN...,1988).

A via comercial do metrô de Sendai está dividida em trechos identificados por marcadores de posição. O trem recebe comandos de velocidade das antenas que captam o sinal do circuito de via e também comandos do sistema ATS (Supervisão Automática de Trens) via rádio. O sistema ATS gera a sinalização de via e efetua a detecção dos trens nos diferentes circuitos de via e transmite comandos via rádio ao equipamento de bordo de cada trem. A Figura 41 mostra a configuração dos equipamentos de bordo dos trens do metrô de Sendai.

O controlador de bordo dos trens utiliza como entradas os sinais provenientes do sistema ATS via rádio e do sistema ATP de via por meio da antena de sinal de via. Uma amostragem do espaço percorrido é efetuada em um intervalo de tempo, resultando em uma estimativa de velocidade do trem. O controlador utiliza como saídas comandos de tração e frenagem para o controle de propulsão e freios do trem, respectivamente.

A modelagem da cinemática do trem envolve forças de resistência ao movimento em função da carga, velocidade, curvas e inclinações. A Figura 42 mostra o diagrama de blocos do controlador de trens utilizado no metrô de Sendai, incluindo o modelo matemático para a cinemática do trem. 


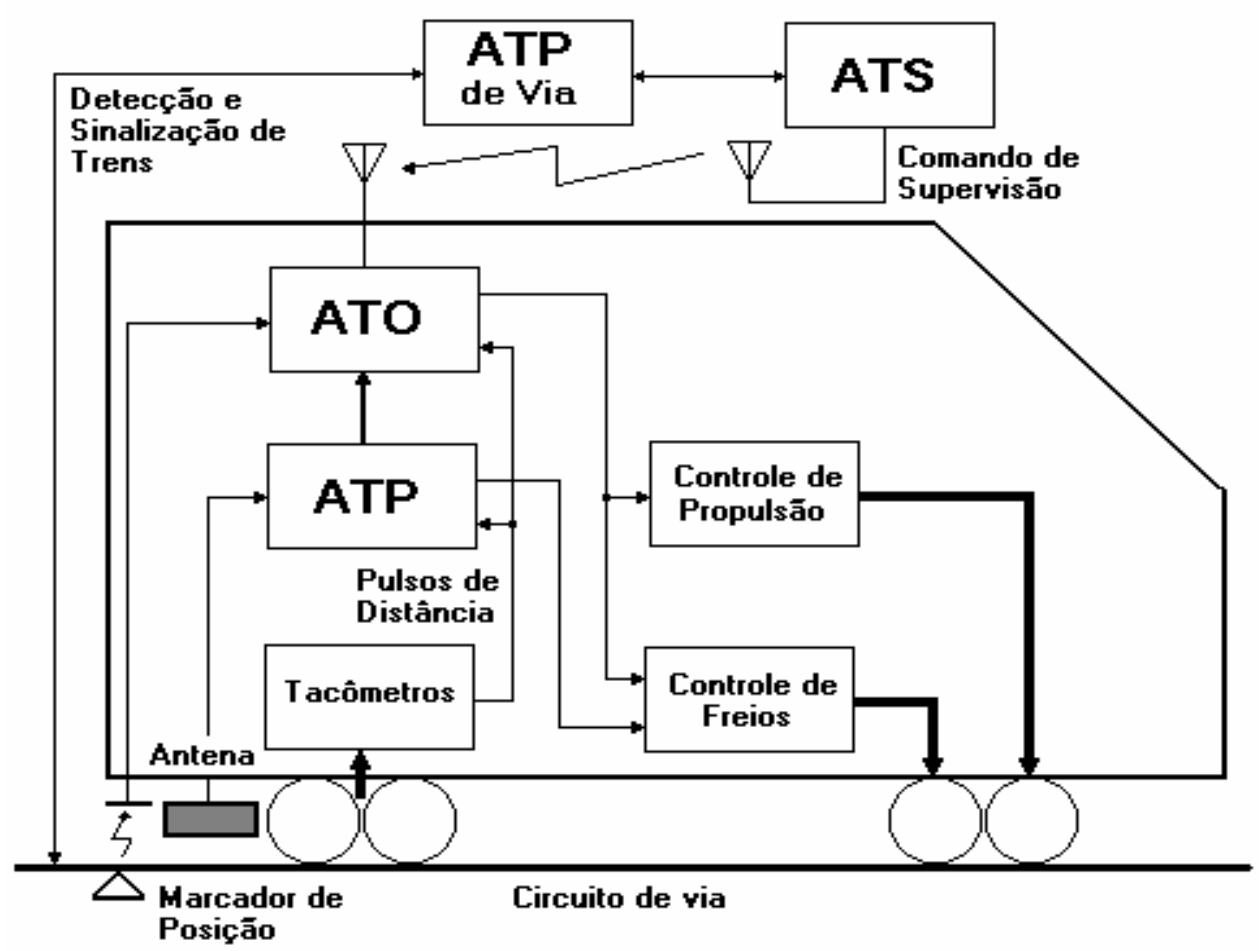

Figura 41. Configuração dos equipamentos de bordo do metrô de Sendai (YASUNOBU et al., 1984).

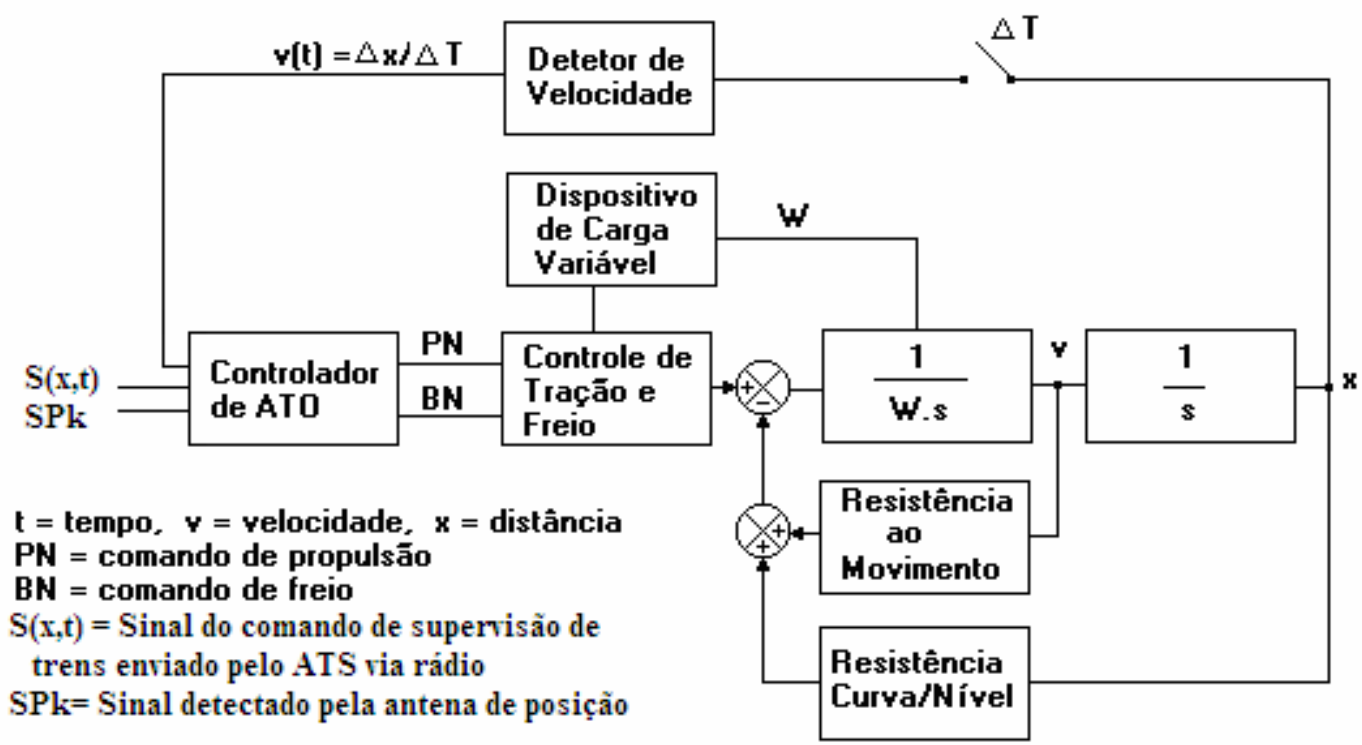

Figura 42. Diagrama de blocos do controlador do metrô de Sendai (YASUNOBU et al., 1984). 
A função do equipamento de bordo é detectar a posição e a velocidade real do trem por meio de leituras dos tacômetros e dos detectores de posição e, com base nos comandos recebidos do sistema ATS, efetuar o controle da tração e do freio do trem.

Este controle é efetuado utilizando lógica nebulosa preditiva e é dividido em duas partes: o CSC (Constant Speed Control) - controlador de velocidade constante (que movimenta o trem e o mantém abaixo da velocidade limite) e o TASC (Train Automatic Stop Control) - controlador de parada automática (que regula a velocidade do trem de forma a propiciar uma parada precisa na plataforma).

Com o trem parado na estação e ao receber o comando de partida, o sistema está na região CSC de operação, gerando o código de velocidade para o circuito de via seguinte ao da estação. Se houver uma restrição de velocidade devido a uma ocupação, o código gerado considera esta ocupação. Ao atingir a velocidade comandada, o sistema efetua a manutenção desta velocidade até atingir o próximo circuito de via com código de velocidade inferior ao atual. Ao detectar o marcador TASC, o sistema entra na região TASC de operação, efetuando a frenagem do trem de forma a efetuar uma parada precisa ao longo da plataforma da estação (YASUNOBU et al., 1984). A Figura 43 mostra um esquema das etapas CSC e TASC de operação do sistema.

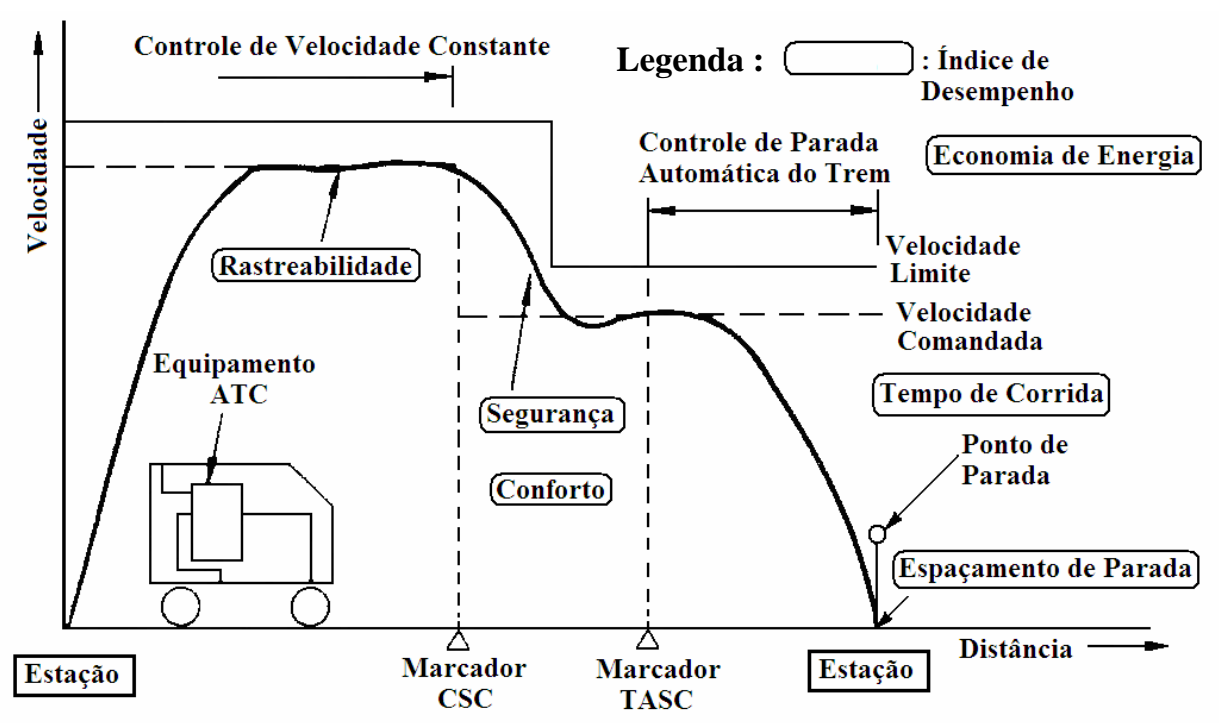

Figura 43. Esquema de operação do metrô de Sendai (JAPAN..., 1988). 
Na operação CSC (Constant Speed Control), o sistema de supervisão de trens gera a velocidade comandada, dentro do limite máximo permitido. Se houver um outro trem na região CSC, uma velocidade comandada mais restritiva é gerada no início do trecho e valem as seguintes regras de controle (YASUNOBU et al., 1984):

- (C-1) Para segurança: Se a velocidade do trem exceder o limite de velocidade, o freio máximo é selecionado;

- (C-2) Para economia de energia: Se nenhuma seleção de propulsão ou frenagem mantiver o tempo de corrida dentro do tempo esperado, esta situação é selecionada;

- (C-3) Para redução do tempo de corrida: Se a velocidade estiver bem abaixo da comandada, uma seleção de propulsão é efetuada;

- (C-4) Para o conforto dos passageiros: Se a velocidade do trem estiver dentro de um limite de tolerância, a seleção de freio ou propulsão não é alterada; e

- (C-5) Para a rastreabilidade de velocidade: Se a seleção de propulsão ou freio for mantida e a velocidade do trem sair da área de tolerância, uma seleção de ajuste é efetuada, de forma a manter a velocidade comandada. Neste caso, para o conforto dos passageiros, a freqüência de mudança de seleção é levada em consideração.

Quando o trem adentra a região de TASC (Train Automatic Stop Control), é iniciado o processo de parada programada na próxima estação e valem as seguintes regras de controle (YASUNOBU et al., 1984):

- (T-1) Para o conforto dos passageiros (1): A seleção de propulsão ou frenagem não é alterada se o trem for parar dentro da região de tolerância de parada;

- (T-2) Para conforto dos passageiros (2): na medida em que o trem se aproxima da região TASC, a seleção é alterada de propulsão para frenagem mínima; e

- (T-3) Para precisão do espaçamento de parada: Se a velocidade do trem indicar que o trem não parará dentro da região de tolerância, uma seleção de ajuste é efetuada, de forma a permitir que o trem pare de forma mais precisa ao longo da plataforma. Também neste caso é levada em consideração a freqüência de mudança de seleções.

O controlador procura atingir seis índices de desempenho: segurança, conforto, consumo de energia, rastreabilidade de velocidade (manutenção da velocidade desejada), tempo de corrida e parada precisa, 
O controlador possui, portanto, seis variáveis de entrada: S (Segurança), C (Conforto), E (Economia de Energia), T (Rastreabilidade de Velocidade), R (Tempo de Corrida) e G (Espaçamento de Parada) e duas variáveis de saída: PN (Comando de Tração) e BN (Comando de Freio) (YASUNOBU et al., 1984).

A variável Segurança $(S)$ é avaliada pelo tempo que o trem levará para atingir a próxima região com velocidade mais restritiva, baseado em sua capacidade de frenagem. Se dentro de um determinado intervalo (4s) antes da região o trem não iniciar uma frenagem, estará em uma condição insegura para o sistema (TERANO; ASAI; SUGENO, 1994). A Figura 44 mostra esta função de pertinência.

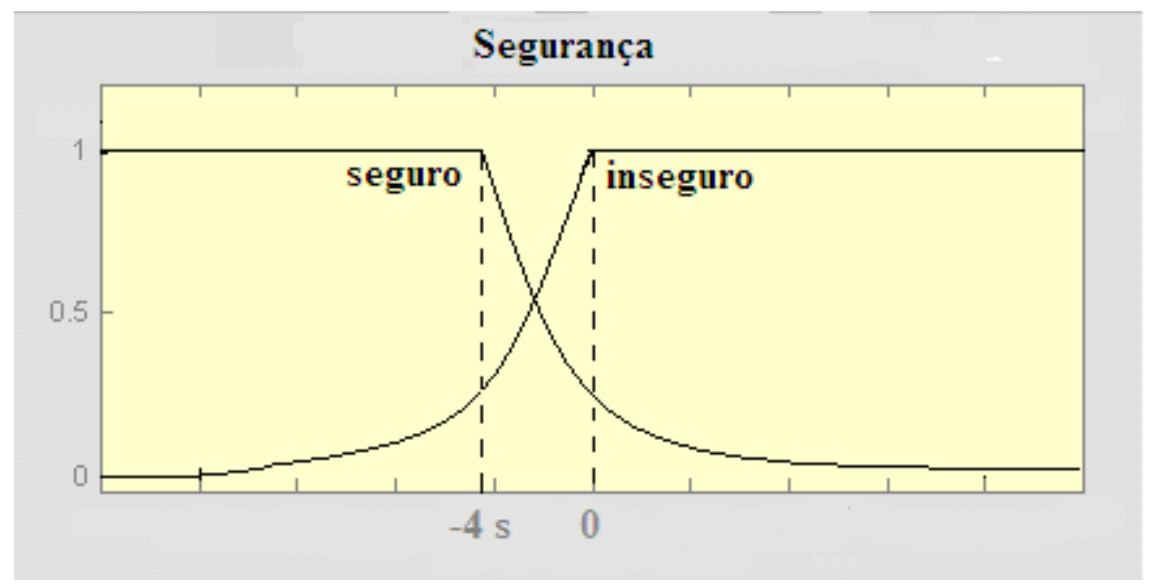

Figura 44. Função de Pertinência da Variável Segurança.

A variável Conforto $(C)$ é avaliada pelo tempo decorrido desde a última mudança de comando de propulsão ou freio. Quanto maior for o tempo decorrido desde a última mudança, maior será o conforto. Tempos menores que 2s classificam o Conforto como pobre e tempos acima de 4s classificam-no como bom (TERANO; ASAI; SUGENO, 1994). A Figura 45 mostra esta função de pertinência.

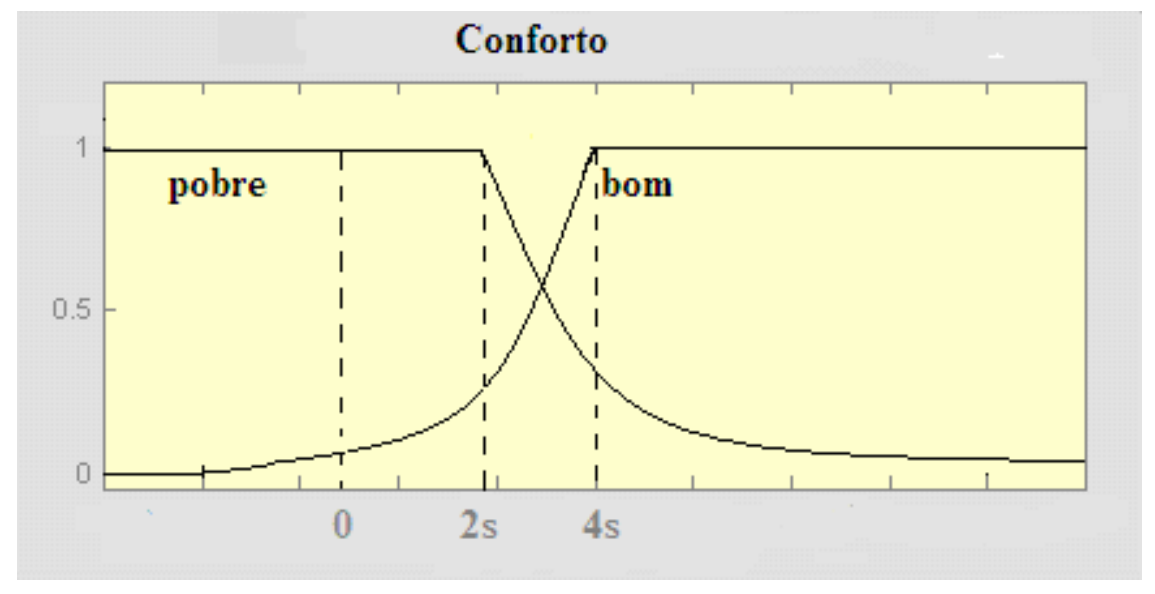

Figura 45. Função de Pertinência da Variável Conforto. 
A variável Economia de Energia (E) é avaliada por meio do erro de distância medido com o tempo esperado de corrida. Se o erro for maior que o esperado em $30 \mathrm{~m}$, significa que o trem andou mais tempo com inércia e está economizando energia; se o erro for menor que 30 m, o trem efetuou propulsão e não está economizando energia. A Figura 46 mostra esta função de pertinência.

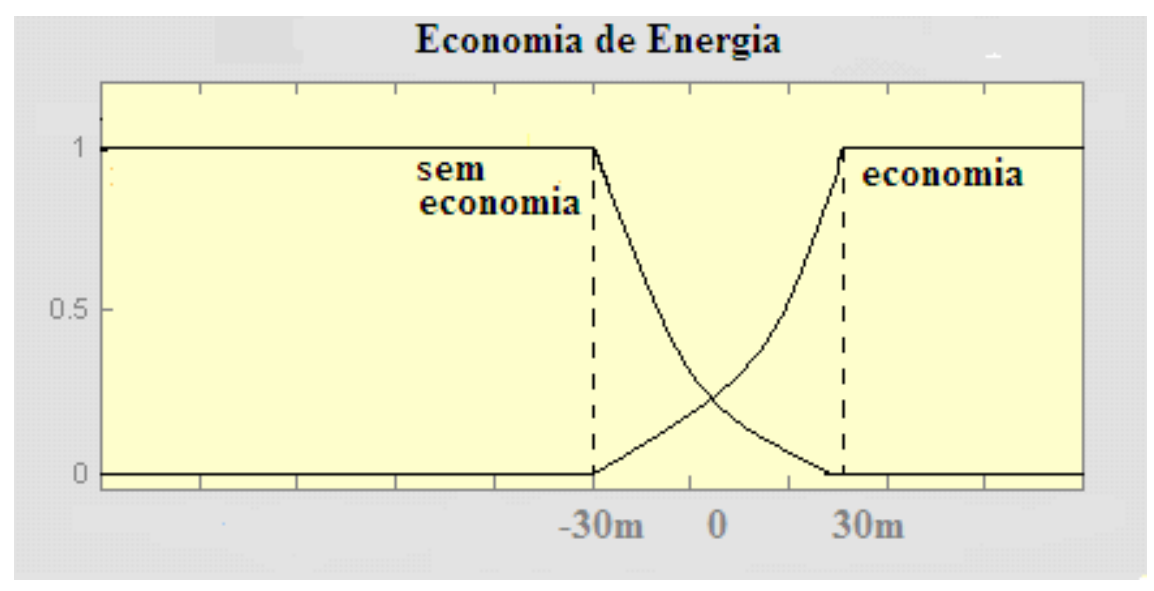

Figura 46. Função de Pertinência da Variável Economia de Energia.

A variável Rastreamento de Velocidade (T) é avaliada pela diferença entre a velocidade comandada ( $v t$ ) e a velocidade real do trem. Uma margem de $1 \mathrm{~km} / \mathrm{h}$ é utilizada como tolerância para classificar a precisão e a manutenção da velocidade comandada. Os valores possíveis de $v t$ são $0,25,45,55,65,75$ e $85 \mathrm{~km} / \mathrm{h}$ (TERANO; ASAI; SUGENO, 1994).A Figura 47 mostra esta função de pertinência.

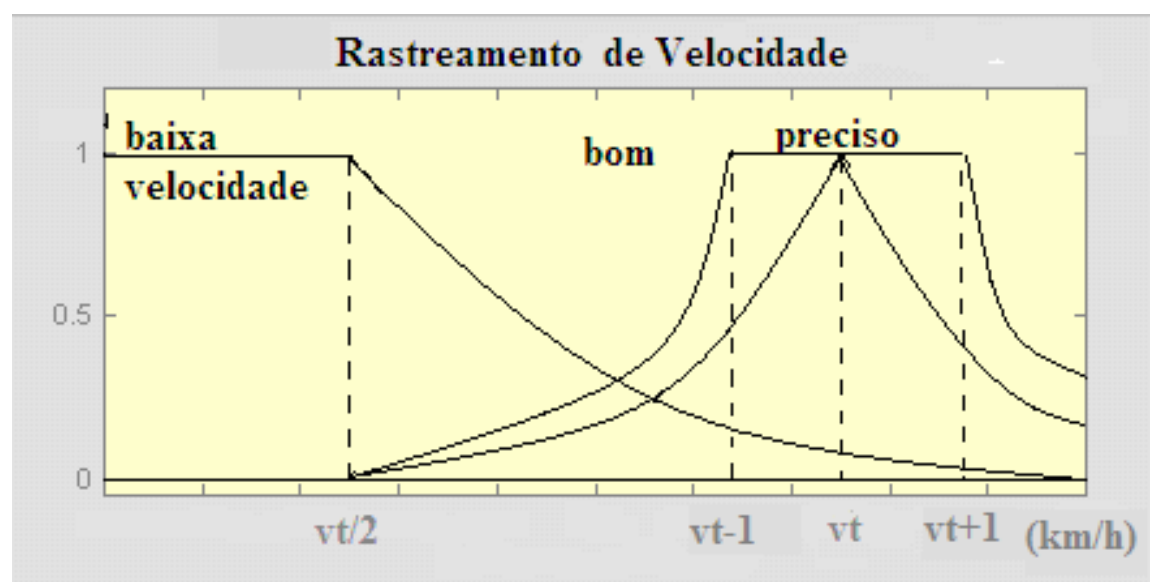

Figura 47. Função de Pertinência da Variável Rastreamento de Velocidade. 
A variável Tempo de Corrida $(R)$ é avaliada pelo erro de tempo decorrido entre o tempo esperado e o tempo real de detecção do marcador TASC (Train Automatic Speed Control). Se o marcador TASC for detectado $5 \mathrm{~s}$ antes do esperado, o trem estará adiantado; se o marcador TASC for detectado 5s após o esperado, o trem estará atrasado (TERANO; ASAI; SUGENO, 1994). A Figura 48 mostra esta função de pertinência.

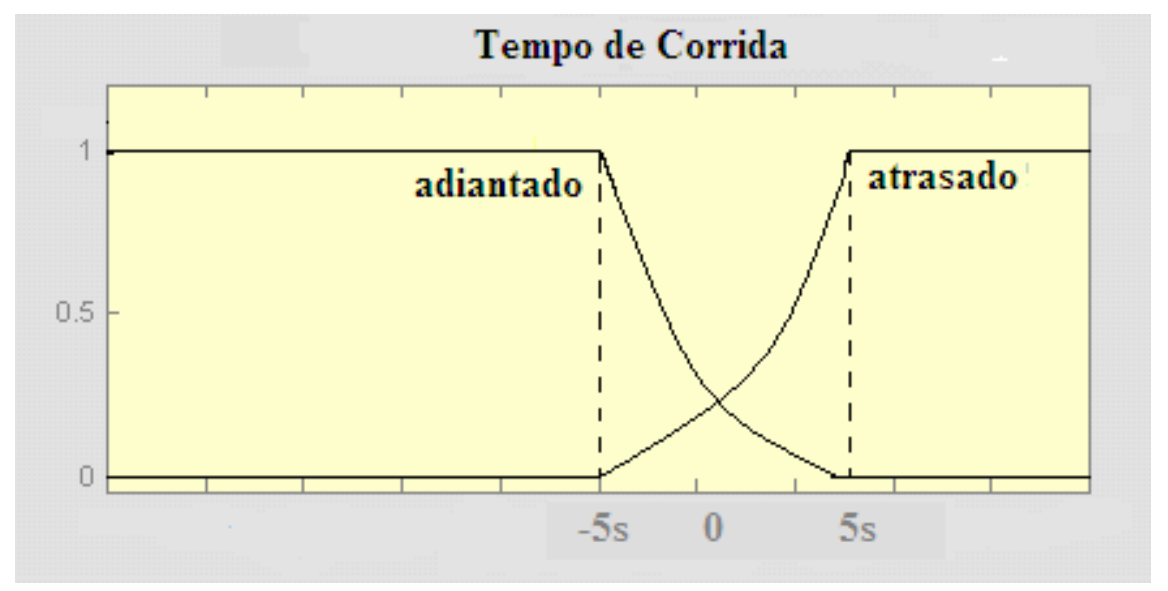

Figura 48. Função de Pertinência da Variável Tempo de Corrida.

A variável Espaçamento de Parada $(G)$ é avaliada pela diferença entre o ponto de parada desejado e o ponto real de parada do trem. Uma margem de $20 \mathrm{~cm}$ é utilizada como tolerância para classificar a precisão com que o trem efetua a parada na plataforma (TERANO; ASAI; SUGENO, 1994). A Figura 49 mostra esta função de pertinência.

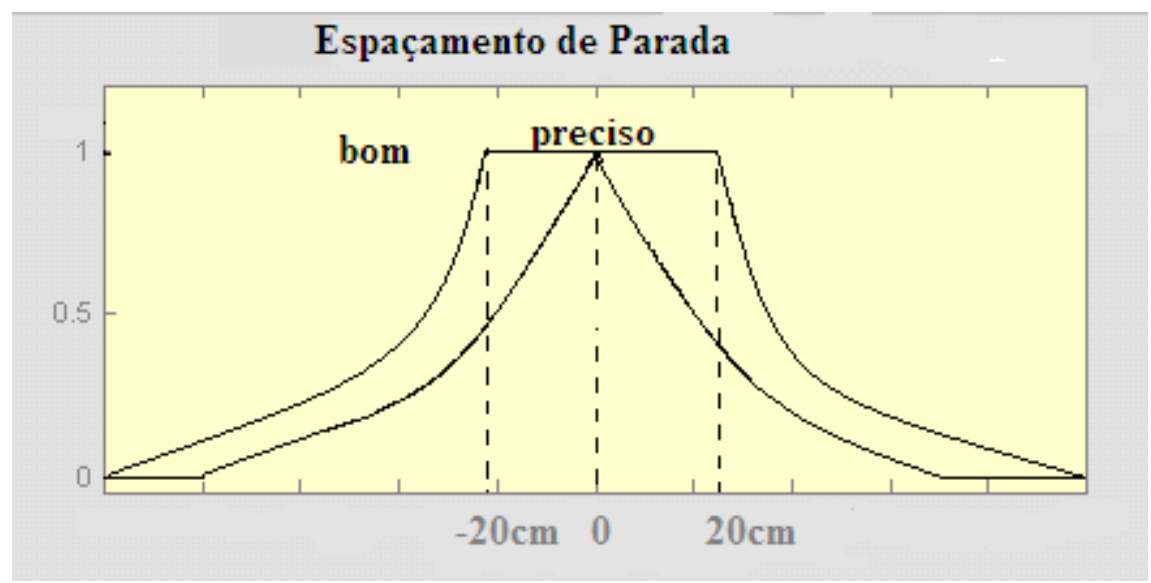

Figura 49. Função de Pertinência da Variável Espaçamento de Parada. 
Estas variáveis de entrada são formadas a partir de informações como tempo, localização do trem, distância ao ponto de parada na próxima estação, distância ao circuito de via onde há um código de velocidade menor que o atual, velocidade do trem, velocidade limite do circuito de via atual e histórico dos comandos de tração e freio selecionados. Estas informações são obtidas por meio das antenas receptoras de código de velocidade, do tacômetro e de informações transmitidas via rádio pelo sistema ATS.

A variável Comando de Tração escolhe um entre sete níveis de propulsão (que vão desde 0 até $3,3 \mathrm{~km} / \mathrm{h} . \mathrm{s}=0,916 \mathrm{~m} / \mathrm{s}^{2}$ ), enquanto a variável Comando de Freio escolhe um entre nove níveis de freio (que vão desde $-3,6 \mathrm{~km} / \mathrm{h} . \mathrm{s}=-1 \mathrm{~m} / \mathrm{s}^{2}$ até $-6,68 \mathrm{~km} / \mathrm{h} . \mathrm{s}=-1,855 \mathrm{~m} / \mathrm{s}^{2}$ ). A desaceleração possui um valor nominal de $-5,14 \mathrm{~km} / \mathrm{h} . \mathrm{s}=-1,427 \mathrm{~m} / \mathrm{s}^{2}$.

\subsection{O Metrô de São Paulo}

O metrô da cidade de São Paulo foi o primeiro sistema de metrô a entrar em operação automática no Brasil e na América Latina, em 1974, e atualmente conta com cerca de $65 \mathrm{~km}$ de extensão em 4 linhas e 54 estações, sendo 27 subterrâneas. A Figura 50 mostra o mapa da linha atual do metrô de São Paulo. 


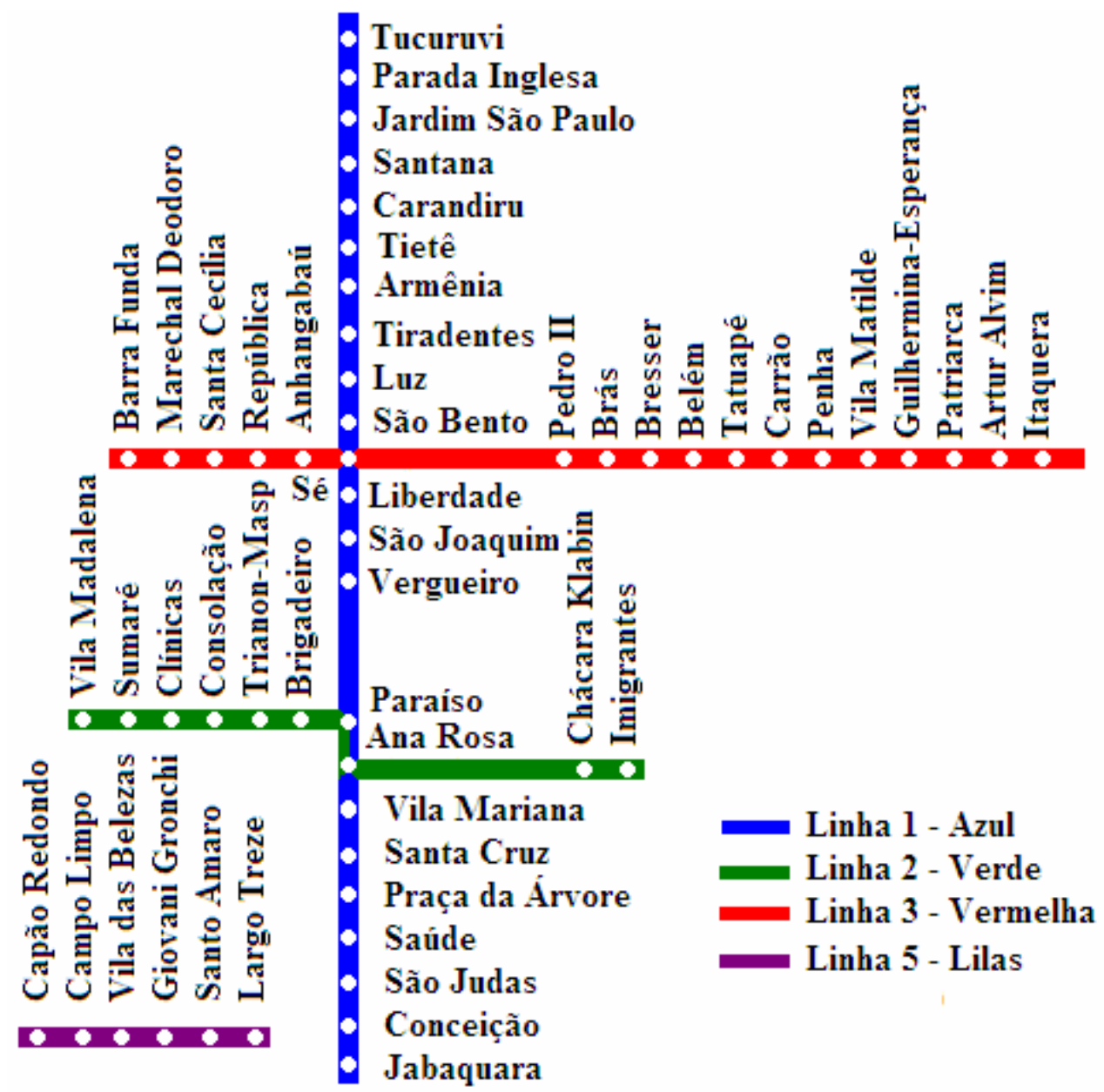

Figura 50. Mapa das linhas do Metrô de São Paulo.

O metrô de São Paulo conta com uma frota de 117 trens, com 6 carros, totalizando 702 carros. Existem 6 tipos de frotas de trens: os trens das frotas 198/108 (Linha 1 - Azul), os trens das frotas Cobrasma e Mafersa (Linha 3 - Vermelha), os trens da frota Alstom Milênio (Linha 2 - Verde) e da frota Alstom A-48 (Linha 5 - Lilás). A Figura 51 mostra os trens das linhas 1,3 e 2 , respectivamente.

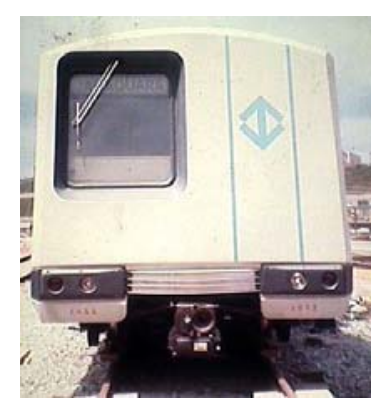

(a)

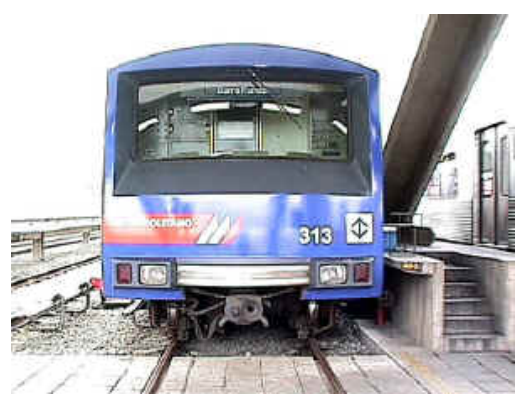

(b)

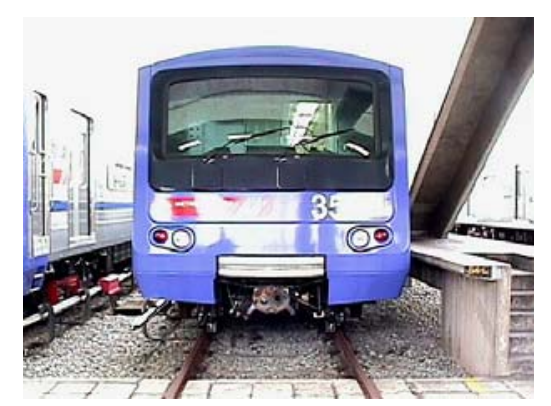

(c)

Figura 51. Trens do metrô de São Paulo das frotas (a)198/108, (b) Cobrasma/Mafersa e (c) Alstom Milênio. 
Os trens do metrô de São Paulo são operados basicamente em três modalidades: ATO (Operação Automática de Trens), MCS (Manual Controlado pelo Sistema) e manual. Na modalidade ATO, o controle de velocidade do trem é efetuado pelo equipamento ATC (Controle Automático de Trens) de bordo, que efetua o controle da aplicação de propulsão ou freios de acordo com a velocidade permitida para o trecho que o trem está percorrendo no momento. Na modalidade MCS, o operador comanda a velocidade do trem com o uso da alavanca de comando localizada no console do operador do trem, porém o equipamento ATC de bordo supervisiona este comando, acionando automaticamente os freios no caso da velocidade do trem ultrapassar a velocidade permitida para o trecho que o trem estiver percorrendo no momento. Na modalidade manual toda a sinalização de via é ignorada e a velocidade do trem é controlada pelo operador com o uso da alavanca de comando; porém, por motivos de segurança, a velocidade do trem é limitada em $20 \mathrm{~km} / \mathrm{h}$.

Como os trens possuem equipamentos de controle nas duas cabeceiras (ou extremidades) do trem, em caso de falha em qualquer um dos equipamentos, o trem poderá ser operado utilizando os equipamentos da outra cabeceira (ou extremidade). Este modo de operação é denominado de operação redundante e pode ser utilizado para qualquer uma das modalidades descritas anteriormente.

Um sistema centralizado comanda toda a sinalização de via, transmitindo os códigos de velocidade a todos os circuitos de via que compõem a via comercial. A função do equipamento de bordo é efetuar o controle da velocidade do trem, de forma que não seja ultrapassada a velocidade permitida para aquele circuito de via em que o trem estiver trafegando.

A sinalização de via é efetuada por circuitos de via do tipo AF (Áudio Freqüência), com comprimento variável entre 120 a 180 metros. Para a sinalização, em cada circuito de via é utilizado um par de freqüências de áudio, sendo uma freqüência para cada bit de informação (0 ou 1) que compõe o código de velocidade.

Para evitar a interferência entre circuitos de via adjacentes, são utilizados quatro diferentes pares de freqüência, denominados de A, B, C e F. A Tabela 5 mostra os pares e os valores de freqüência utilizados na formação dos códigos de velocidade. 
Tabela 5 - Freqüências utilizadas para transmissão dos códigos de velocidade.

\begin{tabular}{|c|c|c|}
\hline Par de Freqüências & Bits de Uns (kHz) & Bits de Zeros (kHz) \\
\hline A & 5,184 & 7,776 \\
\hline B & 5,842 & 8,762 \\
\hline C & 6,624 & 9,936 \\
\hline F & 5,600 & 8,400 \\
\hline
\end{tabular}

A transmissão do código de velocidade é feita utilizando modulação em $18 \mathrm{~Hz}$ da fase do sinal, ou seja, a cada 55 milisegundos (1/18 segundos), o sinal sofre uma inversão de $180^{\circ}$ na fase, para indicar a mudança entre dois bits de sinal.

Este sinal é transmitido aos circuitos de via pelos equipamentos de transmissão localizados ao longo da via. O equipamento de bordo capta este código usando antenas e utiliza esta informação para sincronizar o recebimento dos bits de código de velocidade, o que ocorre a uma taxa de $18 \mathrm{~Hz}$. A Figura 52 mostra a aparência de um sinal de código de velocidade.

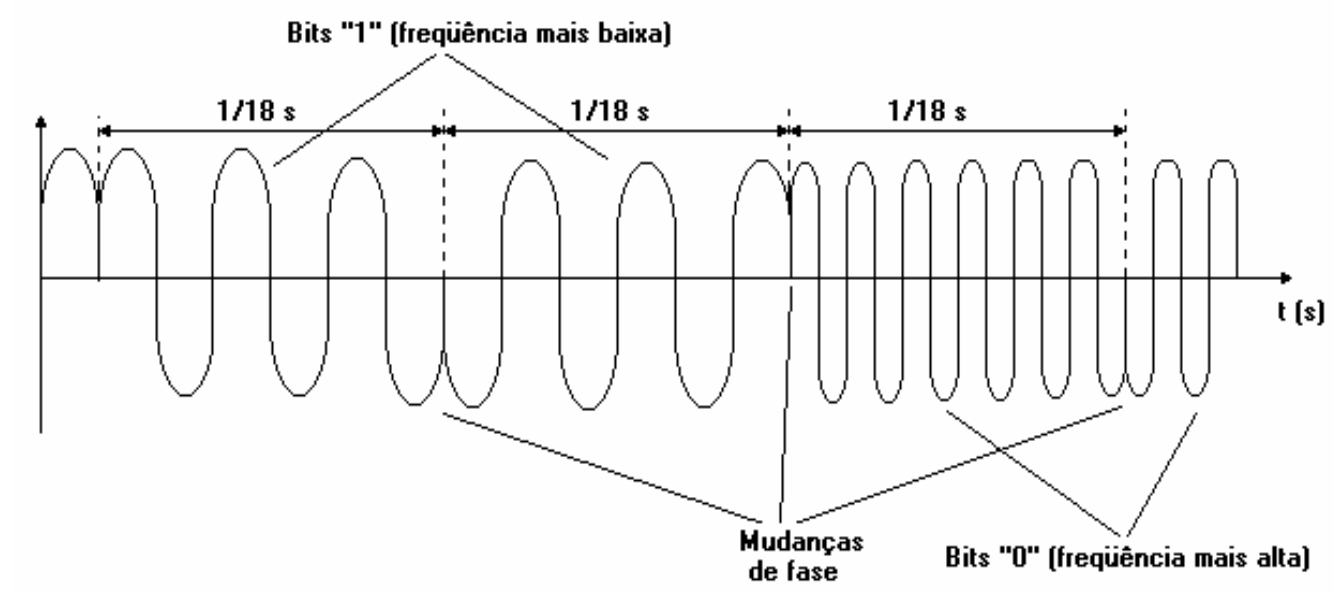

Figura 52. Modulação do sinal relativo ao código de velocidade.

O código de velocidade é composto por uma seqüência de seis bits (denominados de A a F). Nesta seqüência, três bits são utilizados para formatação do código e três bits permitem a codificação de até oito níveis de velocidade, a saber: 0, 10, $30,44,62,75,87$ e $100 \mathrm{~km} / \mathrm{h}$. 
Em uma seqüência válida de código de velocidade, a formatação está nos bits $\mathrm{A}, \mathrm{B}$ e F, que precisam ser, respectivamente, 1, 0 e 1 (condição denominada de A-BNOT-F). A Tabela 6 mostra os bits que compõem os oito códigos de velocidade disponíveis. O código relativo a $0 \mathrm{~km} / \mathrm{h}$ é o único que não obedece a formatação A-BNOT-F, representando, por motivos de segurança, um código inválido. Assim, qualquer decodificação indevida de código será interpretada como código de $0 \mathrm{~km} / \mathrm{h}$.

Para diminuir ainda mais a interferência entre os sinais transmitidos em circuitos de via adjacentes, além da utilização de diferentes pares de freqüência, são também utilizadas diferentes fases de sinal na transmissão. Em virtude do código de velocidade possuir uma formatação do tipo A-BNOT-F, os códigos de velocidade podem ser transmitidos começando por qualquer um dos bits de A a F, possibilitando seis diferentes fases para transmissão dos códigos.

Tabela 6 - Bits relativos aos códigos de velocidade disponíveis.

\begin{tabular}{|c|l|l|l|l|l|l|}
\hline \multirow{2}{*}{$\begin{array}{l}\text { Velocidade } \\
(\mathbf{k m} / \mathbf{h})\end{array}$} & \multicolumn{6}{|c|}{ Código de velocidade } \\
\cline { 2 - 7 } & A & B & C & D & E & F \\
\hline \hline 0 & 1 & 0 & 0 & 0 & 0 & 0 \\
\hline 10 & 1 & 0 & 0 & 0 & 0 & 1 \\
\hline 30 & 1 & 0 & 1 & 0 & 0 & 1 \\
\hline 44 & 1 & 0 & 0 & 1 & 0 & 1 \\
\hline 62 & 1 & 0 & 0 & 0 & 1 & 1 \\
\hline 75 & 1 & 0 & 1 & 0 & 1 & 1 \\
\hline 87 & 1 & 0 & 0 & 1 & 1 & 1 \\
\hline 100 & 1 & 0 & 1 & 1 & 1 & 1 \\
\hline
\end{tabular}

A velocidade comandada transmitida para os diferentes circuitos de via é captada por antenas receptoras de código de velocidade situadas na parte dianteira do trem, enquanto a velocidade real do trem é lida nos tacômetros acoplados aos eixos das rodas do trem. 
O equipamento de bordo efetua a comparação entre as velocidades comandada e real do trem, providenciando a requisição de propulsão ou freio mais adequada para o momento. Esta operação é realizada pelo ATO (Operação Automática do Trem), sendo supervisionada pelo ATP (Proteção Automática do Trem).

A função do ATP é efetuar uma monitoração contínua da velocidade real do trem, mantendo-a dentro dos limites determinados pela velocidade comandada, lida e decodificada dos circuitos de via por meio das antenas. Para manter a velocidade real do trem abaixo da velocidade comandada pelos circuitos de via, o ATP efetua o gerenciamento dos denominados BPMs (Brake Profile Monitor - Monitor do Perfil de Frenagem), de forma a manter o rastreamento da velocidade do trem dentro de determinados níveis de controle de velocidade.

A aplicação do BPM é uma das principais funções do ATP do trem e é o resultado da monitoração das velocidades real e comandada para o trem, sendo uma forma do ATP interagir na operação do sistema, levando o sistema a uma situação segura no caso do surgimento de uma situação potencialmente insegura para o trem.

A Figura 6.15 mostra a configuração dos equipamentos de bordo do metrô de São Paulo.

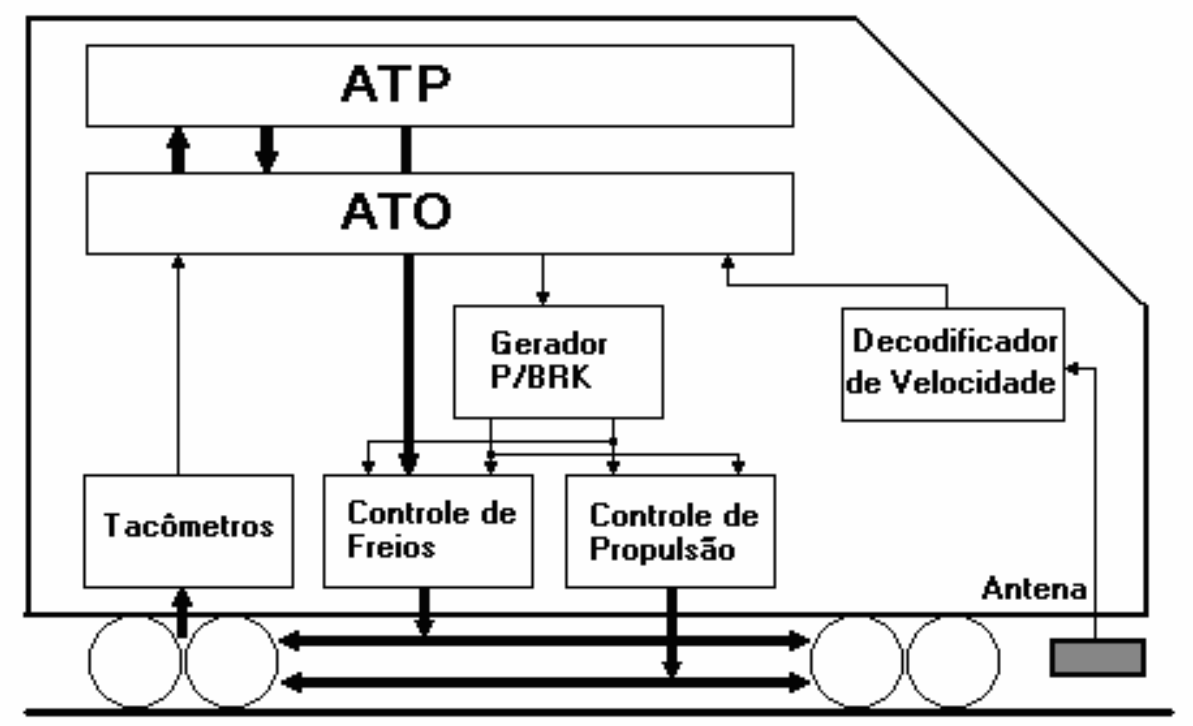

Figura 53. Configuração dos equipamentos de bordo do metrô de São Paulo. 
O controlador lógico utilizado atualmente nos trens do metrô de São Paulo efetua a comparação entre as velocidades comandada e real do trem. A velocidade comandada transmitida pelos equipamentos de via é decodificada pela antena decodificadora. A velocidade real do trem é lida nos tacômetros acoplados ao eixo das rodas do trem. A saída do controlador lógico é um sinal de aceleração, correspondente à diferença encontrada entre as velocidades comandada e real do trem. Este sinal de aceleração é transformado em um sinal de comando para os equipamentos de propulsão e frenagem, aplicando propulsão ou freio, conforme a necessidade operacional. Por fim, o próprio movimento do trem funciona como uma realimentação ao sistema de controle, modificando as velocidades comandada e real do trem. A Figura 54 mostra o diagrama de blocos do controlador lógico utilizado atualmente.

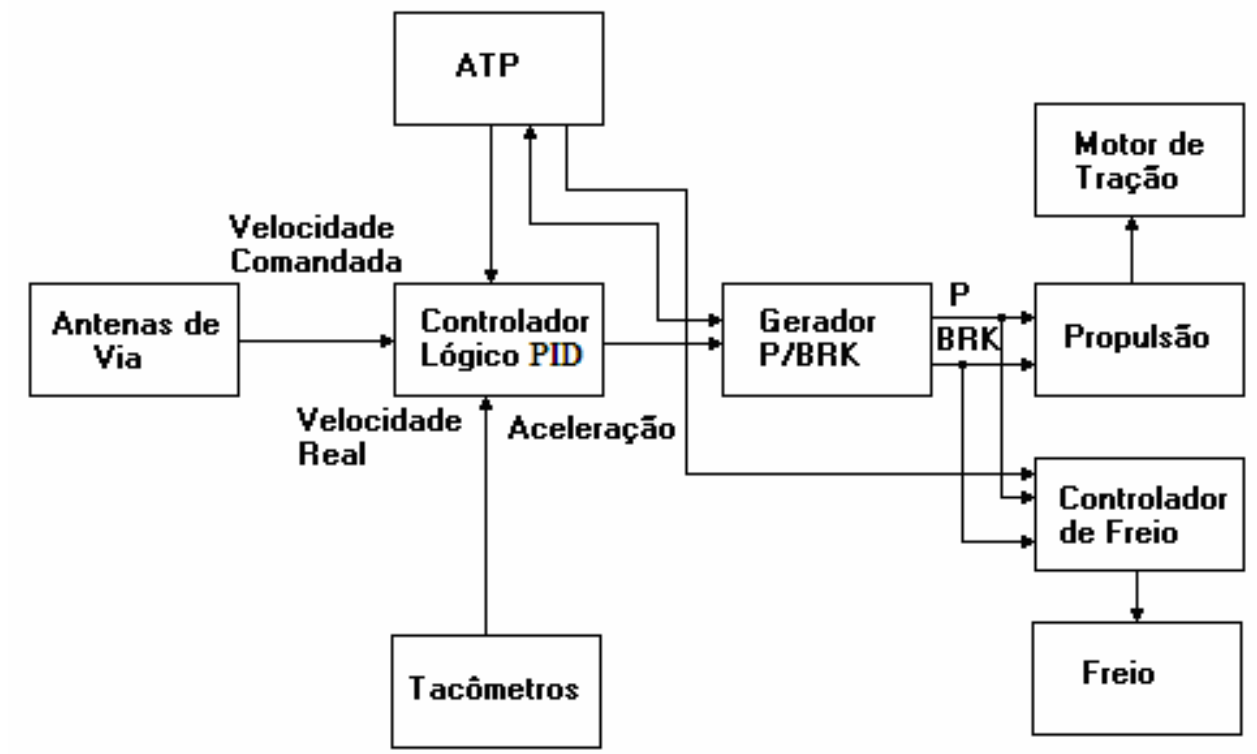

Figura 54. Diagrama de blocos do sistema de controle do metrô de São Paulo

A informação de modificação de desempenho ou ND - Nível de Desempenho (em inglês, PM - Performance Modification) é utilizada para efetuar o controle do headway intervalo de tempo entre dois trens no sistema usando o controle do tempo de percurso entre duas estações.

Quando o trem começar a deixar a região de plataforma, após fazer uma parada na estação, as antenas de identificação da estação começam a transmitir ao trem um código de ND informando as limitações de aceleração e velocidade a serem utilizados pelo trem no próximo trecho entre estações. 
Para controlar a taxa de aceleração e freio de cada um dos carros do trem, que funciona de forma independente, um mesmo sinal de controle deve percorrer o trem todo, de forma a uniformizar os comandos de aceleração e frenagem. Para isto, a saída do equipamento ATC controla um gerador de sinais P e BRK, que gera estes sinais de controle para todo o trem. Os sinais são na forma de corrente, de forma a garantir o recebimento dos sinais de controle por todos os carros do trem.

O sinal P (Propulsion) é um sinal de corrente alternada, com freqüência de $109 \mathrm{~Hz}$ e amplitude variável continuamente entre 0 e $100 \mathrm{~mA}$. Este sinal indica a quantidade requisitada de propulsão ou freio. Se o sinal P for menor que 55mA, uma quantidade de freio está sendo requisitada, sendo 55mA para mínimo freio e $20 \mathrm{~mA}$ para freio máximo. Se o sinal $\mathrm{P}$ for maior que $65 \mathrm{~mA}$, uma quantidade de propulsão está sendo requisitada, sendo $65 \mathrm{~mA}$ para mínima propulsão e 100mA para propulsão máxima.

O sinal BRK (Brake) é também um sinal de corrente alternada de $109 \mathrm{~Hz}$, porém não tem valores intermediários, sendo $0 \mathrm{~mA}$ para freio e $100 \mathrm{~mA}$ para propulsão. A Figura 55 mostra os valores dos sinais P e BRK para as possíveis situações de propulsão e frenagem do trem.

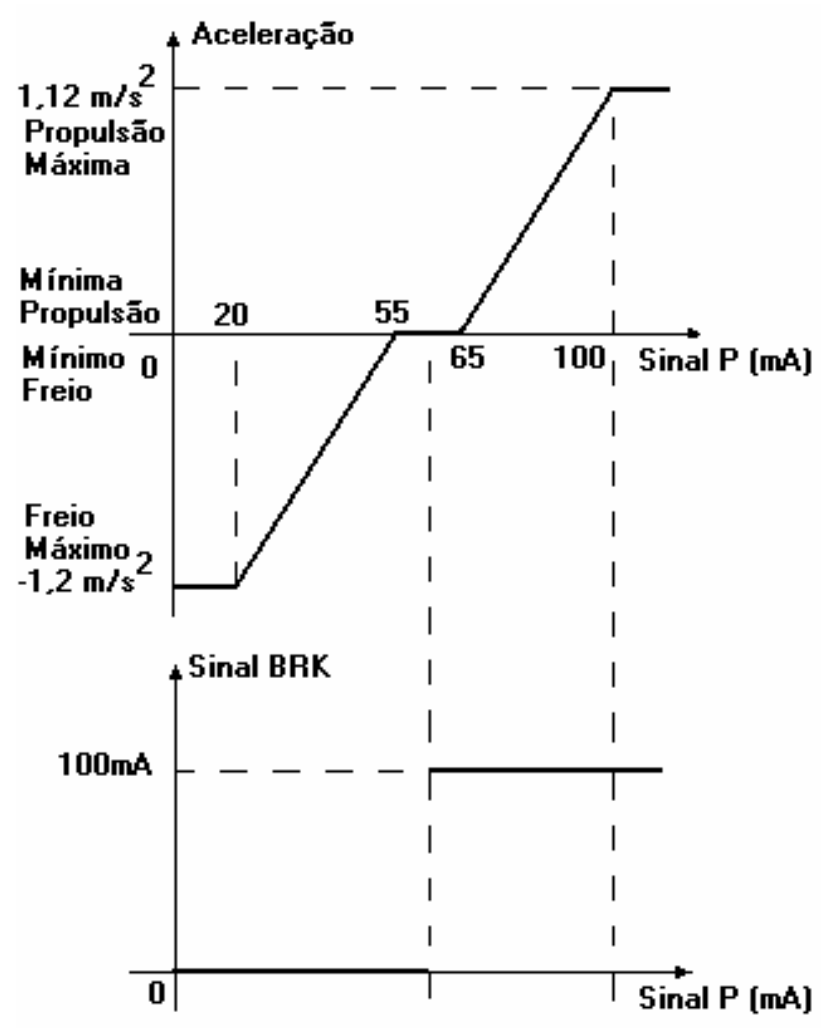

Figura 55. Representação gráfica dos sinais $P$ e BRK para as diversas situações de propulsão e freio dos trens do metrô de São Paulo. 


\subsection{Considerações Finais do Capítulo}

O objetivo deste capítulo foi o de apresentar estudos de caso de utilização de sistemas de controle de movimentação de trens nos metrôs de São Paulo e de Sendai. Esta apresentação procurou fornecer elementos atualmente utilizados em sistemas reais de controle de trens, de forma a fornecer parâmetros para possibilitar a comparação e a avaliação do sistema de controle nebuloso proposto no Capítulo 5.

O próximo passo consiste na simulação de condições operacionais reais para fornecer parâmetros adicionais de comparação e avaliação do sistema nebuloso proposto. As características operacionais de cada sistema serão relacionadas e as diferenças analisadas no Capítulo 7, pois representam características peculiares do comportamento destes sistemas de controle.

Com base no resultado destas simulações, o passo final consiste em se decidir quanto à viabilidade da aplicação do sistema de controle nebuloso proposto, o que será feito no Capítulo 8. 


\section{Resultados Obtidos}

Após a apresentação do modelo proposto utilizando lógica nebulosa preditiva e dos modelos dos sistemas de controle utilizados nos metrôs de Sendai e de São Paulo, este capitulo tem como objetivo a apresentação dos resultados de simulações efetuadas na ferramenta Matlab para todos os sistemas de controle apresentados. Os modelos de todos os controladores (metrô de São Paulo, metrô de Sendai e metrô utilizando o controlador nebuloso proposto) foram inseridos no programa Matlab, sendo selecionadas quatro situações operacionais de forma a avaliar o desempenho de cada um dos controladores $e$ permitir uma comparação entre eles.

\subsection{Introdução}

Para se efetuar uma análise mais profunda do funcionamento do sistema nebuloso de controle de trens utilizando lógica nebulosa preditiva, o modelo matemático deste controlador proposto foi inserido no programa Matlab e algumas situações operacionais foram selecionadas para avaliar seu desempenho.

Para efeitos de comparação, os modelos matemáticos dos controladores utilizados no metrô de Sendai e no metrô de São Paulo foram também introduzidos no programa de simulação, sendo também submetidos às mesmas situações operacionais selecionadas. Esta comparação tem finalidade didática, uma vez que os trens do metrô de São Paulo e de Sendai possuem características físicas (comprimento, peso, bitola, taxas de frenagem, etc.) diferentes.

Os modelos foram inseridos no módulo de Lógica Fuzzy do programa Matlab. Para efeitos de credibilidade da ferramenta e de consistência dos resultados obtidos, algumas das simulações também foram efetuadas no módulo Simulink do programa Matlab e no simulador nebuloso desenvolvido em linguagem $\mathrm{C}$ pelos pesquisadores do KNOMA/PCS/EPUSP (Laboratório de Engenharia de Conhecimento do Departamento de Engenharia de Computação e Sistemas Digitais da Escola Politécnica da Universidade de São Paulo). Neste capítulo são apresentados os resultados obtidos com a utilização do módulo Lógica Fuzzy do Matlab. Os demais resultados (com o módulo Simulink e com o simulador nebuloso desenvolvido em linguagem C) estão apresentados nos Apêndices A e B deste trabalho. 
Foram concebidos quatro cenários operacionais diferentes para a realização das simulações:

a) Uma circulação normal de trens entre duas estações, sem a presença de nenhum trem extra no percurso entre estas estações, de forma a simular uma condição operacional normal entre duas estações;

b) Uma circulação de trens com a presença de um trem extra parado no percurso entre duas estações, de forma a simular uma condição de ocorrência de falha no sistema, provocando a parada do trem que vem atrás do trem extra;

c) Uma circulação de trens entre duas estações com a presença de um trem extra se movendo com velocidade baixa $(30 \mathrm{~km} / \mathrm{h})$ e constante no percurso entre as estações, de forma a simular uma condição de falha na qual existe um trem extra movendo-se na modalidade manual ou sendo rebocado, seguido de um trem em condições normais; e

d) Uma circulação de trens entre duas estações com a presença de um trem extra se movendo com velocidade de via no percurso entre as estações, de forma a simular uma situação de adensamento de trens devido a um aumento de demanda de passageiros.

Para cada um destes cenários, foram feitas simulações de corridas para os trens com os controladores apresentados. Em cada simulação, foram levantados os gráficos da velocidade, da aceleração e da distância percorrida pelos trens em função do tempo.

Nos gráficos apresentados, os resultados das simulações efetuadas para os trens do metrô de São Paulo são apresentados em uma curva azul, enquanto que os resultados das simulações efetuadas para os trens do metrô de Sendai são apresentados em uma curva amarela e os resultados das simulações efetuadas para um metrô com o controlador nebuloso são apresentados em uma curva vermelha. Quando houver necessidade, os resultados do trem extra que compõe o cenário de simulação são apresentados em uma curva verde.

Para cada gráfico apresentado, os comportamentos dos trens são analisados, bem como suas diferenças, pois elas revelam as características operacionais de cada um dos controladores analisados, indicando as vantagens e desvantagens da utilização de um controlador nebuloso. Para a realização das simulações foi escolhido o trecho de via localizado entre as estações Santa Cruz (SCZ) e Praça da Árvore (ARV), no sentido TucuruviJabaquara da Linha 1 - Azul do metrô de São Paulo, por ser um trecho típico entre duas estações na Linha 1, com um maior número de opções de códigos de velocidade comandada. 
A Figura 56 mostra um mapeamento dos circuitos de via contidos neste trecho, com a medida dos comprimentos de cada circuito de via e os códigos de velocidade comandada em cada um destes circuitos, em $\mathrm{km} / \mathrm{h}$, estando entre parênteses a mesma velocidade em $\mathrm{m} / \mathrm{s}$. São também apresentados os perfis de ocupação para cada um dos circuitos de via.

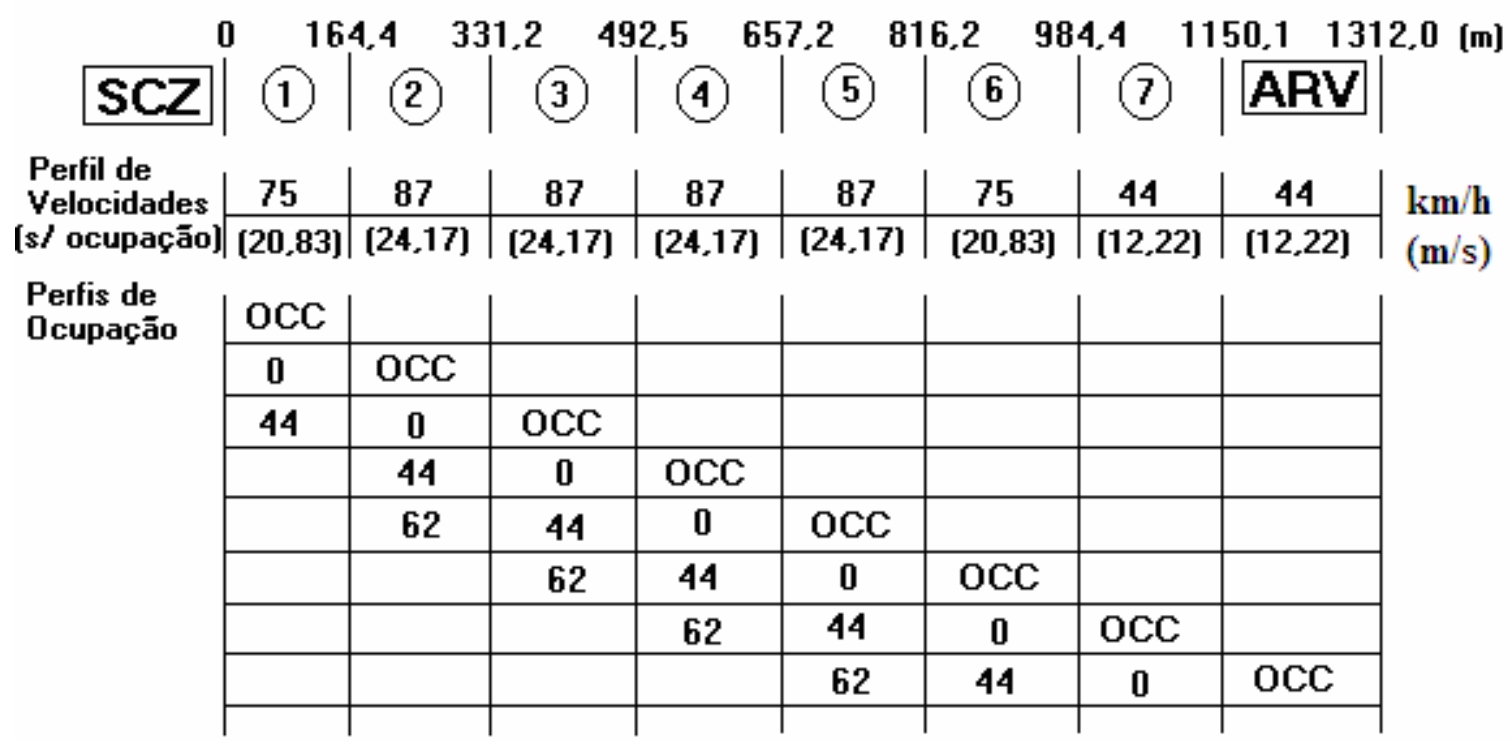

Figura 56. Mapeamento dos circuitos de via entre as estações Santa Cruz e Praça da Árvore do metrô de São Paulo.

Na Figura 56, os circuitos de via são identificados por números dentro dos círculos. Assim, o trecho de 1312 metros entre as estações compreende 8 circuitos de via, sendo que o oitavo circuito está situado na região da plataforma da estação ARV (Praça da Árvore). Ainda na Figura 56, a palavra OCC indica a ocupação de um trecho por um trem. Quando ocorre a ocupação de um trecho, o equipamento de via altera o Perfil de Velocidades (mostrado na $1^{\text {a }}$. Linha da Figura 56) para um dos Perfis de Ocupação (mostrado nas demais linhas da Figura 56), transmitindo códigos de velocidade comandada menores para os trechos anteriores ao da ocupação e formando a chamada "sombra" ou "rastro" do trem. Nos demais trechos em que não há indicação do código de velocidade comandada, o código utilizado é aquele inicialmente planejado no Perfil de Velocidades (1 ${ }^{\mathrm{a}}$. Linha da Figura 56) sem ocupação.

As informações de comprimento e códigos de velocidade dos circuitos de via foram obtidas em desenhos denominados de track plan (mapa da via), que apresentam uma completa caracterização de cada um dos circuitos de via, incluindo marcos topográficos, grau de inclinação da via e localização das antenas, com as freqüências utilizadas na transmissão e recepção do sinal de via. 


\subsection{Circulação Normal de Trens (Situação Operacional Normal)}

Observando o plano de vias mostrado na Figura 56 pode-se verificar que quando não houver um trem no percurso entre as duas estações, o perfil de códigos de velocidade é o perfil apresentado na primeira linha da Figura.

Esta situação ocorre freqüentemente durante a operação comercial, especialmente no “período de vale", quando a demanda de passageiros é reduzida e, portanto, há menos trens em circulação. Esta também é a situação mais simples que pode ocorrer na circulação de um trem entre duas estações.

Nesta situação, os trens partem da plataforma da primeira estação (SCZ) com destino à plataforma da segunda estação (ARV), cada um com suas características operacionais, e sua movimentação não sofre nenhuma interferência, uma vez que não existe nenhum trem extra no percurso entre as duas estações.

Esta configuração é tomada como padrão para as simulações efetuadas, uma vez que se trata da circulação normal de trens. Mais adiante, outras simulações serão feitas variando alguns parâmetros a partir desta configuração original.

A Figura 57 apresenta o gráfico das velocidades dos trens ao longo do tempo de percurso entre as duas estações.

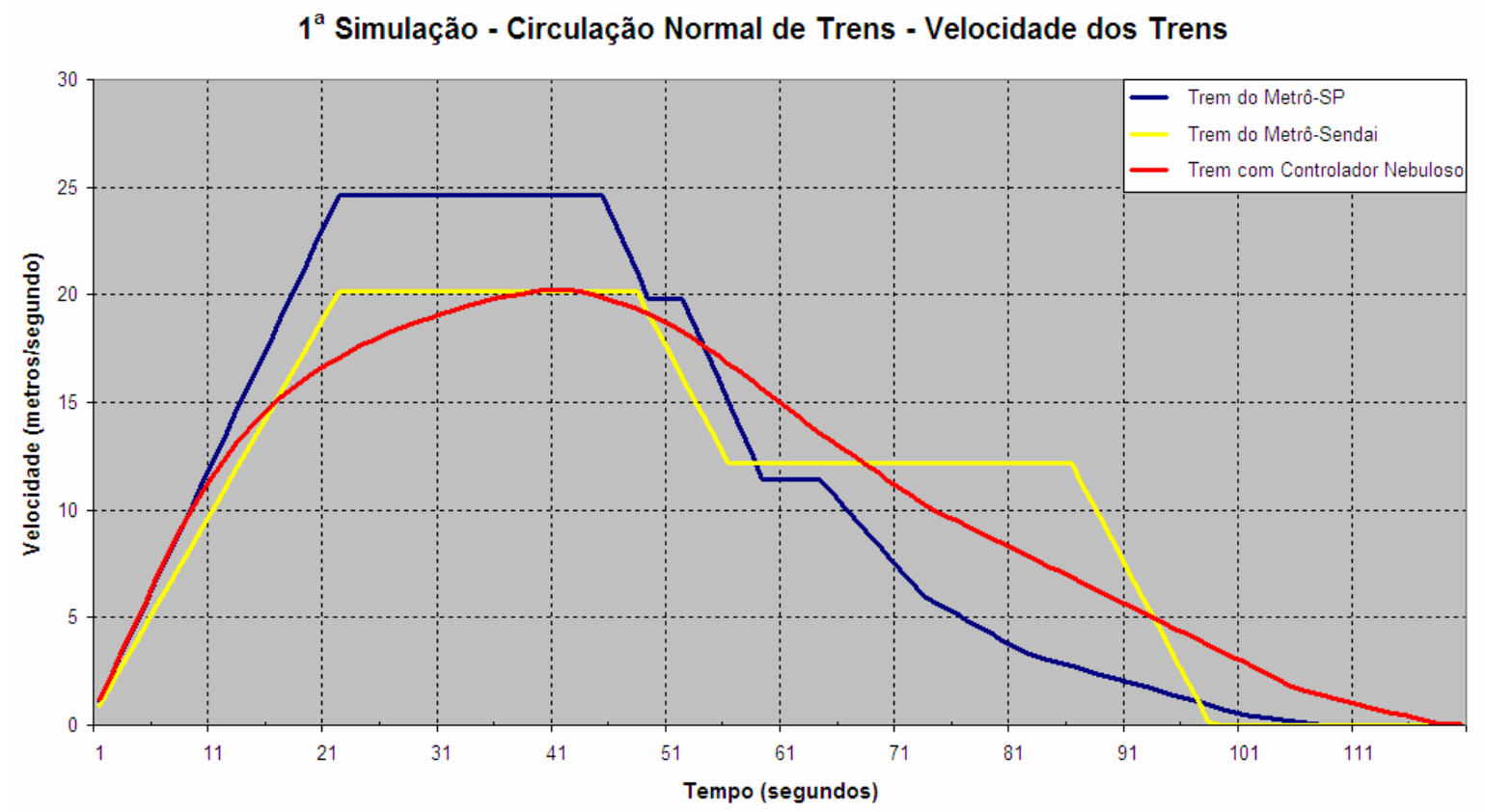

Figura 57. Gráfico das velocidades dos trens para a $1^{\text {a }}$ Simulação. 
Analisando o comportamento das curvas de velocidades dos trens em função do tempo, apresentadas na Figura 57, pode-se perceber que:

- O trem do metrô de São Paulo inicia seu movimento acelerando com a taxa máxima de aceleração $\left(1,12 \mathrm{~m} / \mathrm{s}^{2}\right)$ até a velocidade máxima comandada no circuito de via número 1 $(75 \mathrm{~km} / \mathrm{h}=20,83 \mathrm{~m} / \mathrm{s})$. No circuito de via número 2, a velocidade máxima comandada é maior $(87 \mathrm{~km} / \mathrm{h}=24,17 \mathrm{~m} / \mathrm{s})$ e o trem continua acelerando com taxa máxima até atingir esta velocidade, mantendo-a até o início do circuito de via número 6, onde a velocidade comandada volta a ser menor $(75 \mathrm{~km} / \mathrm{h}=20,83 \mathrm{~m} / \mathrm{s})$. Neste ponto, o trem começa a frear com a máxima taxa de frenagem de serviço $\left(-1,2 \mathrm{~m} / \mathrm{s}^{2}\right)$ até que a velocidade do trem fique abaixo da velocidade comandada. $\mathrm{O}$ mesmo se repete no circuito de via número 7 , no qual a velocidade comandada é menor $(44 \mathrm{~km} / \mathrm{h}=12,22 \mathrm{~m} / \mathrm{s})$ e o controlador faz o trem frear até atingir esta nova velocidade comandada. No circuito de via número 8 (plataforma da estação Praça da Árvore - ARV), o trem inicia o processo de parada programada, a partir da velocidade de $44 \mathrm{~km} / \mathrm{h}(12,22 \mathrm{~m} / \mathrm{s})$, diminuindo gradualmente sua velocidade até a parada total do trem na plataforma;

- O trem do metrô de Sendai inicia seu movimento com a máxima aceleração $\left(0,916 \mathrm{~m} / \mathrm{s}^{2}\right)$ até atingir a velocidade máxima limite da $1^{\mathrm{a}}$. região $\operatorname{CSC}(75 \mathrm{~km} / \mathrm{h}=20,83 \mathrm{~m} / \mathrm{s})$, mantendo esta velocidade até a detecção do marcador CSC, onde então aplica freio mínimo $\left(-1 \mathrm{~m} / \mathrm{s}^{2}\right)$ até atingir uma velocidade mais restritiva, limite da $2^{\mathrm{a}}$. região CSC $(45 \mathrm{~km} / \mathrm{h}=12,22 \mathrm{~m} / \mathrm{s})$. Após a detecção do marcador TASC, o trem inicia o processo de parada do trem, aplicando freio mínimo até a parada total do trem. Para esta simulação, as posições dos marcadores CSC (730 m) e TASC (1182 m) foram determinadas de forma proporcional ao trajeto entre as estações Sendai e Itsutsu-bashi $(1150 \mathrm{~m})$ do metrô de Sendai; e

- O controlador nebuloso inicia o movimento do trem também com uma taxa máxima de aceleração. Isto ocorre porque o controlador nebuloso efetua uma avaliação da distância a ser percorrida e da velocidade atual do trem para produzir a aceleração do trem e, inicialmente, o trem precisa percorrer uma distância grande e está com uma velocidade baixa, o que faz com que o controlador solicite uma taxa de aceleração máxima, diminuindo gradativamente até cerca da metade do percurso, quando o controlador nebuloso inicia o processo de frenagem gradativa com uma taxa que em princípio é pequena e vai aumentando ao longo do tempo. 
Observando-se a Figura 57 pode-se verificar também que o trem utilizando controlador nebuloso demora mais tempo (118 segundos) para percorrer o espaço entre as duas estações do que os trens do metrô de São Paulo (107 segundos) e do metrô de Sendai (97 segundos). Portanto, para esta situação, o headway é maior para o trem utilizando controlador nebuloso e menor para o trem do metrô de Sendai.

Isto ocorre porque o trem com controlador nebuloso desenvolve uma velocidade máxima de percurso menor $(72 \mathrm{~km} / \mathrm{h}=20 \mathrm{~m} / \mathrm{s})$ do que o trem do metrô de São Paulo (87 $\mathrm{km} / \mathrm{h}=24 \mathrm{~m} / \mathrm{s})$ e aproximadamente igual à do trem do metrô de Sendai $(75 \mathrm{~km} / \mathrm{h}=$ $20,83 \mathrm{~m} / \mathrm{s})$, e efetua uma frenagem com uma taxa de desaceleração menor $\left(<0,5 \mathrm{~m} / \mathrm{s}^{2}\right)$ do que os trens dos metrôs de São Paulo $\left(1,2 \mathrm{~m} / \mathrm{s}^{2}\right)$ e de Sendai $\left(1 \mathrm{~m} / \mathrm{s}^{2}\right)$.

A área sob a curva da Velocidade x Tempo do trem indica a distância percorrida, pois significa a integração do valor de todas as velocidades instantâneas ao longo do tempo e, por isso, é igual para todas as curvas apresentadas, uma vez que os trens percorreram a mesma distância.

Os trens do metrô de São Paulo e de Sendai apresentam uma tendência à otimização do desempenho e do tempo de percurso entre duas estações, acelerando o máximo possível no início do trecho, mantendo-se o máximo possível na máxima velocidade permitida pelos circuitos de via, e freando o máximo possível na parte final do trecho.

Já o controlador nebuloso efetua uma avaliação da distância a ser percorrida e procura desenvolver uma velocidade de forma a manter uma relação constante entre a distância a ser percorrida e a velocidade atual do trem, de acordo com as regras estabelecidas no projeto do controlador. O controlador nebuloso busca a otimização da relação Velocidade x Distância a ser percorrida pelo trem contida em sua base de regras.

Com isto, foi observado um compromisso entre o tempo e a máxima velocidade de percurso entre as estações, de forma que, quanto maior a velocidade máxima desenvolvida no trecho entre estações, menor o tempo de percurso entre elas. Da mesma forma, quanto maior a velocidade máxima de percurso, maior será o consumo de energia. A energia de movimentação do trem deve ser igual à energia elétrica consumida para tirar o trem da inércia de repouso e conduzi-lo à velocidade de movimentação.

A Figura 58 mostra a aceleração dos trens ao longo do tempo de percurso entre as estações. 


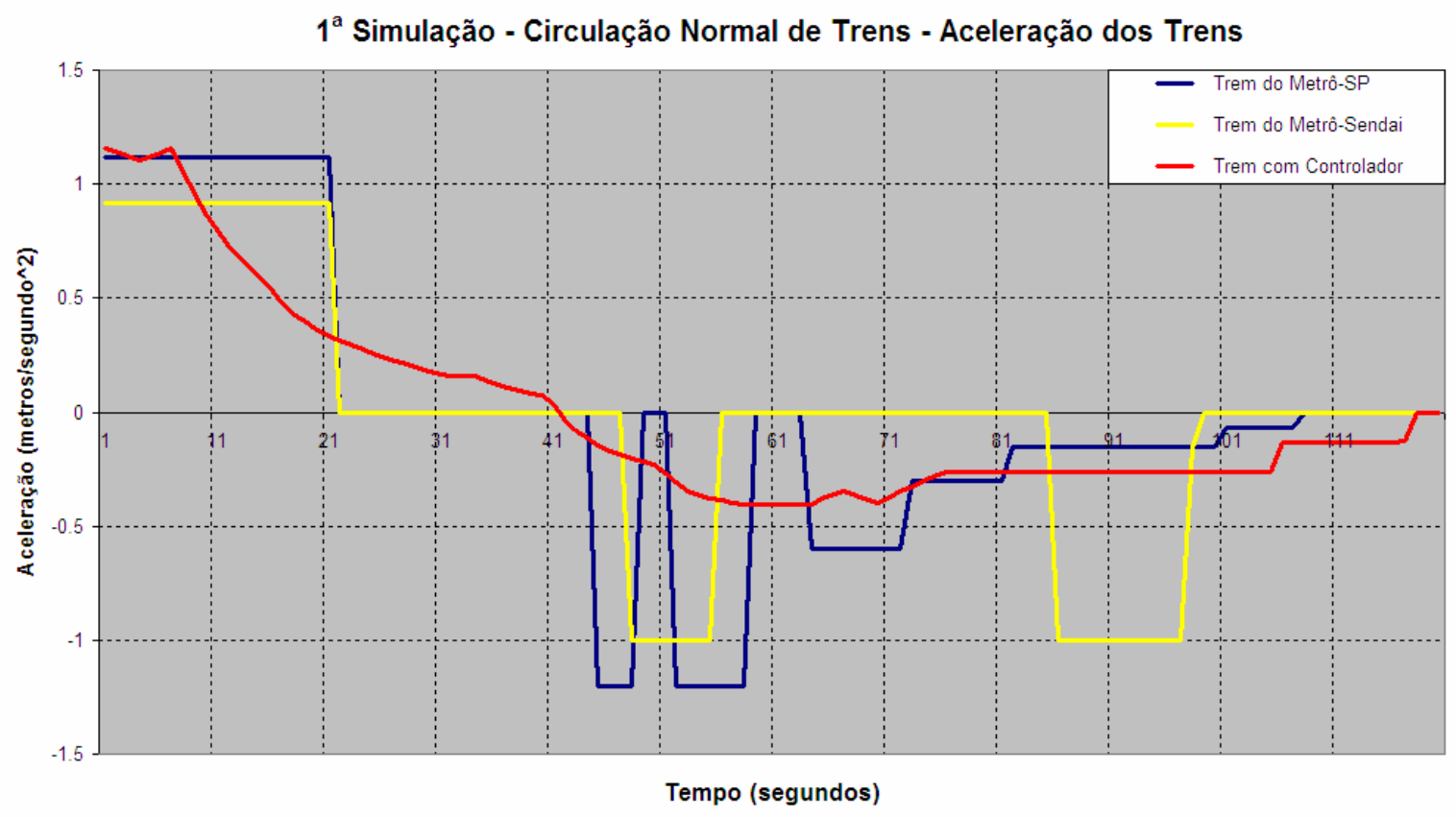

Figura 58. Gráfico das acelerações dos trens para a $1^{\text {a }}$ Simulação.

Analisando o comportamento das curvas de acelerações dos trens em função do tempo, apresentadas na Figura 58, pode-se perceber que:

- O trem do metrô de São Paulo apresenta um número maior de transições entre a taxa máxima de freio e zero. O controlador sempre busca a velocidade comandada para o circuito de via com a taxa máxima de propulsão ou freio, com exceção da parada programada, em que são aplicadas taxas graduais de frenagem para a parada do trem;

- O trem do metrô de Sendai apresenta um comportamento semelhante, porém com taxas menores de aceleração e frenagem. Observa-se também um número menor de transições entre propulsão e frenagem, devido ao número menor de regiões de transição de operação em comparação ao número de circuitos de via. Isto provoca uma otimização da aplicação de propulsão e freios, uma vez que o trem efetua uma aplicação de propulsão ou freio para cada transição de trechos efetuada; e

- O controlador nebuloso não apresenta transições bruscas entre as taxa máxima de propulsão ou frenagem e zero, exigindo uma menor corrente de tração nos motores e uma atuação menor do sistema de freios. Esta característica proporciona um menor consumo de energia e uma menor taxa de manutenção do sistema, além de produzir uma suavidade na curva de resposta de velocidade, refletida no conforto aos passageiros. A desvantagem é que esta menor requisição de tração e freios provoca um aumento no tempo de percurso. 
A área sob a curva de aceleração expressa a velocidade média realizada no trecho entre as duas estações, uma vez que é a integração das velocidades instantâneas ao longo do tempo de percurso entre as estações. Como a energia cinética do trem é proporcional à sua velocidade $\left(\mathrm{Ec}=\mathrm{mv}^{2} / 2\right)$, a área sob a curva está relacionada com a energia de movimentação do trem.

A área da curva situada acima do eixo das abscissas expressa o esforço de tração do trem, enquanto a área da curva situada abaixo do eixo das abscissas expressa o esforço de frenagem do trem. O controlador nebuloso apresenta uma menor área sob a curva e também uma menor área abaixo do eixo das abscissas, apresentando um menor esforço de tração e um menor esforço de frenagem.

Fazendo-se as contas para o esforço de tração, obtêm-se os seguintes resultados:

- Para o trem do metrô de São Paulo, dados técnicos mostram que o trem lotado possui uma massa de 300 toneladas $\left(\mathrm{m}=300 \times 10^{3} \mathrm{~kg}\right)$. Fazendo o cálculo da velocidade média expressa pela área sob a curva na Figura 58, tem-se:

$$
\begin{aligned}
& v=\int a \times d t=1,12 \times 21=23,52 \mathrm{~m} / \mathrm{s} \\
& E=\frac{m v^{2}}{2}=\frac{300 \times 10^{3} \times(23,52)^{2}}{2}=82,978 \times 10^{6} \mathrm{~J}
\end{aligned}
$$

A potência (energia/tempo) utilizada na tração é dada por:

$$
P=\frac{E}{t}=\frac{82,978 \times 10^{6}}{21}=3,951 \times 10^{6} \mathrm{~W}
$$

- Para o trem do metrô de Sendai, a massa para o trem lotado é estimada pela relação entre o comprimento do trem de Sendai $(84 \mathrm{~m})$ e o metrô de São Paulo $(120 \mathrm{~m})$. Transpondo esta relação para a massa, tem-se:

$$
\begin{aligned}
& m=\frac{84}{120} \times 300 \times 10^{3}=210 \times 10^{3} \mathrm{~kg} \\
& v=\int a \times d t=0,916 \times .21=19,236 \mathrm{~m} / \mathrm{s} \\
& E=\frac{m v^{2}}{2}=\frac{210 \times 10^{3} \times(19,236)^{2}}{2}=38,852 \times 10^{6} \mathrm{~J} \\
& P=\frac{E}{t}=\frac{38,852 \times 10^{6}}{21}=1,850 \times 10^{6} \mathrm{~W}
\end{aligned}
$$

- Para o trem com controlador nebuloso utiliza-se, para efeitos de comparação, o mesmo trem do metrô de São Paulo e, portanto, 


$$
\begin{aligned}
& m=300 \times 10^{3} \mathrm{~kg} \\
& v=\int a \times d t=20,246 \mathrm{~m} / \mathrm{s} \\
& E=\frac{m v^{2}}{2}=\frac{300 \times 10^{3} \times(20,246)^{2}}{2}=61,485 \times 10^{6} \mathrm{~J} \\
& P=\frac{E}{t}=\frac{61,485 \times 10^{6}}{41}=1,5 \times 10^{6} \mathrm{~W}
\end{aligned}
$$

O valor da velocidade é obtido integrando-se numericamente os valores de aceleração no intervalo considerado (soma dos valores em intervalos de um segundo). Assim, para o esforço de tração, o trem com controlador nebuloso apresenta um consumo de energia 25,9\% menor que o trem do metrô de São Paulo, porém um consumo 58,2\% maior que o trem do metrô de Sendai. Em termos de potência, o trem com controlador nebuloso apresenta uma potência de consumo 37,96\% da apresentada pelo trem do metrô de São Paulo e 18,92\% menor que o trem do metrô de Sendai.

Para o esforço de frenagem, têm-se os seguintes cálculos:

- Para o trem do metrô de São Paulo:

$$
\begin{aligned}
& v=\int a \times d t=(-1,2) \times 4+(-1,2) \times 7+(-0,6) \times 9+(-0,3) \times 9+(-0,15) \times 19+(-0,07) \times 7=-24,64 \\
& E=\frac{m v^{2}}{2}=\frac{300 \times 10^{3} \times(-24,64)^{2}}{2}=91,069 \times 10^{6} \mathrm{~J} \\
& P=\frac{E}{t}=\frac{91,069 \times 10^{6}}{4+7+9+9+19+7}=1,655 \times 10^{6} \mathrm{~W}
\end{aligned}
$$

- Para o trem do metrô de Sendai:

$$
\begin{aligned}
& v=\int a \times d t=(-1) \times 8+(-1) \times 9+(-1,855)+(-1)+(-0,297)=-20,152 \mathrm{~m} / \mathrm{s} \\
& E=\frac{m v^{2}}{2}=\frac{210 \times 10^{3} \times(-20,152)^{2}}{2}=42,641 \times 10^{6} \mathrm{~J} \\
& P=\frac{E}{t}=\frac{42,641 \times 10^{6}}{8+9+1+1+1}=2,132 \times 10^{6} \mathrm{~W}
\end{aligned}
$$

- Para o trem com controlador nebuloso:

$$
\begin{aligned}
& v=\int a \times d t=-20 \mathrm{~m} / \mathrm{s} \\
& E=\frac{m v^{2}}{2}=\frac{300 \times 10^{3} \times(-20)^{2}}{2}=60.10^{6} \mathrm{~J} \\
& P=\frac{E}{t}=\frac{60 \times 10^{6}}{75}=800 \times 10^{3} \mathrm{~W}
\end{aligned}
$$


Para o esforço de frenagem, o trem com controlador nebuloso apresenta um consumo de energia 34,11\% menor que o trem do metrô de São Paulo, porém um consumo 40,7\% maior que o trem do metrô de Sendai. Em termos de potência, o trem com controlador nebuloso apresenta uma potência de consumo 51,67\% da apresentada pelo trem do metrô de São Paulo e 37,52\% da apresentada pelo trem do metrô de Sendai.

Em termos de energia total, o trem do metrô de São Paulo apresenta uma energia de $174 \times 10^{6} \mathrm{~J}$ e uma potência de 5,606 x $10^{6} \mathrm{~W}$, enquanto o metrô de Sendai apresenta uma energia de $81,493 \times 10^{6} \mathrm{~J}$ e uma potência de $3,982 \times 10^{6} \mathrm{~W}$ e o metrô com controlador nebuloso uma energia de $121,5 \times 10^{6} \mathrm{~J}$ e uma potência de $2,3 \times 10^{6} \mathrm{~W}$. Estes dados mostram que o trem do metrô de Sendai é o que consome menos energia, porém é o controlador nebuloso que apresenta uma menor potência, representando 58,97\% menos potência que o trem do metrô de São Paulo e 42,24\% menos potência que o trem do metrô de Sendai.

Nos trens do metrô de São Paulo, quando é efetuada uma frenagem, a energia contida nos motores é devolvida à linha de alimentação para ser utilizada por outros trens que estiverem acelerando. Este tipo de frenagem é denominado de frenagem regenerativa. Porém, se a linha não estiver receptiva (se não houver outros trens acelerando), esta energia é dissipada em um bloco de resistores no sistema de propulsão do trem. Este tipo de frenagem é denominado de frenagem reostática. Para tentar aproveitar ao máximo a energia dos motores durante a frenagem do trem, a Central de Controle Operacional (CCO) procura sincronizar a aceleração com a frenagem dos trens. Esta sincronização, porém, é complexa e nem sempre passível de ser realizada, principalmente em horários de vale, quando há um número menor de trens em circulação.

Observando a Figura 58, pode-se verificar que o controlador nebuloso não apresenta as descontinuidades na curva de Aceleração x Tempo apresentadas pelos trens dos metrôs de São Paulo e de Sendai. Esta característica não é mensurável, mas se apresenta em termos de um maior conforto aos usuários, uma vez que não existem descontinuidades de velocidade. Com isto, o passageiro a bordo do trem não tem a sensação de "trancos" durante os processos de aceleração e frenagem do trem, sofrendo uma transição mais suave do equilíbrio estático para o equilíbrio dinâmico do trem. Embora o controlador nebuloso não proporcione um regime permanente de velocidade (regime no qual a velocidade do trem permanece constante por um determinado período de tempo), a transição de velocidades é feita de forma mais suave, proporcionando um maior conforto aos usuários. 
A Figura 59 mostra a distribuição espacial dos trens ao longo do tempo de percurso entre as duas estações.

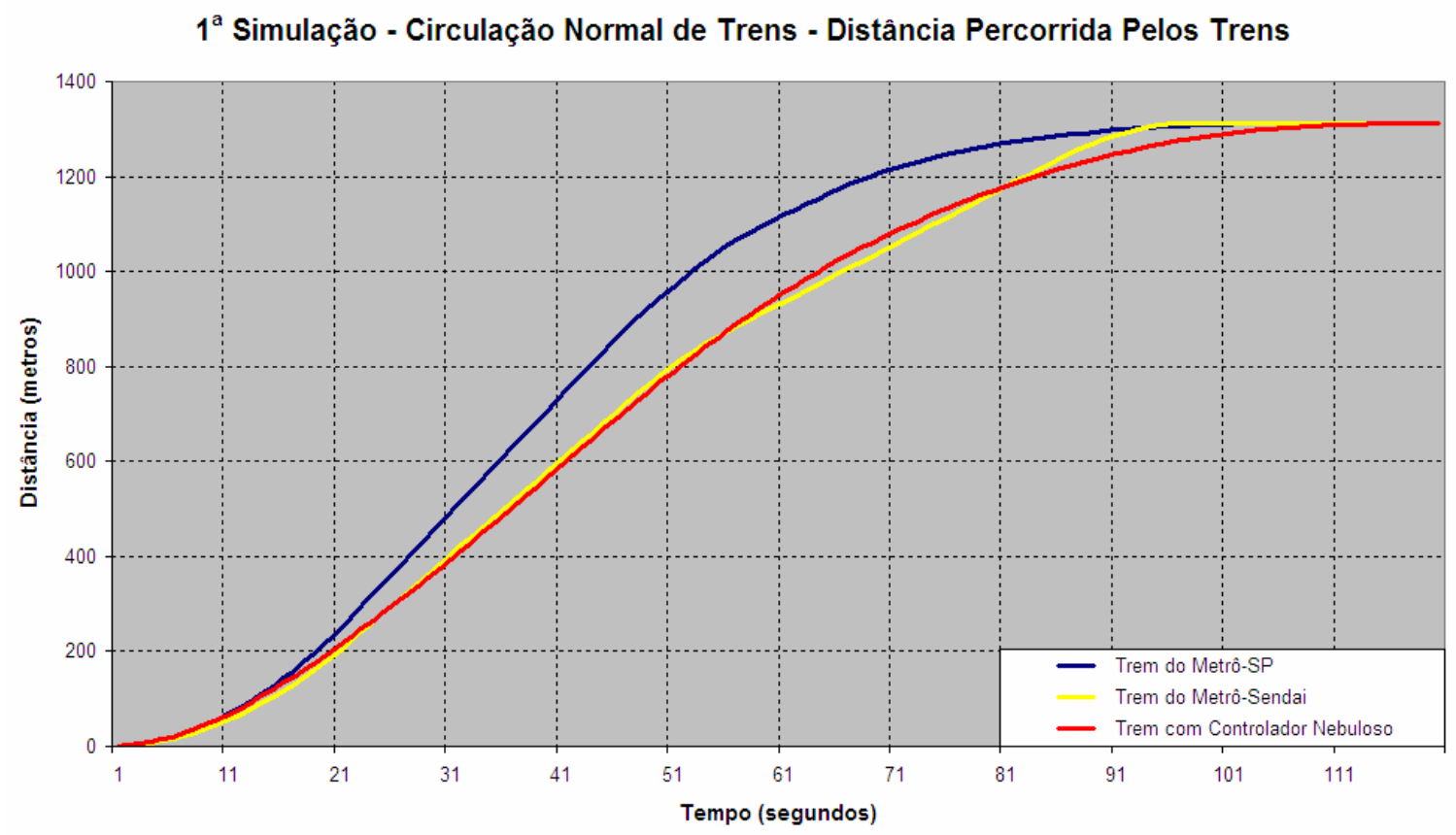

Figura 59. Gráfico da distância percorrida pelos trens na $1^{\text {a }}$ Simulação.

Observando a Figura 59, pode-se perceber que a variação espacial de todos os trens são muito próximas umas das outras. A variação espacial do trem do metrô de São Paulo é um pouco mais acentuada do que as variações espaciais dos trens do metrô de Sendai e do controlador nebuloso. Isto é uma conseqüência do fato do trem do metrô de Sendai e do trem com controlador nebuloso desenvolverem uma velocidade máxima de percurso inferior à do trem do metrô de São Paulo. Na região final do gráfico (região da plataforma da estação ARV) a suavidade das curvas é devida ao processo de parada programada do trem na estação.

Em termos de segurança, esta simulação não fornece parâmetros de análise, uma vez que não há a circulação de outro trem para que a proximidade entre trens possa ser analisada. Durante a maior parte do tempo, nesta simulação, o trem com controlador nebuloso esteve com uma velocidade abaixo da velocidade comandada nos circuitos de via para o trecho em questão.

Os apêndices A e B apresentam resultados gráficos desta $1^{\text {a }}$ simulação para os simuladores Simulink e Knoma e podem servir como parâmetros de comparação dos resultados. 


\subsection{Circulação de Trens com a Presença de um Trem Extra Parado entre Duas Estações (Situação de Falha no Sistema)}

Quando ocorre uma ocupação por um trem em um dos circuitos de via do trecho, o perfil de velocidades é alterado para um dos perfis de ocupação apresentados na Figura 56. Esta situação não ocorre freqüentemente durante a operação comercial, apenas quando ocorre uma falha no sistema ou um transtorno operacional que interrompa a movimentação dos trens.

Para esta simulação, existe um trem extra parado no circuito de via número 4 (ver Figura 56). O trem sob análise deixa a plataforma da estação Santa Cruz (SCZ) com destino à estação Praça da Árvore (ARV), mas tem o seu movimento interrompido por causa de um trem que está parado no meio do percurso.

Esta situação também pode ocorrer em caso de falha na via, na qual o sistema entende incorretamente que o trecho encontra-se ocupado por um trem. Este tipo de falha é denominado "falsa ocupação" e causa o mesmo transtorno que causaria um trem com falha parado sobre o circuito de via em questão.

A Figura 60 apresenta o gráfico das velocidades dos trens para esta simulação.

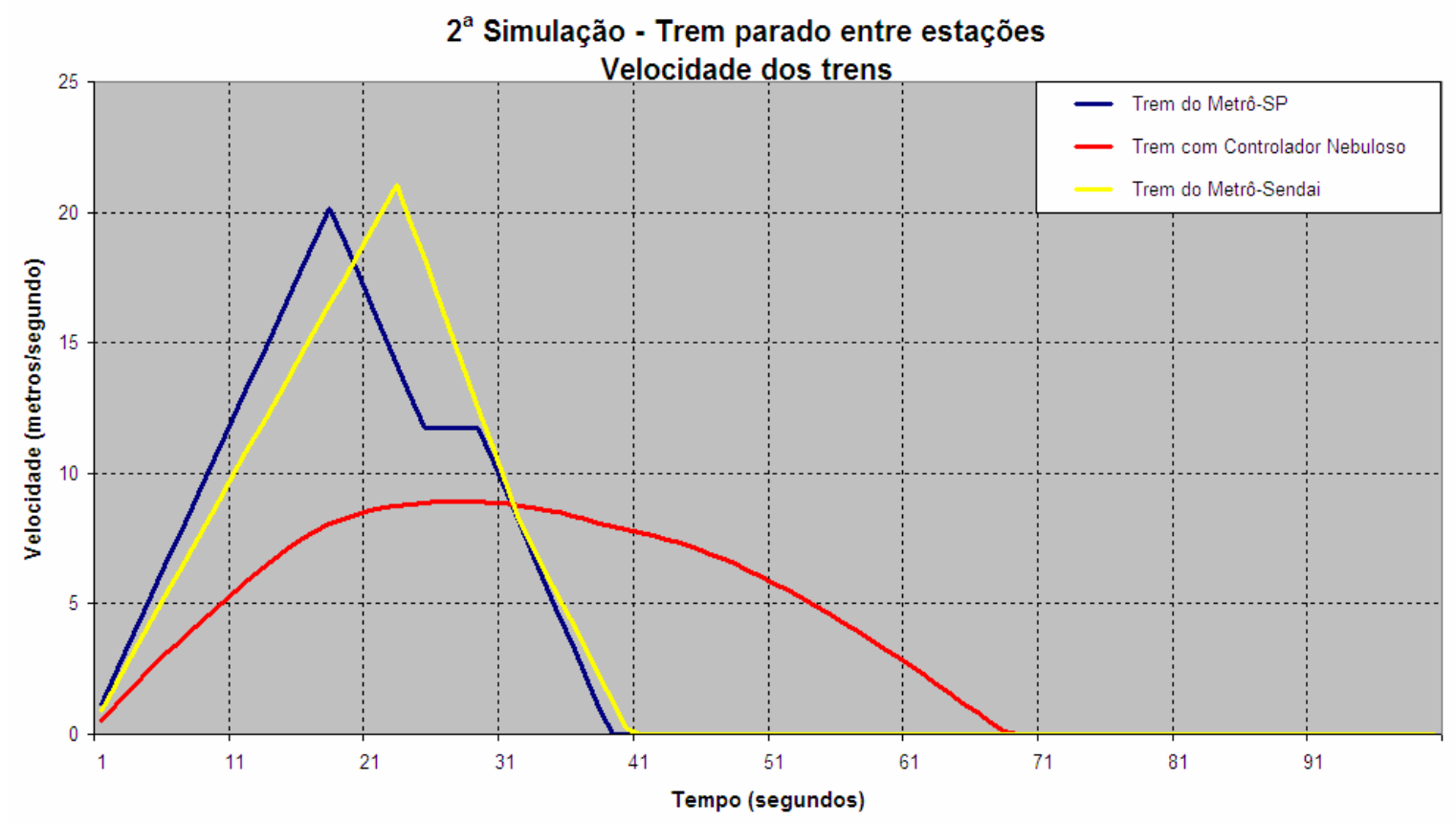

Figura 60. Gráfico das velocidades dos trens para a $2^{\mathrm{a}}$ Simulação. 
Analisando o comportamento das curvas de velocidades dos trens em função do tempo apresentadas na Figura 60, pode-se perceber que:

- O trem do metrô de São Paulo inicia sua movimentação com a taxa máxima de aceleração $\left(1,12 \mathrm{~m} / \mathrm{s}^{2}\right)$ para atingir a velocidade determinada pelo circuito de via número 1 $(75 \mathrm{~km} / \mathrm{h}=20,83 \mathrm{~m} / \mathrm{s})$. Quando o trem adentra o circuito de via número 2, o limite de velocidade que era de $87 \mathrm{~km} / \mathrm{h}(24,17 \mathrm{~m} / \mathrm{s})$ é alterado para $44 \mathrm{~km} / \mathrm{h}(12,22 \mathrm{~m} / \mathrm{s})$ devido à "sombra" do trem que está parado no circuito de via número 4 (4 $4^{\mathrm{a}}$ linha do perfil de ocupações mostrado na Figura 56). Neste ponto, o trem está com uma velocidade acima da comandada e o equipamento de bordo faz o trem frear até que a velocidade do trem fique abaixo deste limite. Ao adentrar o circuito de via número 3 o novo limite de velocidade comandado para o trem é de $0 \mathrm{~km} / \mathrm{h}$, conforme o perfil de ocupações do trem extra que está parado no circuito de via número 4, forçando o controlador a frear o trem até sua parada total antes de alcançar o trem que está parado no circuito de via número 4.

- O trem do metrô de Sendai inicia seu movimento, acelerando com a taxa máxima de aceleração $\left(0,916 \mathrm{~m} / \mathrm{s}^{2}\right)$, porém com uma supervisão constante da capacidade de frenagem do trem. Esta supervisão consiste no cálculo do overlap do trem (distância necessária para o trem parar totalmente a partir da velocidade atual) somado a uma margem de segurança, normalmente definida como o comprimento de um trem. Além disso, o cálculo do overlap é efetuado utilizando a taxa mínima de frenagem de serviço, de forma a fornecer uma margem de segurança adicional se for necessário aplicar os freios a uma taxa maior ou os freios de emergência para efetuar a parada do trem. Ao adentrar na região de overlap, o freio mínimo é aplicado até a parada total do trem, dentro da margem de segurança prevista no projeto do controlador; e

- O trem com controlador nebuloso avalia a distância entre a plataforma da estação e o trem parado no circuito de via número 4 e efetua a movimentação do trem baseado nas informações a respeito desta distância $(492,5 \mathrm{~m})$ e da velocidade real do trem $(0 \mathrm{~km} / \mathrm{h})$. O trem com controlador nebuloso inicia o seu movimento com a taxa máxima de aceleração, que vai diminuindo gradualmente até atingir cerca de metade da distância a ser percorrida. Neste ponto, o trem inicia o processo de frenagem, diminuindo gradativamente sua aceleração até a parada total do trem antes do trem parado no circuito de via número 4. 
O tempo até a parada total do trem com controlador nebuloso (68 segundos) é bem maior do que o tempo até a parada total dos trens dos metrôs de São Paulo e de Sendai (38 e 40 segundos, respectivamente). Isto é devido ao fato de que o controlador nebuloso desenvolve uma velocidade máxima de percurso bem menor $(30 \mathrm{~km} / \mathrm{h}=8,33 \mathrm{~m} / \mathrm{s})$ do que os metrôs de Sendai e de São Paulo $(75 \mathrm{~km} / \mathrm{h}=20,83 \mathrm{~m} / \mathrm{s})$. Além disso, a taxa de frenagem utilizada pelo controlador nebuloso é bem inferior $\left(<0,5 \mathrm{~m} / \mathrm{s}^{2}\right)$ do que as taxas dos trens do metrô de São Paulo $\left(1,2 \mathrm{~m} / \mathrm{s}^{2}\right)$ e do metrô de Sendai $\left(1 \mathrm{~m} / \mathrm{s}^{2}\right)$.

A Figura 61 mostra a aceleração dos trens ao longo do tempo de percurso entre a plataforma da estação e o trem extra parado no circuito de via número 4, enquanto a Figura 62 mostra a distribuição espacial dos trens nesta configuração.

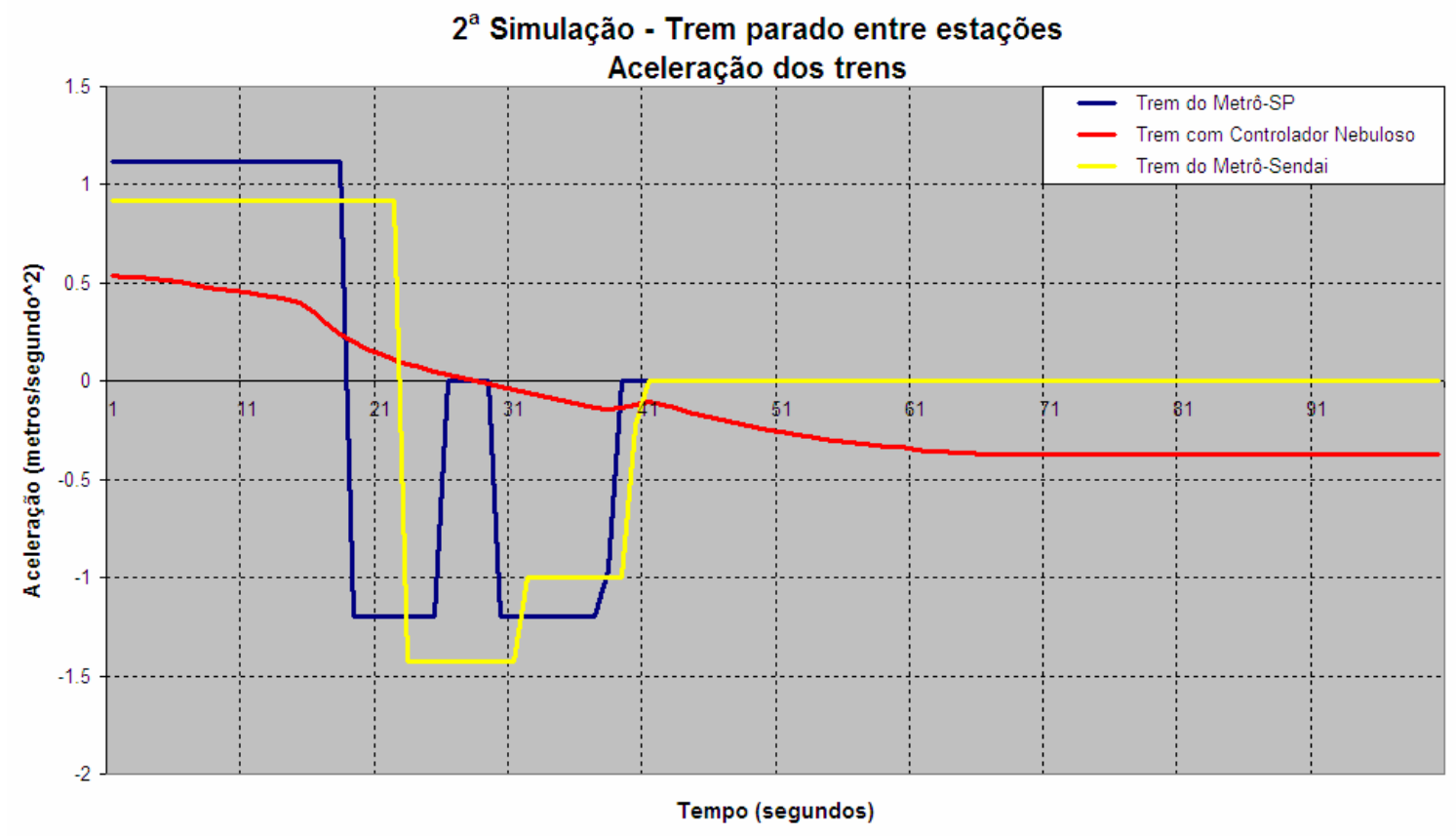

Figura 61. Gráfico das acelerações dos trens para a $2^{\mathrm{a}}$ Simulação.

Observando os gráficos mostrados na Figura 62, pode-se verificar que o ponto de parada para os trens do metrô de São Paulo e do metrô com o controlador nebuloso proposto está em 398 m, indicando uma distância de pelo menos $94,5 \mathrm{~m}$ ao trem extra parado no circuito de via número 4. 


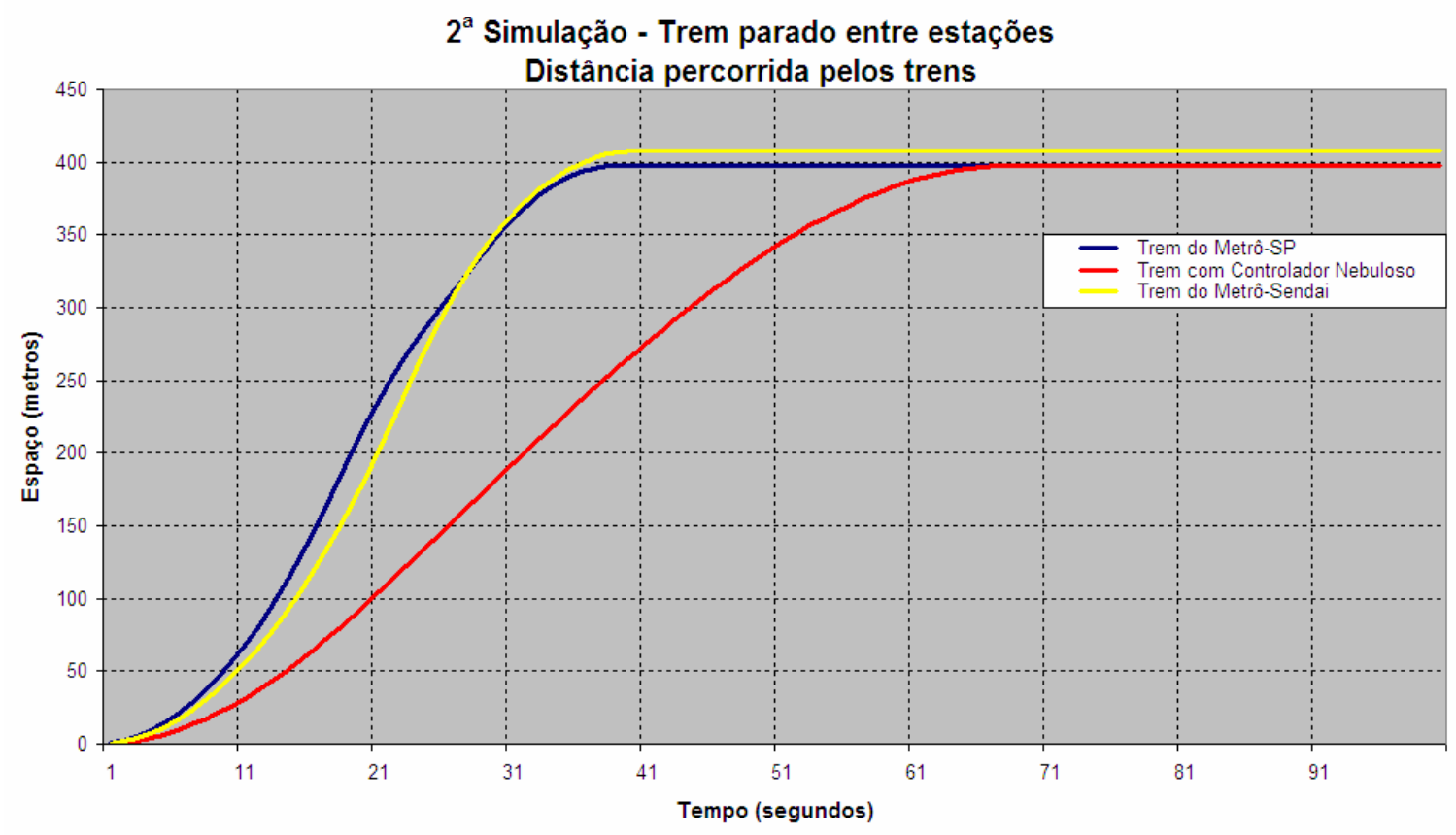

Figura 62. Gráfico da distribuição espacial dos trens na $2^{\mathrm{a}}$ Simulação.

Para o metrô de São Paulo, esta distância representa o comprimento do circuito de via número 3 subtraído da distância de overlap do trem que vem atrás, considerando a velocidade com que este trem adentrou o circuito de via número 3.

Para o metrô com controlador nebuloso, este valor de distância entre os trens pode ser controlado, pois este valor é uma variável de entrada do sistema. Assim, esta distância pode ser regulada de forma a permitir o novo controle do headway do sistema.

Para o metrô de Sendai, o ponto de parada foi em 408 m, indicando uma distância de $84,5 \mathrm{~m}$ (aproximadamente igual ao comprimento do trem) ao trem parado no circuito de via número 4.

Se, nesta simulação, a posição inicial do trem parado fosse movida do circuito de via número 4 para outros circuitos de via, o que se observaria seria apenas a variação do perfil de velocidades de ocupação. Para os trens dos metrôs de São Paulo e de Sendai há apenas a variação do limite de velocidade comandada, podendo o código ser limitado em função da proximidade do trem da frente.

O Apêndice C (Figura 75a) apresenta os resultados de medições reais efetuadas em um trem do metrô de São Paulo para esta $2^{\mathrm{a}}$ simulação, que podem servir de parâmetros para comparação dos resultados obtidos. 


\subsection{Circulação de Trens com a Presença de um Trem Extra Movendo-se com Velocidade Constante entre Duas Estações (Manutenção do Sistema)}

Outro cenário escolhido para a simulação é a circulação de trens com a presença de um trem em movimento com velocidade constante no percurso entre estações. A diferença entre este cenário e o cenário da simulação anterior é que as regiões de ocupação e de "sombra" do trem que se move com velocidade uniforme entre as estações variam ao longo do tempo. Este cenário ocorre quando um trem apresenta uma falha no equipamento de bordo e precisa ser conduzido na modalidade manual ou quando está sendo rebocado para o pátio de manutenção.

Nesta simulação, existe um trem extra entre as estações, movendo-se com uma velocidade constante de $30 \mathrm{~km} / \mathrm{h}(8,33 \mathrm{~m} / \mathrm{s})$, que é a velocidade limite permitida para a movimentação dos trens no modo manual. Para permitir uma comparação com o cenário da simulação anterior, supõe-se que, inicialmente, o trem esteja ocupando o circuito de via número 4, mas movendo-se em direção à plataforma de ARV. Como o trem possui cerca de 120 metros de comprimento, em um circuito de via de cerca de 160 metros, ele inicia o seu movimento praticamente ocupando também o próximo circuito de via (número 5 da Figura 56). A Figura 63 apresenta o gráfico das velocidades dos trens ao longo do tempo de percurso entre as duas estações.

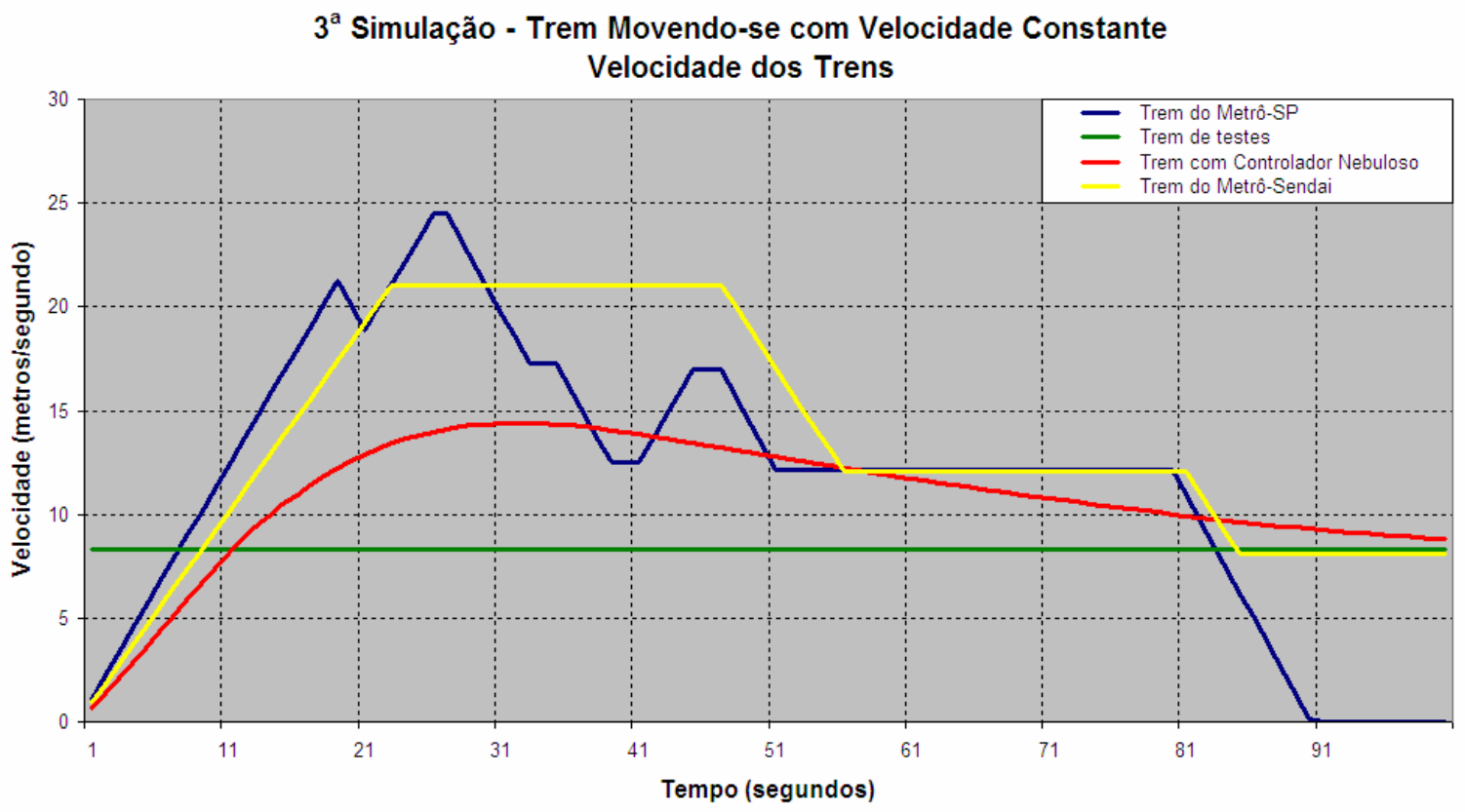

Figura 63. Gráfico das velocidades dos trens para a $3^{\text {a }}$ Simulação. 
Analisando o comportamento das curvas de velocidades dos trens em função do tempo apresentadas na Figura 63, pode-se perceber que:

- O trem do metrô de São Paulo inicia sua movimentação com uma taxa máxima de aceleração até atingir o limite de velocidade do circuito de via número $1(75 \mathrm{~km} / \mathrm{h}=20,83$ $\mathrm{m} / \mathrm{s})$. No circuito de via número 2 , a velocidade comandada é maior $(87 \mathrm{~km} / \mathrm{h}=24,17$ $\mathrm{m} / \mathrm{s}$ ) e o trem continua a acelerar com a taxa máxima de aceleração. Ao adentrar o circuito de via número 3, o trem recebe o código de $62 \mathrm{~km} / \mathrm{h}(17,22 \mathrm{~m} / \mathrm{s})$, referente à sombra, ou rastro do trem da frente que, neste instante, está ocupando o circuito de via número 6 . O controlador faz o trem frear com a taxa máxima de freio de serviço $\left(-1,2 \mathrm{~m} / \mathrm{s}^{2}\right)$ mas, $\operatorname{logo}$ em seguida, o trem da frente deixa de ocupar o circuito de via número 6 , liberando o código do circuito 3 para o código do perfil sem ocupação $(87 \mathrm{~km} / \mathrm{h}=24,17 \mathrm{~m} / \mathrm{s})$, o que faz com que o trem de trás volte a acelerar com a taxa máxima, buscando o novo código comandado. O mesmo processo ocorre no circuito de via 4 onde, novamente, o trem recebe o código de $62 \mathrm{~km} / \mathrm{h}(17,22 \mathrm{~m} / \mathrm{s})$ relativo à sombra do trem da frente. Este processo de variação de velocidade é denominado "batida de ATP", por causa da interferência causada pelo equipamento de proteção do trem (ATP) na velocidade real do trem. A batida de ATP volta a acontecer no circuito de via número 5, quando o trem recebe uma variação de códigos de velocidade relativa ao rastro do trem da frente;

- O trem do metrô de Sendai efetua sua movimentação de maneira semelhante à situação de não ocupação do trecho e só vai perceber a influência do trem seguinte no final da região de $\operatorname{CSC}\left(2^{a}\right.$. descida da curva), onde efetua uma frenagem com freio mínimo de serviço, de forma a manter uma distância segura do trem à frente e acompanhar o seu movimento. Se fosse necessário efetuar uma parada programada na estação, o trem do metrô de Sendai não perceberia a influência do trem da frente; e

- O trem com controlador nebuloso efetua uma avaliação da distância a ser percorrida (que agora é variável e vai de sua posição atual até o começo do trem seguinte) e da velocidade real do trem. A distância ao trem da frente é calculada utilizando-se a região de overlap (espaço para frear o trem, de acordo com sua velocidade) e mais uma margem de segurança (normalmente utiliza-se o comprimento do trem como margem de segurança). A tendência do controlador nebuloso é fazer com que o movimento do trem acompanhe o movimento do trem da frente e a velocidade do trem tenda ao valor da velocidade do trem da frente. Se não houvesse a parada na plataforma de ARV, o trem tenderia a acompanhar o movimento do trem da frente com velocidade constante. 
O único trem que não tende a acompanhar o movimento do trem da frente é o trem do metrô de São Paulo. Isto acontece porque sempre existe um circuito de via com código de velocidade igual a zero entre os dois trens, fazendo com que o trem pare dentro deste circuito de via e não acompanhe o movimento do trem à frente. Quando o trem sai da "sombra" ou "rastro" do trem anterior, o código de via é novamente liberado para o código relativo ao perfil do trecho sem ocupação. Pode ser constatado que, quanto mais próximos os trens estiverem entre si, ocorrerá um maior número de "batidas de ATP".

A Figura 64 mostra a aceleração dos trens ao longo do tempo de percurso entre as duas estações. A aceleração do trem interferente não foi representada, pois é igual a zero.

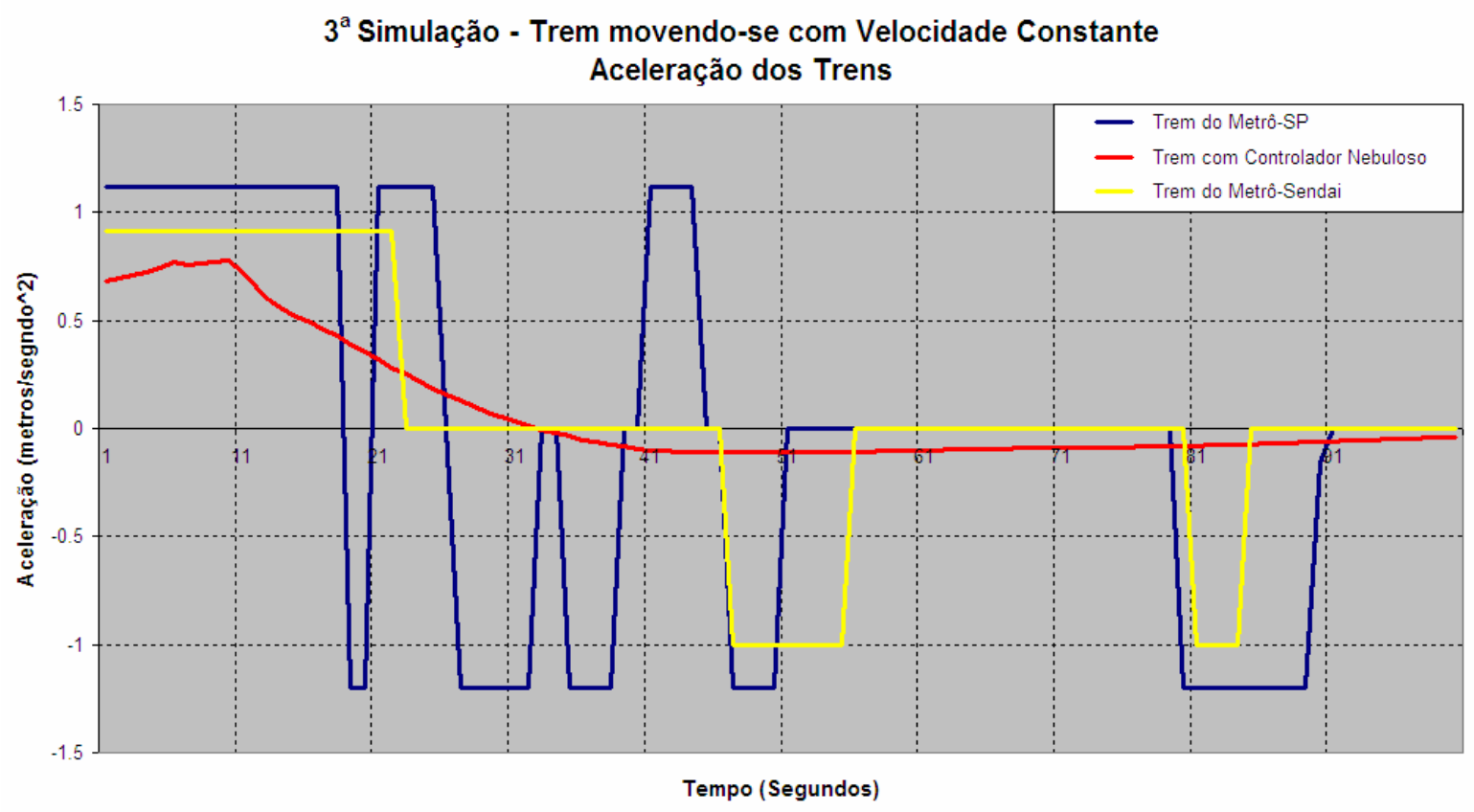

Figura 64. Gráfico das acelerações dos trens para a $3^{\text {a }}$ Simulação.

A "batida de ATP" é uma conseqüência da segurança do sistema, com a existência do "rastro" do trem da frente. Porém, é uma característica indesejável para o desempenho do sistema, pois provoca frenagens e acelerações que, se pudessem ser previstas, poderiam ser evitadas.

Em termos de consumo, esta também é uma característica indesejável, pois ocorrem acelerações e frenagens adicionais, que provocam um consumo adicional de corrente dos motores de tração e um desgaste maior de pastilhas de freio. Em termos de conforto, as "batidas de ATP" provocam trancos aos passageiros, diminuindo relativamente a sensação de conforto a bordo. Em termos de manutenção do sistema, a vida útil do sistema é diminuída, em virtude do aumento do número de acionamentos dos contatores de propulsão e frenagem. 
Nesta simulação, por exemplo, ocorreram três transições de propulsão para freio e duas transições de freio para propulsão. Em cada uma destas transições, a configuração dos motores deve ser alterada de propulsão para freio ou vice-versa, provocando o acionamento excessivo dos contatores que efetuam esta configuração, o que causa um desgaste maior e uma diminuição na vida útil destes componentes.

Para evitar as "batidas de ATP”, quando ocorre uma situação de ocupação entre duas estações, o controlador central transmite um código de ND (nível de desempenho) diferente de $\mathrm{ND}=1$ (máximo), de forma a limitar a velocidade e/ou a aceleração do trem naquele trecho. Assim, ao adentrar a "sombra" do trem da frente, o trem não estará com uma velocidade muito superior à velocidade comandada, limitada pelos circuitos de via em virtude da proximidade do trem da frente.

O trem do metrô de Sendai não apresenta a característica de batida de ATP. Isto ocorre porque o sistema de blocos móveis faz com que o controlador trabalhe com a distância de overlap (também denominado distance to go) como característica de segurança para evitar colisão com o trem da frente. Com isto, o ATP somente atuaria no caso da distância de overlap ser ultrapassada (da mesma forma que o trem do metrô de São Paulo ao adentrar um circuito de via com código de velocidade mais restritivo).

Outra característica que pode ser observada na Figura 64 é o baixo nível de esforço de frenagem utilizado pelo controlador nebuloso. Isto é devido ao fato que o controlador nebuloso não busca a parada do trem, mas busca manter o trem com velocidade constante, de forma a acompanhar o movimento do trem da frente. Para manter o trem a uma velocidade constante dentro do limite desejado é necessário um pequeno esforço de frenagem.

Existe uma diferença entre as acelerações aplicadas nos controladores, que se reflete em termos de desempenho e consumo entre os trens. Como desenvolve uma velocidade máxima menor, o controlador nebuloso apresenta um desempenho inferior aos controladores dos metrôs de São Paulo e de Sendai em termos de tempo de percurso entre as estações.

A Figura 65 mostra a distância percorrida pelos trens ao longo do tempo. 


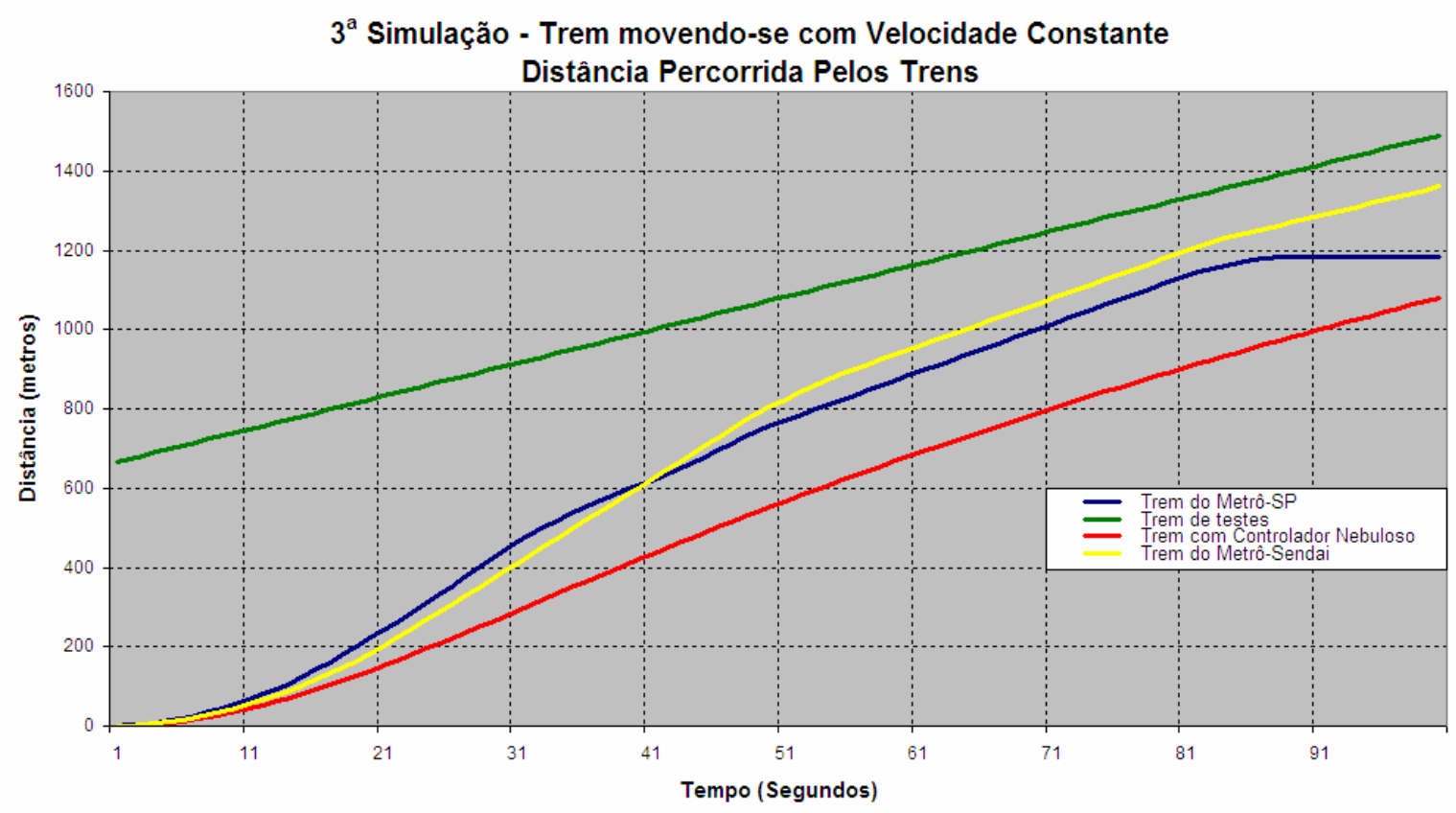

Figura 65. Gráfico da distribuição espacial dos trens na $3^{\text {a }}$ Simulação.

Observando a Figura 65, pode-se verificar que há uma diferença entre as curvas de Distância x Tempo para todos os controladores. A variação espacial para o controlador nebuloso ocorre de maneira mais gradual e linear do que os controladores dos trens do metrô de São Paulo e do metrô de Sendai. Por outro lado, os trens do metrô de Sendai e com o controlador nebuloso tendem a acompanhar o movimento do trem da frente. Nesta simulação o processo de parada programada da estação ARV foi desconsiderado.

O controlador nebuloso e o controlador dos trens do metrô de Sendai utilizam a distância a ser percorrida como parâmetro de avaliação e, por isso, tendem a fazer o trem acompanhar o movimento do trem que está à frente. A distância relativa entre trens é um parâmetro de entrada do sistema fornecido pelo sistema de controle central (ATS).

Regulando-se a distância entre trens, pode-se ajustar o quanto os trens podem se aproximar uns dos outros e, por conseqüência, pode-se controlar o headway do sistema de maneira mais eficiente.

Já para o trem do metrô de São Paulo, o controlador obedece aos limites de velocidade comandados pelos circuitos de via e o trem de trás não se aproxima do trem da frente de maneira uniforme, mantendo uma distância estabelecida pelo limite de velocidade de $0 \mathrm{~km} / \mathrm{h}$ transmitido pelo circuito de via anterior ao trecho ocupado. 
Somente quando o trem da frente passar a ocupar o circuito de via seguinte é que o trecho é liberado, permitindo ao trem de trás que desenvolva uma velocidade limitada pelo código transmitido na "sombra" do trem da frente.

Para esta simulação e para efeitos de comparação foi considerado que o trem da frente estaria inicialmente parado no circuito de via número 4 da Figura 56 e iniciasse o seu movimento simultaneamente com a partida do trem da plataforma da estação Santa Cruz (SCZ). Isto foi feito para escolher uma interferência intermediária da movimentação do trem da frente na movimentação do trem sob análise.

Se fosse escolhido outro circuito de via como ponto de partida para o trem da frente, os resultados obtidos seriam os mesmos, com uma maior interferência da presença do trem da frente no movimento dos trens para circuitos de via anteriores ao escolhido (circuitos de via 1, 2 ou 3) e uma menor interferência para circuitos de via posteriores ao escolhido (circuitos de via 5, 6 ou 7), chegando ao limite de reprodução da primeira simulação se o circuito de via escolhido como ponto de partida fosse o circuito de via número 8 (plataforma da estação Praça da Árvore).

No caso do trem do metrô de São Paulo, quanto maior for a interferência causada pelo trem da frente na movimentação do trem de trás, maior será o número de "batidas de ATP" causadas pelo "rastro" do trem da frente.

No caso do trem do metrô de Sendai, quanto maior for a interferência causada pelo trem da frente na movimentação do trem de trás, menor será a velocidade máxima desenvolvida no trecho e o trem de trás terá a tendência antecipada de acompanhamento do movimento do trem da frente.

No caso do trem com controlador nebuloso, a variação do circuito de via iria influir no valor de velocidade máxima desenvolvida no trecho entre a plataforma da estação $\mathrm{SCZ}$ e o trem da frente e no tempo que o trem considerado levaria para atingir a velocidade do trem da frente.

O Apêndice C (Figura 75b) deste trabalho apresenta os resultados gráficos de medições de velocidade e aceleração efetuadas em um trem do metrô de São Paulo para esta $3^{\mathrm{a}}$ simulação e podem ser utilizados como parâmetro de comparação dos resultados obtidos. 


\subsection{Circulação de Trens com a Presença de um Trem Extra Movendo-se com Velocidade de Via entre Duas Estações (Adensamento de Trens)}

A próxima simulação consiste na circulação de trens com a presença de um trem se movendo com velocidade normal de via entre as duas estações. Foram consideradas duas possibilidades na realização desta simulação: a primeira, na qual o trem da frente se move utilizando um controlador PID semelhante ao utilizado nos trens do metrô de São Paulo e, a segunda, na qual o trem da frente se move utilizando o controlador nebuloso (fuzzy) proposto. Deve ser observado que não há a possibilidade de que os dois sistemas (PID e fuzzy) estejam operacionais de forma simultânea; porém, estas situações foram simuladas apenas para se obter parâmetros de comparação entre os dois sistemas.

A diferença entre este cenário e o cenário da simulação anterior é que as regiões de ocupação e de sombra do trem da frente, que se move com velocidade normal de via entre as estações, também variam ao longo do tempo, porém não de maneira uniforme.

As Figuras 66 e 67 apresentam os gráficos das velocidades dos trens ao longo do tempo de percurso entre as duas estações, sendo que a Figura 66 representa o trem da frente com controlador PID e a Figura 67 representa o trem da frente com controlador nebuloso.

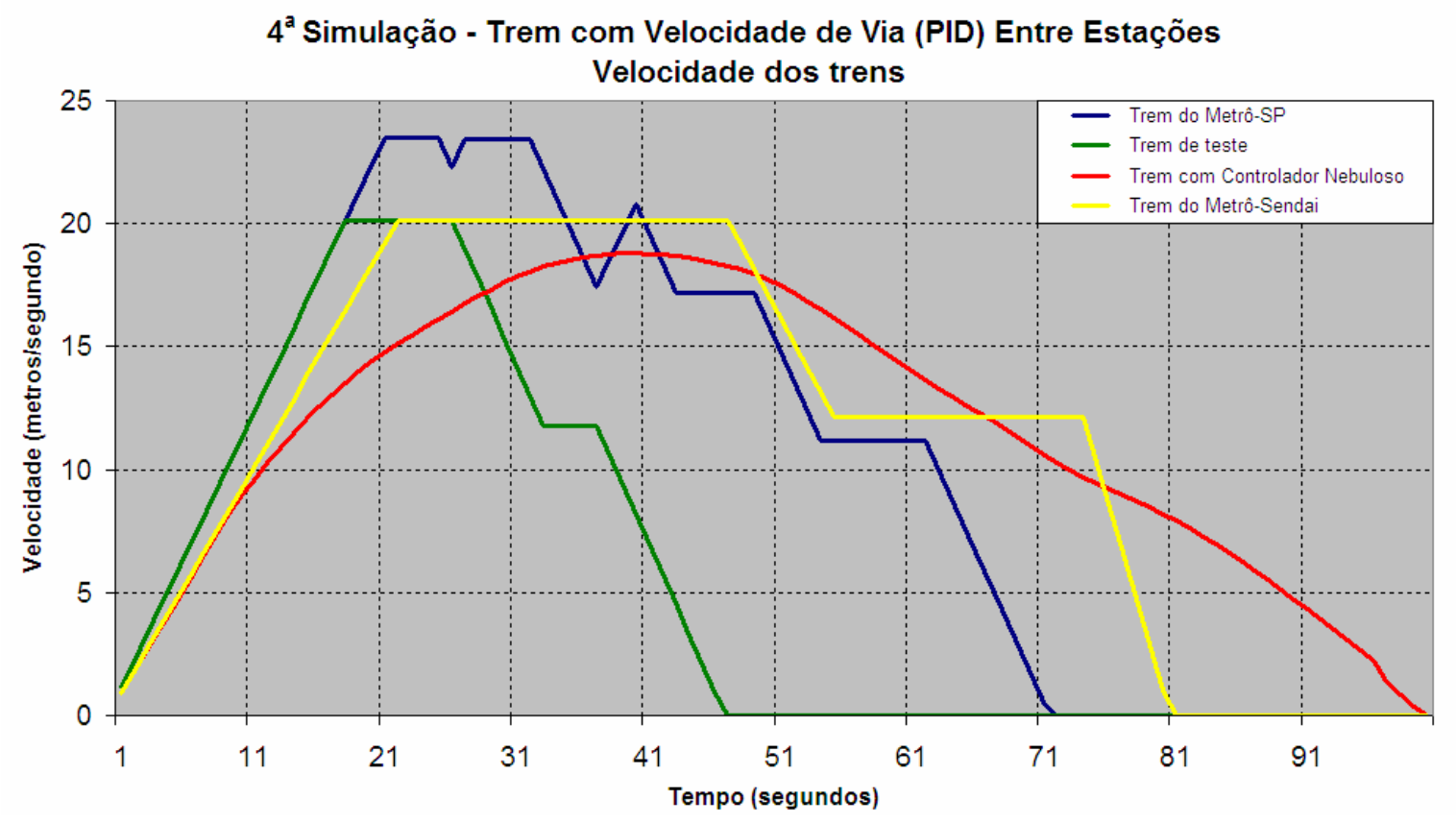

Figura 66. Gráfico das velocidades dos trens para a $4^{\text {a }}$ Simulação com o trem da frente utilizando controlador PID. 


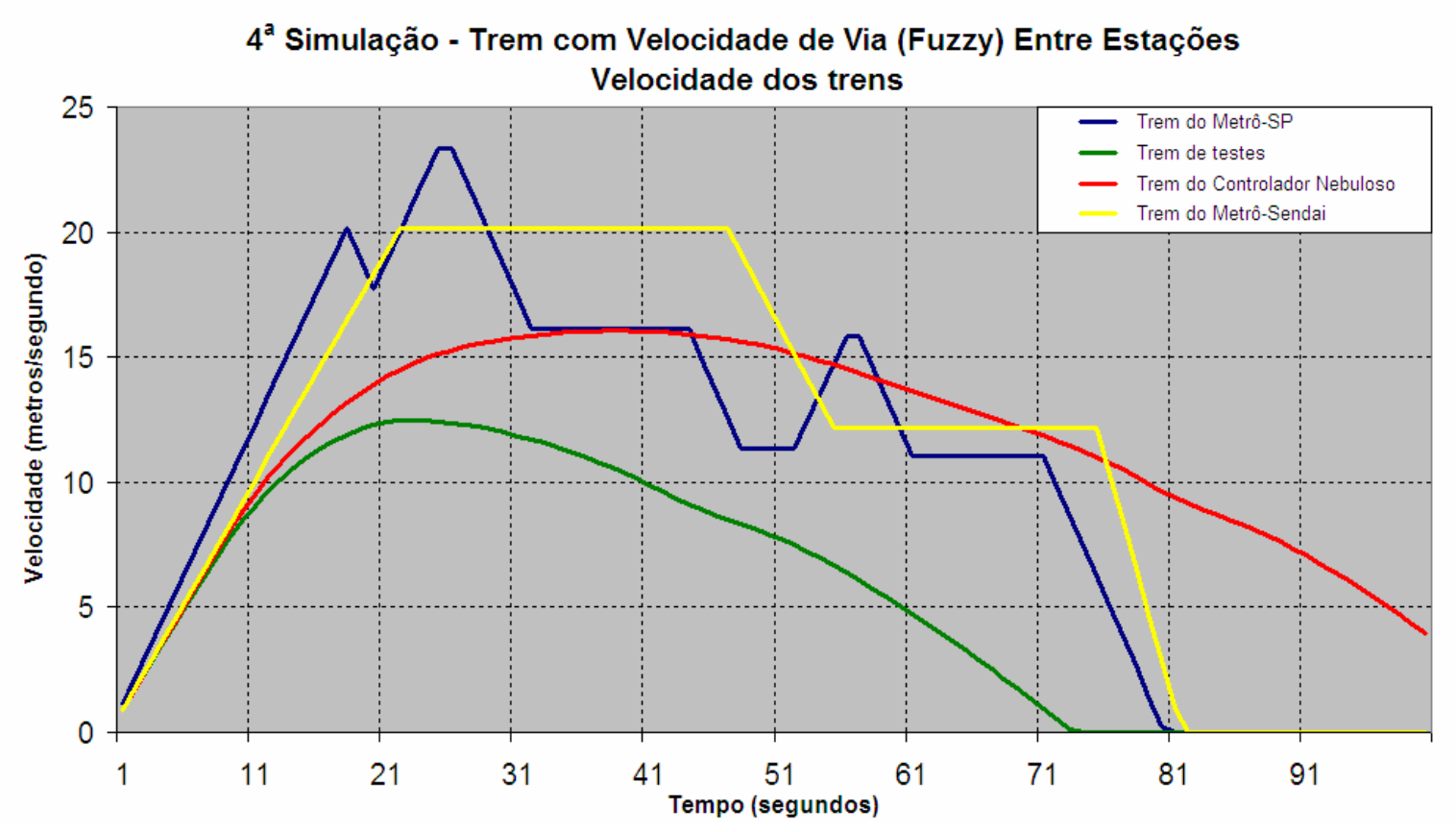

Figura 67. Gráfico das velocidades dos trens para a $4^{\text {a }}$ Simulação com o trem da frente utilizando controlador nebuloso.

Analisando o comportamento das curvas de velocidades dos trens em função do tempo apresentadas nas Figuras 66 e 67, pode-se perceber que:

- O trem do metrô de São Paulo apresentou um desempenho inferior ao desempenho apresentado na primeira simulação (circulação normal de trens). Isto é devido à influência causada pela sombra do trem da frente, que ocasionou uma diminuição da velocidade média desenvolvida pelo trem no trecho entre as estações. Pode-se observar que o número de batidas de ATP aumentou com a utilização do controlador nebuloso para o trem da frente, o que faz com que o trem da frente se desloque com uma velocidade menor e exerça maior interferência na movimentação do trem de trás, em virtude da existência do rastro do trem da frente;

- O trem do metrô de Sendai apresentou o mesmo desempenho da primeira simulação, não sofrendo nenhuma interferência em sua movimentação por parte do trem da frente, qualquer que seja o controlador utilizado. Isto é uma característica de operação do sistema de blocos móveis, onde não ocorrem interferências se não forem violadas as distâncias de overlap entre os trens; e 
- O trem com controlador nebuloso apresentou desempenhos variáveis para cada uma das situações operacionais simuladas, sendo o melhor desempenho o apresentado na primeira simulação (sem interferências) e o pior desempenho para o trem da frente com o controlador nebuloso.

As Figuras 68 e 69 apresentam os gráficos das acelerações dos trens ao longo do tempo de percurso entre as duas estações, sendo que a Figura 68 representa o trem da frente com controlador PID e a Figura 69 representa o trem da frente com controlador nebuloso (fuzzy).

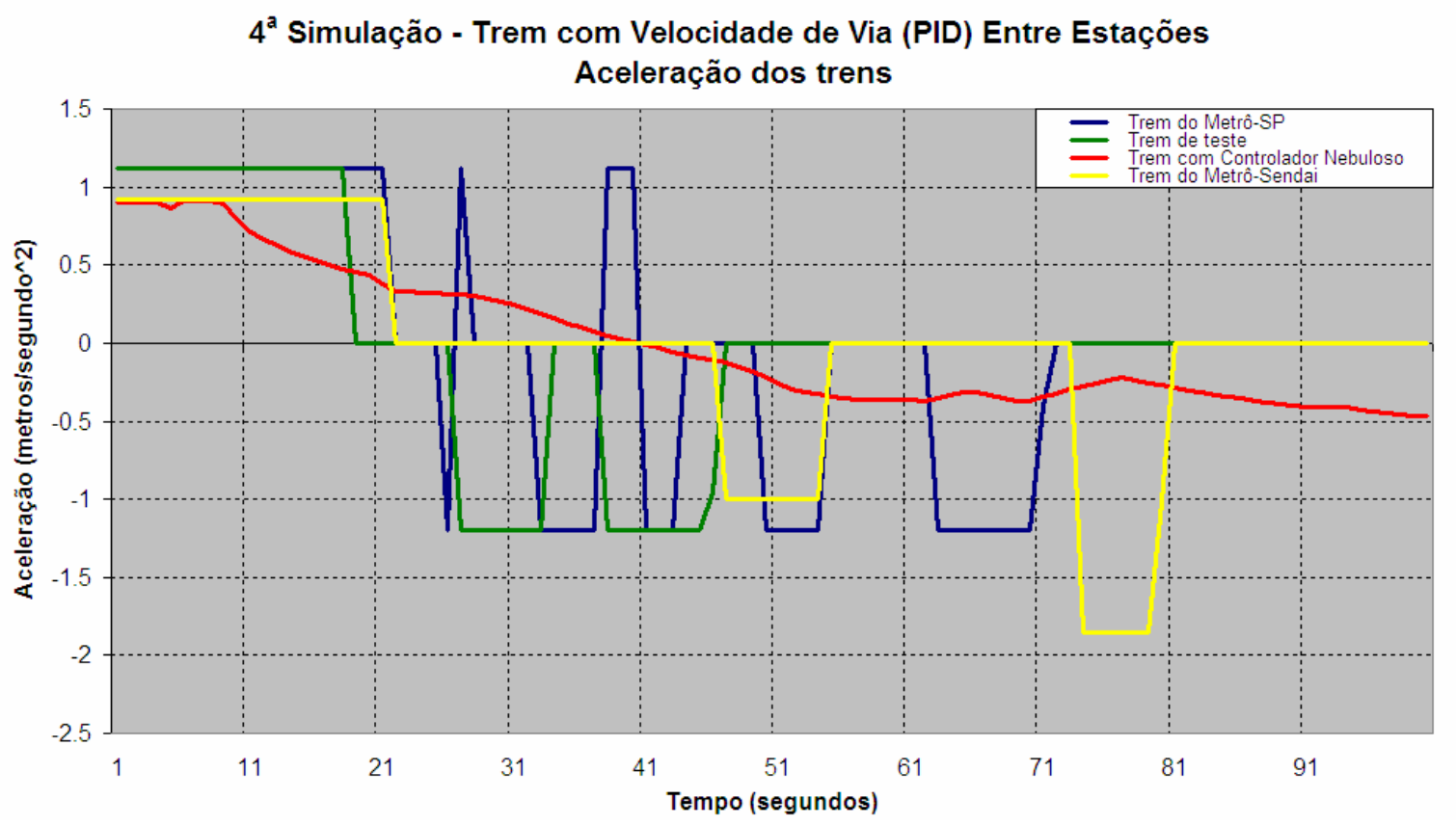

Figura 68. Gráfico das acelerações dos trens para a $4^{\text {a }}$ Simulação com 0 trem da frente utilizando controlador PID.

Observando as Figuras 68 e 69 pode-se verificar que as curvas de Aceleração x Tempo apresentadas pelos controladores é muito semelhante às apresentadas na primeira simulação. A única diferença foi verificada na curva do trem do metrô de São Paulo, que apresentou um número maior de transições entre propulsão e freio do que a curva apresentada na primeira simulação. Isto ocorreu devido às "batidas de ATP" apresentadas, que levou às transições adicionais entre propulsão e freio apresentadas.

Analisando todas as curvas de Aceleração x Tempo apresentadas para as simulações, pode-se verificar que quanto mais os trens se aproximam uns dos outros para os trens do metrô de São Paulo, maior é o número de "batidas de ATP” e maior é o número de transições que ocorrem entre propulsão e freio. 
Com isto, o consumo de energia do controlador de trens do metrô de São Paulo é maior que o consumo de energia do controlador nebuloso, em virtude dos acionamentos adicionais de propulsão e freio proporcionados pelas "batidas de ATP".

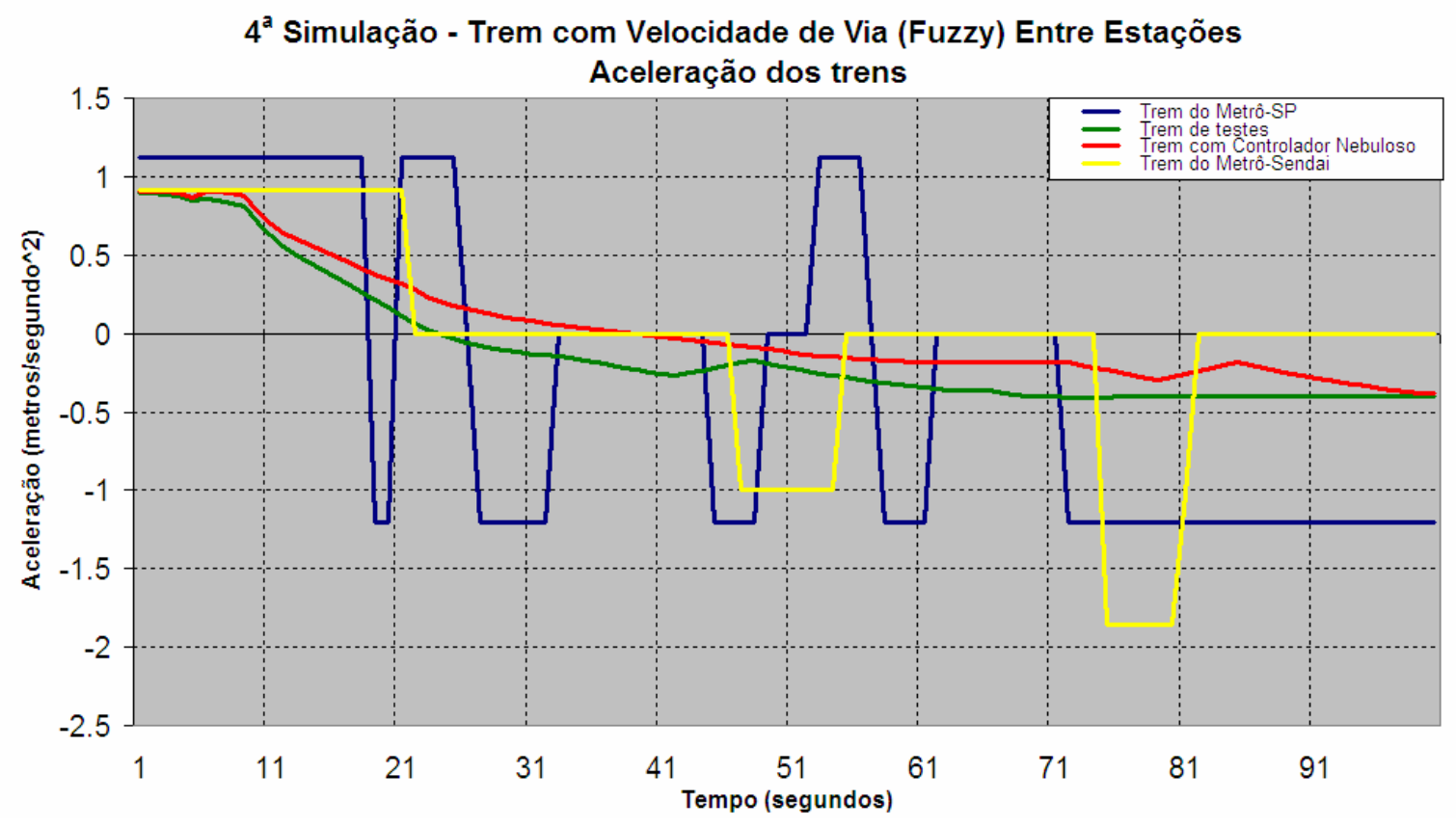

Figura 69. Gráfico das acelerações dos trens para a $4^{\text {a }}$ Simulação com o trem da frente utilizando controlador nebuloso.

As Figuras 70 e 71 mostram a distribuição espacial dos trens ao longo do tempo.

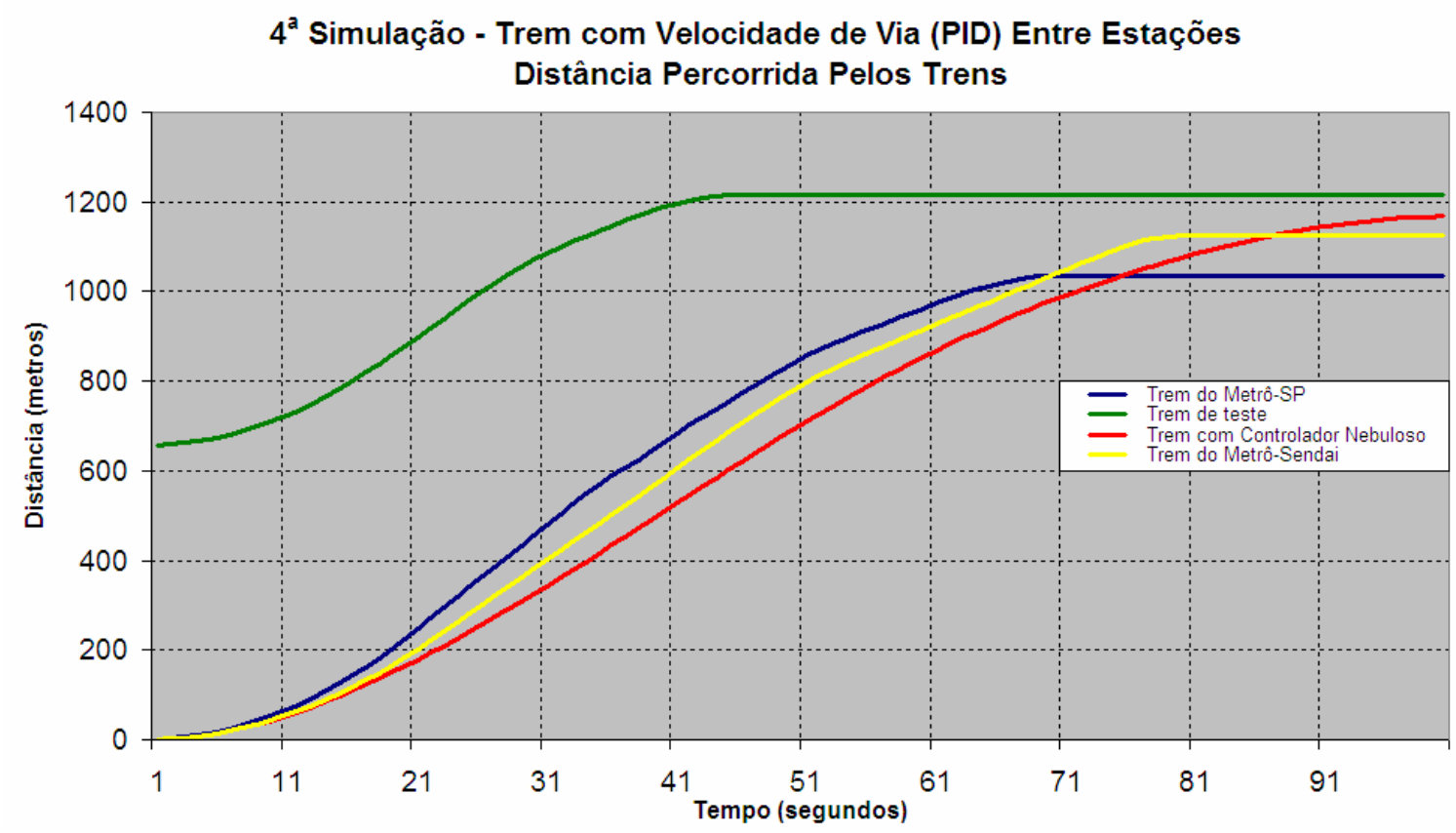

Figura 70. Gráfico da distribuição espacial dos trens na $4^{\mathrm{a}}$ Simulação. 


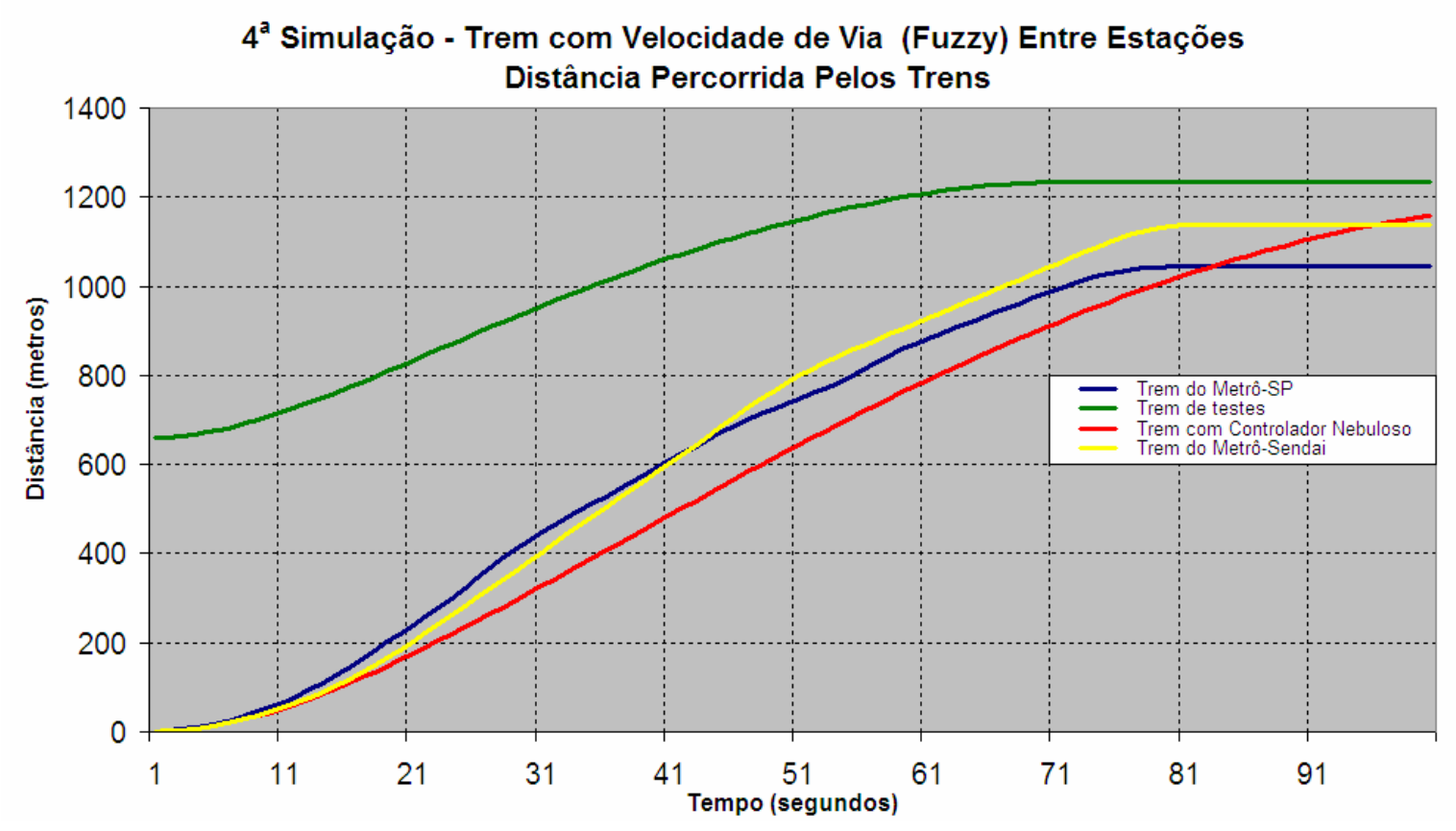

Figura 71. Gráfico da distribuição espacial dos trens na $4^{\mathrm{a}}$ Simulação.

Observando as Figuras 70 e 71, pode-se verificar que o trem utilizando controlador nebuloso se aproxima mais do trem da frente. Esta distância pode ser o novo parâmetro de ajuste de headway para o sistema, regulando o intervalo médio entre trens do sistema pelo ajuste direto de espaçamento entre trens, e não indiretamente, pelo ajuste do tempo de percurso entre duas estações, como é feito para os trens do metrô de São Paulo.

O Apêndice C (Figura 75c) deste trabalho apresenta os resultados de medições reais de velocidade e aceleração efetuadas em um trem do metrô de São Paulo para esta $4^{\mathrm{a}}$ simulação e podem servir de parâmetros de comparação com os dados obtidos. 


\subsection{Outras Simulações Efetuadas}

Para se determinar outros parâmetros que pudessem influenciar no desempenho dos controladores de trens apresentados, outras simulações foram efetuadas. Estas simulações foram feitas variando-se alguns fatores a partir da configuração original de simulações prevista na primeira simulação efetuada (vide item 7.2).

Em uma destas simulações, a distância entre estações foi variada e dois outros trechos foram selecionados: o primeiro trecho escolhido foi o trecho entre as estações Carrão e Penha da Linha 3 - Vermelha. Este trecho foi escolhido por ser o trecho mais longo entre duas estações consecutivas das linhas do Metrô de São Paulo, com 2304 metros de extensão. O segundo trecho escolhido foi entre as estações Liberdade e Sé da Linha 1 - Azul, escolhido por ser o menor trecho entre estações, com 550 metros de extensão.

Os resultados das simulações efetuadas não trouxeram informações adicionais e, portanto, os seus resultados não foram reproduzidos aqui. A simulação para o segundo trecho escolhido apresentou resultados muito similares aos resultados da segunda simulação efetuada, com um trem extra parado entre duas estações, pois é como se existissem duas estações muito próximas uma da outra (vide item 7.3).

Uma outra simulação efetuada consistiu na variação dos índices de desempenho nas execuções das corridas efetuadas na primeira simulação. A Figura 72 mostra as curvas para cada um dos níveis de desempenho simulados $(\mathrm{ND}=1$ até 6 , sendo que $\mathrm{ND}=1$ é o melhor desempenho e $\mathrm{ND}=6$ é o desempenho mais degradado), em comparação aos resultados apresentados pelo controlador nebuloso durante a primeira simulação.

O Apêndice C (Figuras 76 e 77) apresenta os resultados de medições reais de velocidade e aceleração efetuadas em um trem do metrô de São Paulo para os diferentes NDs e podem servir de parâmetros de comparação com os gráficos apresentados na Figura 72. 


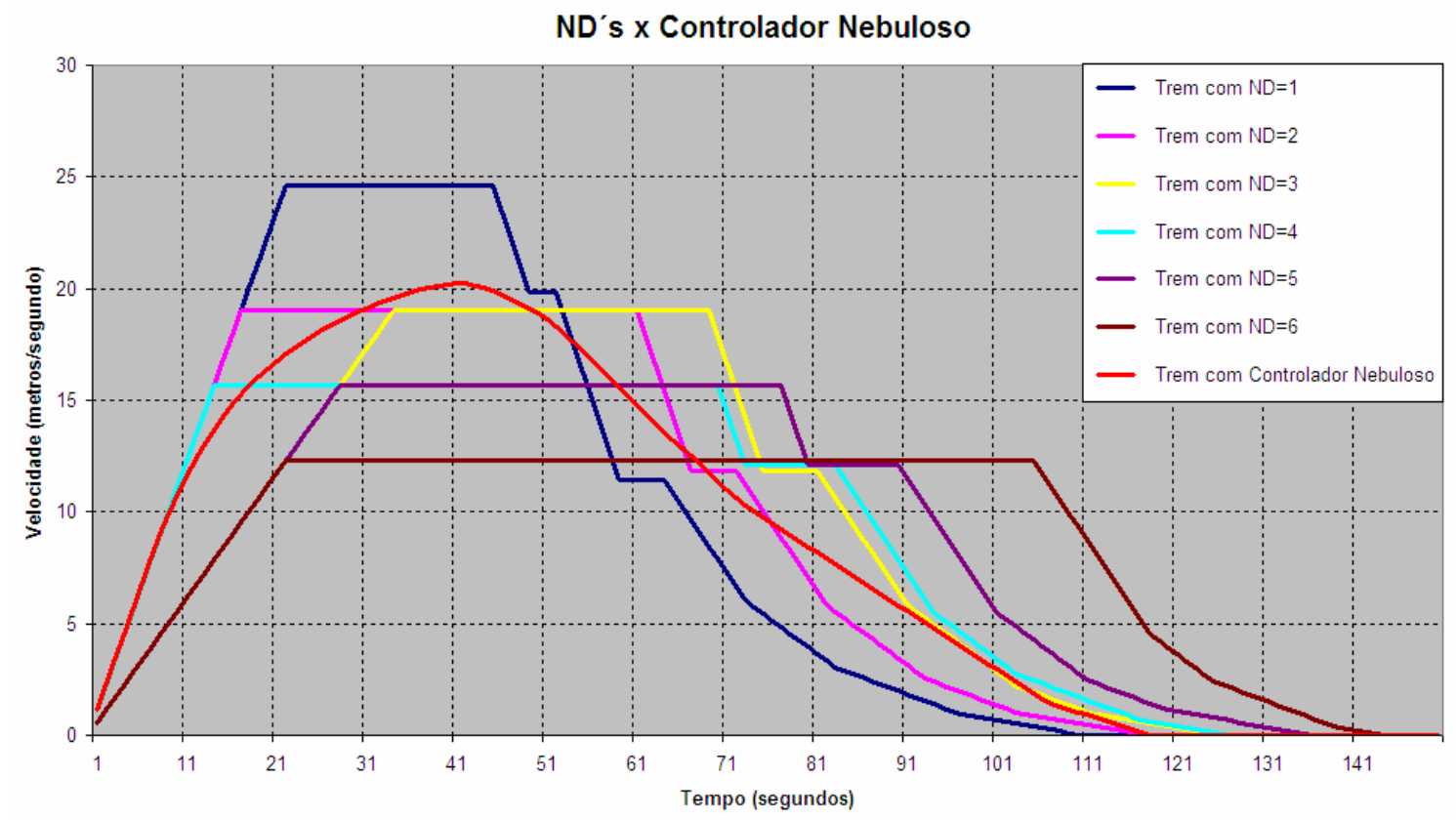

Figura 72. Variação de ND do controlador dos trens do metrô de São Paulo em comparação ao controlador nebuloso proposto. 


\subsection{Considerações Finais do Capítulo}

Neste capítulo o controlador nebuloso proposto e apresentado no Capítulo 5 foi testado por meio de simulações efetuadas no programa MatLab. Estas simulações também envolveram os estudos de caso dos controladores dos trens do metrô de São Paulo e do metrô de Sendai, apresentados no Capítulo 6. O objetivo destes testes foi o de analisar o desempenho do controlador nebuloso proposto e comparar este desempenho com os desempenhos dos controladores dos metrôs apresentados nos estudos de caso.

As principais situações operacionais foram analisadas, incluindo a circulação normal de trens e situações de falha, onde um trem parado ou movendo-se com velocidade constante foi introduzido para efetuar interferências operacionais no desempenho dos trens sob análise. Por fim, uma situação de adensamento de trens foi introduzida para verificar o desempenho dos controladores apresentados em uma situação de aumento de demanda de passageiros, com a diminuição do intervalo e do espaçamento entre trens.

Outras simulações adicionais foram também efetuadas para se determinar outros parâmetros que pudessem vir a influir no desempenho operacional dos controladores de trens sob teste.

O próximo passo consiste na decisão sobre a viabilidade da aplicação do controlador nebuloso para o controle da movimentação de trens em um sistema metroferroviário. Com base nos resultados apresentados e nas características de implementação do sistema com lógica nebulosa preditiva, uma discussão será efetuada sobre a questão da segurança com a utilização de ferramentas de Inteligência Artificial em sistemas críticos de controle. 


\section{Considerações Finais}

Este capitulo tem como objetivo apresentar as considerações finais do estudo, as conclusões e sugestões de próximos passos a serem seguidos decorrentes deste trabalho. Também são apresentadas as dificuldades encontradas na elaboração deste estudo e as alternativas encontradas para contornar estas dificuldades, bem como uma delimitação do modelo proposto. Por fim, uma discussão a respeito da questão da segurança na utilização de técnicas de Inteligência Artificial em sistemas críticos de controle é efetuada, levando à conclusão sobre a viabilidade da aplicação proposta, desde que um módulo supervisor de ATP execute as funções relativas à segurança do trem, garantindo a segurança do sistema.

\subsection{Introdução}

Após a apresentação dos elementos teóricos envolvidos no projeto de um controlador nebuloso proposto, do seu detalhamento e análise de seu funcionamento, em comparação a estudos de caso, como os sistemas de controle dos trens dos metrôs de Sendai (Japão) e São Paulo, o próximo passo consiste em se fazer uma avaliação dos resultados obtidos e decidir quanto à viabilidade da aplicação de lógica nebulosa preditiva no controle de movimentação de trens.

Os resultados apresentados no Capítulo 7 mostram que o controlador nebuloso possui vantagens e desvantagens com relação ao sistema PID utilizado atualmente no sistema de controle do metrô de São Paulo e também com relação ao sistema nebuloso de blocos móveis utilizado no sistema de controle do metrô de Sendai.

Entre as vantagens do sistema de controle nebuloso, destaca-se a suavidade de variação da velocidade ao longo do percurso entre as estações. Esta suavidade é resultado da busca de um compromisso entre as variáveis de entrada do sistema (Distância e Velocidade) e a variável de saída (Aceleração), que variam linearmente ao longo do percurso. Este compromisso buscado possui a tendência de manter sempre otimizada a relação entre as variáveis de entrada, por meio da escolha do valor mais adequado da variável de saída do sistema de controle. 
Esta característica de otimização reflete-se imediatamente em uma grande vantagem aos passageiros, que é o conforto proporcionado. Por não existir variações bruscas de velocidade, os passageiros deixam de sentir os "trancos" ocasionados por mudanças no comando de propulsão e freios. Indiretamente, esta característica se reflete em uma menor taxa de manutenção do sistema, uma vez que o sistema de propulsão e freios é menos exigido, o que prolonga a vida útil de seus componentes, principalmente os componentes eletromecânicos envolvidos no acionamento dos motores de tração e dos cilindros de freio.

Entre as desvantagens está o aumento no tempo de percurso entre duas estações e a aparente rigidez do sistema de controle. Como o sistema de controle sempre busca um comportamento otimizado das variáveis de entrada, parece, em princípio, que o sistema não possui nenhuma variável de ajuste para que o comportamento do sistema seja alterado. Por outro lado, em situações operacionais nas quais não se exige uma maior oferta de trens (horários de vale), o sistema de controle nebuloso parece atender bem às necessidades operacionais.

Atualmente, o sistema de controle dos trens do metrô de São Paulo utiliza o método de modificação de desempenho para alterar os parâmetros cinemáticos do trem (velocidade e aceleração), de forma a possuir um controle do espaçamento entre trens, de acordo com a demanda de passageiros e as necessidades operacionais do sistema. Esta forma de controle é fundamental ao sistema central e permite um ajuste dinâmico da oferta de trens ao longo da operação comercial de trens.

A implantação do sistema de sinalização por blocos móveis surge como uma conseqüência da utilização do controlador nebuloso, uma vez que a distância entre trens passa a ser uma variável de controle do sistema. Esta necessidade de implementação do sistema de sinalização por blocos móveis também representa uma desvantagem para a implementação do controlador nebuloso. Todas as mudanças necessárias, como a implementação de um canal de comunicação de rádio entre trens e a necessidade de modificação dos circuitos de hardware dos controladores atualmente utilizados nos trens representam custos de implantação do sistema novo, custo este que deve ser compensado pelos ganhos operacionais obtidos com a implantação do novo sistema. 


\subsection{Dificuldades Encontradas}

A principal dificuldade encontrada na elaboração do sistema de controle nebuloso proposto foi que este não possuía uma variável para o ajuste do comportamento do sistema em função das necessidades operacionais, como é feito no método de modificação de desempenho utilizado no sistema de controle dos trens do metrô de São Paulo.

Foi constatado, posteriormente, que esta variável é muito importante para o ajuste das características operacionais do sistema e que a falta desta variável deixa o sistema de controle muito rígido e sua aplicação fica limitada a determinadas condições operacionais.

Uma possibilidade para se contornar este problema consiste na remodelagem do sistema de controle, incluindo o tempo de percurso entre estações como uma variável de entrada adicional para o sistema e cujo valor iria também influir na decisão sobre qual aceleração seria a mais adequada para manter a otimização entre a velocidade real do trem, a distância a ser percorrida e o tempo gasto no percurso do trem.

O próprio sistema de controle do metrô de Sendai utiliza o tempo como variável para o cálculo de alguns de seus parâmetros de desempenho, como o conforto (tempo entre mudanças de comando de propulsão), a segurança (tempo até a região com código de velocidade menor) e o tempo de percurso propriamente dito.

Por outro lado, a utilização do tempo como variável de entrada do sistema provocaria um aumento da complexidade do funcionamento do sistema, exigindo a aplicação de regras mais elaboradas, diminuindo a simplicidade proporcionada pela ferramenta de lógica nebulosa preditiva. Uma vez que todos os mecanismos de inferência nebulosa foram compreendidos, analisados e detalhados durante o projeto do sistema de controle, pode-se efetuar a introdução da variável Tempo no sistema.

Uma outra possibilidade para se efetuar o controle do desempenho do sistema é fazer com que a variável relativa ao tempo de percurso do trem atue no sistema não como uma variável de entrada, mas como uma seleção de ajuste de desempenho do sistema. Desta forma, diferentes bases de regras seriam construídas para cada uma das condições operacionais desejadas e o controle seria efetuado com a seleção da base de regras mais adequada à situação operacional desejada. 
Para se implementar este tipo de controle, a sensibilidade do modelo do sistema controlador nebuloso com relação à variação de sua base de regras deve ser testada. Para testar a sensibilidade do sistema, foram construídas duas bases extras de regras, sendo que em uma delas, a seleção da variável de saída (Aceleração) foi mais limitada (o ajuste permitido limitava-se às categorias Propulsão Máxima, Neutro e Freio Máximo) e na outra base, a seleção da variável de saída (Aceleração) foi mais diversificada (alguns ajustes previstos como Propulsão Máxima passaram para Propulsão, outros passaram de Freio Máximo para Freio e outros ainda de Propulsão ou Freio para Neutro).

Os resultados mostraram que a forma como a base de regras (e, portanto, o conhecimento do especialista) é empregada influi drasticamente no desempenho do sistema. No primeiro caso, o tempo de percurso foi reduzido drasticamente, porém a velocidade máxima ultrapassou a velocidade de projeto para o trem de $100 \mathrm{~km} / \mathrm{h}(27,77 \mathrm{~m} / \mathrm{s})$, o que exigiria a implementação de algum mecanismo para a limitação da velocidade máxima a ser aplicada ao trem. Ao se efetuar a implantação desta limitação, o comportamento do sistema tende a se igualar ao comportamento apresentado pelo controlador PID utilizado no metrô de São Paulo.

No segundo caso, o resultado foi um aumento em cerca de dez vezes no tempo de percurso entre as estações, com a velocidade máxima desenvolvida no trecho sendo bem abaixo da velocidade desenvolvida pelo sistema controlador utilizando a base de regras originais. Esta situação não apresenta nenhum interesse prático, além de demonstrar a influência da base de regras no desempenho do sistema de controle.

Ajustes intermediários, porém, poderiam ser efetuados na base de regras do sistema de controle nebuloso proposto, permitindo a seleção de diferentes bases de acordo com as necessidades operacionais. Entretanto, seria necessário a elaboração da forma de implementação deste controle (na forma como este controle seria feito, como seria efetuada a transmissão deste comando aos trens, como seria efetuada a decodificação deste comando pelos equipamentos de bordo, etc.).

Outra dificuldade encontrada é a necessidade de implementação de um circuito de comunicação entre trens que funcione com a filosofia fail-safe, pois, como foi visto, a comunicação entre trens tornou-se fundamental ao funcionamento do sistema de controle, devendo ser, portanto, objeto exaustivo de estudos no que diz respeito à integridade e confiabilidade das informações transmitidas e recebidas. 


\subsection{A Questão da Segurança na Utilização de Ferramentas de Inteligência Artificial em Sistemas Críticos de Controle}

Uma das dificuldades encontradas foi a questão da segurança na utilização de ferramentas de Inteligência Artificial (IA) em sistemas críticos de controle. Esta questão surgiu em virtude de que, para o projeto do sistema de controle nebuloso proposto, foi utilizada a lógica nebulosa preditiva, que é uma ferramenta na área de IA.

Por outro lado, as normas européias, em especial a norma EN50123 (ESRA, 2003; IEC, 1997), que trata da especificação de software para aplicação em sistemas críticos de controle metroferroviário, não recomendam a utilização de ferramentas de IA em sistemas críticos de controle, especialmente em sistemas de sinalização e controle metroferroviário.

O conservacionismo das normas européias deve-se ao caráter não-determinístico das ferramentas de IA. Isto quer dizer que, em um sistema de controle que utiliza ferramentas de IA não é possível se determinar de maneira unívoca, em todas as situações, as causas que levaram um sistema a um determinado estado. Alguns sistemas utilizam técnicas de aprendizagem, que efetuam uma variação das regras e dos dados inicialmente fornecidos a eles, podendo levar o sistema a situações não previstas inicialmente, o que é inconcebível tratando-se de sistemas críticos de controle (FRITH, 1996).

Porém, as ferramentas de IA proporcionam várias vantagens em sua aplicação, conforme pode ser comprovado no objeto deste estudo, e o conservacionismo exagerado pode fazer com que o analista/projetista do sistema não utilize estas vantagens para deixar o projeto conforme esta norma.

A saída para este problema é obtida implementando-se um módulo de segurança adicional, que efetua a monitoração constante das variáveis de entrada e saída do sistema de controle, e atua de forma preferencial à ação do sistema de controle, caso alguma margem de segurança do sistema seja violada.

É desejável que as entradas e saídas do módulo de supervisão ATP sejam isoladas das entradas e saídas do módulo de controle ATO, para evitar a interferência das variáveis do módulo ATO no desempenho do módulo ATP (RACHEL; CUGNASCA, 2006). 
Embora a lógica nebulosa possa ser interpretada como uma fonte de imprecisão ao sistema, o sistema de supervisão implementado mantém as variáveis de controle dentro de limites pré-determinados, reforçando a classificação do sistema de controle como sendo previsível e determinístico, além de garantir sua operação segura.

Uma das vantagens da utilização de lógica nebulosa preditiva em sistemas de controle é a similaridade desta com o raciocínio humano, tornando o processo de controle mais simples e inteligível, uma vez que se aproxima da forma como o comportamento humano efetuaria o controle do sistema.

A lógica nebulosa permite a manipulação e operação lógica e matemática de conceitos vagos e imprecisos contidos na linguagem e no pensamento do especialista do sistema. Além disso, conceitos complexos podem ser traduzidos na forma de comandos simples ao sistema de controle, tornando o sistema simples e facilitando a compreensão de seu funcionamento (RACHEL; CUGNASCA, 2006).

A utilização de inteligência em sistemas especialistas, mais especificamente em sistemas de controle, faz com que a inteligência embutida no sistema seja tratada como um componente, classificando este uso em duas categorias: como componente serial e paralelo. $\mathrm{Na}$ utilização como componente serial, o elemento inteligente realiza funções essenciais dentro do sistema, enquanto na utilização como componente paralelo, o elemento inteligente realiza tarefas de supervisão das funções do sistema (FRITH, 1996).

No caso do controlador nebuloso proposto, o elemento que utiliza as ferramentas de IA (ATO) está configurado como componente serial e realiza as funções de controle propriamente ditas. As tarefas de supervisão, essenciais nas aplicações de sistemas críticos, são realizadas pelo módulo de controle (ATP).

Se as margens de segurança forem mantidas, não há razão para se evitar a utilização das ferramentas de Inteligência Artificial, nem deixar de utilizar as vantagens proporcionadas pela aplicação destas técnicas, uma vez que estas técnicas não restringem o desempenho do sistema, e sim aprimoram este desempenho.

Desta forma, é possível utilizar as ferramentas de IA, em especial a lógica nebulosa preditiva em aplicações críticas de segurança, sem comprometer a segurança destas aplicações (RACHEL; CUGNASCA, 2006). 


\subsection{Estudos Futuros}

Os estudos futuros previstos para a continuidade deste trabalho consistem na pesquisa e elaboração de alternativas às dificuldades encontradas na execução deste estudo e também na especificação das condições para possibilitar a implantação do sistema de controle nebuloso proposto em sistemas metroferroviários.

Desta forma, os estudos futuros envolvem a remodelagem do sistema de controle nebuloso proposto acrescentando-se a variável de entrada Tempo. Outras alternativas de variáveis de entrada podem ser analisadas, de forma a possibilitar o controle de índices de desempenho desejáveis no controle de movimentação de trens metroferroviários.

Seguindo o exemplo do sistema de controle nebuloso utilizado nos trens do metrô de Sendai, no qual variáveis secundárias derivadas do tempo de percurso, da distância percorrida e da velocidade real do trem são utilizadas como variáveis de entrada do sistema de controle, sendo a variável de saída uma escolha de um determinado nível de propulsão ou frenagem, outras variáveis secundárias podem ser formadas e utilizadas como variáveis de entrada do sistema de controle proposto.

Da mesma forma, estudos futuros podem incluir o processo de parada programada ao longo da plataforma das estações, processo este não considerado neste projeto inicial. Como o controlador nebuloso proposto envolve a combinação das variáveis Distância e Velocidade, nem sempre é possível uma associação perfeita, não garantindo uma parada precisa, com velocidade igual a zero em um ponto determinado. Assim, ajustes para pequenas distâncias (da mesma forma como foi implementada a variável Espaçamento de Parada no metrô de Sendai) devem ser efetuados e podem ser temas para futuros estudos.

Além disso, uma completa especificação de todo o sistema de comunicação entre trens para este tipo de aplicação crítica de controle, incluindo suas características fail-safe e características que garantam a integridade e correta atualização das informações, como códigos de controle de transmissão e verificação de erros, também constituem importantes fontes para futuros estudos.

Uma vez especificado todo o hardware necessário para a implantação do sistema de controle nebuloso e do sistema de sinalização por blocos móveis, uma análise de segurança completa do sistema poderá ser efetuada, também em estudos futuros. 


\subsection{Conclusões}

Com a análise dos resultados das simulações e medições efetuadas e apresentadas no Capítulo 7, pode-se concluir pela viabilidade da aplicação de lógica nebulosa preditiva para o controle da movimentação de trens metroferroviários. Conforme pode ser observado, esta aplicação traz vantagens e desvantagens com relação ao sistema de controle utilizando PID atualmente utilizado nos trens do metrô de São Paulo.

Algumas destas vantagens já puderam ser comprovadas na análise do estudo de caso efetuada para o controlador utilizado nos trens do metrô de Sendai. Em operação desde 1987, este sistema de controle de trens já havia demonstrado a viabilidade da aplicação da lógica nebulosa preditiva para o controle da movimentação dos trens.

Entretanto, uma maneira alternativa, mais simples e envolvendo o controle de apenas uma variável de saída (Aceleração), com base na combinação de duas variáveis de entrada (Distância e Velocidade) foi proposta em um controlador nebuloso, que também demonstrou a viabilidade da aplicação da lógica nebulosa preditiva para este tipo de sistema de controle.

As desvantagens apresentadas podem ser perfeitamente contornáveis e são objetos para estudos futuros para o aperfeiçoamento desta técnica de controle. 


\section{REFERÊNCIAS}

BARWELL, F.T. Automation and Control in Transport. Pergamon Press, Oxford, 1973.

CAMARGO JÚNIOR, J.B. Estudo da Segurança em Sistemas de Controle Metro-

ferroviários. 1996. 142p. Tese (Doutorado). Escola Politécnica, Universidade de São Paulo, São Paulo, 1996.

CMW SISTEMAS LTDA. Memorial Descritivo - Equipamento ATC do Veículo. São Paulo, 1985.

CUGNASCA, P.S. Modelos Baseados em Lógica Nebulosa Para Avaliação de Sistemas Tolerantes a Defeitos. 1999, 236p. Tese (Doutorado). Escola Politécnica, Universidade de São Paulo, São Paulo, 1999.

DRIANKOV, D.; HELLENDOORN, H.; REINFRANK, M. An Introduction to Fuzzy Control. Spring-Verlag, Berlin, 1996.

ESRA - EUROPEAN SAFETY AND RELIABILITY ASSOCIATION. Standard EN 501236, 2003.

FERRAZ, A.C.P.; TORRES, I.G.E. Transporte Público Urbano. São Carlos, Rima, 2001.

FRITH, K. Can We Justify Artificial Intelligence in Safety-Related Systems? The SafetyCritical Systems Club Newsletter, v.5 n.5, 1996. Disponível em:

$<$ www.cs.ncl.ac.uk/old/research/csr/clubs/scsc_articles/Ken_frith.html $>$. Acesso em: novembro.2002.

HITACHI, LTD. The Future of Railway Systems. Japão, [s.n.], 2003. Disponível em: $<$ www.hitachi-rail.com/rail_now/seminor/train_systems/train_system1.html $>$. Acesso em: maio.2005.

IEC - INTERNATIONAL ELETROTECHNICAL COMISSION. Functional Safety of Electrical, Electronic and Programmable Electronic Safety-Related Systems, Standard IEC 1508, 1997.

INSTITUTION OF RAILWAY SIGNAL ENGINEERS European Railway Signalling. A\& C Black, London, 1995.

JAMSHIDI, M.; VADIEE, N.; ROSS, T.J. Fuzzy Logic and Control: Software and Hardware Applications. PTR Prentice Hall, Englewood Cliffs, New Jersey, 1993.

JAPAN ROLLING STOCK EXPORTES ASSOCIATION. Japanese Railway Information - Railway Systems and Components, v.36, p.1-9, 1988.

JOHNSON, B.W. Design and Analysis of Fault Tolerant Digital Systems. USA, AddisonWesley Publishing Company, Inc., 1989. 
KLIR,G.J.; YUAN, B. Fuzzy Sets and Fuzzy Logic - Theory and Applications, Prentice Hall, 1995.

LEE, C.C. Fuzzy Logic in Control Systems: Fuzzy Logic Controller - Part I. IEEE Transactions on Systems, Man and Cybernetics, v.20, n.2 , p. 404-418, 1990a.

LEE, C.C. Fuzzy Logic in Control Systems: Fuzzy Logic Controller - Part II. IEEE Transactions on Systems, Man and Cybernetics, v.20, n.2 , p. 419-435, $1990 \mathrm{~b}$.

MAMDANI, E.H. Applications of Fuzzy Algorithms for Simple Dynamic Plant. Proceedings... IEEE, v.121, n.12, p.1585-1588, 1974.

MARKS II, R.J. Fuzzy Logic Technology and Applications. IEEE Technical Activities Board, New York, 1994.

MATHWORKS INC. Applications of Fuzzy Logic in Control Design. MA, USA, MathWorks Inc., 1996.

MCNEILL, F.M.; THRO, E. Fuzzy Logic - A Practical Approach. Academic Press Inc. 1994, p.1-82.

MITCHELL, T.M. Machine Learning. New York, McGraw-Hill, 1997.

PEDRYCZ, W. Fuzzy Control and Fuzzy Systems. New York, Wiley, 1993.

RACHEL, F.M.; CUGNASCA, P.S. Using Artificial Intelligence Techniques in Critical Safety Systems. Proceedings...1 1st IEE International Conference on System Safety, London, 2006.

SUGENO, M; KANG, G.T. Structure Identification on Fuzzy Model. Fuzzy Sets Systems, v.28, n.1, p.15-33, 1988.

TERANO, T.; ASAI, K.; SUGENO, M. Applied Fuzzy Systems. MA, USA, AP Professional, 1994.

TRILLAS, E.; GUTIERREZ, R. Aplicaciones de la Logica Borrosa. Consejo Superior de Investigacciones Cientificas (CSIC), Madrid, España, 1992.

UNITED STATES CONGRESS - OFFICE OF TECHNOLOGY ASSESSMENT. Automatic Train Control in Rail Rapid Transit. U.S. Government Printing Office, Washington DC, May, 1976.

UNIVERSITY OF SHEFFIELD. Railway Technical Web Pages. [S.I.], Railway Technical Web Pages. Disponível em: < $\underline{w w w . r a i l w a y-t e c h n i c a l . c o m>. ~ A c e s s o ~ e m: ~ m a i o ~} 2005$.

URBANRAIL.NET. Sendai Japan, 2004, [S.I.]. Disponível em:

$<$ www.urbanrail.net/as/send/sendai.html $>$. Acesso em: setembro.2005.

WEYRICK, R.C. Fundamentals of Automatic Control. Tokyo, McGraw-Hill, 1975. 
WORLD BUSINESS COUNCIL FOR SUSTAINABLE DEVELOPMENT. Mobilidade 2001 - Relatório Sintético. [S.I.]. Disponível em:

$<$ www.wbcsd.org/web/projects/mobility/portuguese_executive_summary.pdf $>$. Acesso em: maio.2005.

YASUNOBU, S.; MIYAMOTO, S.; IHARA, H. Fuzzy Control for Automatic Train Operation System. Proceedings... 4th IFAC/IFIP/IFORS - International Congress on Control in Transportation Systems, Baden-Baden, 1983.

YASUNOBU, S.; MIYAMOTO, S.; TAKAOKA, T.; OHSHIMA, H. Application of Predictive Fuzzy Control to Automatic Train Operation Controller. Proceedings... IECON 84, p.657-662, 1984.

YASUNOBU, S.; MIYAMOTO, S. Automatic Train Operation System by Predictive Fuzzy Logic Control. Industrial Applications of Fuzzy Control (M. Sugeno ed.) NorthHolland, 1/18, 1985.

ZADEH, L.A. Fuzzy Sets. Information and Control 8 , p.338-252, 1965.

ZADEH, L.A. Outline of a New Approach to the Analysis of Complex Systems and Decision Processes. IEEE Transactions on Systems, Man and Cybernetics, v.SMC-3, n.1 , p.28-44, 1973. 


\section{APÊNDICES}

APÊNDICE A - Simulação Utilizando o Simulink do MatLab APÊNDICE B - Simulação Utilizando o Simulador do Knoma APÊNDICE C - Medições Reais Efetuadas no Metrô de São Paulo 


\section{APÊNDICE A - Simulação Utilizando o Simulink do MatLab}

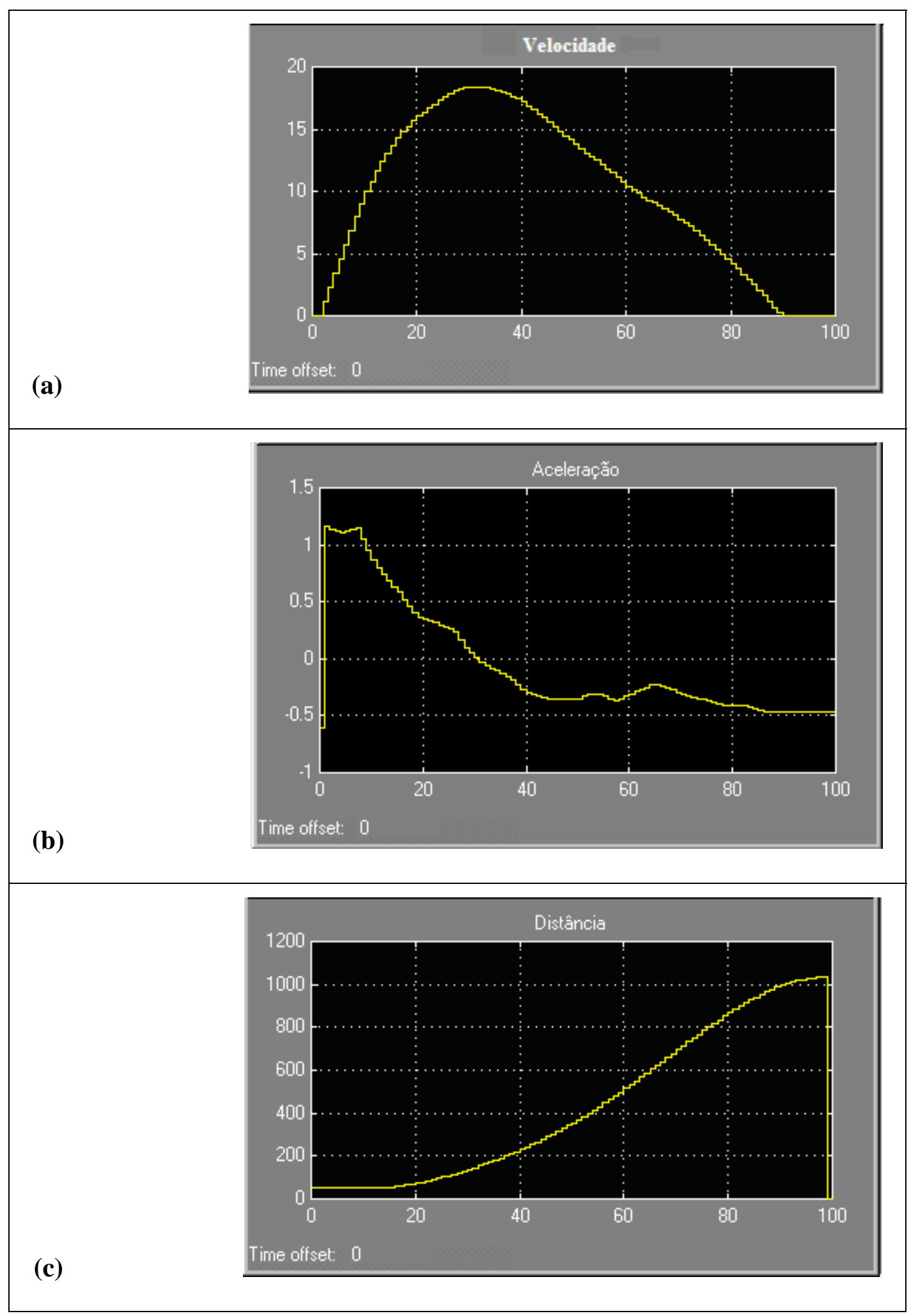

Figura 73. Resultados gráficos da velocidade (a), aceleração (b) e distância percorrida (c) da $1^{\text {a }}$ simulação - Circulação Normal de Trens utilizando o Simulink. 


\section{APÊNDICE B - Simulação Utilizando o Simulador do Knoma}

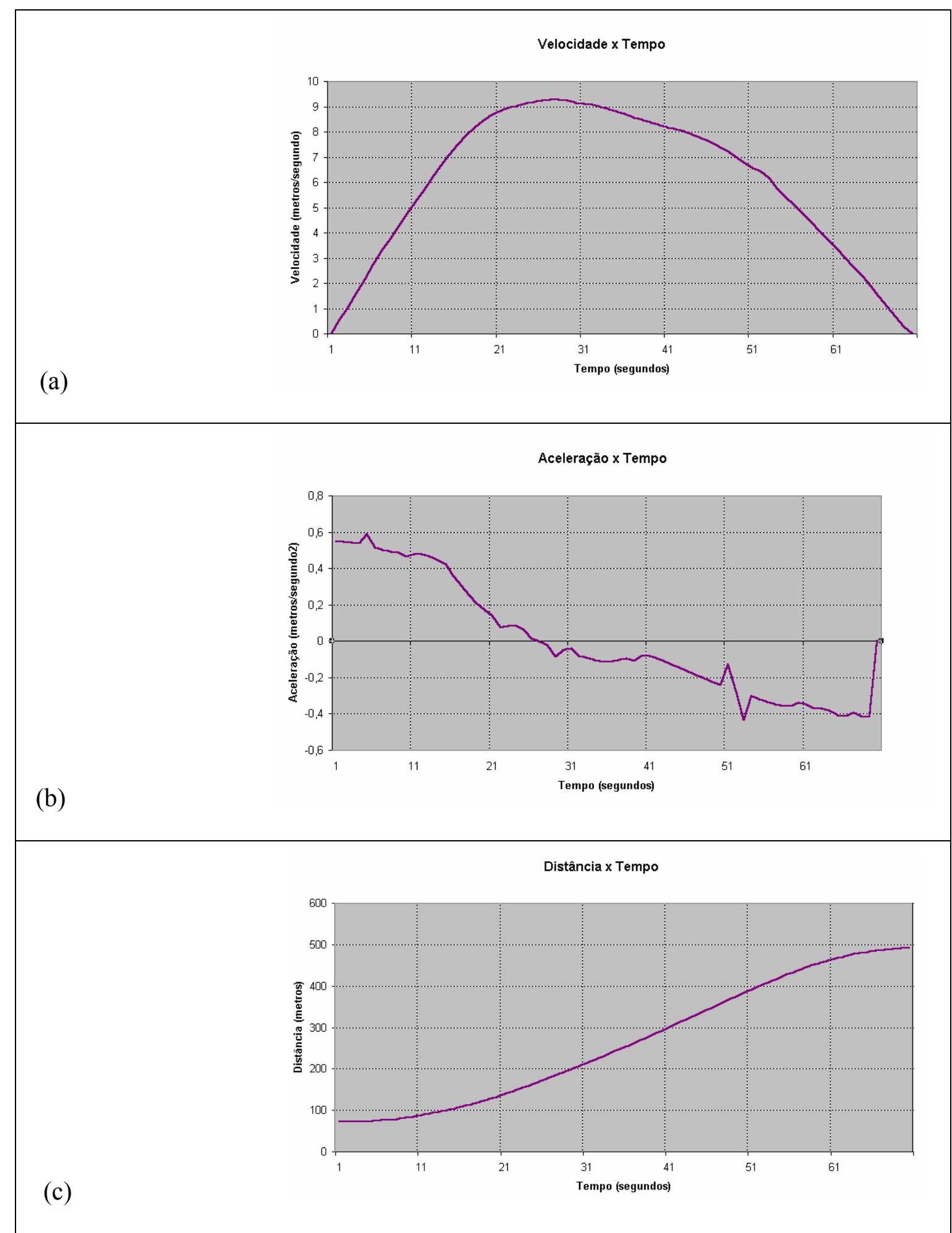

Figura 74. Resultados gráficos da velocidade (a), aceleração (b) e distância percorrida (c) da $1^{\text {a }}$ simulação - Circulação Normal de Trens utilizando o simulador desenvolvido no KNOMA/PCS/EPUSP. 
APÊNDICE C - Medições Reais Efetuadas no Metrô de São Paulo

(a)

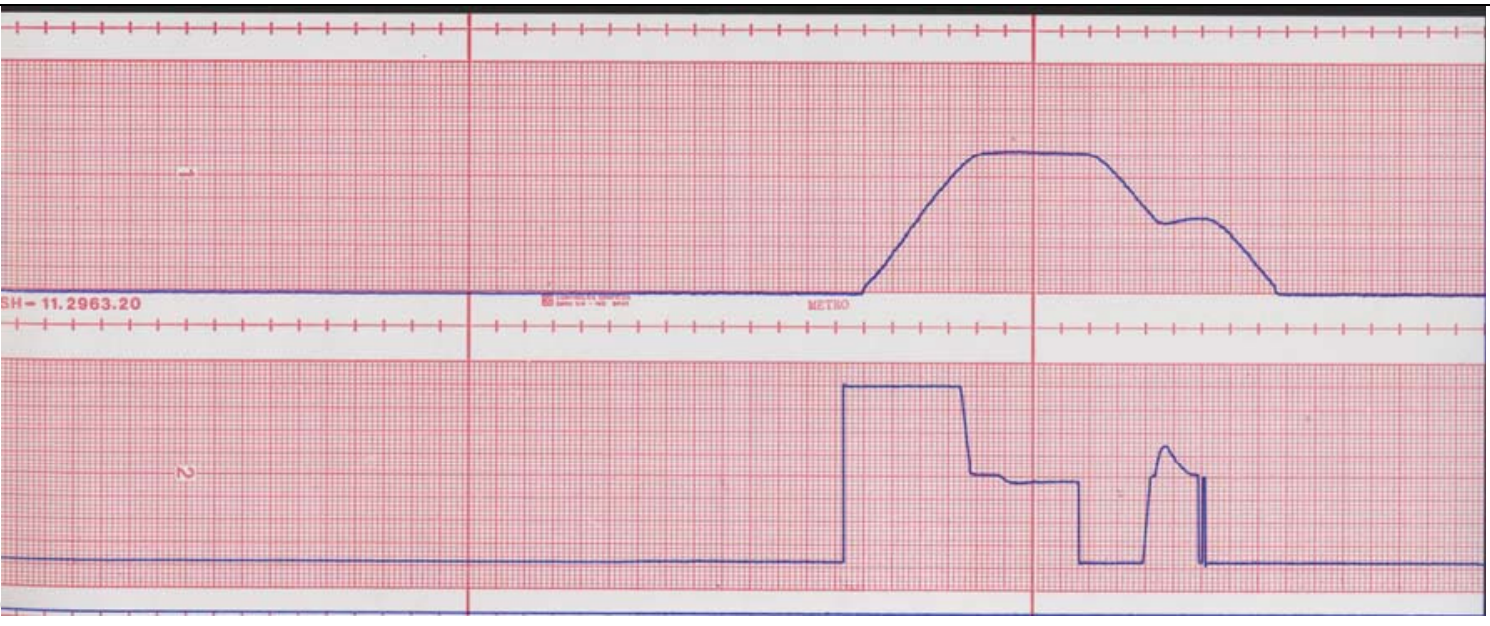

(b)
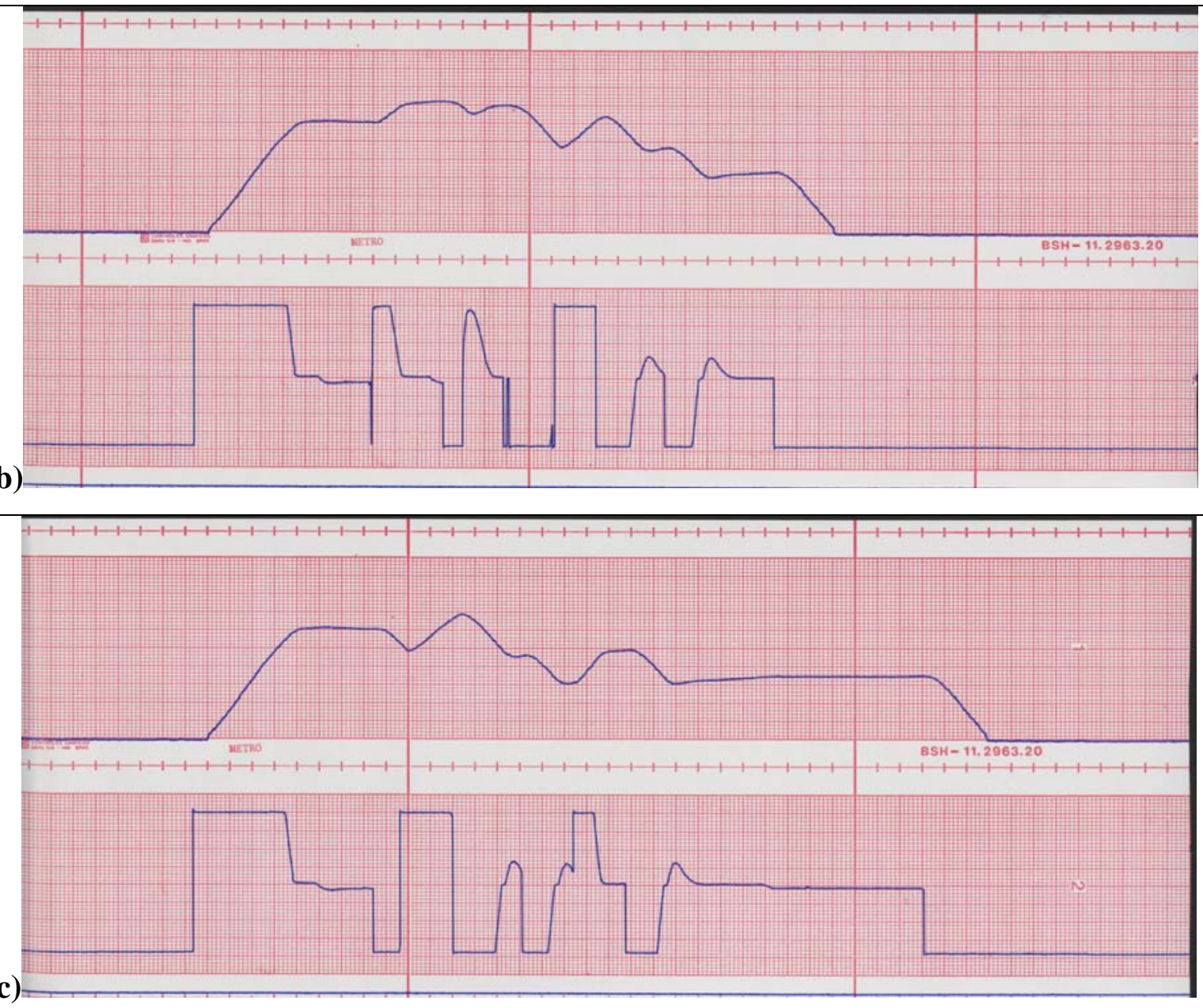

Figura 75. Resultados gráficos das medições de velocidade e aceleração para o trem do Metrô de São Paulo circulando entre SCZ e ARV nas condições: trem parado entre estações ( $2^{a}$ simulação) (a); trem movendo-se com velocidade constante entre estações ( $3^{a}$ simulação) (b) e trem movendo-se com velocidade de via entre estações (4 ${ }^{\mathrm{a}}$ simulação) (c). 


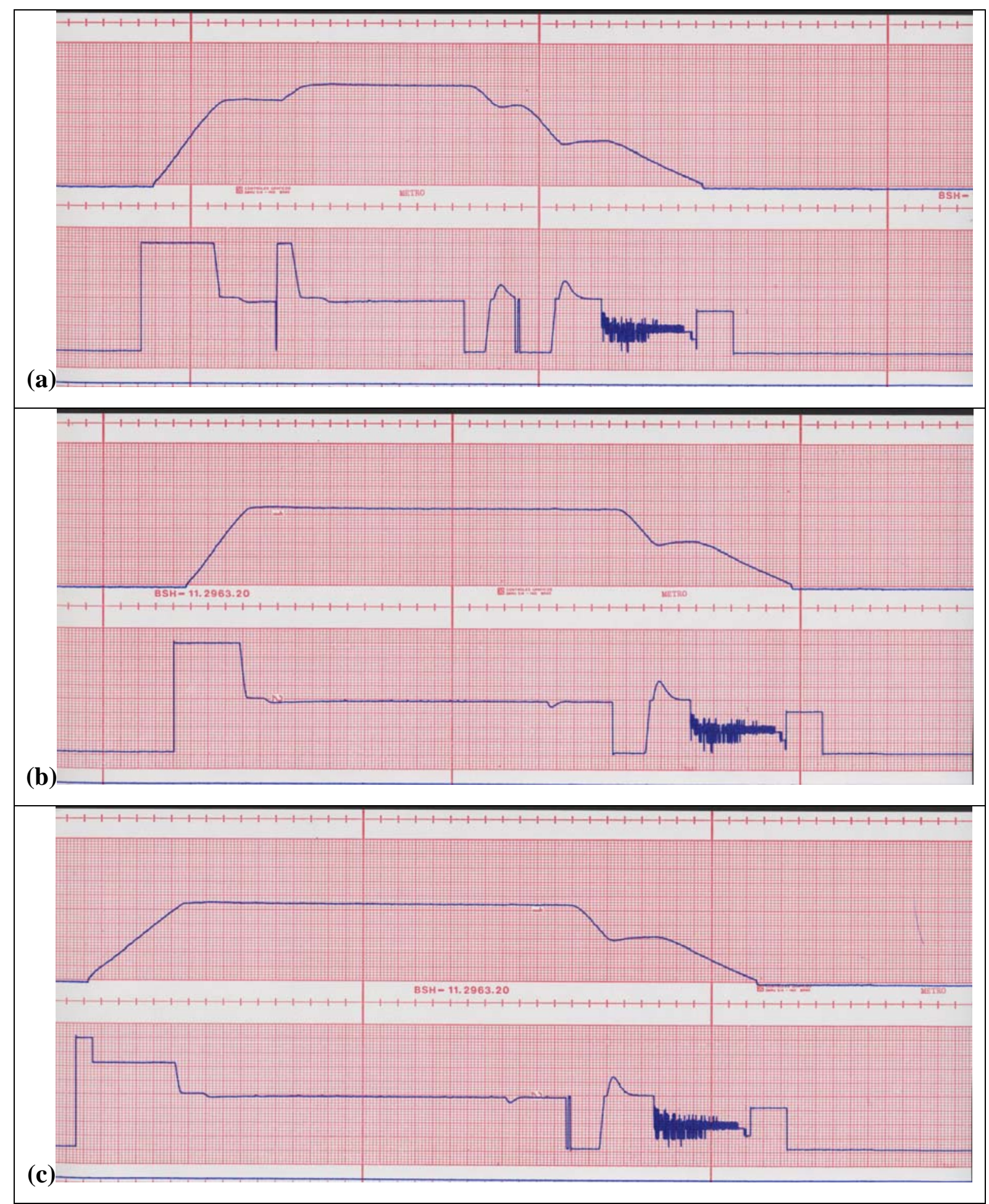

Figura 76. Resultados gráficos das medições de velocidade e aceleração para o trem do Metrô de São Paulo em circulação normal entre SCZ e ARV ( 1a simulação) com ND = 1 (a), ND = 2 (b) e ND = 3 (c). 
(a)

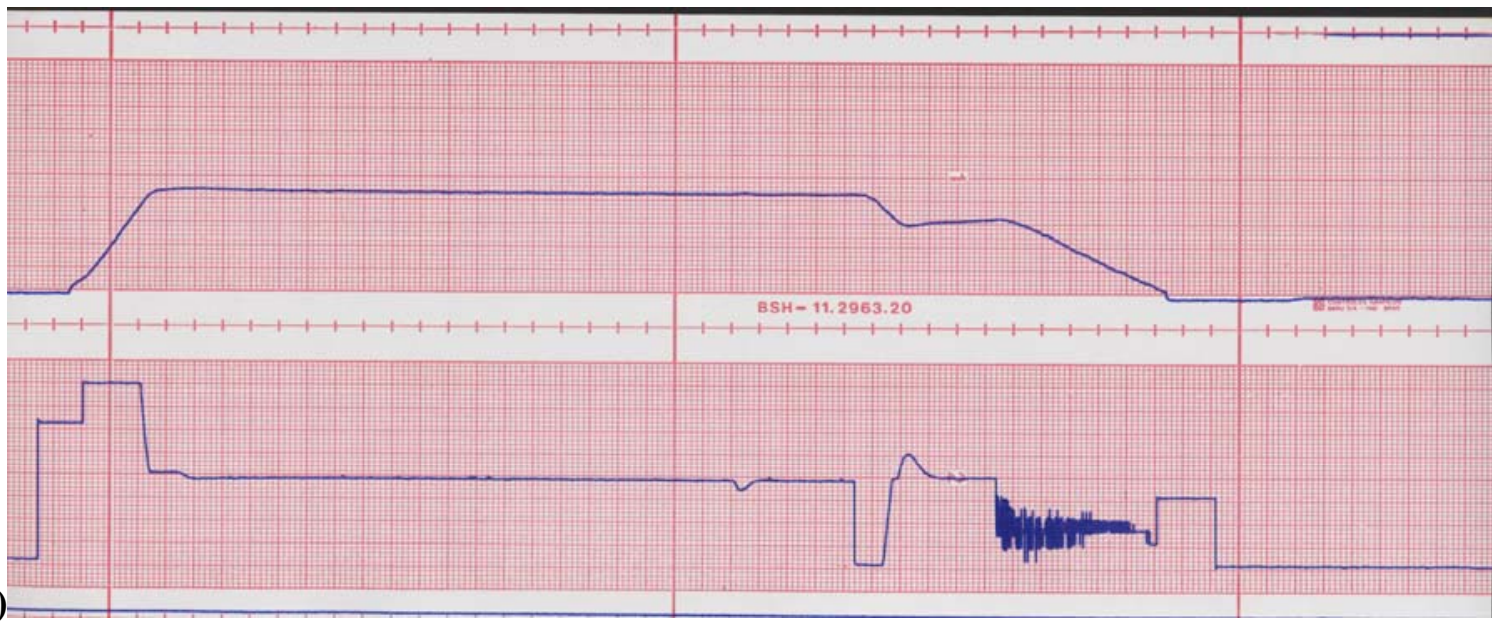

(b)
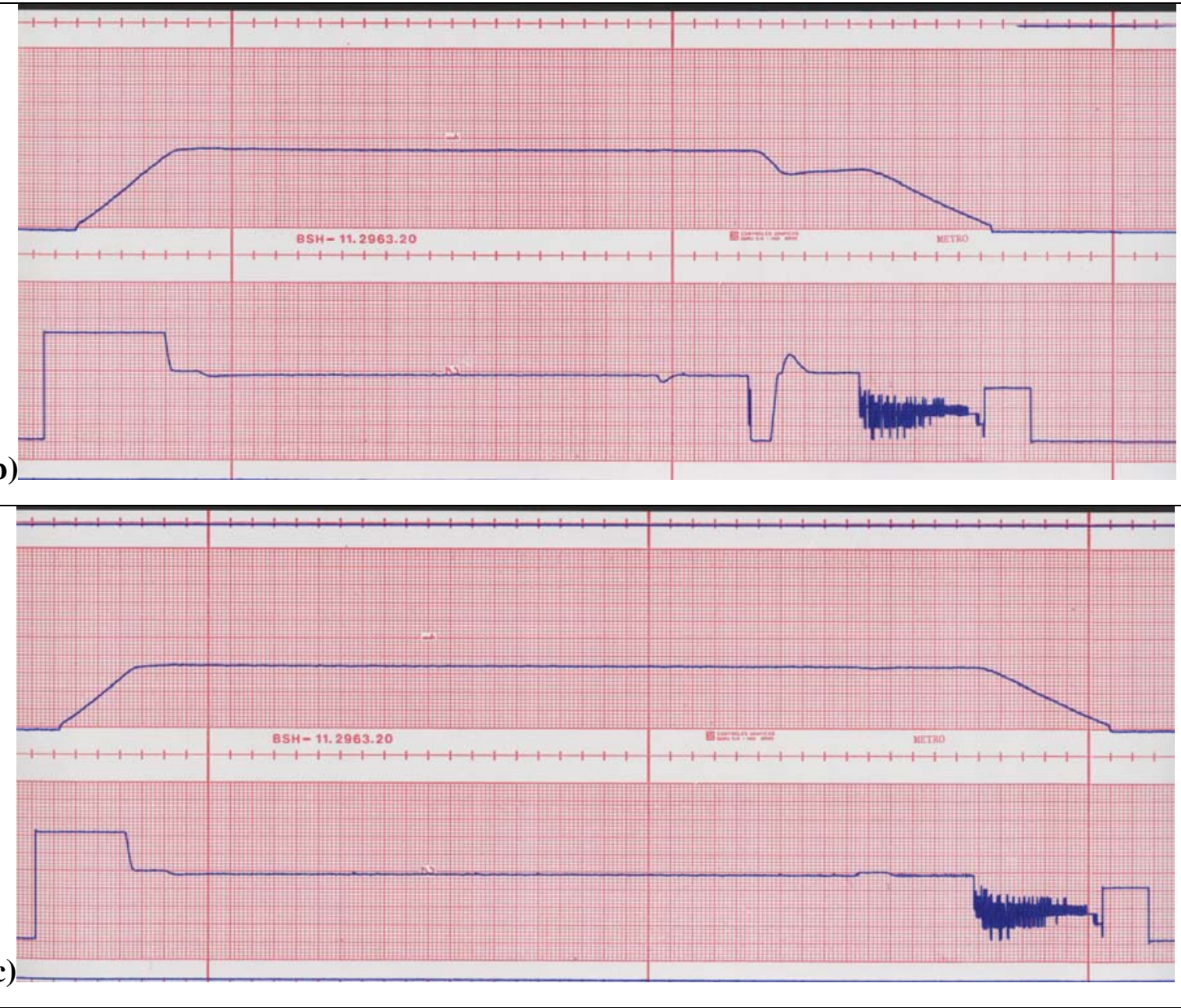

Figura 77. Resultados gráficos das medições de velocidade e aceleração para o trem do Metrô de São Paulo em circulação normal entre SCZ e ARV ( 1a simulação) com ND = 4 (a), ND = 5 (b) e ND = 6 (c). 